\title{
DIE REGENERÁTION
}

\author{
VON
}

GEWEBEN UND ORGANEN

BEI DEN

\section{WIRBELTHIEREN,}

\author{
BESONLERS
}

AMPHIBIEN UND REPTILIEN.

$10 N$

\section{PAUL FRAISSE}

UR. MEU. F'T PHIL.

PRIVATDOCENT AN DER UNIVERSITÄT LEIPZIG.

MI'T 3 TAFELN.

CASSEL UND BERLIN

VERLAG VUN THEODOR FISCIIER. 


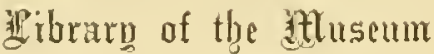

OF

\section{COMPARA'TIVE ZOÖLOGY,}

AT HARTARD COLLEGE, CALBRLIJGe, HaSS.

Jounded by pribate subscription, ín 1861.

Deposited by ALEX. AGASSIZ.

$$
\begin{aligned}
& \text { No. I/, Cot } \\
& \text { uerild, } 586
\end{aligned}
$$










\section{DIE REGENERATTION}

\section{VON \\ GEWEBEN UND ORGANEN \\ BEI DEN \\ WIRBELTHIEREN,}

BESONDERS

AMPHIBIEN UND REPTILIEN.

VON

PAUL FRAISSE

UR. MED. ET PHIL.

PRIVATDOCENT AN DER UNIVERSITÄT LEIPZIG.

MIT 3 'T'AFELN.

CASSEL UND BERLIN

VERLAG VUN THEODOR FISCHER.

1885. 
$7^{419}$ 
Die nachstehende Arbeit, welche bereits im Jahre 1879 begonnen wurde, hat mit einer solchen Menge ungünstiger Verhältnisse zu kämpfen gehabt, dass ihr Erscheiren längere Zeit hindurch iiberhaupt in Frage gestellt war. - Erst durch das liebenswïrdige Entgegenkommen des Herrn Verlagsbuchhändler Th. Fischer wurde es mir möglich, an die Vollendung des Verkes zu denken, nachdem ein Theil der Druckbogen schon jahrelang geruht hatte.

Hierdurch wird so manche Ungleichmässigkeit erkliirt, und nur im Vertrauen auf die Nachsicht der Fachgenossen wage ich es, auch die älteren Druckbogen unveräindert zu lassen, obgleich eine ganze Reihe von neueren Werken in denselben naturgemäss nicht erwïhnt sind, da der Druck von Bogen 1-9 schon seit 2 Jahren abgeschlossen ist. So viel wie möghich habe ich mich bemïht, in den letzten Capiteh und namentlich im Schlusspassus diesen Fehler zu verbessern, doch konnten auch lier die nenesten Arbeiten von Flemming und dessen Schiilern nicht mehr beriicksichtigt werden, da das Manuseript am 5. April 1884 abgeschlossen wurde und leider wiederum äussere Verhältnisse cinen beschleunigten Druck rerhinderten.

So iibergebe ich dem das, was mich seit Jahren beschäftigte, der Oeftentlichkeit, wohl wissend, dass das berührte Thema mit dem Wenigen was ich bicte noch lange nicht erschöpft ist; - musste ich doch das Capitel iiber die Regeneration des Anges ganz fortlassen, da sonst wiederum eine Verzögerung eingetreten wïre. In nicht zu langer Frist hoffe ich jedoch den Fachgenossen eine Separatabhandlung hieriber vorzulegen.

Ein Abschluss wurde wie gesagt erstrebt, aber nicht erreicht. Liegt doch in den so äusserst interessanten Erscheinungen, welche uns die Regeneration darbietet, eine ganze Entwickelungsgeschichte der gesammten Gewebe, zu acren vollständiger Erforschung ein volles Menschenalter wohl kaum geniigen diirfte. Dennoch hoffe ich durch den Grundgedanken, welcher sich durch die ganze Arbeit zieht, daranf hingewiesen zn haben, dass anch auf diesem Felde noch manche Frucht eingebracht werden kam, wem man versucht, die grossen Ideen Darwins anch auf die Histologie und Histogenese anzuwenden. Vor Allem war es aber die Vergleichung 
der histogenetischen Vorgänge bei dem Regenerationsprozess mit der embryonalen Entwickehung der Gewebe und Organe, die fü meine Darstellung den leitenden Faden bildete und welche, wie ich hoffe, nicht ganz ohne Resultat geblieben ist.

Für die fremndliche Unterstiitznng mit zum Theil sehr kostbarem Material, besonders mit philippinischen und anderen ostasiatischen Ascalaboten bin ich Herrn Professor Semper tiefsten Dank schuldig, elsenso Herm Dr. Looss für seine trefflichen Zeichnungen und die Durchsicht der Correcturbogen.

Leipzig, im Januar $18 \$ 5$.

P. Fraisse. 


\section{I n ha a l t.}

I. Ueber die Regenerations-Erscheinungen in Allgemeinen

Seite

A. Die Regenerationsversuche und ihre Resultate bei den verschiedenen Thierklassen

1. Geschichtliche Entwickelung der Regenerationsfrage in Bezug auf die wirbellosen Thiere

2. Geschichtliche Entwickelung der Regenerationsfrage in Bezug auf die Wirbelthiere, besonders Amphibien uud Reptilien

II. Eigene Beobaehtumgen

A. Untersuchungs Methoden

B. Specieller Theil

1. Die Receneration der Epidernis und anderer Epithelien

2. ". Cutis . . . . . . . . 1

3. " " "Hautdrïsen und Hautsinnesorgane . . . . . . . 81

4. " " des Skeletsystemes . . . . . . . . . . . . . . . 88

5. ,. " " Rüickenmarkes . . . . . . . . . 108

6. " " " peripherischen Nervensystem _ . . . . . . . . 119

7. " " . . . . . . . . . . . . . . . 124 124

8. " " , . . . . . . . . . . . . . . . . . . . 131

9. Schlussbemerkungen . . . . . . . . . . . . . . . 140

III. Tabellen ïber einige Yersuchsthiere _ _ _ . . . . . . . . . . . 155

Tafelerklärung . . . . . . . . . . . . . . . . . 160 
Motto:

Multum egerunt, qui ante nos fuerunt sed non peregerunt;

Multum adhuc restat operis, multumque restabit;

Nec ulli nato post mille saccula praecludetur occasio aliquid adbuc adjiciendi.

Seneca. 


\section{Ueber die Regenerations-Erscheinungen im Allgemeinen.}

Regeneration und Reproduction sind zrei Worte, mit welchen wir in der wissenschaftlichen Sprache oft dieselben Erscheinungen zn bezeichnen pflegen, obgleich beide Ausdriicke auch wiederum in scheinbar ganz rersehiedenen Sinne gebraucht werden können.

Man spricht von der Regeneration wie von der Reproduction verloren gegangener, vom Körper völlig abgetrennter Theile und drïekt dadureh die Wiederherstellung, das Nenhinzuwachsen derselben aus, aber man benutzt das Wort Regeneration auch in physiologisehem Sinne und bezeichnet damit die am lebenden Körper fortwährend stattfindende Ernenerung unbranchbar gewordener und abgestossener Elementartheile, während man Reproduction auch für Fortpflanzung anwendet.

Gewiss werden hierdurch bei oberflächlicher Betrachtung viele Missverständnisse und Unklarheiten hervorgerufen; gehen wir jedoch näher auf die äusserlich so versehiedenen Naturerscheinungen ein, welche mit den gleichen Worten benannt werden, so finden wir eine ursprünglich so weit gehende Uebereinstimmung zwisehen ihnen, dass es wenigstens unverständlich erseheint, wenn in neuester Zeit behauptet wird, dass die beiden Bedeutungen des Wortes Regeneration in durchaus keinem innern Zusammenhange stehen sollten.

Fasst man den Begriff der Regeneration noch weiter, so muss man eigentlich die sämmtlichen uns wahrnehmbaren Erscheinungen des Lebens, den ständigen Stoffwechsel, als eine fortwährende Regeneration betrachten, welche in der ganzen Entwickelungsreihe von der einfachsten Zelle bis zum höehstorganisirten, ausgebildeten Thiere dauernd in Thätigkeit ist; dann tritt, wenn ein gerisser Punkt des Wachsthums erreicht ist, eine andere Erscheinung hinzu, die man als Wachsthum über das individuelle Mass hinaus bezeichnet hat, die Fortpflanzung oder Reproduction.

So sehen wir die Erscheinungen der sogenannten physiologisehen Regeneration oder Reproduction täglich vor Augen, obgleich wir in unserem eigenen Körper nichts davon bemerken, da die vegetativen Verrichtungen unserer directen Wahrnehmung entzogen sind. Hürt dieser ständige regenerative Stoftwechsel auf, so tritt der Tod ein und die Materie zerfällt wieder in ihre Grundbestandtheile, um in anderer Form den Kreislauf ron neuem zu beginnen.

Das Wachsthum wird von der neueren Schule, besonders seit Virchow seine bahnbrechenden Werke in Würzburg herausgab, auf die Mechanik des Zellenlebens zuriickgefiihrt, anf weleher 
iiberhaupt die Einheit aller Lebenserseheinungen beruht. Dass man durch die in dieser Richtung angestellten Untersuchungen und Experimente einen bedeutenden Scluritt weiter gekommen ist, unterliegt keinem Zweifel; dass man aber bisher noch nicht im Stande gewesen ist, alle Vorgänge im thierischen Körper auf rein meehanische Ursachen zurïckznführen, ist ebensn klar.

Wohl keine Untersuchung kann der berïhnten Lehre Virchow's förderlicher sein, als die über die Regeneration. Tirchow selbst betonte ja die Wiehtigkeit dieser Vorgänge und rief dadureh eine ausserordentlieh grosse Menge ron Arbeiten hervor, deren Resultate sich jedloch oft so stark willersprechen, dass eine klärung der schwebenden Frage bis zun heutigen Tage noch nicht erzielt ist.

Nur dam, wenn wir auf der festen Grundlage der Virchow'schen Iypothese reiterbauen, dass der Organismus der höheren Thiere, zusammengesetzt aus selbstständigen Elementarorganismeu, als "Zellenstaat" zu betraehten sei, werden wir entsehiedene Fortschritte bei der Untersuehung der Regenerationsfrage zu verzeichnen haben.

Leider werden wir aber anch dann noch trotzdem Grenzen finclen, iiber die wir nicht hinausschreiten liönnen. Dass ein abgeschnittenes Bein bei den Urodelen stets in der Art sich wieciererzengt, dass ein dem abgesehnittenen Theil entsprechendes Stiick nachwäelst, ist zwar hüchst wunderlıar, lässt sieh aber doch dureh meehanische Ursaehen erklären. Warum aber einzehe Glierlmassen, Organe und Gewebe sich nun nach einem ganz besonderen Typus neubilden, der dem embryonalen vollständig fremr ist, künnen wir hierdurch allein sicher nicht ergründen. Dazu bediirfen wir anderel Huilfsmittel und das bedentendste hat uns wohl Darwin in seinen unsterblichen Werken hinterlassen. Die anregenden Ideen dieses gewaltigen Geistes sind von seinen Schïlern und Anhängern naeh allen Richtungen hin ansgebant worden und dureh die Fiille der hierdureh beeinflussten Arbeiten wirł es uns ermöglicht, so manches Dunkel zu lichten, das bisher undurehdringlieh sehien.

Vor allen hat es nenerdings Roux unternommen, die darwinistischen Grundsätze anch anf die Gewebe und Organbildung in thierischen Körper anzuwenden; hierdureh sind wir in den Stand gesetzt, wenn wir anf dem einmal eingeschlagenen Wege weiter wancleh, Resultate zu erlangen, die frïher merreichbar sehienen.

Neben den Regenerationserscheinungen, welche allein dureh functionelle Anpassung der Gewebe erklärt werden künnen, sehen wir solche auftreten, bei denen ein Verständniss nur erzielt wird durch die Betrachtung der phylogenetischen Ahnenreihe des betreffenden Thieres, und oftmals wird uns hierdurch eine fast an das Wunderbare grenzende Anfklärung der schwierigsten Verhältnisse zu Theil. So werden wir bei den Fragen, die uns hier zu beschäftigen haben, die höheren Probleme streifen und erkennen, dass vielleicht, wie Marshall einmal sagt, ,früher orler später das einfache normale Wachsthum und die Regeneration, die Theilungsfïhigkeit in allen ihren Phasen und versehiedenen Nuancen, als ungeschlechtliehe und gesehlechtliche Fortpflanzung, sich nur als Variationen einer Grundmelodie heransstellen werden — vielleicht, dass man eiust nicht mehr sagen wird: Die Regeneration ist eine Erscheinung der Vererbung, sondern die Vererbung ist eine Erseheinung der Regeneration." 


\section{A. Die Regenerationsversuche und ihre Resultate bei den verschiedenen Thierklassen.}

\section{Geschichtliche Entwickelmug der Regenerationsfrage in Bezug auf die wirbellosen Thiere.}

Betrachten wir diejenigen Erscheimngen im Allgemeinen, welche man gewïhlich mit dem Ansdrncke „Regeneration“ bezeichnet, so finden wir, dass in den niedrigsten Thierformen die Grenzen der versehiedenen Bedeutungen des Wortes vollständig verwischt sind.

Ein A möbe theilt sich von selbst in mehrere stiicke und jerles derselben wird wiederum zu einem vollständigen Thier, wemı dasselbe giinstige Lebensbedingungen erhält.

Dasselbe findet statt, wenn wir dieses einzellige Thierehen kiinstlich theilen, d. h. zerschneiden; anch dam werlen allmaihlich die einzelnen Theilstiickelien sich zu ganzen Thieren abrunden.

Diese Eigenschaft besitzen sämmtliche Zellen, deren Protoplasma keine Metamorphose erlitten hat, und die man daluer als proliferationsfähige oder amöboicle bezeichnet.

Anch bei den niedrigsten zusammengesetzten Thieren, den Cïlenteraten, sind die verschiedenen Begriffe noch vollständig identiseh.

Dic Actinien pHanzen sich meistens durch Theilung firt; zcrschneidet man sie in mehrere Stiucke, so wird aus jedem derselben ein neues Thier, das in kurzer Zeit die Organisation des alten erlangt hat. Nach Hoyg, Wright und Warington wachsen kleine Stiteke der Fussseheibe zu nenen Thicren heran; nach Gosse kommt boi manehen Formen (z. B. Anthea Cereus) freiwillige Läingstleihug als Fortpflanzungsmudus vor.

Die interessantesten, wahrseheinlich an einer Coryactes genannten Actinienform gemachten Beobachtungen rühren von einer Dame, Mudame Thyme, her: Im ersten Jahre theilten sich die Polypen iiber Krenz der Lïnge nach in vier, häintig ungleiehe Stiicke, wobei die Theilung von der erweiterten IIndiiffunng ansging, spiiter fand nur 'Theilung' in zwei oder drei stïcke, danehen aber anch Knnspung statt, und zwar vollzog sich dieser Prozess w lebhaft, dass nach zwei Jahren 
zwei Exemplare sich auf '20 vermeht hatten. (Marshall.) Trembley's höchst interessante Versuche an einem gewöhnliehen Sïsswasserpolypen (Hydra) liessen erkennen, dass derselbe dureh Zersehneiden in 4-6 Stiicke verwandelt werden kann, ja dass sogar aus einem abgesehnittenen Tentakel ein nenes Thier sich bildet. Dem berihmten Leydener Anatomen Bomhard Siegfried Allin entging die Tragweite dieser Versuche nicht, und aus seinen Darstellungen wird klar, dass er den innerlichen Zusammenhang der Regenerationsersehemungen wol erkannt hat. Im vorigen Jahrhundert sehlossen ieh an die Untersuchungen ron Trembley noeh die von Balier und Rösel ron Rosenhof, die zum Theil die Angaben Trembley's widerlegten. Im Uebrigen aber konnten die Experimente der Alten mit gleichem Erfolge wiederholt werden: Längs- und Querschnitte der verschiedensten Form und Grösse vereinigten ihre Schnittrïnder, wurden zu Hohlschliutuehen, die, wie abgesehnittene Tentakeln, einen Mumd bekamen, Fangarme trieben und lebenskräftig weiterwuchsen, wobei sich freilieh die Arten des Süsswasserpolypen etwas verschieden verhielten; am besten eignete sieh Hydra vulgaris, der gemeine grane Polyp, zu solchen Versuchen. Neuerdings hat Marshall es unternommen, die älteren Untersuchungen zu priifen und durch neue hochinteressante Thatsachen ein Verständniss der Regenerationsverhältnisse dieser Thiere anzubahnen. Aus seiner eigenen Darstellung theile ieh Folgendes hier mit: „Auffällig ist es, dass bei der Regeneration der Selinittstücke und anch der Tentakeln die Wachsthumsrichtung des Mutterthieres dergestalt imnegehalten wird, dass an dem nach dem urspriingliehen Muncie zu gelegenen Ende sich immer der nene Mund und die netten Tentakeln bilden, während das nach der Ansatzstelle zugewendete zur neuen Ansatzstelle wird. Diese Tendenz ist so stark, dass die abgesehnittenen Fangarme, deren mit der Leibeshöhle des Thieres communieirender Hohlraum am freien Ende geschlossen ist, nieht etwa einmal an dem offenen Sehnittrande 'Tentakeln treiben; dieser schliesst sich viehmehr und wird, während die geselhossene Spitze sich zum Munde öffnet und einen Tentakelkranz erhält, zur Ansatzbasis. Diese merkwürdige Eigenschaft, die Allman und Dalyell auch bei Meerespolypen (Tubularia indivisa) nach künstlicher Theilung beobachteten, und der ersterer den passenden Namen „Polarität" gab, dürfte vielleicht auf Vererbung beruhen, und gewinnt beim Vergleich mit der Strobilation der Scheibenquallen ein erhöhtes Interesse. In beiden Fällen sehen wir, wie quere Theilstiicke des Polypen zu neuen Wesen heranwachsen können, die das eine Mal zu Quallen, das andere Mal wieder zu Polypen werden, welche beile Formen nach dem früher Entwiekelten in gewissem Sinne gleich sind: in beiden F:illen wird eine Nachkommenschaft erzengt, die entweder aussehliesslieh geschleehtlieh (Quallen), oder, wemn aueh anfangs durch seitliche Knospen ungeschlechtlich, später durch befruchtete Eier anch geschleehtlieh (Hydra) sich fortpflanzt. Irrelerant ist für diesen Vergleich aneh, dass der Process an der Strobilation der Meduse freiwillig gesehieht, bei dem Siisswasserpolyp aber durch experimentirende Menschenhände bedingt wird." A. v. Heyder macht ferner in seiner Arbeit uiber die Gattung Cladocera (Sitzungsber. Acad. Wiss. Wien 84. Bd.) die Beobachtung, dass die Polypen der Cladocera bei langem Verweilen in Aquarium rerkïmmern und dann ein neutes kleineres Skelett innerhalb des alten Kelehes ausseheideu. Ein nahe am Kelchrande abgesehnittener Polyp bekam an seinem aboralen Ende eine nene Mundscheibe mit Tentakeln.

Die ebenfalls in das Gebiet der Regeneration fallenden Umkehrungsversuche Tremuley's wurden in der Nenzeit wiederholt geprifft und zwar war Th. $\boldsymbol{W}^{r}$. Engelmam in Utrecht der letzte, welcher die Unhaltbarkeit der in dieser Richtung angestellten Tremuley'schen Untersuchungen nachwies. 
Die Fähigkeit, abgeschnittene Stiicke wieder zu ersetzen, kommt aber auch denjeniger Formen der Pflanzenthiere in ansgiebigstem Masse zu, welche die Fähigkeit, siel spontan zu theilen, nicht besitzen.

So machte Oscar Schmidt mit dem Batleschwamme, welchen er in mehrere Stiicke zertheilte, böchst interessante Anptanzmngsversuche an verschiedenen Küistenstrichen des Mittelmeeres. Die einzelnen Stïcke rundeten sich zu vollkommenen Schwämmen ab; dem materiellen Erfolge war jedoch die Langsamkeit des Wachsthms hinderlich.

In derselben Weise bessem diejenigen Anthozwen und Hydromedusen, welche sich nicht durch Theilung fortptlanzen kömnen und vielleicht auch die Ctenophoren die durch Zufall erlittenen Defecte ans.

Es fchlen leider ïber diese interessanten P'mkte nenere Untersuchungen, weluhe, da die zarten Thiere schwer sich längere Zeit in Aquarien lebend erhalten lassen, auch wolıl anf grosse Schwierigkeiten stossen dïrften. Güde erzälılt uns in seinen Beiträgen zur Anatomie und Physiologie der Medusen (Berlin 1816), dass die Śchnittfäche bei verletzten Thieren sich nach wenigen Stunden abrunde, dass die Mertusen aber sonst kein grosses Reproductionsvermögen besässen. Dieselben leben jedoch fort, wem ilnen der Magensack niclat verletzt ist.

Aehnliclies beobachtete Eimcr an Ctenophoren, welche er in mehrere Theile zerschnitt, die alle munter für sich umherschwammen, wenn sich ein Theil der sogenannten "Rippen", welehe mit hyalinen Ruderplaittehen besetzt sind, an ihnen befand. Nur an einer einzigen kleinen Meduse ans der Gruppe der Thaumantiaden konnte Haeckel neuerdings eine vollkommene Regeneration der Theilstiicke naehweisen.

Nach den älteren Beobachtungen ron Rícumur, Spallanzani, Limé, Schueiger, Walch, Göze, Bemard de Jussieu, Guetiarl, de Villars, Otto Friedr. Mïller u. A. m. besitzen die abgesehnittenen Strahlen der Asterien und Ophinren nicht dis Vermögen, einen neuen Körper zu reproduciren, wohl aber emenert der Könper innerhalb kurzer Zeit die abgebrochenen Arne. Zuerst erscheint nach Spallanzani ein kleiner Stumpf oder eine Zunge, welche nichts weiter ist, als der Keim eines nenen Armes. Spallanzani beobachtete diese Vorgänge auf einer Reise an die Gestade des 1 littelmeeres im Jahre 1781 und fand, dass besonders Asterias rubens eine bedentende Reproductionskraft besässe. (Mem. de Matem. e Fisica, Verona 1782. Tom 1., p. 589.) Dalycll komte bei seinen Untersuchungen an Asterias constatiren, dass die Reproductionsfähigkeit eine ganz enorme sei, dass diese Form nicht nu verloren gegangene Arme mit Leichtigkeit ersetzen kömne, sondern dass anch einzelne losgelïste Arme zu ganzen Thieren regenerirten; ja es kommt nach nuserem Forscher freiwillige Abtrennung und Ausweelsselung von Amen vor, womit also die Regeneration zu einer wahren Fortptlanzung durch Theilung wird. Dassellue bestätigten auch Kócalewsliy und Lïtlien, die sogar noch eine mehrfache Art der Regeneration fanden. An dentlichsten ist die Erscheinung bei gewissen sechsarmigen Sehlangensternen (Ophiothela, Ophioctis und Ophicoma), die besonders leicht während der Jugend (Ophicoma nur wihrend dieser Zeit), seltener spiiter sich durch (Qnertheilung in 2 symmetrische Hälften zerlegen, die sich nach und nach wieder zu einem tadellosen Schlangensterne vervollständigen. Bei anderen Formen (Linckia, Ophidiaster) erscheint der Vorgang" als sogenannte radiüre Theilung modificirt, indem sich die Ame nich und nach von der Scheibe trennen, und ein jeder num ron der Trenmmgsstelle aus eine nene Scheibe und nene Arme bildet, während die alte Scheibe selbst anch wieder Arme erhält. 
Für Hacckel ist es bekanntlich eine ausgemachte Sache, dass die Stachelhäuter Thierstöcke oder Cormen, die Seesterne speciell Sternstöcke oder Asterocormi sind, darans hervorgegangen, dass eine bestimmte Anzahl (meist 5) ron jetzt leider ausgestorbenen Gliederwürmern eimmal zu irgend einer, wahrscheinlich schom sehr lange vergangenen Zeit, denn die Echinodermen sind mit die ältesten, fossil erhaltenen Geschüpfe, mit den Kopfenden verwachsen sind; er sieht in diesen legenerationserscheinungen, die eine llauptstiitze seiner Verwaehsungstheorie bilden, einen wirkliehen Generationswechsel. An der Trennungsfläche cines, wie bei Ophiactis, oft freiwillig sieh alogelöst habenden Strahls sprossen zunäehst die jungen Arme lıervor, als IIundïffnung fungirt das oftene Rissende des Strahlenarmes; erst wenn die nenen Strahlen eine gewisse Länge erreicht haben, bildet sich die Scheibe, in deren Mitte dann das Darmende als IIund rïckt. Fin soleher regenerirender Seestern hat natïrlich im Anfange ein einigermassen barockes Ansehen, indem er einen Arm von normaler Länge und 4 kurze hat. Haeckel bezeichnet diese Form selır passend als „Kometenform". Am umfassendsten wurde diese Art der Regeneration (Schizogonie) von Simroth bei einem kleinen Schlangenstern (Ophiactis vireus) verfolgt: An der Bruchstelle versehliesst sich die Wunde durch die nach unten ïberwachsende Rückenhant, während die Nenbildungen von Organen an der Banchiseite ihren Ursprumg nehmen; bei ler Queruptur der Scheibe werden nur deren feste Elemente symmetrisch getheilt, alles Uebrige, Magen, Gefässe, Nerven etc. werden ganz umegelmässig zerrissen. Diese Theilung aber als eine Forn des Generationswechsels aufzufassen, ist nach Simroth nicht recht zulässig, weil Exemplare von jeder Grösse und jedem Alter diesem Processe unterliegen. (Marshall.)

Ueber die höchst interessanten Vorgänge, welche sich bei den Holothurien finden, scheint den älteren Autoren Nichts bekannt gewesen zu sein. Erst durch Baur und Dalycll ${ }^{1}$ ) erfahren wir Näheres ïber die bekannte Fähigkeit der Synapta digitata, sich freiwillig in zahlreiche Stiicke quertheilen zu künnen. Letzterer machte ausserdem noch sehr eingehende Beobachtungen iiber die Regeneration verstimmelter Holothurien, welche Scmper ${ }^{2}$ ) zum Theil durch eigene Experimente bestätigen kounte.

Scmper erzielte vor Allem an der kleinen, sehr zählebigen Holothuria scabra Jäger mehrfach ähnliche Resultate.

Höchst wumderbar ist die Fähigkeit aller Stichopus und einiger Colochirus-Arten, gereizte Theile ihrer IIant lokal abzulösen und die Eigenschaft gänzlich isohrter Hautstiickehen, ebenfalls auf mechanische Reize durch weitere Anflösung oder Zerfliessen zu antworten, was Semper dureh die eigenthïmliche Innervation erklärt.

Ueber das Ausstossen der Cuvier'sehen Organe und die Regeneration derselben sagt Semper Folgendes:

„Nachdem mehrere Exemplare dieser Species (Holothuria scabra Jäger), in_meine Schalen gesetzt, ihren Darmcanal mit den Geschlechtsorganen, Gefässen und der linken Lunge völlig ausgestossen hatten, wechselte ich das Wasser und liess sie uun, unter täglich einmaligem Wechseln des Wassers, ruhig leben. Kurz nach dem Ausstossen sahen diese Thiere elend genug aus, aber doch ging fast Keines zu Grunde. Sie begannen nach kurzer Zeit trotz des Mangels des Tractus das Spiel ihrer Athembewegungen, die sich durchaus regelmässig, wie bei gesunden Thieren wiederholten. Die Mehrzahl derselben öffnete ich nach 2-3 Tagen, sie hatten alle ihren Darmeanal dicht hinter dem Wassergefässring abgetronnt, ein einziges Exemplar liess ich länger leben. Am neunten Tage öffnete ich auch dieses und fand nun in

1) Dalyell, Powers of the Creator, Vol. I. 1851 p. 49 eqq. (Ueber Thyone fusus und Ocnus lacteus).

2) Semper, Reisen im Archipel der Philippinen. I]. Theil I. Band. Holothurien pag. 200. Wiesbaden 1868. 
ilim den Darmeanal rollständig in typischer Gestalt wiedergebildet; doch war er noch etwas dünn und gänzlich lecr, wie nicht anders zu erwarten stand, da in der Schale durchaus kein Sand vorbanden war. Auch die linke Lunge hatte sich schon wieder gebildet, war aber noch klein; ron Geschlechtstheilen war noch keine Spur zu sehen.“

Bei den verschiedenen Classen, welche gemeiniglich mit dem Namen der "Würmer" bezeichnet werden, ist das Regenerationsvermögen am ansgeprägtesten und an besten untersucht bei den Anneliden, obgleich es auch, wie ich mich selbst iiberzengen konnte, in hohem Grade den Plattwümern, besonders den Turbellarien zukommt.

Bei den Cestoden fällt wie bekamt die Reproduction mit dem Wachsthum oder der Fortpflanzung vollkommen zusammen, da die ron Zeit zu Zeit alogestossenen geschlechtsreifen Glieder sich fortwaihrend durch den Torgang der Strobilation erneucrn.

Die Anneliden endlich besitzen in Allgemeinen ein ausserordentlich grosses lieprodnetionsvermögen; dasselbe ist jedoch ebenso wie Jei anderen Classen bei den einzelnen Arten rerschieden, und einigen fehlt sogar die Fähigkeit, verlorene Theile wieder zu erzengen, vollstindig.

Seln Jeachtenswerth sind lierfür die iilteren Arbeiten von Récumur, Treviramus, Spallanzani Schweiger, Mïller, Rösel und hesonders Bomet, die zum Theil ganz ausgezeichnete Bcobachtungen enthalten. Hierdmeh erfahren wir, lass grosse abgerissene Stiicke des Schyanzes von Nereis sich vollständig wiedererzengen, ja das abgeschnittene Theile ganze Individuen regeneriren. (MLïler.)

Bei Naiden wächst das aljgeschnittene liopf- und Schwanzende mehr als zwölfmal nach (Rösel, Bonnet), aber das abgeschnittene Kopf-oder Schwanzende muss nach Bonnet, um zu einem ganzen Wum heranzuwachsen, wenigstens eine Länge von 11/2 Linien haken, wogegen man den Kürper seltust in 4-6 und mehrere Stiicke theilen kam, welche alle sich zu ganzen Thieren anszubilden im Stande sind.

Auch bei den Regenwïrnern kann man sowohl den Kopf wic den Schwanz ohne Gefahr für das Thier absehneiden, da sich clieselben innerhalb kurzer Zeit emeuern, nur darf man kein zu grosses Stück des Kopfes abnehmen (Spallanzani, Bonnet). Schmeidet man einen Regenwurm in der Mitte quer durch, so sollen zwei nene Wiumer entstehen, doch bildet sich der. Sehwanz an dem Kopftheil bedeutend schneller, als der Kopf am Schwanztheile. Auch ein ausgesehnittenes Mittelstiick wird zu einem neuen Wurme.

Nach Spallanzani geschieht die Regeneration nicht durch die Entwickelung nener, sondern Jurch die Auswickelung der älteren linge - eine Ansicht, welche durch die eigenthimlichen Anschaum gen seiner Zeit erk]ïrt wird.

Noch eingehendere Untersuchungen wurden von Bonnet ${ }^{3)}$ ibler die Regeneration einiger Wiirmer des süssen Wassers gemacht: besonders ïber Lumbrieulus und seine Verwandten, welehen in noch bedeutend höherem Masse die Fïhigkeit, verloren gegangene Theile zu reproduciren, zukommt, als den vorhergenamnten Ameliden. Bomnt beobachtete sograr, dass sich diese Wiumer zu gewissen Zeiten des Jahres, in IIai und Juni, spontan durch Theilung fortpflanzen.

Den Blutegeln scheint dagegen das liegenerationsvemögen vollstïndig zu fehlen, wie wir aus den älteren Angaben von Selweiger und Johnson a) erfahren.

Zu wierlerholten Malen wude auch bei den Anneliden dic Möglichkeit eines Ersatzes des

1) Bonnet, Collection complete des oeuvres. Neuchatel $17 \varangle 1$.

I) A treatise on the medical leech. Edinburgh 1516 . 
verloren gegangenen Kopfes bezweifelt, bis Dugés ${ }^{1}$ ) durch treftliche Versuche dieselbe definitiv nachwies.

Quutrefoges, ${ }^{2}$ ) aneh hiedurch nuch nicht zufriedengestellt, wiederholte im Jahre 1865 die Experimente, gelangte aber zu demselben Schlusse, dass bei den Regenwirmern nach Fortnahme der vorderen Kö̈persegmente, welche den Schlundring und die ersten Ganglien enthalten, der Kopf sich mit allen diesen Organen wieder bildet.

Nach den Beobachtungen von Leidy ${ }^{3}$ ) ]flamzt sieh Stylaria fossularis (Nais) den Sommer iiber ausschliesslich durel Theilung fort; erst im Herlost, wo die Fähigkeit dieser ungeschlechtlichen Vermehrung erlischt, bekommen die Individuen zwitterhafte Geschlechtsorgane. Anch Nerport ${ }^{4}$ ) bestätigt die Angaben von Bonnet und Spallanaani ïber das Reprodnctionsvermögen von Lumbricus terrestris und Maier ${ }^{5}$ ) von den Naiden. Letzterer gelangt zu der Erkenntniss, dass diejenigen Theilstïcke der Naiden, welche zu ganzen Thieren answachsen kömnen, mindestens immer ein Ganglion und einen Abschnitt des Blntgefässsystems in sich einschliessen müssen. -

Ueber dieselben Verhältuisse bei Meeresanneliden finden sich nur wenige Untersuchungen. van Beneden ${ }^{6}$ ) macht die Beobachtung, dass Serpulaceen und andere Kopfkiemer nicht bloss die verloren gegangenen T'entakel wicder ersetzen, sondern mitunter auch in seheinbar leeren Röhren aus kleinen Bruchstiieken wieder zu ganzen Thieren auswachsen.

leh selbst hatte Gelegenheit, bei einer Spirographis, welche in meinem kleinen Seewasseraquarium durch einen Zufall ilner Tentakel beraubt war, den ersten Beginn der Neubildung zu beobachten; leider ging das Thier, wahrschcinlich in Folge von Nahrungsmangel, zu frülı zu Grunde, als dass ich weitere Beobaehtungen an demselben hätte machen können.

Macdonald 7) erzählt uns femer, dass er bei Gelegenheit der Untersuchung des sogenannten Palolowumes die auffallende Thatsache bemerkt habe, dass alle seine Exemplare des Kopfendes entbehrten; er lıält dies nieht für zufällig, sondern glaubt vielmehr an eine bei bestimmten Gelegenleiten normal auftretende T'remung, an einen der Abstossung der Proglottiden ähnlichen Vorgang.

Ferner existirt noeh eine Vittheilung von Quatrefuges, ${ }^{8}$ ) dass er in der Sammhng les Pariser Mnseums einen Wurn (Diopatra uncinifera) mit nengebildetem Vorderende gefunden habe, und dann eine Arbeit von Kinberg, ${ }^{9}$ ) in welcher eine Amphinomee (Lycaretus neocephalicus) beschrieben wirk, an ter er gleiche Verhältnisse beobachtete.

Ehlers ${ }^{10}$ ) endlich beschenkte uns im Jahre 1869 mit einer vortreffliehen Arbeit iiber den anatomischen Befund bei zwei nengebildeten Köpfen von Diopatra fragilis.

Bis vor Kurzem standen wir in Bezng auf die Kenntniss der Regenerationsvorgänge bei

1) Dugés, Recherches sur la circulation, la respiration et la reproduction des Annélides abranches. Annales des scienc. nat. 5. XVI 1828. 1. 316.

2) Quatrefages. Histoire naturelle des Annelćes. T. I. 1Y65. p. 126, Note 3.

3) Leidy, A flora and fauna within liv. Anim. Smithson. Contrib. V. p. 11 Aum.

1) Nexcport Ann. nat. hist. XIII. 1854. p. 423.

5) Muier: Verhandl, d. naturf. Vereins d. preuss. Rheinlande. Bd. XVI. S. 43 ff.

в. ren Beneden, Comptes readus. T. 49. p. 453.1859.

7) Maedonuld, Ann. of nat. soc. 1859.

8) Quatrefuges. Histoire vaturelle des Annelées. T. I. p. 121, 342.

8) Kinberg, J. G. H. Om regeneration af liufrudet och de främre segmenterna hosen Aunulat. Ozfrersigt af kongi, Vetenskaps dkademiens Förhandlingar 1867 N. 2. p. 53.

to) E. Ehlers. Dis Neubildung des līopfes und der vorderen Körpertheile bei polychaeten Anneliden. Erlangen 1869. 
den Ammetilen noch so ziemlich auf dem Standpunkte, den Bomct in dieser Frage eingenommen hat, bis wir denn durch die bahnbrechenden Arbeiten ron Clans, Tauber und Semper iuber die Knospung der Saiden zu der Ausicht gefihlut wurden, dass Knospung und Regeneration nur graduell, nicht principiel] rerschiedene Bildungsweisen sind. Auch Bülow hat in seiner Arbeit ${ }^{1}$ ) höchst interessante Wittheilungen über die histologische Organisation des Schwanzendes ron Lumbriculus gegeben; rorher hatte cr in seiner Abhanllung über Theilungs- und liegenerationsvorgänge bei Wïrmem ${ }^{2}$ ) die allgemeinen Regenerationsverhältnisse des Lmmbriculus in der exactesten Weise dargestellt, olme jedoch näher auf die histologischen und histogenetischen Fragen dabei einzugehen. Aus diesen Arbeiten sollen nur die allerwichtigsten Punkte hervorgehoben werden, da sie ja wohl den sämmtlichen Fachgenossen bekamnt sein werden.

Nach Beobachtmugen rom 13. Juli bis Anfang Uctober waren im Durchschnitt nur $7 \%$ nicht regenerirte Thiere rorhanden. Spontane Theilungen wuden anch im Artuarium beobachtet, so dass B. die Ansicht ansspricht, dass bei Lumbriculus neben der geschlechtlichen Fortptlanzung anch eine ungeschlechtliche durch einfache freiwillige Quertheilung (Schizogonic) rorkomme. Dabei wird im Gegensatz zum Terhalten der Naiden und Syllideen vor der Theilmg keine Kinospungszone gebildet

Das neue Hinterende entstelit als ein kleiner Wulst, dur ganz aus neuen Zellen gebildet erscheint und iiber und iiber flimmert. Die Knospe wächst, die Flimmerung verschwindet wieder, und nach und nach beginnt die Segmentirung. Auch der neue Kopf legt sich als ungegliederte Knospe an, in der erst spaiter die Segmentation cintritt. Während die Zahl der regenerirten Schwanzsegmente eine ganz unbestimmte ist, crreicht der regenerirte Kopf nur eine beschränkte Grösse. Bei eincr freiwillig vor sich gehenden Theilung werden 10 nene Segmente erzeugt, zwei rordere borstenlose, den Mund umschliessende, und acht borstentragende, der contractilen, blinul endigenden Gefässanlage enthehrende. Es scheint daher berechtigt, these Segmente als "Kupfsegmente" in Anspruch zu nehmen. Schneidet man von den Kopfsegmenten eine bestimmte Zahl ab, so wird stets die gleiche Zahl regenerirt, wïhrend dic abgeschnittenen nicht lebensfähig sind. Sobald jedoch an den Kopfsegmenten auch mur $11 / 2$ oder 2 Rumpfscgmente sich befinden, kann ein nenes Schwanzende gebildet werden.

Ton höchster Wichtigkeit ist vor allem das Auftreten besonders scharf abgegrenzter Keinsehichten an Schwanzende, welehe den embryonalen Keimblättern zu vergleiehen sind. Dann treten in der mittleren Kcimschicht, welehe ihren Ursprung sowohl ans dem Ektoderm, wic ans dem Entolerm nimmt, zwei Mesodermkeinstreifen auf, welche sich friher gliedern, als die zugleich sich bildende neurale Ektodermrerdickmg. Das gesammte Bauchnerrensystem mit den „Spinalganglien" entsteht aus dem Ektoderm; dic Muskel)łatten und die sonstigen muskulïsen Elenente sind dagegen mesodermalen Ursprungs; ebenso Segmentalorgane, Leberzellen und Blutgefisssystem. Die Borsten und die nervösen Seitenlinien kommen aus dem Ektoderm, ihre Nebenapparate (Muskulatur und Borstentaschen) aus dem Mesoderm. Eine Vergleichung dieser Entwiekelungsvorginge mit den im Embryo sich vollziehenden lässt nach Bülou's Mcinung folgcnde Behauptung rechtfertigen: Die drei woh] unterscheidbaren Schichten im normalen, wachsenden Afterende ker Anneliden, die candalen oder Schwanzkeimschichten, sind den cmbryonalen Keimblättern dynamisch

1) Bulow. Die Keimschichten im wachsenden Schwanzenle von Lumbriculus variegatus, nebst Beiträgen zur Anatomie und Histologie dieses Wumes. Zeitschr. f. " iss. Zool. Bd. XIXIX. H. 1. pag. $64 \mathrm{ft}$.

2) Separataburuck aus d. Areh. für Natgesch. 49. Jabrg. No. 1. 
gleichwerthig da sie dieselben, Organe bilden, wie diese. Nur in der Entstehnng der Mesodermschicht als des ersten Differencirungsproductes der primären zwei schichten, ist eine Modification eingetreten; sie nimmt nicht melur, wie beim Embryo ans dem Entoderm ihren Ursprung, sondern aus der Stelle, wo äussere und innere caudale schicht in einander iibergehen. Krurz: bei den Oligochaeten sind eandale und embryonale Keimsehichten dynamisch gleichwerthige Prinitivorgane." Auch mit den l'rocessen, wie sie ron Semper bei der Knospung der Naiden geschildert werden, vergleicht bïlow die eben angegebenen Vorginge, da er schr wohl erkannt hat, dass Knospung und liegeneration nur graduell, nicht principiell verschichene Bildungsweisen sind. Er stell seine Hypothesen kurz sn zusammen: „Die histologischen Vorginge bei der Bildung der einzeluen Organe im wathenden Schwanzende und in sich regenerirenden Theilen des Annelidenkörpers sind denjenigen gleich, welche bei seinem Auflau im Embryo stattinden." In wiefern dieser Satz auch auf andere Thiergruppen ausgedehnt werden kamn, lässt Bülow. dahingestellt bleiben.

Weder bei den Polychaeten, Hirudineen, Cestuden, Trematoden, Gephyreen und anderen zu den Wiumern gerechneten Thieren ist ein derartig grosses Regenerationsvermögen bemerkbar, wie bei den oligochaten, auch bei den Tunicaten ist dasselbe bisher noch kam beobachtet worden. Dagegen fallen uns wieder die Bryozoen in die Augen, bei welehen zeitweise naclı Claparède und Vitsche eine eigenthümliche Regeneration in den verödeten Zellen eintritt, die nit der Knospung viele Aehnlichkeit besitzt. Auch den Nemertimen kann der Riissel nach $\boldsymbol{I}$ c. Intosh oftmals wieder wachsen, während das Reproductionsvermögen des iibrigen Kürper's ziemlich gering ist. In seiner grossen Monographie der Pantopoden macht Dohw femer aufmerlsam auf die bedeutende Regenerationsfähigkeit dieser kleinen spinnenihnlichen seethiere.

Unter den Arthropoden herrscht in bezug auf die Regenerationsfähigkeit ein grosser Unterschied bei den verschiedenen Girupen. Hochinteressant sind die Jittleilungen von Huxley ${ }^{1}$ ) und Frediricq ${ }^{2}$ ) zu denen Dewitz ${ }^{3}$ ) einige kritische Benerkungen linzufügt. Während die Regeneration abgestossener Beine bei Krabben und beim Flusskrebs bereits bekannt war, lenkten diese Forscher die Aufmerksamkeit auf das spontane Abzuwerten der scheeren und Beine bei Krabben und dem Flusskrebs. Nach Frédiricq berulit das Abwerfen der Beine auf einer Reflexbewegung; das F'esthalten des Beines allein bewirke keineswegs das Abwerfen, sondern nur ein Reizen der Emptinhlungsnerven dureh starkes Drieken, Durchschneiden des Gliedes anf chemischem orler electrischem Wege und cndlich die Anwendung von Wirme. Durch diesen Reiz werden gewisse Muskeln reflektorisch in Thätigkeit versetzt und rufen den Bruch des Beines hervor. Während Fredericr's Experimente am Flusskrebs misslangen, wiederholte Dewitz dieselben gerade an diesem Thiere und komnte eonstatiren, dass auch der Fhusskrebs im stande sei, die Scheeren abzuwerfen, doch ebensu wie nach $F$, dic Krabben, nur infolge eines starken Reizes; nicht, wie Huxley sagt, infolge blossen Festlaltens. Die Anwentuug ron heissem Wasser blieb erfolglos, dagegen bewiilurte sich das Durchschneiden der Scheere oder die Versengung durch eine Flamme. Nach dem Experiment gerith das Thier in Zuckungen mul entledignt sich des verletzten Beines. Die Abtrennung findet stets dil statt, wo die Schecre sich auch bei todten (gekoehten) lírebsen am leichtesten ablüsen lässt.

1) Der Krebs. Internationale wissenschaftliche Bibliothek Bil 48. 1S81. p. 32.

2) Sur lautonomie ou mutilation par voie reflexe comme moyeu de défénse chez les animax. Arehives de zool. expérimentale. 2me Sér. T. 1. 1883. p. 413-26.

3) Ueber das Abwerfen der scheeren des Flusskrebses. Biologisches Centralblatt. Bd. IV. No. 7. p. 201. 
Réaumur ${ }^{1}$ ) hat zuerst die Thatsache entdeckt, dass dem Fluskrebs abgeschnittene oder ausgerissene Beine, Scheeren und Antennen leicht wieder wachsen. Der Stumpf wird zuerst ron einer röthlichen Haut bedeckt, welche sich allmählich zu einem kleinen Kegel erhebt, in dem dann die weitere Differenzirung vor sich geht.

Weitere Beobachtungen sind hierüber nur noch einige wenige gemacht worden; so finde ich im Zoological Journal Nr. 12, 1828 eine Bemerkung, dass C. Heineken zu Funchal auf Madeira Versuche und Beobachtungen über die Regeneration der Füsse bei Krebsen und Spinnen gemacht liat.

Nach 1\%. Culloch (im Edinb. Journal 1890) sollen die Krabben an einer besonderen Naht ihre Glieder abverfen und wieder reproduziren, beides aber nur an dieser Stclle. Heineken untersucht diese Angaben und erstattet Bericht über seine Versuche an Krabben und Spinnen, wobei er zu dem endgültigen Schluss kommt, dass eine Reproduction bei diesen Thieren nur dann möglich ist, wenn dieselben sich noch häuten, d. h. wenn sie noch nicht ganz ausgewachsen sind. Ganz fertige Blattae, Forficulae, Acridia reproduziren die Fühlhörner nicht, wolnl aber die Onisci.

ln Spanien soll man von einer lírebsart, Boccace genannt, nur die Scheeren geniessen; die derselben beraubten Thiere werden lebendig wieder in's Wasser gew'orfen und sollen die Seheeren in Kurzem wieder erlangen.

Dalyell hatte mehrere Taschenkrebse in einen Behälter gesetzt und bemerkte, dass die stärkeren über die schwächeren herfielen und sie ihrer Extremitäten beraubten. Einen Taschenkrebs, der nur noch 3 Beine hatte, isolirte el und bemerkte zu seinel grössten Verwunderung, dass derselbe nach der bald darauf eingetretenen Häutung alle 10 Füsse hesass; dieselben hatten sich unterhalb des alten Panzers neu gebildet.

Uejer die Regeneration der Insecten, Arachniden und Myriapoden ist ausser der angefülnrten Mittheilung von Heineken nichts bekannt.

Grossen Streit und gewaltige Aufregung verursachten andererseits die an den Mollusken angestellten Experimente.

Da indessen in diesem Jahre eine eingehende Arbeit meines Freundes Dl. J. Currière ${ }^{2}$ ) über diesen Gegenstand erschienen ist, die mit besonderem Fleisse die historische Entwickelung der Regenerationsversuche behandelt, so kann ich mich hierüber sehr kurz fassen.

Auch hier ist es wieder Spullansami, welcher die erste Anregung zu ernsteren, consequent durchgeführten Versuchen gegeben hat. Nach seinen Experimenten regeneriren sich bei den Landschnecken nicht nur die abgeschniltenen Tentakel mit den Augen, sondern auch die Köpfe mit allen ihren Bestandtheilen, ,die Regeneration findet statt, ob man den Kopf vor oder hinter dem Gehirn abschneidet, da in letzterem Fall das Gehirn sich ebenfalls neu bildet."

1) Réaumur: Mémoires pour servir a l'histoire des lnsectes.

$\left.{ }^{2}\right)$ Studien über die Regenerations-Erscheinungen bei den Wirbellosen. I. Die Regeneration bei den Pulmonaten von Justus Carrère, unit 2 Tafeln. Würzburg. Staudinger. $18 s 0$. 
Nach Spallansani rrzielte Schieffer in grüsserem Masse günstige Resultate. Auch Roos. Latwuisier, Otto Friedrich Vüller, Voltaire, Pater Scarella in Brescia, Abbé Troilo in Modena, Bonnet. ein Anonymus, der Genfer Bibliothekar Senebier, Sunders in Karlsruhe, stellten sich auf die Seite Sprullanarmi"s, für welchen ihre Erfolge sprachen.

Unter die Gegner Spallmanis sind zu zälılen: Adanson, G. Wartel, Schröter, Talmont de Bomare, Colle, Murray, Argenrille, Aldildyaard und Presciani. Vor und wälırend der Publikation seiner vervollständigten Versuche in den Mem. di IIatematica e Fisica della Societa Italiana Tom. I und II. traten nun noch folgende kïmpfer fǜ Spallansani auf: Pratolungo, Girardi, und Culduri. Ein sehr unbefangener Beobachter, A. F. Schoeigger, kommt in seinem Handbuche der Naturgeschichte ctc., nachdem er die eigenen Prïharate Spallunsani's betrachtet, zu dem Schluss, dass derselbe sich in Bezug auf die Wiedererzeugung des Schlundringes getäuscht habe, da sich nachweisen lasse, dass Spallansani denselben fast nie verletzt habe. -

Currière macht nun besonder's darauf aufmerksam, dass die Jahreszeit cine grosse Rolle bei der Regeneration spiele, man dürfe keine Schnecken zu den Versuchen verwenden, welche elsen erst den Winterschlaf durehgenacht haben, da dieselben 7. schwach seien, un eine derartige Verletzung zu ertragen und auszubessern.

Zu den Versuchen eignen sich besonders H. hortensis, nemoralis und H. pomatia, während I. fruticum und besonder's H. arbustorum sehr empfindlich sind. Nacktschnecken eignen sich nicht, da sie sich zu selwwer in kleineren Gefüssen halten lassen.

Im günstigsten Fulle regenerirt H. hortensis die Augen nach 50-60 Tagen rollkommen.

„Es hildet sich nach dem Typus der embryonalen Entwickelung zuerst eine Einstülpung les Epithels, dann entsteht eine rundliche Blase, welche noch durch einen äusserst kurzen, holllen Stiel mit dem Epithel zusammenhängt. Hierauf wird zunächst die Einstülpung geschlossen, indem das Epithel übel- derselben zusammenwächst.

Mit dem fortschreitenden Wachsthum gehen wichtige Umbildungen in der Augenblase ror. Sie selbst löst sich von dem Epithel vollständig ab und gleichzeitig lässt sich cine Differenzirung ihrer bisher ziemlich gleichartigen Zellen in zwei Gruppen erkennen, Hand in Hand gehend wit dem ersten Auftreten des Pigmentes.

Ein wichtiger Bestandtheil des Auges, welcher in den früheren Stadien noch fehlte, tritt jetzt auf, indem vou hicl an sich in den Augenblasen auch eine Linse vorfindet.

In den Verhälnisse, wie dje Angenblase wächst und sich vergrössert, tritt anch die Unnbildung der ursprünglichen Epithelzellen zu den charakteristischen Bestandtheilen des Helix-Auges schäıfer hervor und beide Zelformen näherı sich mehr und mehr ihrer normalen Gestalt."

Die Hauptresultate del Arbeit Curviere's sind:

1. Nit dem Schlundring alggetrennte Köpfe werden nicht regenerirt.

9. Die Regeneration des Epithels geht in derselben Weise ror sich, wie bei den Wirbelthieren. 
3. Alggetrennte Organe, wie z. B. das Auge, erlangen bei ihrer Neubildung genau denselben Grad der Vollkommenleit wieder, den sie im normilen Zustande vor der Operation besassen.

1. Die Bildung des Auges bei der Regeneration findet genau in der gleichen Weise statt, wic bei der embryonalen Entwickelung.

Höchst interessant ist lerner eine biologische Eigenthümlichkeit, welche verschiedenen tropisehen Schnecken ans der Gattung Helicarion ${ }^{1}$ ) zukommt; dieselben werfen nämlich, wenn sie gereizt werden, einen Theil ihres Fusses spontan ab und regeneriren denselben wahrseheinlich innerhatb sehr kurzer Zeit. Jedenfalls dlient dieses Abwerfen des Fusses ten Thieren in ähnlicher Weise zum Schutze, wie den Eidechsen die leichte Brechbarkeit ihres Schwanzes.

Erwälnen muss ich noch die ausserordentlich merkwürdige Regeneration des Hectocotylus bei einigen Cephalopoden, olme mich jedoch näher auf dieselbe einzulassen, da wir es hier mit einem rein physiologischen Vorgang zu thum haben.

Die Uebersicht über die Regenerationserscheinungen bei den Wirbellosen wïre hiemit geschlossen. In hohem Nasse ist die Fähigkeit, rerloren gegangene Theile des Körpers wieder zu erzeugen, den niederen Thieren eigen, und oft wachsen die wichtigsten Organe in kurzer Zeit zu der ursprünglichen Grösse und Vollkommenheit heran.

Dass bei denjenigen Thieren, welche sich dureh spontane Theilung fortpflanzen, die Reproductionskraft eine bedeutend grössere ist, wie bei den nächsten Verwandten derselben, welche diese Eigenschalt nicht besitzen, ist ganz natürlich; ebenso wircl das weniger hoch organisirte Thier leichter regeneriren, wie ein lı̈̆ler organisirtes.

Dann machen wir schon bei den wirbellosen Thieren die überraschende Entdecknng, dass den im Wasser lebenden Thieren eine grösser'e Reproduktionskraft zukommt, als denjenigen, wetehe reine Landbewohner sind.

Wir haben ferner gesehen, dass die Temperatur im Allgemeinen, die Jahreszeit im Besonderen eine bedentende Rolle hierhei spielen.

Von noch allgemeineren Grundsätzen, welche wir durch die Betrachtung der Regenerationsverhältnisse bei den Wirbellosen gewonnen haben, werden wir folgenden für dieselben Verhältnisse bei clen Wirbelthieren sehr wohl beniitzen kömen:

Je weniger complicirt die verloren gegangenen Theile gebaut sind, desto leichter regeneriren sie.

Ein sehr wichtiger Satz, den uns die interessanten Verhältnisse bei der Regeneration der Würmer erkennen liessen, bei denen sich del Schwanztheif bedeutend rascher und rolkständiger regenerirt, als der Kopftheil.

') Semper, Reisen im Archipel del Philippinen. II. Theil, Band III, Heft I. 


\section{Geschichtliche Entwickelung der Regenerationsfrage in Bezng ant die Wirbelthiere, besonders Amplibien mud Reptilien.}

Schon den allen Griechen unł Römern war die merkwürdige Naturesscheinung bekannt. dass einzelnen Wirbelthieren abgeschnittene oder verloren gegangene Gliedmassen wieder nachwachsen.

Der Altmeister (lej Naturwissenscliaften, Aristoteles, ${ }^{1}$ ) kannte diesen Vorgang bei den Eidechsen und Blindschleichen (serpentes) und lyemerkt nachträglich, dass Einzehne behaupten, auch bei den jungen Schwathen würden die ausgestochenen Augen wiedererzeugt.

Scin minder geistreicher Interpret und Absclreiber Plinius ${ }^{2}$ ) der Jügere behauptet dasselbe, und fügt hinzu, dass bei den Eidechsen auch doppelte Schwänze rorkommen (lacertis invenimulur et geminae).

Erst in Mittelalter finden wis dann wieder einige Bemerkungen über die Regeneration und zwar ist es Hieromymus Cardanus, ${ }^{3}$ ) welcher zuerst die Angaben der berühmten Naturforscher des Alterthums prüft unı weiter auslührt: ..Proprium videtur esse mimalibus a putredine genitis. quae insecta sint, ut pracisa membra illis renascantur: ut caudae serpentum et lacertorum, chaelac cancrorum, oculi hirundinm certe, ef ut multi existimant etian serpentum. Causa hujus est quod jmperfecta sunt: unde non hirundinibus, sed pullis hirundinum oculi renascantur, et in foetibus etiam persaepe dum in utero sunt membra oblaesa restaurantur. Mledici ob id quod humidiora sunt dicerunt. Forsan utraque causa vera dici potest. tu genere igitur insectorum erunt testudines et elocodili, el chamaeleontes. et quaecumque quadrupeda ex ovis, ut pisces vel volucres. ut inferius demonstrabimus, generantur, sed ob naturae imperfectionem. Igitur his ex talibus, membra. praecisa restamrantur, ignobilis enim natura ovi et seminis, vestigium vix in his discernitur."

Ferner finden sich einige Bemerkungen bei J. B. Porta, ${ }^{4}$ ) der viele Eidechsen mit doppeltem und dreifachem Schwanze gesehen hat, von denen el annimmt, dass sie durch Zwillingsbildungen entstanden seion (,, ne alio modo natas possibile est esse, nisi ex dilecythis ovis").

In derselhen Weise spricht sich ildrovundus ${ }^{5}$ ) aus: „Siepe etian lacertae chabus et tribus caudis lefertae nascuntur, quas vulgus ludentibus farorabile esse nugalur. Quae monstra

1) Aristotelis historia de aninalibus, Julio Caesare, Scaligero interprete, cum ejustem Commentariis. Tolosae MDCiSIX. Iji). II c. XX p. 27 S.

2) Plinii secundi listoria mundi. Lib. XXXYll. Lib. Xl c. L. de caulis.

3) Tieronymi Cardani Mediolanensis, medici, de subtilitate. Lib. XX. Lugduni MDLXXX lil, IX. p. 331.

4) Jo. Liptistae I'ortue Veapolitani magine naturalis libri viginti. Rhotomagi MDCiL lib. 11. De variis animalibus gignendis Cap. XVIII. Ser]entes pluris capitihus candihusque.

5) Tlysas A7drovandi patritii boloniensis de quadrupedihns digitatis oviparis. lib. 1t. Boloniae MDCXXX.XY. 1. $630-63]$ и. 635 - 636, mil desselben Historia monstrorum NUCXLII, Caj.VIII, p. $593-96$. 
non ab alia causa, nisi ab oris dilecythis, id est, geminis dimanare possunt. Verun magis admiranda fuit lacerta quadricauda, quae anno Domini 1596 nobis dono data fuit. Etenim longior cauda tres alias lanquan ramusculos producebal. Quod monstrificum animal ex abundantia materiae natum fuisse existimamus, et praecipue, quoniam ceterae corporis partes justo grandiores erant." Und fernel" in seiner Historia monstrorum:

„Hactenus de prava caudarum conformatione actum sit; modo de earum geminatione el multiplicatione nonnulla sunt punderanda. Etenim, licet vitulis, agni et canes duabus caudis referti raro observantur; nihilo minus in alio animantium genere, nimirum in lacertis caudarum multiplicatio saepe conspicitur. Namque lacertas bicaudas, tricaudas et quadricaudas conspicati sumus quas vulgus postea insultissime ludo favorabiles praerlicat. Has autem candas a nulla alia causa prodire posse. nisi ab ovis delecythis Joannes Bapliste Portu in Magia naturali opinabatur. IIas lacertas monstrificas in icone II spectandas lectori exhibemus. Sed inter alias magi: admirabilis fuit lacerta quadricauda, quae anno post sequimillesimum nonagesimo sexto nobis donn data fuit."

Dann folgt Albertus llagnus ${ }^{1}$ ), dessen Ausführungen ich ebenfalls hier nach den Originallext folgen lasse: „Oculi autem serpentis a principio nativitatis sunt humiditatis incompletae, cujus major pars est in capite non adunata ad locum oculi : et illa quae est in capite, est spiritus formativus et formativa virtus oculi: et ideo si pungantur parri et jam nati serpentis oculi, recrescunt propter eandem causan. Cauda vero serpentis generatur maxime de humido cibali, sicut el canda lacertae: et est corpus ejus simile ei quod non indiget diversitate spiritus formantis et virtutum formantiun varietate: sed formalur unum membrum ex alio sibi simili: et ideo cauda serpentis abscissa, iterum recrescit sicut et cauda lacertae: et in ommibus similiun complexionum membris ct animalibus, istud invenitur, nisi membra principalia, quae figura et virtute differunt ab aliis, Juerint anputatae, sicut est caput, col', stomachus et hepar et ejus modi; el hiee quidem de composilione colporum serpentum universaliter lice, quamris etiam in antehabitis libris ista sint ostensa."

Juhames Johnstomus ${ }^{2}$ ) elwïhnt in seiner Naturgeschichte die Angaben seiner Vorgänger und schliesst sich der Meinung an, dass die doppelten Schwänze Missbildungen seien. Er gil)t auch die erste Abbildung eines regenerinten Schwanzes.

Comrad Gesner, ${ }^{3}$ ) oder wie er mit Forliebe genannt wird, ,der alte Gesner" kennt dic merkwürdigen doppelschwänzigen Eidechsen nur aus den früheren Wrerken und aus einer Abbildung, welche ilm von einem Arzt aus Meissen, Jo. lientmamus, zugesandt wurde.

1) Beati Albertimagni, Ratisbonniensis episcopi, ordinis praedicalorum de animalims, lib. X. V V operum L.ti. Lugduni MDCLI. Jih. XXV, P. 662.

$\left.{ }^{2}\right)$ Joamnes Johmstomus M. D. Ilistoriae naturalis de ruadrupedibus liliri cum Aeneis liguris. Amstelodaui HDCLVII. t. I lib. IV c. II art. I u. art. II, P. I34 tab. L I IVII.

${ }^{3}$ ) Commdi Gesneri Tigurini, ned. et pliil. professoris in schola Tigurua, listoriae animalium lib. IJ, qui =et

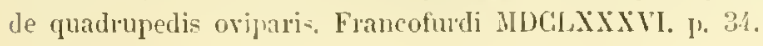


Der Reisende Gewry Murcyrav $\left.{ }^{1}\right)$ erzihhlt uns ron brasilianischen Eidechsen, die in ihrer Ileinath Tejuguacu und Temapara genannt werden. Sie verlieren ihren Schwanz leicht, aber ebenso leicht wächst el ihnen nach.

Eine besondere Art glaubt er in der Ameiva genannten Form entdeckt zu hahen, welche stets einen gespaltenen Schwanz besilzt, sonst aber der von den Eingeborenen Taraguira genamnten Eidechse rollkommen gleicht.

Die erste Abhandluug, welche auch hente noch einen anderen als rein historischen Werth Inat, ist die von Perraut, ${ }^{2}$ ) da derselbe sogar schon die anatomischen Eigenthümlichkeiten eines regenerirten Eidechsenschwanzes erkannt hat.

Er hescheibt z. B. eine Lacerta viuidis von etwa 7 Zoll Lünge, deren Schwanz abgeschnilten war. Innerhall, 14 'Tagen bildete sich ein Stück neu, welches dem verloren gegangenen an Grösse gleich war; aber dieses neue Organ hatte eine andere Farbe wie das ursjoüngliche, denn es war graugrün. Dann bemerkte er ferner, dass das regenerirte Stück keine Wirbel enthielt, sondern vielnehr eine Art Knorpel von dem Unfang einer dicken Nadel, bedeckt von einer Hant, welche der urspüunglichen vergleichbar war und zwar nicht allein im Innern durch die Mnskelbündel und die Gefïsse, sondern auch äusserlich durch die Schuppen.

Die Reproduction des Schwanzes der Eidechsen geht nach Perraut auf eine ganz andere Weise rol sich, als diejenige der Zühne, der Federn und der Hirschgeweihe. Er macht über diesen Gegenstand lange Reflexionen und glaubt, dass alle entwickelten Theile ursprünglich zusammengefaltet und zusammengepresst wären. Er vergleiclit diese Regeneration mit der Entwickelung der Fleischwärzchen, welche die Höhlıngen der Wunden anfüllen oder mit Geschwüren, welche einen Substanzverlust bedingen.

Die kouische Form des neuen Schwanzes erklärt er dadurch, dass er annimmt, die ersten Theile seien als die nächsten Nachbarn derjenigen Organe, von denen die Ernülırungsflüssigkeit zuströnt, anch grösser und breiter, weil sie davon eine grössere Quantität eslıalten und kömnten sich in Folge dessen auch besser entwickeln wie die folgenden.

Therenot ${ }^{3}$ ) schnitt einer grïnen Eidechse den Schwanz ab und sah einen nemen hervorwachsen, der dieselbe Gestalt halte. Innerhalb 19 Tagen erreichte er eine Länge von \& Linien: 20 Tage nachher hatte er sich bedeutend vergrössert. Ebenso sieht Ducerney, der dasselbe Experiment machte, einen neuen Schwanz entstehen, in welchen ilm auch die knorpelige Consistenz des Wirbelrohres nicht entging:

Marchanl ${ }^{4}$ ) demonstrirte in dej Academie eine Eidechse mit zwei Schwänzen, die jedoch riel kürzer waren, als die normalen. Ueber del Gabel befand siclı ein Anhängsel ron 2 Linien

3) Georgi Marcgravi de I.iebstadt, misnici germani, listoriae rerum naturalium Brasiliae libri octo lib. VI. cap. XII. p. 241.

$\left.{ }^{2}\right)$ Pcraut, de la Génération des parties qui reviement a quelques animaux aprés aroir èté coupées. Essai de Physique t. IV. MOCLXXXvil p. 1 etc.

3) Thevenot: 1686 in i]. Hẻmoires de l'Académie des sciences.

4) Murchant: Ifémoires de l'Acalímie des sciences. - Annẻe 1718, p ọt. 
Lïnge, aus dem ein dritter Schwanz zu werden schien. Die Prälparation zeigte, dass sich im Innern aller drei Schwänze keine Wirbel, sondern nur Knorpelröhren befanden, wodurch sie weniger brüchig und ricl biegsamer wurden. Die von Marchant ferner angestellten Experimente hatten keinen Erfoly.

I. Néedham ${ }^{1}$ ) berichtet, dass in Portugal sich sehr häufig Eidechsen mit regenerirtem Schwanz fänden; auch solche mit zwei Schwänzen hat or gesehen. Die Ursache des hälufigen Verlustes des Schwanzes sollen die Kinder sein, welche mit den Eidechsen spielen und sie geflissentlich verstümmeln. Wenn ein Schwanz der Länge nach gespalten ist, sollen sich die beiden Theile wieler abrunden und so zwei Schwänzc entstehen.

Ferner beschreibt Téedham die Brüchigkeit der W'irbel, die sich sehr leicht von einander trennen lassen.

Die von Seba an ausländischen Reptilien gemachten Beobachtungen bespricht Néedhum ebenfalls im Anschluss, an seine Nittheilungen

Arnoull de Nobleville ${ }^{2}$ ) behauplet in Gegensatz zu seinen Vorgïngern, dass der doppelte Schwanz nicht das Pesultat eines regencrativen Vorganges sei, sondern er kommt auf die schon fast vollständig abgethane Hỵpothese zurtick, dass es sich hier um eine Missbildung handle. „Hais. quant à la conjecture qu'il (Néedham) arance, touchant la double queue du lèrard, il nous semble qu'on peut la regarder comme pou fondée. Ce qu'il a de certain, c'cst que nous avons eu en vie un lézard commun qui arait deux queucs de même grosseur et longueur sans nulle apparence de blessure ou de cicatrice, et qui fut trouvé dans un endroit où les enfants ne pouraient pas l'avoil' mutilé.

Ciclui que Rédi a répresenté, avait trois quencs inégales ct toutes diftẻrentes; or; ne scrait il pas pilus raisonnable de penser que se sont là autant de monstruosités qui dépendent de la nature, larpuclle se jone tous les jour's de mille manieres dans ses operations? "

In der zweiten Hälfte des 18. Jahrhunderts tritt die Geschichte der Versuche über die Regeneration in ein anderes Stadium, denn mit del' Publication seines Prodromo machte Sprallam: ani $\left.^{3}\right)$ die Frage zu einer brennenden.

Bisher hatte man sich hauptsïchlich nul mit den Eidechsen abgegeloen, bei denen das Vorkommen doppelschwänziger Thiere an meisten in die Alugen fiel; jetzt zcigtc Spallansani, dass noch eincr sehr grossen Anzahl anderer Thiere das Vermögen zukommt, rerloren gegangene

1) M. Nëedham. Nourelles observations microscopiques avec de décourertes intẻressantes sur la composition et la décomposition des corps organisés. Paris HuCCL C. Xitl.

${ }^{2}$ ) Amoult de Nobleville et Salerne: Suite de la matiére médicale de Geoffroy. t. 12. MILCCLSI 2en partie.

3) Spullanzani: Prorlromo di un opera da imprimersi sopra le riproduzioni animali dato in luce dall abate Spallunzani. Modena MDCG L \VIII; in demselben Jalue auf Velanlissung Pomet's in's Französische übersetzt und il Genf unter dem Titel: „Programm ou précis d’un ourrage sur les réproductions animales ctc." par M. B..... Ile la Sabiomne erschienen. 
Theile wieder zı elzengen. Ausser den Polypen sind dies die Regenwïrmer, die Würner des süssen Wassers (Lumbriculus), die Froschlarren, die Landschnecken, die Wassersalamander (Triton) und sogar Frösche und kröten, welche ihr Wachstlıum noch nicht beendet liaben.

Es unterliegt keinem Zweifèl, dass schon ror Spallansami Versuche mit fast allen diesen Thieren gemacht worden sind, was hauptsïchlich aus der Einleitung zum Prodromo hervorgeht; doch war dieser berühmte Naturforscher der ersle, wetcher die Experimente nach einer leitenden Grundidee durehführte und deren Resultate mit schneidiger und beredter Zunge zu vertheidigen wusste. Ausserdem finden sich über Tritonen, Froschlarven und die anderen von ihm verwandten Reptilien und Anphibien keine früheren Angaben in der Literatur, so dass die Experimente Spullansanis als der Grundstein zu betrachten sind, auf welehem die Gelehrten und Laien seiner Zeit fortzubauen im Stande waren.

Die Arbeiten seines Freundes Bonnet ${ }^{1}$ ) sind jedoch in so inniger Weise mit seinen eigenen Forschungen rerknüpft, dass man eigentlich nicht recht beurtheilen kann, wem von beiden der Ruhm gebührt, die grosse Tragweite der Regenerationsfrage zuerst erkannt zu haben. Bomet ist unstreitig der erste, welcher Versuche mit dem Regenwurm anstellte, scine Experimente an 'T'ritonen etc. scheint er jedoch erst auf die Anregung Spallansani's begomen zu haben.

Im Allgemeinen beschiäftigten sich im vorigen Jahrhundert nicht nur Gelehrte, unter denen die Namen Trembley ${ }^{2}$ ) und Récumur ${ }^{3}$ ) besonders hervorragen, sondern überhaupt fast jeder gebildete Mensch mit den höehst interessanten Erscheinungen der Regeneration.

So kommt es, dass sich der über die Werke Bonnet's und Spullansani's erhebende Streit ungeheuer ausclehnte und eine grosse Anzahl von Schriften fïr und wider entstanden, die alle dasselbe Thema behandelten. - Es liegt mir zu fem, hier die ganze historisehe Entwickelung dieses Streites zu geben, zumał es sich in demselben am wenigsten um Amphibien und Reptilien handelte und nur die Schnecken die Hauptrolle spielten; wo jedoch auch die mein Thema betreffenden Fragen hauptsächtich in die Polemik hineingezogen werden, will ich nicht unterlassen, die wichtigsten Punkte zu erörtel'n.

Spallansami gibt pag. 33 seines Prodromo eine Beschreibung des Sehwanzes bei den Frosehlarven, nachdem er vorhes im Allgemeinen die anatomischen Verhältnisse berülırt hat.

1) Bomnet: 1. Considerations sur les corps olganisés. Amsterdan 1762.

2. Contemplation de la Nature. Amsterdam 1764.

3. La palingénésie philosophique. Généve 1769.

4. Traité d'insectologie

5. Observations sur la physique etc. par Rozier. 1. Mém. - Tome A. Paris 1777 pag. 385 - 405. - 2. Mém. ibid. Tome Xll1 p. 1-18.

fi. Collection complete des oeurres. Neuchatel 1781. Tome Xi p. 62-179.

$\left.{ }^{2}\right)$ Abhandlung zur Geschichte einer Polypenart etc. Aus den Französischen übersetzt von Joh. Aug. Ephr. Grüze. Quedlinburg 1775. S. 377 if.

3) Mémoires pour servir a l'histoire des Insectes. T. V1. und Sur les diverses reproductions, qui se font dans les ecrevisses etc. mit 1 Tal. in Hem. Acal. Scienc. p. 223-211 Paris 1712 und p. g63-74 Paris 1718. 
Schneidet man Froschlarven den Schwanz vollständig odel nalıezu ganz ab, so sinken sie unter und sterben; nimmt man jedoch nur einen Theil desselben fort, so l'egeneriren sie ihn ohne Unterschied. Je jünger die Larven sind, desto leichter regeneriren sic; ganz jungen Thieren kann man den Schwanz mehrfach abschneiden, er wird jedesmal nachwachsen. Die verstümmelten Thiere bleiben im Wachsthum bedentend hintel ihren Altersgenossen zurïck. Auch dic Temperatur hat einen grossen Einfluss, denn bei kaltem Wetter ist der Fortschritt des sich neu bildenden Theiles kein bedentender. Eingehend bespricht Sp. die Bildung der neuen Gefüsse in dem regenerinten Schwanz, welche sich ron den Nebenästen der IIaptarterie des Stumpfes abzweigen und innerhalb weniger Stunden den nenen Theil durchsetzen, und betont des Felılen eines Hauptstammes in demselben.

Auch die Muskehn und die Haut elneuem sich und nehmen nach und nach das Ansehen del ursprünglichen Organe an:

„ll qual tempo ì cosa mirabile quanto contribuisca a far simili le code riprodotte alle naturali, o sia non mutilate."

Die ron ihm zu diesen Experimenten benutzten Thiere waren Frosch- md Krötenlarven verschieclener Arten; der Erfolg war bei allen der gleiche.

Bei der Besprechung der Regeneration des Schwanzes del Tritonen (Salamandra aquatica) betont Spallansani pag. 79 ror Allem, dass sich bei diesen Thicren selbst die Wirbel und die Knochen neu bilden. Un die Sache jetzt eingehend zu untersuchen, legt sich Spablanzani verschiedene Fragen vor, dic so interessant sind, dass ich sie an dieser Stelle einschalten will.

1. Frage: Findet eine Regeneration bei allen uns bekannten Salamandern statt und in welchem Alter? Wie muss ihl' Aufenthalt sein, müssen sie auf rlem 'Trockenen oder im Wasser verweilen? An welcher Stelle des Schwanzes muss man die Amputation rornehmen?

2. Frage: Erreicht der regenerirte Theil dieselbe Grösse, gleichviel ob man ein grüsseres oder kleineres Stück rom Schwanze gleichalteriger und specifisch gleicher Salamander aisschneidet? Was geschieht, wenn die Salamander von derselben Species, aber von verschiedenem Alter sind, oder wenn sie sich im Alter und del Species unterscheiden?

3. Frage: Sind diejenigen Theile, welche den neuen Scluwanz zusanmensetzen, an Zahl, Art oder in Bezug auf ihre Verbindung dem abgeschnittenen Theil des schwanzes analog? Sind sie es in allen Stïcken ungeachtet der Tereinigung gleichel' und ungleicher Theile? Sind clie hauptsïehlichsten Theile, welche den Schwanz zusammensetzen: die Epidermis (cuticola), die Unterhaut (pelłe), die Drüsen, Nuskeln, knöchernen Wirbel, dlas Rü̈ckennark (liı spinale midolla allungata) und die Blutgefïisse?

4. Frage: Gleicht die Zahl der regenerirten, knöchernen Wirbel derjenigen der alten Wirbel, welche man alygeschnitten hat? Geht die Reproduktion der Wirbel successiv vor sich am Ende des neuen Schwanzes? Welchen Zeitraum brauchen die neuen Wirbel. um die Grösse und Consistenz der alten zu erreichen?

5. Frage: Was geschieht erstens: wenn man den Schwan\% del' Länge nach, in der Richtung des Rückenmarkes, ron del Spitze bis zur Wurzel theilt, ohne ihn jedoch rollständig rom Körper zu trennen? 
Zweitens: wenn der Schnitt nicht die Wurzel des Schwanzes erreicht?

Drittens: wem die Richtming des Schnittes einen scharfen Winkel mit der Achse des Schranzes bildet?

Viertens: wem man entweder die beiden Seiten des Schwanzes longitudinal durchschneidet, oder nur eine dersulben, olne nur das Rückennark zu berühren?

6. Frage: Was geschieht erstens: wenu man den Schwanz im Zusammenhang lïsst und nur das Rückenmark an eincr oder mehreren Stellen durchschneidet?

Zweitens: wenn man den Schwanz quer durchschneidet bis zum Rückenmark. ohne dasselbe zu berühren, so dass dasselbe mit dem Stumpf nur durch einen kleinen Faden verbunden ist?

Drittens: wenn man die Muskeln an mehreren Stellen durchschneidet; wenn man ein Scgment ablöst (levato $m$ anello) oder wenu man ein Stück Fleisch quer durchschneidet?

7. Frage: Weun man die regenerirte Partie des Schwanzes rollständig abschneidet. whïlt man dann cine ncue Reproduktion: -

Auf alle diese Fragen gibt sich Spallansani zum grossen Theil befriedigende Antworten. welche rou dem grossen Geschick zeugen, mit welchem der berühmte Naturforscher mit unzureichenden Hilfsunitteh dieses schwierige Thema zu behandeln wusste.

Die Reproduktion der Beine der 'Tritonen geht nach Spallansami (pag. 89) cbenfalls sehr' rasch ror sich und zwar auch dann. wemn man sie rollstïndig im Gelenk abgelöst, d. h. exartikulirt hal, gleichviel welcher Species sie angehören oder welches Alter sie haben.

TVens man alle 4 Beine abschneidet, so erseheinen die vorderen zuerst wieder: wesshalb dies geschicht, kann Spallansani nicht erklären. Die jüngeren Thicre (Larven) regeneriren wiedermu am besten und die der kleineren Species (Triton taeniatus?) angehörenden, erwachsenen Exemplare besser als die grösscren (Triton cristatus?). Zuerst bildet sich ein einfacher liegel auf dem Amputationsstmmp, an dem dam zwei seitliche Auswüchse auftreten, welche der erste Aufang der mittleren Finger sind. Die Girculation des Blutes ist in den reproduzirten Beinen dieselbe wie in den ursprünglichen.

In derselben Weise regeneriren sich die Epidermis (cuticola), die Unterhaut (pelle), die Drüsen, Muskehn, Knochen und Nerven.

An meisten interessirt ihn die Reproduction der Knochen, die sich in derselben Anzahı ${ }^{1}$ ) und Form, Lage und Structur wieder neu bilden. Ein rolles Jahn ist nicht genügend, dass die regenerirten Knochen ihre natürliche Festigkeit erlangen. Dabei ist es ganz gleichgültig, ob man die Salaniander gut füttert, oder ob man sic ganz der Nahrung beraubt. Letztere magern allerdings ab, aber die sich regenerirenden Theile hören democh nicht anf zu wachsen; dabei stehen die neuen Knochen in einem proportionalen Verhältniss zu einander. Spallansani vergleicht diesen rorgang bereits mit den enbryonalen V'crhältnissen. Stets bildet sich eine den abgeschuittenen Theilen entsprechende Anzahl ron linochen wieder; jedoch kommen ab und zu Unregelmässigr-

1) Spallonzani hat 99 Knochen in allen 4 Extremitäten der Tritonen grezählt. während es 102 sind. 
keiten ror. Man kann dic Beine mehrfach abschneiden: sie wachsen immer wieder. Spallansani hat eine sechsmal hintereinanderfolgende Rejroduktion derselben gesehen. Er hat gezühlt, dass ein Thier im Zeitraum ron 3 Monaten, Juni, Juli und August 687 Knochen reproduzirt hat. Bei eincm anderen zählte er während eines Jängeren Zeitraums 1374 regencrirtc Ḱnochen. Ein gcbrochener Fuss heilt bei den Tritonen langsamer, als sich cin vollständig abgeschnittener wieder erzcugt. Verhindert oder wenigstens sehr verzügert wird die Neubildung, wenn man die Gliedmassen vollständig exartikulirt, wenn man in den Stumpf einen kleinen Ring einschneidet, der bis auf den Knochen geht, wenn man die Circulation darlurch verhindert, dass man eine Ligatur anlegt, wenn man den knochen des Beines mehrfach bricht, oder wenn man auch nur ein kleines Stück von dem Knochen des Stumpfes herausschneidet.

In lelzten Kapitel fügt Spallunzani (pag. 99) hinzu, dass die Tritonen nicht allein den Schwanz und die Beine, sondern auch die Kinnbacken regeneriren. Nan sieht an dem Amputationsstumpf sehr bald neu hinzuwichsen ḱnochen, Knorpel, Muskeln, Venen, Arterien und sogar Zähne.

Nach Spallanzani besilzen die Frösche und dic gewöhnlichcn Kröten, wenn sic noch jung sind, ein ähnliches Rejroduktionsvermögen wie die 'Tritonen. El' with gesehen habon, dass dieselben in normaler Weise ihre Beine ebenfalls regenerirten und behauptet sogar, dass dies bei vollständig ausgewachsenen Thieren ebenfalls der Fall sein soll, wenn dieselben auch hierzu einen hedeutend grösseren Zeitraum nöthig hätten als die 'Tritonen.

Weiterc Ausführungen fehlen jedoch in seinem Prodromo und sind auch später nicht nachgeholt worden, so dass hieraus ałlein schon eine gewisse Unsichcrheit der letzten Behauptungen hervorgeht.

Das grosse Werk, welches Spallunsuni dureh seinen "Prodromo* ankündigte, erschicn nicht, in verschiedenen grösseren und kleineren Aufsïtzen und Bliefen verthcidigte er jedoch mit ausserordentlicher Gewandtheit, in schöner und kräftiger Słrache scine Versuche, wobei cr sich hauptsächlich allerdings mit der Reproduction des Kopfes bei den Schnecken beschäftigte. Doch finden wir im ersten Artikel ${ }^{1}$ ) noch cinige Stetlen, welche auf Amphibien Bezug haben, unter denen ich folgende hervorheben will, da sie den Antheil Réaumur's an den Experimenten bestätigen.

(Pag. 587.) ,S'illustre Ricaumur ì stato il primo a far vectere, che comincia a manifestari il principio della riproduzione delle gambe nei granchi d'acqua dolee, col'apparire al centro del troncone un picciol cono, la cui base e fenza taragone più picciola di quella del troncone, e che solo in proceder di tempo si fa grande al pari di lici."

Wir gehen nun über zu del Betrachtung derjenigen Experimente, welche Bonnet, jedenfalls angeregt durch das eben erschienene Werkchen seines Freundes Spallanami, an den gewölnlichen Tritonen vornahm und delen Pesultate er vor Allem in den ,Observations sur la Physique“ niederlegte ${ }^{2}$ ). In scinem ersten Artikel gibt $\mathrm{el}^{\circ}$ an, dass er seine Silamander (den rerschiedenen

1) Memoria di Matematica e Fisica della Societa italiana. Tomo I. Verona 1782. Risultati di esperienze sopra la riproduzione della Testa nelle Lumache Terrestri p. os1.

2) Bomet: Observations sur la phisirque etc. par Foziel. 1. Mem. Tome X. Paris 1777. pag. 345-405. உ. Mem. ibjd. Tome XIII. p. 1-18. 
rorhandenen Abbildungen nach scheint Bomet nur den Triton cristatus zu seinen Versuchen benutzl zu haben) einzeln in relschiedene Gefässe gosetzt und mit Picgenwürmern gut gefüttert habe. Er kennt die geringe Reaktion, welche diese Thiere auch gegen grosse Terstümmelungen zeigen, und suh z. B., dass ein Triton, dem das linke Vorderbein und das rechte Hinterbein rollstündig abgeschnitten war, nach cinel Viertelstunde 2 Regenwümel verschlang. Bomnet geht ferner auf einige biologische Eigenthümlichkeiten dieser Thiere ein und bespricht besonders eingehend die Häutung. An 6. Juni fing el seine Experinente über die Regeneration bei 15 Salamandern an.

1. Experiment: Linem sehn grossen Triton sehnitt er die rechte Hand und den rechten Fuss nahe im Stamm ab. Das Blut hörte nach einer Ninute auf zu fliessen; das Thier zeigte clurchaus kein Uebelhefinden, doch sehwamm es nicht so leicht wie rorher. Nach einem Monat war an Rande des Stumpfes cine kleine, konische, grauviolette Warze entstanden, die cr am 14. Juli in Figur b und e abbilden liess. Die Warze wuchs jetzt mehr in die Länge als in die Broite, in den nächsten Tagen bilkte sie cinen kleinen Stumpf (moignon!. An 1. August waren die regenerirten Theile 2 Linien lang und an hinteren Fuss komnle man bereits eine begimnende Zweitheilung heobachten. (Fig. 2 und 3.) Am 7. August sind zwei Zehen am Hinterbcin-leicht unterscheidbar; am Vordcrbein ist noch keine Theilung eingetreten, der Stumpf ist nur etwas gewachsen. Am 9. August wurde derselbe Arm gezeichnet. Es sind schon 3 Finger sichtbar und unan bemerkt mit Vergnügen die kleine Hand in der vollsten Entwicklung. Dic 3 Finger haben eine ungleiche Grösse, der mittlere ist der längste; an Hinterbein sind inzwischen 4 Zehen entstanden, ron denen der erste und zweite lang, die beiden anderen aber sehr kurz sind. Am 22. August erscheinen die regenerirten 'Theile schon so weit gefürbt und gefleckt, dass man die Grenze des regenerirten nicht mchr genau unterscheiden kann. Die Hand hat 4 wohlgeformte Finger, der Fuss ebenfalls nur 4, aber wohl ansgebildete Zehen. Am 20. September macht bonnet cine Zusanmenstellung, die ich hier wiedergeben will.

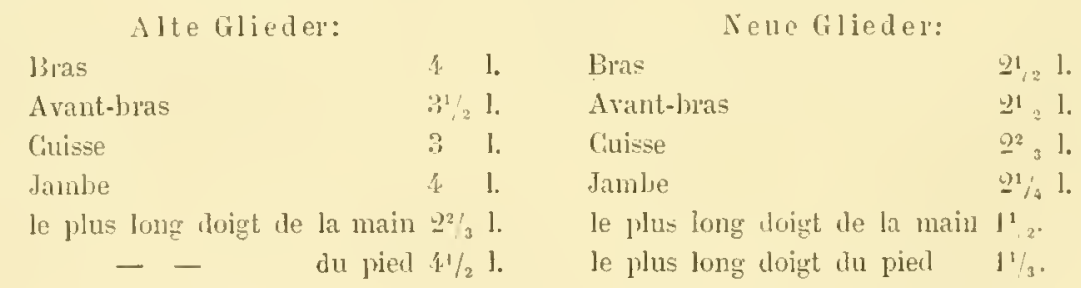

Anz 1. Oktober war der ว. Zehe des Hinterbeines noch nicht erschienen.

9. Experiment: Ein kleineres Thier wurde am 12. Juni in derselben Teise ampulirt. Am 8. Juli wal eine kleine Warze entstanden, welche Mitte Juli sich \%u theilen anfing, aus der nach und nach bis zum 19. Juli 4 Finger sich differenzirten. An 21. August war die Regeneration vollstïndig. Bonnet lïllt es auf, dass die nenen Gliedmassen durchseheinender sind als dic alten und er vergleicht sie bereits nit den Füssehen der jungen Larren.

3. Experiment (pag. 396): Am 15. Juli wurden einem grossen Triton 2 Finger der Hand und 3 Fingel des Fusses abgesehnitten. Am 20. Juli entstand cine kleine Warze an del 
Spitze jeden Stumpfes (Figur 15 und 16); am 1. August haben sich die 3 abgeschnittenen Zelen schon ein grosses Stück neugebildet.

4. Experiment: Am 3. August wurde die rechte Hand eines Triton der Länge nach gespalten, so dass 2 Finger abgeschnilten wurden. Die linke Hand wurde durch einen Querschnitt getheilt. Am 92. zeigte der linke Vorderarm die bekannte konische Warze; am 30. hatte dieselbe angefangen sich zu spalten und man konnte deutlich 3 sich bildende Finger erkennen. An denselben 'Tage erschien auf der rechten frand ein neuer Finger (Fig. Is aa). Am J. Scptember trat wieler ein nener Finger an dic Seite des alten. Am 4. September wurle die der Lïnge nach gespaltene Hand in Figur 19 rr abgeljildet mit den rollständig nachgewachsenen 2 Fingern.

5. Experiment (pag. 397): Am 21. August wurde dic rechle Hand eines Triton vollstïndjg abgeschnitten, so dass nur der erste Finger stehen geblicben war. Am 13. September erscheinen 4. sehr kleine, aber deutliche Warzen. Am 21. September bemerkt Bonnet, dass dic Bildung nicht ganz regelmässig vor sich geht. Der erste und zweite Finger (a und b) sind wie zusammengeklebt und die Distanz zwischen len beiden letzten isl eine zu grosse. Die Hand besass demnach 5 unregelmässige Finger. Auch Spallansani hat solche Missbildungen beobachlel. Bomet fügl hinzu: „On comprend assez que l'endroit ou l'on fait la section, la manière dont on la fait, l'citat actuel de la prartie ef des jarties voisines peurent donner naissance à une multitude de rarićtés ou de bisarreries apparentes, dont plusieurs seront de rraies monstruosilés, les unes par exces, les autres par défaut; d'autres enfin par transposition."

Aufallend erseheint Bomnet, dass bei dem letzlen Experiment nicht zuerst cine einzige Warze cntstanden ist, dic sich später theilt, sondern ron Anfang an 4 kleine, welche genan auf der Schnitlinic hervorsprossten.

6. Experiment: Regencration des Schwanzes. Bumet schickt vorauf, dass er nur die vorzüglichen Beobachtungen, welche Spallansuni gemacht hat, bestïtigen will. Wenn er den Schwanz dicht an Ursprung abgeschnitten hatte, starben ihm die Thicre olme Ausnahnue. ${ }^{1}$ ) Bonnet hatte so lange keinen Erfolg, his er den Sclıwanz elwa in der Mitte amputirte, dureh einen senkrecht zur Axe geführten Schnitt. 2-3 Minulen lang blutete das Thier, bis die grossen Gefässe sich schlossen und man an ihrer Oeftnung nul noch cinen rötllichen oder brüunlichen Punkt sah. Das abgescluniltene Stück behïlt noch 1-2 Stunden lang Leben und Bewegung und wenn es endlich todt zu scin scheint, braucht man es nur an Ente zu berühren, um ihm die Bewegung wieder zu geben. Dic Bewegungen ähnehn denen eines Wümes und sind wellenförmig. Gleich nach der Operation zeigt der Stumpl cine rerlängerte Ellipse. Der kleine Durchmesser beträgt fast 1 Linie, der grosse j- 6 Linien. In Nittelpunk befinden sich die Wirbel und die Blulgefüsse. Der Rest der Wundflïche zeigt sich angefüllt von kleinen lebhaft weissen Körperehen von rundlicher Form, welche man für klümpchen Felt oder fül Drïsen halten könnle. Allmälig

1) Waluscheinlich wurde bei diesen Amputationen die (dloake verletat. in welchen fall die Thiere allerlings stets zu Grunde gehen. 
verändert sich das Aussehen des Selmittes; dic entgegengesetıten Fläehen der Wunden suchen sich zu nälhern; die oben erwähnten körperchen erscheinen weniger und weniger weiss, man sieht neues Fleisch cntstehen, welches sich ron Tag zu Tag vermchrt und durch welches man 1 oder 2 braune Linien crkennt, welehe die Mitte des neuen Sehwanzes einnehmen und welehe den Platz der Wirbel und Gefässe anzeigen. In Fig. 이 bildet er ein kleines Stück regenerirten Sehwanz ab und beschreibt ihn folgendermassen: „Er ist kleiner und durehsichtiger, als der ursprüngliehe; an der Spitze befindet sieh ein kleiner Ausschnitt, der in der Abbildung leicht erkennbar ist." Bonnet hat diesen Ausschnitt bei allen sieh regenerirenden Schwänzen gesehen. Der in Frage stehende Theil war am 11. Juli abgesehnitten und latte am 14. August etwa $33^{1 / 2}$ Linien Länge und an der Basis $4^{1 / 2}$ Linien Breite errcicht. An 20. September war er bereits 10 Linicn lang und seine Form näherte sieh der des normalen Schwanzes. Bonnet fügt hinzu, dass er niemals den geringsten Unterschied geschen hat in der Bewegung des regenerirten Selnwanzes und eines normalen. Er bedatuert, dass er gezwungen ist, aus Rücksicht für scine Augen feinere anatomische Untersuehungen zu unterlassen, allein die Thatsache, dass die Tritonen überhaupt regeneriren, befriedigt ihn rollstïndig.

Allgemeine Resultate (pag. 400): Bomnet hat noch vorschiedene andere Experimente gemaelit, die jedoeh alle denselben Erfolg hatten. Während bei den Ammen der Polypen und den Würmern des süssen Wasser's, welehe wic diese durch Zerstüekelung vervielfïltigt werden kömnen, die Peproduktion sehr schnell vor sieh geht und man im Frühling wie im Sommer sehon mach 1-2 Tagen die Anzeiehen der Regeneration an ihnen entdeckt, geht sie bei den Salamandeln im Gegentheil seh. langsan vor sieh, so dass man erst nach mehreren Wochen die Anzeiehen der Reproduktion bemerken kann. Die jüugeren Thiere regeneriren sehneller, als die alten. Bonnet vergleicht die Regenerationsrerlü̈ltnisse der Tritonen mit denen, wie sie bei Schneeken volkommen. Die Warze, welehe stets an dem amputirten Stumpt zuerst auftritt, seheint ihm homolog zu sein mit dem Vegetationspunkt bei Pflanzen (bouton animal - bouton vẻgetal). Bonnet glaubt, dass die Warze bereits sümmtliehe Glieder der neuzubildenden Extremität in sieh eingesehlossen enthült, wenn auch sehr coneentrirt und klein. "Giest que les membres qui remplacent ceux quion a retranchés, ne sont pas proprement sugendrés, mais quilts précxistoient originairement et très en petil clans le grand tout organique ou ils ne font que se développer."

„Il est done, au moins, trés probable que le membres qui se produisent. précxistoient dans des germes où ils étoient dessinés très en miniature et dans le plus grand détail."

Er nemnt diese germes: reparateurs.

In seinem zweiten Hémoire bespricht Bonnet zuerst die lortschreitende Entwickelung bei denjenigen Tritonen, welehe el im Jahre 1777 amputirt hatte; einzelne hielten sich den Winter hindurth seh" gut, andere starben jedoch. Er setzt die Experimente 1778 fort, und zwar mit. gutem Erlolge. Das Hauptresultat derselben ist, dass die Regeneration del Glieder dureh die Kälte ungemein verzögert wird, und dass man die Gliedmassen 4, j oder 6mal hintereinander abschneiden kann, ohne ihre Regenerationsfühigkeit zu zerstören. 
lun dritten Mémoire ${ }^{1}$ ) beschreibt er die im Jahre 1779 fortgesetzten Versuche und bespricht hauptsïchlich rerschiedenartige Monstrositïten, und kommt dann 7 den höchst interessanten Experimenten über die Regenerationen der Augen bei den Tritonen. Am 13. September 1779 exstirpirte Bonnet das rechte Auge eines grossen Triton, verletate dabei jedoch, wie er selbst sagt, die rerschicdenen Hüute. „Nach dicser grausamen Operation," fährt $B$. fort, "habe ich an Stelle des Auges eine tiefe, blutige Wunde gesehen und glaubte nicht anders, als dass der Triton sein ganzes Leben lang blind bleiben würde. Aber wie gross war mein Erstannen, als ich am 31 . Mai 1780 benerkte, class ein neues Auge sich zu bilden anfing; die Iris und die Connea waren schon genügend differenzirt, aber es fehlte ihnen noch der Grad der Durchsichtigkit, del ihnen sonst eigenthümlich ist. An I. September schien das Auge sehr gut ausgebildet zu sein und die Cornea hatte fast dieselbe Durchsichtigkeit, wie die des anderen Auges, mit welcher ich sic ottmals verglich. Dic fris wal wohl unschrieben und hatte eine goldgelbe Farbe angenommen, die dieser' Art von Tritonon eigenthümlich ist; mit einem Wort: es erschien unmöglich, in diesen so gut ausgebideten Auge die geringste Sur der ausserortentlichen Operation zu erkennen, der ich das Thier unterzogen liatte. In Verlauf des Monats und in der folgenden Zeit vermehrte sich die Durehsichtigkeit der Cornea tagtäglich und zu der Stunde, wo ich dies schreibe: am S. Norember I780 hat sie vollständig die Vollendung derjenigen des anderen Auges erreicht. Es sclieint mir einzig und allein, dass das regenerirte Auge etwas kleiner ist, wie das andere und dass die Iris odcr der goldene Kireis nur etwa über die llälfte der Pupille fungirt."

Gleichzeitig mit den Arbeiten Bonnet's finden wir eine kleine Notiz von Valmont de Bumare ${ }^{2}$ ). in welcher derselbe den Grund der Zweitheilung des Eidechsenschwanzes bespricht. El glaubt hanptsächlich herabfallenden Steinen etc. die Ursache zuschreiben zu müssen, dass den Eidechsen der Schwanz oft gespalten wird; nur derjenige Schwanz, welcher Wirbel habe, sei der ursprüngliche, dic anderen seien neugebildet.

Mit den Versuchen über die Regeneration beschäftigten sich ferner in dieser Zeit, ausser Réaumu und Trembley noch folgende Forscher: Ilerissant, Cavalicre Turgot, H. Müller (Kopenhagen: remium terrestrium et fluviatilium succincta historia, 1769) Pater Scarella von Brescia, Schacffer 1770, Ziegenbaly 1758, Boscovich 1768, Abbi Troilo, Senebier, Adanson, Calduni, Girardi, Pratolongo der Jüngere, ITartel 1767, Pusini 1784, Wrisberg 1768, Presciani und Andere.

Die Experimente Spallansani's wurden wiedcrholt ron Cotte $1770-1773$ und ron Abbate Rosier, dann ron V'almont de Bomare ${ }^{3}$ ), der im Verein mit Borie de St. rincent arbeitete; ferner von Inwray, Argencille, Scleröter, Tissot, Burletli, Rinos und Lavoisier.

Obwohl die Regenerationsfrage auch in Deutschłand lelshaft disculirt und eine Menge von Experimenten gemacht wurden, so war es doch erst Blumenbuch vorbehalten, eine allgemeine Ansicht übcr dieselbe auszusprechen.

1) Collection complete des veurres de Charles lionnet. Tome XI, p. 151.

${ }^{2}$ ) Iralmont de Bomare: Dict. rais, univ, d'histoire naturelle t. 5. HUCCL XXY1. p. 96.

${ }^{3}$ ) Im Journal de Berne rom 4. Februar 176!\% 
„Obgleich die Regencrationsfihhigkeit (vis reproductiva)," sagt Blumenbuch, .,im Allgemeinen kaun irgend einem butführenden Thiere völlig abgeht, so ist sic doch keiner anderen Cilasse in so reichem IIasse zu Theil geworden, wie den meisten Amphibien und Reptilien. Die ausgedehnten Experimente, nach denen feststcht, dass den Wasser- und Land-Eidechsen die abgeschnittenen Schwänze nachwachsen, sind zu bekannt, als dass ich sie hier aufzählen sollte."

Da aber nach Bumet selbst das herausgerissene Aure der Tritonen (Iacertae lacustris) sich regeneriren soll, stellte Blumenbach sclbst Versuche an, welche den Erfolg hatten, dass das Auge sich niemals regenerinte, wenn der Bulbus vollständig entfernt war, da sehr bald ein weisslicher Pilz die ganze Augenhöhle anfüllte, an dem die Thiere zu Grunde gingen.

Bei einem vierten Triton schnitt Blumenbach in Mai 1784 zuerst die Comea cin, so dass die Linse und die ïbrigen Flüssigkeiten herausflossen; dam nahm cr die übriggebliebenen collabirten leeren Häute so fort, dass ein geringer 'T'heil derselben mit dem Opticus im Znsammenliang blieb.

Bei diesem Thicrchen war die Augenhöhle in den nächsten Monaten durch die Angenlider geschlossen, im 6. Monat aber nach der Operation erschien ein kleiner Bulbus, der aber noch in April 1786, also 11 Monate später, sehr viel kleiner war als der andere, obgleich er ihm sonst völlig glich. Auch mit dem echten Salamander (Salamandra maculata?) stellte Blumenluch Versuche an, welche dessen liegenerationsfühigkeit bewiesen.

Der. dritte Theil des Schwanzes und ein Finger wurden ihm abgeschnitten und wuchsen allerdings seln langsam innerhalb eines Jalıres zur ursprünglichen Grösse heran.

Die Fühigkeit der Reproduction ist nach Blumenbach so ziemlich auf die kaltblütigen Thiere beschränkt und wenn bei Warmblütern auch einzelne Gewebe sich regeneriren können, so wird es doch nie möglich sein, dass ein so hoch organisintes 'thier ganze Ghiedmassen neubildet.

Bei Lacépèd $c^{2}$ ) finden wir ferner einige Bemerkungen über abgebrochene und wiedergewachsene Schwänze bei Manereidechsen, ,et suivant qu'elle a ité divisée en plus ou moins de parties, elle est remplacée tar deux et mêne quelquelois par trois quenes plus ou moins parfaites dont une senle renferme des vertibres; les autres ne contiennent qu'm tendon."

Obgleich Lacépède sich nicht ganz deutlich ansdrückt, scheint democh aus den cben angeführten Aufsat\% hervorzugehen, dass Lacépède die toppelten und dreifachen Schwänze als das Resultat einer longitudinalen Theilung ansieht.

Erst im Jahre 1817 besplicht hicraul Bosc ${ }^{3}$ ) in seiner Naturgeschichte die Struktur des neuen Schwanzes der Eidechsen, indem er sich dabei strenğ an seine Vorgänger hält: „la quene

$\left.{ }^{1}\right)$ Specimen physiologiae comparatae intes animantia calidi et frigidi sanguinis; in conmentationes soc. reg. scient. Gottingensis Vol. VIIl. Gottingae 1787. p. 95.

$\left.{ }^{2}\right)$ Lacépède: Histoire naturelle des quadr. ovip. et des serpentes, 1. Edition ca. 1790. ㄱ. Edition precédée de lèloge de Lacépède par Cuvier, avec des notes et la nouvelle classification de G. A. Desmaret. Paris 1857.

$\left.{ }^{3}\right)$ Bosc: Nouveau dictionaire d'histoire nat. t..17. 1817. art. Lé:ard. 
des lézards est, dit-il, composie d'artieulations, qui se séparent an moindre effort. Il n'est personne, qui n'ait expérimenté que pour peu qu'on la touche, soit avec la main, soil avee un bâton, elle se casse en deux ou plusieurs moreeaux, qui conservent pendant quelques instants des mouvements vitaux très-remarquables. Il se produit peu de temps après une nourelle queue, mais dont l'organisation ne parait pas la même que celle de la précédente; e'est selon Mlarchant, une espèce de prolongement tendineux sans vertẻbres; eependant il est à eroire qu'arec le temps elle prend une contexture semblable; car on ne voit pas de lézards avec une vieille queue reproduite. Au reste, il y a encore beaucoup d'expériences à laire sur cet objet, pour se former une idée préeise du morle de eette reproduction. Celles qu'on a tentées jusqu’iei n'ont point produit de résultats completement satisfaisants."

Weiter sagt er: „Les doubles et triples queues des lézards dont les charlatans tirent souvent parti pour duper les ignorans, peuvent être produits artificiellement. Il ne s'agit que de fendre l'extrémité d'une queue de lezard préalablement cassée."11)

Auch Bory de Saint V'incent ${ }^{2}$ ) hat einige Notizen über regenerirte und doppelte Schwänze bei Eidechsen. Bei letzteren findet er den einen gewöhılich kleinel als den andern. Ueber den Grund der Versehiedenartigkeit sprieht er sich in folgender Weise aus: „Les eirconstances qui donnent naissance à l'un ou plusieurs des appendices de ees queues monstrueuses, sont réellement les eauses qui déterminent quelque fois leur déreloppement."

In seinem „Règne animal“" gibt Cuvier"3) bei der Beschreibung einzelnel ausländischer" Eidechsen an, dass dieselben mehrfach regenerinte Sehwänzc gehabt haben. El weist vor Allem die von Marcgraw aufgestellte Spezies hin, welche derselbe hauptsïchlich dadureh charakterisirte, dass diese Thiere einen doppelten Schwanz haben. - Auch in den ..Recherehes sur les oss. foss." findet siel eine kurze Beschreibung und die Bemerkung, dass eine genauere Untersuchung sehr interessant sein würde. (II. Müller.)

Bei weitem am bekanntesten sind die Versuche, welche Dugès ${ }^{4}$ ) an Eidechsen verschiedener Arten gemaeht hat. Um so mehr muss es auffalien, dass H. Müller von diesen Arbeiten keine Notiz genommen lat, da sie jedenfalls einen anderen als rein historisehen Werth haben.

Dugès gibt zuerst eine sehr genaue Besehreibung des einfach regenerinten Schwanzes und ïber die Thatsache der Entwickelung desselben. Das neue Organ enthält nicht melı Wirbel, wie alt das regenerirte Stück auch sei, sondern ein knorpelrohr. Von Mr. Morquin hatte er erfalıren,

$\left.{ }^{1}\right)$ Eine sehr interessante Dissertation wurde 1821 ron Dr. Joh. Chr. Eggers in Würzlourg üler die Wiedererzeugung veröfentlicht. Obgleich der Autor weniger eigene Experimente machte, als nur die älteren ausgiebig benutzte, so findet sich democh in diesem Buche eine solche Fülle von Anregungen. dass es unbedingt zu den brsten Erzengnissen der betreffenden Literatur gehört. Ueber die Amphibien und Reptilien bringt Ėggers nur das bereits Bekannte.

$\left.{ }^{2}\right)$ Dict. class, d'list. nat. t. 9. (1829) art. Lézarts p. 388.

3) Cuvier: „Règne aninale" t. II. (1899) p. 29.

4) Dugès: Memoile sur les espèces indigènes du genre Lacerta, inséré dans le cahiel d'Arril du tome 16 (1529) des Annales des Sciences naturelles. 
dass derselbe den Anfing eines neuen Scluwanzes über einem unvollständig abgebrochenen beobachtet habe. Wr hat darauf hin mehrfach rersucht, partielle oder unvollendete Rupturen den Thieren beizulyringen, in der Hoftuung, einen neuen Schwanz nehen dem alten entstehen zu sehen; aber immer hat die Bewegung des Thieres die vollständige Ablösung bewirkt. Desshalb glaubt Dugès, dass die doppelten Schwänze sich durch eine simultane Reproduktion bilden. Ueber die Ursachen macht er folgende Reflexionen: „A quoi tient ce phénomène singulier? Il semble être inherent à quelque disposition ou aptitude individuelle, et l'on ne peut expliquer que de cette façon l'existence d'une queue trij)le. Si les bouts sont reillement tous trois de nourelle formation, il faut bien alors qu'une première rupture, arrivéc à l'une des branches de la lifurcation, ait renouvelé au bout rle celle-ci la même duplication; c'est tonjours, en effet, de deux bouts différents et non d'un même lieu, que naissent les trois ajpendices."

Wir kommen jetzt zu einem Autor, dessen Wrerke wenig bekannt sind. der aber doch in Bezug anf unsere Frage unberlingt die ausfühlichste und rorzüglichste Abhandlung der ersten Hälfte unseres Jahrhunderts geschrieben hat. Gachet ${ }^{1}$ ) gibt nicht nur ein äusserst reichhaltiges Literaturverzeichniss, aus den ich ausgiebig geschöpft habe, sondern es sind auch seine vielseitigen Experimente derart vorzüglich und sicher angestellt, dass man vollständiges Vertrauen zu der Richtigkeit derselben hegen darf.

Guchet beginnt damit, dass er sagt, das neue Organ sei nicht durchaus mil dem alten Sehwanz zu vergleichen. Er findet regenerirte Schwänze nicht allein bei Eidechsen, sondern auch bei andern Sauriern, denen die Regenerationsfïhigkeit in grösserem oder geringerem Masse zukommt. Er untersuchte (pag. 230) 5. Eidechsen mit doppeltem Schwanze, vielo mit einfachem regenerirten Schwanze und einige Exoten mit einfachem oder doppeltem regenerirtem Schwanze. Unter den europäischen Arten fanden sich Lacerta ocellata. Lacerta viridis, Lacerta muralis. Unter den Exoten, welche er voll der Direktion des stïdtischen ILuseums in Bordeaux crhiclt, Jefanden sich Anolis (Anolis à crête), deren regenerirter Schwanz cinen Knorpelstab besass, der in seiner ganzen Ausdelmung stark verknöchert war. Iguana (Igruane ardoisé) und Ameiva.

Bei Iguana war der Schwanz an der verletzten Stelle stark aufgequollen, der regenerirte Theil weniger comprimirt, als der normale und stumpfer exdigend. Die Schuppen hatten kaum ein Viertel der Grösse derjenigen des gewöhnlichen Schwanzes, sie waren weniger breit und besassen an ihrem Ende nicht die kleine Spitze der normalen Sehuppen. Auch ist die Stellung der Ringe unregelmässiger. In der Mitte befindet sich ein Knochen, der viel voluminöser ist, als die normalen Schwanzwirhel dieses Thicres; derselbe erstreckt sich von der Basis Jis zur Spitze, nicht

1) Memoire sur la reproduction de la queue des reptiles sauriens par. M. $I$. Gachet in Actes de la societẻ linnéenne de Bordeaux $\mathrm{Nr}, 36$, 25. Juillet 1834. 
cylindrisch, sondern unregelmässig zusammengedrückt und zwar auf die Art, dass seine Form derjenigen des Schwanzes entspricht. Das Ende ist knolpelig. Dieser Knochen ist durchsetzt in seiner ganzen Ausdehnung von einen breiten Kanal, welcher den neugebildeten Theil des Rückenmarkes einschliesst. Die Wände dieses Kanals sind sehr dicht und bilden drei Lagen, von denen zwei schmal, gelblich und verknöchert sind, die dritte nittlere sehr breit, weiss und knorpelig. Dieser regenerirte Schwanz hatte eine geringe Lünge. Der regenerirte Schwanz der Ameiva hatte die Länge und das Aussehen eines normalen Schwanzes; w war jedoch durchsetzt von einem Knorpelrohr.

Von Reptilien mit doppelten Schwanze untersuchte or 1) Lacerta muralis, welche einen doppelten und difformen Schwanz hatte, in dessen beiden Theilen sich ein Knorpelrohr befand. Gachet macht in Folge dessen darauf aufmerksam, dass nicht immer. Wirlel in dem einen der beiden Schwäinze vorkommen, wie dies Lacépède und Abbé Bonnaterre angeben. Die zwei Knorpelrohre zweigen sich von dem letzten Wirbel ab. Hier weist er auclı die Ansicht von Bose zurück und sagt, dass dieser Kinorpel mit der Zeit nicht durch Wirbel ersetzt wird, sondern einfach rerknöchert, ohne seine Gestalt zu rerändern. Bei einen andern Exemplar beobachtete er zwei einen Zoll lange Schwänze, ron denen der eine mehr ausgebiddet wie der andere sich ror zwei alten Ringen befand. Er erklärt dies durch unvollkommene Amputation (Dugès). Bei einem dritten Exemplar waren die Knorpelstäbe 6 Linien lang vereinigt, ehe sie sich theilten. Auch eine Ameiva mit doppeltem Schwanze untersuchte Gachet anatomisch. El fand, dass die beiden Kanäle durchsetzt waren von einel Verlängerung des Rückemmarks. In Allgemeinen sagt er, dass die Knorpelstïbe der regenerirten Schwänze stets sich an den Intervertebralknorpel (Fibro-cartilages intcrvertébraux) ansetzen. Nachden Gacket dann in ausserordentlich eingehender Weise die Literatur seines Themas besprochen hat, unterzieht er in einem Pisume sämmtliche Fragen noch eimmal einer genauen Durchsichtung und kommt zu heute noch allgemein gültigen Schlusssïtzen (pag. 246): Das Reproduktionsrermögen bei den Sauriern ist so ausserordentlich gross, dass schon eine partielle Ruptur genügt, einen nenen Schwanz hervorzurufen. Lacerta, Iguana, Gecko, Scincus, Aneiva, Anolis L., ja sogar die grosse amerikanische Lacerta teguixin, L. ceruleocephala und auch Bipes (nach Cuvier) besitzen eine bedeutende Regenerationskraft; dieselbe mangelt rollständig dem Krokodil und dem Chamaeleon, von denen Grıchet eine genügende Anzah! untersuchte, um zu diesem Ausspruch berechtigt zu scin. Alle diejenigen Reptilien, welche sich durch eine grosse Reproduktionsfähigkeit anszeichnen, haben einen ausserordentlich zerbrechliehen Schwanz; sie bewohnen besonders Gegenden, welche den Wohnungen der Menschen nahe liegen, ja zum Theil findet man sie in den Häusern. - Die Regeneration ist in gewissem Masse abhängrig von der Temperatur. Thevenot hat einen Schwanz von S Linien nachwachsen selıen, während Dugès bei sehr warmer Witterung in derselben Zeit ein Wachsthum ron $1 \frac{1}{2}$ 2 Zoll beobachtete.

Einen regenerirten Schwanz kann man leicht auch äusserlich von eineun normalen unterscheiden. Die Länge, Farbe, Form und Proportion, die Form und Grösse der Schuppen sind anders als bei dem ursprünglichen Schwanz, dessen Länge nur ausnahmsweise erreicht wirt. Die Schuppen behalten oft nicht die Eigenthümlichkeit ihrer Species; es fehlen meistens die Iöcker- 
chen, die Kämme (crêtes) und andere Verzierungen, die den primitiven Schwanz der meisten Saurjer schmücken.

In den ersten Tagen wird das regenerirte Stückehen durch eine homogene, gräuliche, dichte und zähe Masse gebildet; einige Tage später differenzirt sich die Haut und darauf bildet sich der Knorpel im Mittelpunkt, weleher, nachdem er einmal fest anhängt, sich sogleich ringslerum init Muskeln ungibt.

"La portion de nouvelle formation ne contient point de vertèbres, mais un cartilage d'une seule pièec, blanc, flexible, fistulenx et rempli d'un prolongement du cordon ou faisceau nerveux rachidien; il est cylindroïde, lisse et peu adhérent aux muscles, qui l'entomrent, et les muscles sont moins rẻgulicl's que les primitifs, quoiqu'anssi forts, aussi contractiles."

Auf die eben wörtlich angeführte Stelle werde ich gelegentlich zurückkommen. Gachet wirft Dugès ror", dass er ungenau beobachtet habe, da derselbe sagt: in der Mitte des regenerirten Schwanzes befinde sich ein Knorpel, Guchet aber die Verknöcherung desselben beobachtet hat. Gachet vergleicht den Knorpelstrang mit den ateromatös entarteten Blutgefïssen eines Greises, da dieselben nach und nach, und zwar von anssen nach innen rollständig verkalken.

Ueber die Verbindung des Knorpelstranges mit den ursprünglichen Wirbeln sagt Gachet folgendes (pag. 955): „Pendant que cet os est encore à f'état cartilagineux, il est continu arec la derniere vertebre à cause de son union intime arec le cartilage articulairc; cependant il se sépare assez facilement dans certaines circonstances. Lorsque son tissu a changé de nature, il n'y a plus de continuité, ils est uni à la dernière vertèbre comme les rertèbres entr'elles, ses "deux os se soudent - ils ensemble plus tard par l'effet de l'âge?"

Es ist dies die einzige Beobachtung Gachet's, die nicht ganz exact ist. Ieh werde mir desshall, Gelegenheit nehmen, an geeigneter Stelle auf dieses Citat zurückzukommen. Zum Schluss weist Guchet noch die Ansichıt von Dugès zurück, dass es sich bei den doppelten odel* mehrfachen Schwänzen um eine Disposition oder ein individuelles natürliches Gesehick (Aptitude) handle, und behauptet, dass dies nur das nothwendige Resultat del ausserordentlichen Regenerationsfähigkeit der Sanrier sei.

Die Hauptresultate der elsen besprochenen Ablsandlung sind für uns folgende:

Gachet hat die Structur des Knorpelrohres zuerst erkannt; er sah bereits, dass dasselbe aus 3 Lagen besteht, von denen die beiden äusseren schmal und verkalkt, die mittlere bedeutend breifer und knorpelig ist. Noch wichtiger ist jedoch, dass Guchet den im Lumen des Ḱnorpelrohres befindlichen Strang bereits als Fortsetzung des Rückenmarkes erkannte.

Nit der Arbeit von Gachet endet die zweite Periode der Versuche über die Regeneration; auf dieser; sowie auf den Ahhandlungen Bonnet's und Spallansani's müssen die Nachfolger weiter bauen, um zu einem gewissen Erfolge zu gelangen. Leider ist dies nun bisher durehaus nicht der Fall gewesen. Es wurden in unserem Zeitalter die historischen Studlien derart vernachlässigt, dass hie und da sogar Forscher auftraten, die über die Regeneration gearbeitet hatten und sich 
brüsteten, die eigenthümliche Struetır des regenerirten Schwanzes hei den Sauriern zuerst erkannt zu haben, obgleich es feststeht, dass nicht Duyès, Cucier oder gar H. Müller der Puhm gebüln't, zuerst die eigenthümliche Structur des regenerirten Schwanzes bei den Eidechsen erkannt \%u haben, sondern Perraul, der diese Verhïltnisse schon im Jahre $168 s$ erkannte.

Bei der modernen Vielsehreiberei kann es uns nicht Wunder nehmen, zu sehen, dass fast alle Erfolge der in biologischer Beziehung so ausserordentlich bedeutenden Versuche Bonnet's und Gachet's vergessen wurden. Und wenn aueh in der Mitte unseres Jahrhunderts ein nentes Mloment hinzutrat, welches die nochmalige genane Untersuchung der Regenerationsfrage durch die Fortschritte der vergleichenden Anatomie und Histologie rom veränderten Standpunkte aus als höchst interessant crscheinen liess, so jist es doch durchaus nicht zu entschuldigen, wenn man darüber die in anderer Richtmg angestellten Vorarbeiten vollstündig vernachlässigt.

In Jahre 1847 finde ich eine Notiz, dass Higgintıotom über die Zahl der Arten und die Entwickelung der Tritonen Grossbritanniens in der royal society eine kleine Abhandlung veröffentlichte. $\left.{ }^{1}\right)$ Hiernach kommt die Reproduktionsfähigkeit verlorener Glieder diesen Thieren nur bei einer 'Temperatur von $48-57^{\circ} \mathrm{F}$. zu; sie verlieren dieselle bei kälterer Witterung und im Winter. Auf wolche Species sich diese Angaben beziehen, ist nieht gesagt; es kommen jedoeh Verschiedenheiten bei den rerschiedenen Arten ror.

In Jahre 1849 erzihlt $\mathrm{Ph}$. Gosse in den Annals III p 307, dass einem scincartigen Reptil von Jamaica Maboyia agilis der Schwanz leicht abbricht und wieder wächst. 1853 gibt Liurneth in den Proc. Boston. Soc. IV. p. ag kleine Notizen über die Zerbrechlichkeit des Schwanzes der' Glasschlange (Ophisaun rentralis). Die Aluskeln gehen nicht ron einem Wirbel zum andern, sondern es heftet sich ein Theil der Fasem an dic Haut an und der andere mitten zwischen zwei Wirbeln endigend. Dasselhe fand er bei Scincus fasciatus (Troschel).

1854 besehreibt derselbe wiederum einen Ophisaurus ventralis, der vor zwei Monaten seinen Schwanz verloren und ihn schon auf cine Lünge von 3 Zoll reproduzirt hatte. ${ }^{2}$ ) Aeusserlich war die Ansatzlinie sichthar und die Schuppen an dem ersten Zoll des neuen Theils waren unregelnüssig. An den letzten zwei Zollen waren sic in deutlichen Reihen, wie am alten, geordnet. „Offenbar bildete sich ein Wirbel nach dem andern; zuerst bildete sich ein Wirbel an dem letzten Wirbel des alten Theils, dann folgen nacheinander die ührigen, bevor noch jedesmal der vorhergehende rollendet ist." Verfassel fand, dass die Bildung wie in der Embryologie stattfände; auch das Rückenmark war reproduzirt (Troschel).

Es wäre sehr wunderbar, wenn diese Beobachtungen nicht durchaus auf Tüuschungen beruhten; denn wenn bei den nächsten Verwandten der Glasschlange, bei unserer Blindschleiche oder den scincartigen Eidechsen sich in dem regenerirten Schwanze ein Knorpelrohr befindet, wie dasselbe überhaupt bei allen regenerationstähigen Reptilien von zuverlässigen Forschern gefunden wurde, so wäre es höchst merkwürdig, wenı bei einem Angehörigen dieser Fanilie sich auch die

$\left.{ }^{1}\right)$ Institut 1817, pag. 253. Annales $\mathrm{XX}$, pag. 70.

3) Boston Proc. IV, p. 309. 
Wirbel und sogar in der embryonalen Weise neu bilden solłten. Obgleich ich nicht Gelegenheit hatte, selbst eine Glasschlange auf ihre Regenerationsfithigkeit zu prüfen, so glaube ich dennoch nach den Analogien berechtigt zu sein, die Angaben Burnett's als falsch zurückzuweisen.

Ueber die Regeneration bei Reptilien spricht erst wieder Rankin, ${ }^{1}$ ) dessen Versuche einigermassen ausführlich sind, wenn sie auch keinen Vergleich mit den früher besprochenen aushalten. Der Verlust des Scliwanzes ist nach $R$. bei den Blindschleichen olt allein das Resultat instinktiver Anstrengung. Zuerst fliesst Blut aus, welches den Stumpl wie mit einer Kruste bedeckt. Von Tag zu Tag soll dann eine Verlängermng von ungefähr 1/2 Linie eintreten. Dieses Resultat hängt jedoch augenscheinlich ab ron dem Alter, welches das Thier erreicht hat. Das neue Stück ist zuerst bedeckt mit einer unvollkommenen Haut, welche bald abgestossen wird; in 4-6 Monaten sind die Scluppen gebildet und der Reproduktionsprozess ist zu Ende. In einem Falle betrug der reproduzirte Theil, welcher 3 Zoll hinter der Cloake anfing, 5 Linien und bei einem jüngeren Exemplar, wo er 2 Zoll hinter der Cloake begann, 7 Linien. Im ersten Fall war das regenerirte Stück bedeckt ron 7 Reihen Schuppen, im zweiten von 10 Reihen, einscluliessend die letzte konische Schuppe. Dieselben sind rergleichsweise stark, schmal und zahlreich. Im ersten Falle hatte die Trennung dort stattgefunden, wo 10 Schuppen am Umfange des Schwanzes stehen; (die neuen Schuppen am Punkte der Vereinigung mit den alten sind 20 an der Zahl); im anderen Falle befanden sich 12 Schuppen an der Trennungsstelle. An der Vereinigung des reproduzirten Theiles mit dem alten Schwanze standen 18. Wirbel wurden nicht regenerirt.

Leydig hat in scinem Lehrbuch der Histologie, Hanm. 1857 pag. 62, eine kleine Notiz über einen regenerirten Schwanz einer Eidechse. ,An einer 1/a Zoll langen, äusserlich und auch aul' dem Durchschnitt schwärzlich pigmentirten neugebildeten Schwanzspitze einer Eidechse war die Muskulatur aus verhältnissmässig kurzen Schläuchen gebildet, welche eine Rinden- und Achsensubstanz zeigten und in letzterer dicht apeinander gereihte querovale kerne. Mitten durch die regenerirte Schwanzspitze zog ein weisslicher Streifen, einer Chorda dorsalis vergleichbar, bestand aber nicht aus den grossen Zellen der Chordasubstanz der Fische und Batrachier, sondern aus kleinen spindelförmigen, eng aneinander liegenden Zellen." Er kommt selbst später hierauf zurück und auch für mich ist es zweckmüssiger, mit der Besprechung derselben bis zur nächsten im Jahre 1872 erschienenen Abhandlung Leydig's zu warten.

Kneeland beschreint in Proc. Boston VI. p. 371 und 428, ,lass kleine Fische scinen Menobranchus die Kiemen abgefressen hätten, so dass nach 10 Tagen nu1 noch die Kinorpelansïtze derselben, hie und da besetzt nit einer Kiemenfranze, übrig waren. Als nun die Fischchen entfernt waren, begannen sie wieder zu wachsen und hatten im Laule von 6 Monaten die Hälfte ihrer nolmalen Grösse wieder erlangt. Da die Lungen allein ausser dem Wasser nicht ausreichen, sondern die Thiere schon nach 4 Stunden starben, in diesem Falle sie jedoch durch das Fehlen

3) Dan. R. Runkin on the Structure and Habits of the Slowworm (Anguis fragilis). Linn. in Edinlurgh new Plilosophical Journal. Vol. V. New. Series 1857. 
der Kiemen nicht litten, so glaubt Verfassel ammehnen zu dürfen, dass die Hautrespiration in Wasser die Lungen hinreichend unterstütze, um die Bhutumänderung zu bewirken." (Troschel.)

Eversmann ${ }^{1}$ ) sah in den Sammlungen in Algier einige Eidechsen mit doppeltem und eine mit dreifachem Schwanze; mitunter war einer der Schwänze der ursprüngliche, häufiger jedoch waren beide ergïnzt.

Wie zwei Schwänze entstehen können, hat Gliuckselig ${ }^{2}$ ) in neuester Zeit an Thieren in der Gefangenschaft beobachtet. Es entsteht öfter durch irgend einen äusseren Einfluss eine Spalte am Wundrande, und diese ist es, welche die spätere Gabelung bedingt.

In den rorzüglichen Untersuchungen der vergleichenden Anatomie der Wirbelsäule bei Amphibien und Reptilien kommt Gegenbaur ${ }^{3}$ ) auf die Regeneration der Schwanzwirbelsüule zu sprechen (pag. 48). El prüfte die von $H$. Müller in den Würzburger Verhandhungen It. Bd. 1852 p. 66 gemachton Beobachtungen mol fügt über die histologische Structur des Knorpelrohres einige Details hinzu. In Betıeff des Rückenmarkes hat Gegenbaur eine völlig von $H$. Müller und den früheren Beobachtem, die ihm jedoch sümntlich unbekannt zu sein scheinen, abweichende Ansicht. Er sagt darüber: „Die Wirbelsäule setzt sich in das Knorpelrohr, das Rückenmark in das Contentum des Centralkanals fort. Die neu gebildete, an das Rückenuark sich anfügende Masse scheint jedoch nicht aus den Elementartheilen des Rückenmarks zu bestehen, so dass eine Regeneration der Mejulla spinalis nicht statt hat. Ich zweifle nicht daran, dass dasselbe Verhalten auch an dem von II. Müller untersuchten Doppelschwanze sich fand."

Gegenbuur wird hauptsïchlich dadureh in seiner Ansicht bestärkt, dass er nirgends regelmässige Communicationen nach aussen ron dem kianal des Knorpelrohres abgehen sieht.

Auch bei Hemidactylus fand Geyenbaur dieselben Verhältnisse, wie bei den Eidechsen. Hier salı er ab und zu nach oben gehende, die Wandung des Kanales senkrecht durchsetzende Communicationskanäle.

„Was hier aus- oder eintritt, bleibt mir unklar. An Nerven möchte jedoch nicht leicht gedacht werden können, denn in Kanale finde ich ausser lockerem Bindegewebe nur $2-3$ Röhren von verschiedenen Talibel, die ich für Blutgefässe halten muss."

Gegenbaur hat diese Beobachtungen nur ganz nebenbei an einigen wenigen Exemplaren bei Gelegenheit seiner Untersuchungen über die Wirbelsäule gemacht.

Da seine Methoden der Untersuchung für diese zarten Elemente viel zu derb waren (er führte eine Borstensoncle ziemlich weit vorn in den Rückgratkanal ein und fand, dass dieselbe aus dem Rückgratkanal in den Kanal des Knorpelrohrs eindrang), so ist es klar, dass Geyenbaur die ausserordentlich zarte Fortsetzung des Rückenmarks nicht erkennen konnte.

\footnotetext{
1) Eversmann, Erinnerungen aus einer Reise in's Ausland 1557-1S5̈ in Bulletin d. maturalistes de Moscau 1858.

$\left.{ }^{2}\right)$ Glückselig, Ueber das Leben der Eidechsen, Verhandlungen des zool -bot. Vereins in Wien 1 s63.

3) Leipzig 1862 .
} 
Die zunächst zu besprechende Arbeit von Itinrich ,Wüler ,Ueber Regeneration der Wirbelsäule und des Rückenmarkes bei Tritonen und Eidechsen" ") ist die letzte, welche die atlgemeinen regenerativen Vorgänge bei Amphibien und Reptilien eingehender behandelt.

Die einschlägige Literatur ist II. Müller allerdings fast ganz fremd, er kennt nur die kurze Notiz ron Cutier und eine andere Angabe von Js. Geoffroy St. Hilaire, welche beide nur kurz und unbestinmt gehalten sind, so dass es sich lierdurch erklären lässt, dass H. Müller sich eine Entdeckung zuschreibt, welche schon fast zweihundert Jahre vorher von Perrmut ${ }^{2}$ ) gemacht worden war.

Bereits im Jahre 1852 trug Müller in der physikalisch-medizinischen Gesellschaft zu Wüızburg ${ }^{3}$ ) über die eigenthümliche Structur eines regencrirten doppelten Eidechsenschwanzes ror; im Jahre 1857 veröffentlichte er seine erweiterten Untersuchungen auf der Naturforscherversammlung in Bom ${ }^{4}$ ) und trat endlich 1864 mit der abgeschlossenen Arbeit vor das Forum der Wissenschaft.

Müller änderte seine Meinung über das Knorpelrohr und das regenerirte Rückenmark einige Male, kam aber endlich zu einer Ansicht, welche schon von Dugès und Gachet vertreten wurde.

Ueber die Regeneration der Wirbelsünte bei Tritonen verbreitet er sich austührlich und geht auch auf die gewebliche Differenzirung genauer ein, so dass ich Gelegenheit haben werde, bei der Ausführung meiner eigenen Beobachtungen wiederholt auf diese Arbeit zurückzugreifen.

Als Hamptresultat ist anzuführen, ,dass sich eine vollständige knorpelige Wirbelsäule entwickelt, welche aus einer Reihe von Körpern mit oberen und mteren Bogen besteht. Die Axe des regenerirten Wirbelsystems bildet ein continuirlicher Knorpelstrang, welcher sich mmittelbar an dic Reihe der ursprünglichen Wirbelkürper anschliesst und an vorderen Ende die Dicke derselben erreicht." Sehr wichtig ist die Entdeckung II. Müller's, dass das Ende des normalen Tritonenschwanzes nicht von einer knöchernen Wirbelsäule, sondern von einem knorpeligen Strang durchzogen ist, obgleich sich Müller nicht völlig der ausserordentlichen Tragweite dieser Entdeckung bewusst ist.

Sehr wohl hat el jedoch gesehen, dass die regenerirten Wirbel sich aus einem continuirlichen Knorpelstrang ohne eine voraufgehende Chorda entwickeln, gerade wie dies dic letzten Wirbel eines ursprünglichen Scliwanzes ebenfalls thun.

Das regenerinte Rückenmark bei Tritonen ist zuerst dem Filum terminale des ursprünglichen Schwanzes zu rergleichen, es vergrössert sich jedoch allmählich und nimmt so nach und nach Gestalt und Structur des normalen Rückenmarkes an.

Auch die Spinalganglien werten vollzählig regenerirt. Ueber das Knorpelrohr des regenerirten Eidechsenschwanzes bringt Müller wenig Neues, da er aber, wie gesagt, die ältere Literatur nicht kennt, so verbreitet er sich ausführlich über die Structur und Entstehung desselben.

1) Gratulationsschrift der physikal.-medizin. Gesellschaft in Würzburg zu der Jubelfeier der Senkenberg'schen Stiftung. Frankfurt a. M. 1 s6f.

2) Perrut 1. c. (pag. 11) $168 \mathrm{~s}$.

3) Verhandlungen Bu. II, S. 60.

4) Antlicher Bericht lür $185 \pi$. 
Die Continuität des das Lumen des Knorpelrohres durchsełzeilden Stranges mit dem Rückenmark weist er überzengend nach und hält denselben auch rlem ursprünglichen Rückenmark für morjhologisch gleichwerthig, indem er sagt: „In diesen aus dem Rückenmark hervorwachsenden Strang sind nun nervöse Elemente mit Sicherheit zu erkemen."

Sicherer als Ganglienzellen glaubt or feine markhaltige Nervenfasern nachweisen zu können.

Die von Müller angestellten physiologischen Versuche geben allerdings ein mehr negatives Resultat, denn der regenerirte Schwanz macht weder automatische Bewegungen, wenn er völlig von den ursprünglichen getrennt ist, noch lassen sich an demselben nach mechanischer Picizung Retiexberregungen mit Sicherheit nachweisen.

Spinalganglien fehlen dem regenerirten Rückenmark vollständig und cbensowenig sind regelmïssige Oeffungen vorhanden, durch welche Nervenfasem lindurehgehen könnten. Auch bei anderen Reptilien beobachtete Müller regenerirte Schwänze, so bei den Geckotiden und bei Anguis und theilt mit, dass sich in der zootonischen Sammlung in Würzburg ein Skelet ron Draco volitans befindet, ..wo an die vordere, erhaltene Hälfte des 19. Schwanzwirbels sich ein über $2 \mathrm{~cm}$. langer Strang aus stark verkalktem Knorpel ansehliesst, der an Dicke die Schwanzwirbel cher übertrifft."

Bei einem Skelet ron lguana ist die Wandung des Knorpelrohres des regenerirten Schwanzes durchsetzl von einer grossen Anzahl kleiner Kanäle. dic von meh: oder weniger vollkommener Knochensubstanz umgeben sind.

Bei der zweischwänzigen Eidechse, welche Miller auf dicse Untersuchung leitete, waren Knorpelröhren in beiden Theilen rorhanden; auf das merkwürtige Verhalten des Rückennarkes komme ich später zurïck.

Aus dem soeben mitgetheilten kleinen Auszug sieht man, dass Müller die Untersuchung schon von einem anderen Gesichtspunkte aus begronnen und zum Theil anch gläcklich durchgeführt hat. Eines seiner Hanptresultate rerdankt or der Vergleichung der regenerirten Theile mit dem normalen Schwanzende und der embryonalen Entwickelung. Wenn wir anch bedanern müssen, dass Müller dic früheren diesbezüglichen Arbeiten nicht kannte, so wird in scinen Versuchen doch stets so viel des Lehrreichen zu finclen sein, dass jeder spätere Forscher dieselluen genau studiren und ihre Erfolge als Basis für seine Untersuchungen benützen muss.

Da ich in der historischen Uebersicht nur diejenigen Arbeiten aufführe, welche sich mit den allgemeinen Erscheinmgen der Regeneration befassen, dagegen die Untersuchungen über dic Regeneration einzelner Gewebe erst in dem speziellen Theil besprechen und benützen werde, so habe ich bis auf die Arbeiten von Leydig und Plilippeaux nur wenige kleinere Vittheilungen zu erwähnen, welche ich hier der Reihe nach aufzählen will, um mit den genannten grösseren Arbeiten dicse Abtheilung zu beschliessen.

Im Jahre 1863 bespricht Tyller') den Farbenwechsel, die Häutung und die Regeneration des Schwanzes bei den Ascalaboten. Er hat bei 9 Arten die Wiedererzeugung dęs Schwanzes

1) Joumal of the Asiatic soc. of Bengal. 1865. p. 535. 
beohachtet und glaubt, dass cine Zeit ron 3 Wochen für diese Thiere genügend sei, den Schwanz rollstïndig 7.11 reproduziren.

Giebel ${ }^{1}$ ) hat cine Eidechse mit I Schwänzen erhalten, geht aber nicht auf den anatomisclen Bau derselben ein.

Ilolfert ${ }^{2}$ ) berechnet auf jeden Tag im Durchschnitt $2 \mathrm{~mm}$. Wachsthum für einen sich regenerirenden schwanz bei Lacerta agjis.

Wiclersheim ${ }^{3}$ ) beobachtet das Nachwachsen der k̈jemen bei Siren lacertina, und Frïulein v. Chauxin ${ }^{4}$ ) dieselbe Erschcinung bei dem Axolotl, wodurch dic frïheren Beobachtungen ron Dumeril ${ }^{5}$ ) bestäligt werden.

Erber $\left.{ }^{G}\right)$ hatte Gelegenheit, cine Siren lacertina lebend zu beobachten. Als er das junge Thiel uhiclt, waren ihn die Füsse und Kiemen gänzlich abgefressen; dieselben entwickelten sich aber vollkommen wieder.

Da schon Siebold ${ }^{7}$ ) in Jahre 1898 darauf aufmerkšam macht, dass monströse Extremitäten keine seltenen Erscheinungen bei Molehen und dass dieselben in der Picgel nicht angeboren, sondern Regenerationserseheinungen sind, so wird es wohl angezeigt sein, auch über die in letzter Zeit so hänfig beobachteten Missbildungen etwas hinzuzufügen

So bildet ror Allem Dumerils) eine ganze Reihe Monstrositäten, dic er an Axolotin beobachtet, ab. Dieselben bezichen sich besonder's auf die Bildung dor Zehen und sind sicher sämmtlich durch abnorm rerlaufende Regeneration in diesel Weise doformirt. Dann gehören hierher die oftmals beobachteten Tritonen mit abnorm gebildeten Extremitäten und der Triton mit ż Beinen, welehen Reuter ${ }^{9}$ ) in der naturwissenschaftichen Gesellschaft zu Chemnitz rorzeigte. Sehr unwahrscheinlich ist es mir jedoch, dass die üherzïhligen Extremititen der Anuren dureh cine abnorm verlaufende Fiegeneration entstanden sein sollten, unter ähnlichen Bedingungen, wie die doppelten schwänze der Eidechsen. Auffallend ist allerdings die grosse Zahl der beobachteten Fïlle, (lenn Gervais, $\left.{ }^{10}\right)$ Dumeril, $\left.{ }^{11}\right)$ Cisternas ${ }^{12}$ ) und Giebel ${ }^{13}$ ) beschreiben Batrachier mit überzähligen Extremitäten und ich selbst habe Gelegenheit gehabt, bei Herm Dr. Fröllich in Aschaffenburg einen lebenden Frosch mit drei Hinterbeinen zu beobachten.

1) Zeitschrift f. d. ges Naturw. 24. p. 28. 186\%.

2) Sitzungsher, der Gesellschalt Isis in Dresten IS69. p. 14.\$.

$\left.{ }^{3}\right)$ Morphol. Jahub. Ill. Heft 4.

4) Zeitschr. f. w, Zool. Xxvil. Heft 4.

s) Bulletin de la societé imp. d'acclimat. Oct. IS67. Nonvelles Archives du Museum d'histoire nat. III. p. Is9 und Cicmptes rendus 1567. p. 919.

$\left.{ }^{6}\right)$ Verhandlung. der zool.-hot. Gesellsch. in Wien 1S76. p. II (nach Troschel Jahresher.).

7) ¿. Siebold, Observationes quaedam de Salamandris ef Tritonibus. Diss. Berolini j8q8.

$\left.{ }^{8}\right)$ Nunvelles Archives du Museum d'histoire nat. III. 1). 119, pl. อ̃.

9) Bericht d. Gesellsclı. Is75. p. 26.

iv) Comptes yendus p. 59. p. 801. 1864. mil herue et magasin de zoologie XVI Г. 330.

11) Comptes rendus P. 60. 156\%. Revue et mag. de Zoulogie 17. p. 170. Nourelles archives du Museum 1, p. 309. pl. 20.

12) Rerue et mag. d zool. 17. 1, 9857.

13) Zeitschn. t', the ges. Natum. 29. P. 504. 
Auch Leydig1) erwähnt eine Anzahl von Mlissbihdungen, deren Entstehung nicht klar ist.

Da meine Versuche über dic Regenerationsfühigkcit der Extremilïten jüngerer und ällerer Anuren, wic ich hier schon rolaufschicken will, ein durchaus negatives Resultat hatten, so bin ich der Ueberzengung, dass hier wirklich angeborene Missbildungen rolliegen, gerade wie dies bei den ebenfalls so häufig beobachteten und unter Anderen von de Bella, Schroll, Dobson, Dorner, Yurrow und Kingsley beschricbenen zweiköpfigen Schlangen der Fall ist, welche Formstörmugen in ilnnlicher Weise ihre Elklärung finden, wie die durch Verwachsung mehrerer Embryonen entstandenen, oft so wunterlar verzerrten Monstra aus der Chasse der Süugethicre oder der Vögel.

Ungemein interessant ist es, einen Forscher wie Leydiy sich über die wichlige Regenerationsfrage aussprechen zu hören. Nü nebenbei herührt Leydig") in seinem grossen Werke über die einheimischen Saurier die Regeneration des Eidechsenschwanzes, abel dennoch ist eine Fülle ron anregenden Gedanken in diesen wenigen Seiten enllualten.

Der Grund der leichten Brechbarkeit des Eidechsenschwanzes beruht nach Leydig wahrscheinlich in der Qucrtheilung der Schwanzwibel, wobei der Unstand sehr bemerkenswerth ist, dass gerade in del' Gegend des siebenten Wirbels (wo die Quertheilung begimnt), del' Schwanz am leichtesten abknickt. Ferner trägt dazu bei dic Anordnung der Schuppen, der Schwanzmuskulatur und die massenhafte Ansammlung von Fett um die Wirbel herum.

Ueber den Regencralionsprozess beobachtete Leydiy Folgendes: Nachdem die Wunde sich zusammengezogen hat, beginnt dic Neubildung sofort in Form einer schwälz]ichen Warze, welche sich kegelförmig verlïngert. Der nengebildete Theil ist meistens gleich anfangs stark pigmentirt, seltener hell wie bei Lac. muralis val. campestris, wo crst später der Rücken einen schwärzlichen Streifen crhält als Fortsetzung der dunklen Bandstreifen des unversehrten Schwanzes.

Im Winter ist das Wachsthum des nenen Theiles kam nennenswerth.

Den eigenthümlichen Knorpelfarden, der die Stelle des knöchernen Wirbelsystemes vertritt, hat Leydig mehrfach untersucht und seine Resultate stimmen in Allgemeinen nit denen der älteren Forseher überein. Er hält das Knorpelrohr in cinem gewissen Sinne, besonder's auch nach sciner Bedeutung für Chordaälnlich, wofür er auch den morphologischen Belund anführt, dass hei einem nachgewachsenen Schwanz einer Lac. agilis „dic Zellen durch Grösse und sonstige Beschaffenheit doch etwas an das Gewebe del Chordasubstanz crinnern." Dit Benutzung der Untersuchmg Geyenbaur's über die Wirbelbildung koumt Leydig zu folgendem Schlussatz:

„Vergleichen wir mit diesen Vorgïngen den Knorpelfaden im regeneriten Schwanz, so $\mathrm{i}_{\text {st }}$ hier allerdings die Chorda im engeren Sinne, oder in ihrem Axentheil, nicht vorhanden; aber zugegen sind die Rinden oder scelettbildenden Schichten, das heisst ein rerkalkender Knorpel und ossificirendes Bindegewebe als Grundlage für Wirbelkörper und obere Bogen. Die wirkliche Sonderung und Gliederung in Wirbel erscheint aber meist gehemmt oder nur auf eine Strecke des „Knorpelfadens“ beschränkt, so dass der grüsste Theil in sonst volübergehenden Zustand sich crhäit."

') Die anuren Batrachier der deulschen Fauna. Bonn 1577. Nit 9 Taf. (Anhany).

2) Die in Deutsclıland lebenden Arten der Saurier. Tübingen 1S72. prag. bí ff. 
„Aber gleich wie man sagh, die Chlorda sei bei Embryonen ein Vortäufer, bei manchen Fischen dauernd ein Vertreter der Wirbelsäule, so lässt sich auch rom Knorpelfaden in Schwanz der Eidechsen behaupten, dass er jene Schichten und Theile in sich begreift. welche sonst aus der Scheide der Chorda iluren Ursprumg nehmen; das ganze Gebilde behalte sonach etwas Chordaähnliches und sei in genissem Sinne auch Chorda. Und nach diesel Auftassung liegt kein Widerspruch darin, wenn man hinwiederum gelten lässt: der Knorpelfaden stelle ein unfertiges Rïckgrat ror."

Da ich auf diese Arbeit im speziellen Theil noch öfter zurückkommen werde, so behalte ich mir die Besprechung einiger anderer Stellen bis dahin ror und will hier nur noch erwïhnen, dass Leydiy selbst bei nomalen Exemplaren ron L. viridis, L. muralis und L. vivipara im Innern des Schwanzes ein knorpelrohr ron zwei bis drei Zoll Lïnge gefunden hat, das sich ganz so verhiell, wie das knorpelrohr des regenerirten Schwanzes. Ob Leydig sich in diesem Punkte nicht getïuscht hat, wage ich nicht zu entscheiden; nach meinen Beobachtungen jedoch liegt stels eine Regeneration ral, wem ein knorpehohr die Stelle der knöchernen Wirbel vertritt. Sollten dennoch Eidechsen rorkommen, deren normalè Schwanz den anatomischen Bau eines regenerirten zeigte, so liesse sich dies vielleicht durch Alavismus erklären, wemn es nachgewiesen wäre, dass solche Indiriduen ron Eltern mit regenerirten schwïnzen abstammten. Auf die sonstigen Theorien. welche sich hieran knüpfen liessen, komme ich ebenfalls später zurück.

Die letzten Arbeiten allgeneineren Inhaltes, die ich an dieser Stelle noch zu besprechen habe, sind die ron Philipperux, welcher seit Jahren die Regenerationsfrage bearleitet und dem wir einige recht hübsche Resultate verdanken. Durch seine ersten Experimente ${ }^{1}$ ) wies cr nach, dass die Gliedmassen ron Triton cristatus nur dann sich regeneriren, wenn wenigstens del Basaltheil derselben an seiner Stelle bleibt; im nüchsten Jahre folgten Versuche über den Axoloth, ${ }^{2}$ ) die den Beweis dafür beibrachten, dass die Vorderbeine nur dann sich regeneriren, wenn der Sclubltertheil am liörper zurückbleibl; im anderen Falle wird die Wunde nur remarbt.

Von späleren Albeiten desselben Forschers sind mir zugänglich geworden: Note sur les résultats de l'exstirpation compliete d'un des membres antèrien's sur l'Axolotl et sur la salanandre aquatique, ${ }^{3}$ ) unct: Expériences montrant que les mamelons exstirpés sur de jeunes Corlıons al'Inde ne se rérẻnèrent point. ${ }^{+}$)

Im letztangeführten Aufsatz beschreilst der Verfisser, dass nach vollkommener Exstirpation der Brustwarzen bei jungen Meersehweinchen, ungeachtet die Thiere trächtig wurden, die Brustdrüse und die ductus galactoplıori sich entwickelten, niemals eine Regeneration der Warze.

In einer ferneren Arbeit ${ }^{5}$ ) zeigt Philippeux , dass anch dic Milchdrüsen sich nicht wieder neubitden, ebensowenig wic andere innere Organe, ja selbst die Fischflossen dürfen nicht ganz abgeschuitlen sein, wenn sie nachwachsen sollen.

1) Comptes rendus Uct, 1866 P. 576-57s. Anmales nat. Hist. 19. p. 72.

$\left.{ }^{2}\right)$ Comptes rendus Juni 1867 . Annales nal, list. 20. p. 1.9. Annales des scienc. nat. VII. p. gese.

3) Gaz. mél. de Paris 1574. p. 105.

4) Comptes rendus \&. Febr, 1876. 1. 402.

$\left.{ }^{5}\right)$ Expériences montrant que les mamelles enteves sul de jeunes Cochons d'Inde femelles ne se régénèrent roint; in Comptes rendus T. S1. p. 201. 
Die Experimente über Trilonen wiederholt Philippeaux ${ }^{1}$ ) noch einmal und kommt zu dem Resultat, dass auch exartikulirte Gliedmassen der Amphibien sich nicht mehr regeneriren.

Aus allen seinen Versuchen zieht er den Schluss, dass tine Regeneration von Organen nur dann möglich sei, wenn diese Organe nicht rollständig enifernt worden sind.

Im speziellen 'Theil werde ich nachzuweisen versuchen, wie weit dieser Satz allgeneine Gültigkeit hat und wie weit er auf Täuschung des französischen Forschers beruht, der entsehieden zu weit geht, wenn er die Resullate der bei Sïugethieren angestellten Versuche direkt auch aul' die Amphibien überträgt, welche sich dureh eine bedeutend grössere Reproctuklionskraft auszeichnen. Ausserdem ist der Satz auch durchaus nicht neu, denn schon Bomet und Bhumenbach erwähnen ihn bei der Regeneration des Auges der Tritonen.

Hier sollten nun noch Experimente ron allgemeinerer Bedeulung über die Regenerationserscheinungen bei Fischen, Vögeh und Süugehieren besprochen werden, dieselhen fehlen aber ausser den wenigen schon erwähnten Versuchen vollständig oder sie sind trotz allgemeiner Bedeulung doch nur an einem einzelnen Organ oder Gewebe angestellt worden, so dass sie zweckmässigel in dem speziellen Theil ihre Stelle finden. ${ }^{2}$ )

Was über die Regeneration bei Wiblthieren sonst noch bekamt isl, lasst sich in wenigen Worten zusammenfassen.

Höchst interessant sind ror allen Dingen diejenigen Regenerationsersclreinungen bei den lı̈̈leren Thieren, welche ansehcinend pathologisch dennoch als rein physiologische bezeichnet werden müssen, wie das Abwerfen und Neubilden der Geweilıe bei den hirschähnliehen Thieren. Die so enorm grosse Gewebsmasse, welche in den Hirschgeweihen enlhalten ist, wird in verhällnissmässig ku'zer Zeit erneuert und innerhalb 4. - J Monaten prangt das nene Geweilı in cler Slattliehkeit des alten. Sicher ist es, dass durch das jührliche Abwerfen auch Defecte oder Missbildungen, mit denen das alte Geweil behaftel war, verloren gehen, und das neue Geweih slets bestrebt ist, sich möglichst dem normalen Typus anzupassen.

In ähnlicher Weise fesselt ms die Mausel del Vögel. ${ }^{3}$, da bei diesem Prozess imnerhalb sehr kurzer Zeit das ganze Federkleid erneuert wird. Eine einzehe abgeschnittene Feder wälehst nicht wieler nach, sondern der Stumpf bleibt bis zur nüchsten Mauser, so ulass die Beobachtnng von Treciramus und Arnemam, welche das Gegentheil bei einem Huhn gesehen haben wollen, in den Bereich der Fabel zu rerweisen sein dürfte. Ebenso wird es sich wohl mit der Wiedererzeugung des Schnabels rerhalten. Ob die Angabe ron Aristoteles und Plinius, dass den jungen Sehwalben T. S2. Nr. 20.

1) Les membres de la Salamandre aquatique bien extirpes ne se regénérèrent point. in Comptes rendus

2) Trotzlem die grosse Arbeit ron Demurquai: de la régenération des organs ot des tissus viele allgemeine Gesiehtspunkte herührt, ziehe ich es doch vor, die einzehnen Capitel derselben in speziellen Theil zu bespreehen, da jch mich rielfach mit derselben zu beschältigen habe.

3) Ueber die Regeneration der Federn vergl. man the netere Arbeit ron S. Samuel: Archiv f. patholog. Anat. u. Mhysiologie etc. ron Firchow, 50. Band, 1880, p. 323 ff. 
die ausgestochenen Augen nachwachsen, dasselbe Schieksal verdient, dürfte wolıl noch einer nüheren Prüfung zu unterziehen sein. Trotz des sehr raschen Stoffwechsels ist die Regenerationsfïlugheit der Tögel ausserordentlich gering und da sich bei den Fischen, welelıe sich dureh grosse Langsamkeit des Stoffirechsels auszeichnen, dieselhe Erscheinung zeigt, so kann man hieraus den allgemeinen Satz formuliren, dass die Sehnelligkeil des Stoffrechsels keinen Einfluss auf die Regenerationserscheinungen ausüht.

Sicht man bei den Fischen ab ron den sich während der Fortpflanzungsperiode auf der Epidermis bildenden Verdickungen und perlartigen Auswüchsen, so beschränkt sieh die Regenerationsfïhigkeit auf die Ausbesserung rerstünmelter Flossen und kleiner Hautlleile, auch werden die Schuppen, wenn anch nur in geringer Anzalıl, neugebildet. Dass die Zühne bei den meisten Fischen fortwährend neugebildet werden, ist bekannt, gehört jedoch als vollständig physiologischer Aet nicht hierher.

Es beschränkt sich somit die pathologische Regeneration bei den Fischen, Vögeln und Sängethicren auf einen einfachen Wundheilungsprozess, auf das Nachwachsen der Epidermis und die Neubildung ron Epidelmisbildungen wie der Nägel, Haare, Hörner und Geweilıe, wïh rend rol Allem ganze Organe oder gar Organsysteme ron der Regenerationsfähigkeit völig ausgesehlossen sind. Was die Gewebe anbelangt, so regeneriren vor allen Dingen bei sämmtlichen Thieren diejenigen am besten und leichtesten, deren Wachsthum ein unbegrenztes ist, wie z. B. die Intercellularsubstanzen, und unter diessen ausser Blut, Lymphe und anderen Secreten rorzäglich die Pseudocuticulae und der Hyalinknorpel.

Fernere für die folgende Untersuchung werthrolle Resultate, welche aus der rorhandenen Literatur geschöpft werden können, sind

Erstens: Der schon bei der Wrurmregeneration bekannt gewordene Satz- je weniger complizirt dieverloren gegangénen Theile gebaut sind, desto leiehter regeneriren sie - muss dahin elweitert werden, dass die Wiedererzeugung um so schneller, leichter und rollkommener geschicht, je allgemeiner die Bedeutung des verloren gegangenen Theiles ist.

Zweitens: Junge Thiere regeneriren leichter und rollkommener als äItere; bei einzelnen Arten Irört das Reproduktionsrermögen nach abgeschlossenem Waehstlum sogar vollstïndig auf.

Drittens: Die Reproduction ist abü̈ngig von äusseren Umständen, besonders ron den Einflüssen der Jahreszeit und der Witterung. Dann aber übt auch die direkte Umgebung einen sichtbaren Einfluss aus, da der Wasseraufenthalt entschieden günstiger ist, als der Landaufenthalt.

Viertens: Je höhel organisirt das Thier ist, desto geringer ist seine Reproduktionsfäbigkeit, jedoch soll damit nicht gesagt werden, dass die auf niederer stufe stehenden Thiere stets besser regeneriren müssten, als die höher organisirten. 


\section{Eigene Untersuchungen.}

\section{A. Untersuchungs-Methoden.}

Da meine Torarbeiten im ungünstigsten Honat les Winters, im Januar begonnen wurlen, so musste ich mich zunächst daran beschränken, conservirtes Material zu benützen, welches mir denn anch in reichstem Masse durch die Herren Profesor Semper und Dr. Brann zur Verfügung gestellt wurde.

lch erhiclt hierdurch eine sehr werthrolle Reihe regenerirter Theile ron ausländischen Ascalaboten md anderen Reptilien, aber auch ron enropüischen Amphibien, so dass ich die Wintelmonate hindurch vollständig mit del Zerlegmng dieses Materials in Schnittserien beschäftigt war.

Als die Witterung günstiger wurde, sammelte ich sofort diejenigen Amphibien und Peptilien, welche die Ungebung Würburgs darbot, auch bezog ich einige seltenere Thiere ron Gebrüder Sasse in Berlin. Neine Anfmerksamkeit murde bald auf Pleurodeles Waltlii gelenkt, der sich durch ausserordentliche Reproductionskraft auszeichnet, so dass ich mit diesen 'Thiere ganz besonders zahlreiche Tersuche anstellen konnte.

Benutzt wurden vongeschwänzten Amphibien in frischem Zustande: Pro te us ang u in eus. Siredon pisciformis und rerschiedene Tritonen wie Tr. taeniatus, Tr. eristatus. Tr. alpestris. Tr. lielveticus, Tr. marmoratus in elwachsenen Zustande, sowie die Larven von Triton taeniatus und Tr. cristatus: ferner Salamandra maculosa elwachsen und als Lare, und wie rorher erwïhnt Pleurodeles Waltlii.

Von anuren Amphibien untersuehte ich die Laren ron Hyla arborea, Pelobates fuscus, Bufo rulgaris, Bufocalamita, Bombinatorigneus, Rana esculenta und Rana temporaria.

Das lcbende llaterial an Reptilien war schwieriger zu beschaffen, ich erhiclt jedoch hübsche Regenerationsstadien nach eigenen Experimenten von Lacerta agilis, Lac. ocellata, Platydactylus facetanus und Anguis fragilis. Regenerinte Schwantheile ron Lacerta muralis (auch von deren Tarietiten Lac. Lilfordi und Lac. faraglionensis), Platydactylus 
rerus, Pl. mulilatus, Plyllodactylus europacus Hemidactylus frenatus, Hem. platyurus und Scnira bicolor standen mir nun in conservirtem Zustande zur Verfügung.

Auch bei den leljend gelialtenen Thicren wurde das Haujtgewicht auf rorzïglich conservirte und in Schnittserien zerlegte regenerirte Theile gelegt, die Untersuchung an frischen Geweben dagegen mur zur Controle angewendet.

Für die rerschiedenen Organe, sowie für die aufeinanderfolgenden Stadien war cine sehr differirende Conservirungsmethode nothwendig, was clurch die verschicdenartige Consistenz der Gewebe leicht erklïrbar wird.

Im Allgemeinen rïume ich bei älteren Stadien der Chromsïure den Vorzug vor allen anderen Reagenzien ein. Ein etwa drei Wochen alter regenerirter Schwanz von Triton taeniatus oder anderen erwachsenen Urodelen wurde ea. sechs Stunden in zweiprozentige Chromsïure gelegt und dann tüchtig in fliessendem Wasser ausgewaschen, woran sich die bckannte Methode mit rerdünntem Spiritus bis zum Einbetten in Paraffin anschliesst.

Waren die betreffenden Theile bereits verkalkt, so wurde nach vollkommener Härtung in absolutem Alkohol mindestens dreiprozentige Salpetersïure zum Entkalken benutzt, in welcher dieselben 12 bis 94 Stunden verweilten. Darauf wurde wiederum in fliessendem Wasser sorgfältig ausgewasehen und dann gefärbt.

Als Tinction verwandte ich in erster Zeit fast nur Pikrokarmin, das in der von Dr. Braun bekannt gegebenen Weise bereitet wurde, später auch die Kleinenberg'sche Haematoxylinlösung in der von Strasser zuerst angewendelen Jodification, dann aber theilte mir Herr Dr. Born in Breslau scine Methode der Methylvioletfïrbung mit, welche ich in der Folge für dickere Oljecte fast ausschliesslich benützte und mit der ich rörtreffliche Resultate erzielte. Für letztere Fürbung ist jedoch die vorhergehende Behandlung mit Salpetersïure auch bei solehen Theilen unerlässlieh, welche durchaus noch nicht rerkalkl sind; erst nach derselben erhält man ausserordentlich sehöne Bilder mit stark differenzirter Kernfärbung und dunkler Knorpelgrundsubstanz.

Die selır zarten Gewebe der ersten Stadien werden ebenfalls am besten mit weinfarbener Chromsäure behandelt, deren Einwirkung jedoch nur so lange währen darf, bis die zu untersuchenden Gewebstheile abgetödtet sind, also bei der sich neubildenden Epidermis lö̈hstens zehn Minuten. Gute Resultate erziclte ich bei ganz jungen Geweben auch dureh die Anwendung von Ucberosmiunsäure, welelıe in einep Verdünnung von 5-10 pro Mille angewendet wurde. Pierinsïure und Kleinenberg'sche Picrinschwefelsäure waren nur bei ïlteren regenerirten Reptilicnschwänzen anwendbar, wo sic zu gleicher Zeit zum Entkalken benutzt wurden. Ganz unbrauchbar crwiesen sich die sonst verwendeten Chromsalze, besonders auch für junge Stadicn, wie dies schon von Flemming und Mayzel für die Epithelien herrorgchoben wurde.

Da aus den in ersten Theil in weitläufiger Weise besprochenen früheren Regenerationsversuchen hervorgeht, dass solche Thiere, welche ein wahrliaft amphibisches Leben führen, das heisst einen Theil des Jahres auf dem Lande, den anderen aber im Wasser zubringen, in diesem Elenent eine grössere Reproductionsfïhigkeit besitzen, wie in der Luft, so hielt ielı die versehiedenen Tritonenarten sowic Pleurodeles Waltii in kleinen Beckenaquarien, die soweit mit Wasser 
gefüllt waren, dass die Thicre dasselbe nie ganz verlassen konnten, am Athemholen jedoch nicht behindert waren, da ilmen hineingelegte Steine das Hinaukklettern bis an den Wasserspiegel ermöglichten. Da Pleurodeles ${ }^{1}$ ) sich sehr wahrscheinlich sein ganzes Lehen hindurch im Wasser aufhält, so fühlten sich meine Exemplare unter den angegebenen Bedingungen auch höchst behaglich, weniger war dies bei den Tritonen der Fall, welche auf alle mögliche Weise versuchten, dem immerhin engen Behälter zn entkommen. Die Fühllosigkeit, mit welcher die Urodelen im Allgemeinen und besonders die Tritonen selbst bedeutende Verstümmehngen crtragen, hebt den Beobachter gö̈cklicherweise äber moralische Bedenken hinweg, welche leicht eintroten kümnten, wenn man die oft sehr grausame Art betraclitet, mit der diese Geschöpfu oftmals zum Dienste del Wissenschaft gemartert werden müssen. Einige Beispiele werden jedoch bezengen, dass diese Thiere besonders im Larvenzustand auch gegen grosse Verletzungen fast gar nicht reagiren. so schnitt ich im August 1879 eincr beinalıe vollständig erwachscnen, eben gefungenen Larve von Triton cristatus ein zolllanges Stück vom Schwanze mit einer scharfen Scheere ab. Das Thierchen wechselte kamm den Platz in seinem Behälter und schnappte begicrig nach dem sich lebhaft bewegenden abgeschnittenen Schwanzstück, das ich ihm einige Ninuten spätel mit der Pinzette vor das Maul hielt. Am unempfindlichsten zeigte sich Pleurodeles, dem seine Fressberier übertraf stets den Schmerz, welchen er bei den vielfachen Amputationen doch erdulden musste; ein erwachsenes Weibchen verzehrte ruhig einen grossen Riegenwurm, wïlrent ich ihm ein Stück Schwanz, und ein Hinterbein ampntirte. Bedeutend empfindlicher sind bereits die ausgewachsenen Salamandra maculosa und besonters sämmtliche Reptilien. Die Eidechsen empfinden sehr walırscheinlich lebhaften Schnery, wenn ein grösseres Stück ihres Schwanzes verloren geht, olygleich viele Momente daraul hinzudeuten scheinen, dass teleologisch betrachtet del Eidechsenschwanz ganz danach beschalfen ist, durch seine leichte Brechbarkeit dem Thiere selbst zmm Schutze zu dienen, es sich bei der Reproduction desselben also $\mathrm{um}$ einen physiologisehen Act handelt.

Dennoch sind die rerstümmelten Thiere nicht so munter wic sonst, nehmen fast keine Nahrung zu sich und suchen sich möglichst gut unter Moos oder Steine zu verkriechen. Da man in Würzburg zu jeder Zeit im Sommer eine grössere Anzahl ron Lac. agilis bekommen kann, welche regenerirte Schwänze besitzen, so komnte ich meine Versuche an diesen Thicren sehr einschränken und amputirte nu' drei oder vier Exemplaren ein Stück des Schwanzes mittelst einer scharfen Scheere, einigen anderen dagegen wurde ein Theil des Schwanzes ausgerissen, um möglichst dieselben Verhültnisse herzustellen, unter denen die Eidechsen in der Freiheit genöthigt sind, den Deiect wieder anszubessern. Da der Schwanz, wie bereits durch Leydiy nachgewiesen ist, stets an den gleichen Stellen abbricht, so werden lei letzterem Versuch stets ïhnliche Resultate erzielt.

Sehr empfindlich ist ferner der anch ausserdem schwer in Gefangenschaft zu erhaltende Platydactylus facetanus gegen jede Verstümmelung.

1) Fraisse: Beiträge zur Anatomie von Pleurodeles Waltlii. Würzłurg Staudinger. 1sso. pag. 17. 
Es gelang mir jedoch, vier dieser Thiere etra 6 Wochen lang lebend \%u erhalten. obgleich ich allen ein gutes Stück ihres Schmanzes abgebrochen hatte.

Da dic Gecko's abel jede Jahung rerschmälıten, war ich genöthigt, sie mit Stubenfliegen und anderen weichï̈utigen Insekten zu stopfen. was dem auch den Erfolg hatte, dass sie sich regelrecht häuteten und wïhrend der sechs Wochen ein gutes Stück Schwanz reproducirten. Un jüngere Regeneralionsstadieı zu erhalten, amputirte ich den grüssten derselben mehrere Male, jedoch nur zuerst mit Ertolg, da das Thier etwa in der vierten Woche an Erschöpfung zu Grunde ging. Anguis fragilis und die übrigen untersuchten Reptilien rerhalten sich ähnlich wie Lac. agilis, weshab ich hierauf rerweise. Da es mich zu weit führen würte, die Versuche, welche ich an den einzehen Thieren machte. alle der Reihe nach zu beschreiben. so werde ich mich darauf beschränken, die Hauptergebnisse kurz in den einzelnen Kapiteln zusammenzufassen und nur diejenigen Thiere noch genauer zu besprechen, bei denen Abreichungen irgend welcher Art rorkommen. Bei kejner anderen Arbeit wird soviel aul' ein allgeneines Schema zurückgeführt werken künnen, wie gerade bej del Untersuchung del Regenerationsrorgänge. 


\section{B. Spezieller Theil.}

\section{Epidermis mol andere Epithelien.}

Bei jeder äusseren V'erwundung ist es die Epidermis, welche zuerst verletzt wirk, inclem ih'e einzelnen Theile entweler völlig von einander gelrennt oder wenigstens gequetselnt oder sonst wie zerstört werden. Aber ebenso leicht, wie sie verwundet wird, bessert sie auch den Schaden wiedel aus, demn der Heihngsprozess ist bei keinem Gewebe ein so intensiver und rasch rerlaufender, wie bei der Ejidermis, auch ist die Regeneration keines Gewebes rerbreiteter im ganzen Thierreieh, wenn man ron Blut und Lymphe absieht, als die dep Epidermis. Das ïussere Integument wild in grösserem oder geringerem Masse von allen Thieren reproduzint, ja selbst del Mensch besitzt diese Fähigkeit in nicht unbedeutendem Grade.

Ilit der Reproduction der Epjdermis ist eng verknüptt die Rereneration solcher Theile, welche aus der Epidermis hervorgehen, wie der Haare, Në̈grel, Federnn u. s. w.

Betrachten wir die biologischen Erscheinungen dieses Gewebes eingehender, so finden wir, dass bei den Wirbelthieren ein ununterbrochenes Wachsthum statffindet, dass aber auch in denselben Masse eine Abstossung der obersten Schichten vor sich geht, welche entweder ebenfalls ununterbrochen oder periodisch auftritt. Es findet also eine natürliche Regeneration statt, welche geeignet ist, uns über resschiedene Punkte der pathologischen Veubilıung Aufsehluss zu geben. Derjenige Theil, aus welehem bei der geschichteten Epidermis der Wirbelthiere die sämmtlichen übrigen Theile dieses Gewrbes hervorgehen, ist das sogenamte Rete Malpighi oder die Sehleimschicht, das heisst die unterste cylindrische Zellage. Un jedorh ein Verständniss der älteren Ansichten üher die Regeneration der Epidermis gewimnen zu können, müssen wil' einen kleinen historischen Rüekblick thum und diejenigen Arbeiten durchmusters, in denen für ilure Zeit bahnbrechende Idcen enthalten sind.

Wie bekannt, wurke die Epidermis der löheren Thiere in der erslen Zeii des Wiederaufblühens der Anatomie für cine strukturlose Membran gehalten, die schiehtenweise aus den 
darunterliegenden Gefässen ausgeschieden sein sollte. Es war demnach die Epidermis nach den Ansiehten IIalpighi's nichıts als cine den gesammlen Körper ungebende, an der Oberfläche ersłarte Schleimschicht. ( $16 \$ 5$.

Schon Albinus (1737) hatte hierin von Malpiglei abweichende Ansichten und beobaclitete vor Allem dic Znsammengehörigkeit des Rete glutinosum mit den ïbrigen Scluichten der Epidermis. und seine Anschanung wurde lange \%cit ron fast allen Forschem angenommen.

Die zcllige Structur der Epidemis wurde jedoch erst duch delle Chicje 1897 entdeckt. der wiederun üher dic kerne zu einer falsehen Ansicht gelangte, da er dieselben für vertrockncte Blutkörperchen hiclt. Nachdem man in der nächsten Zcit wiederun rielfach die Strukturlosigkeit del Epidermis behauptet hatte, wurde 1835 festgestellt, dass das Epithel ans Zelten mit Kemen bestcht, welche Thatsache Jesonders durch die Schüler des obengenannten Forschers, Raschluro und I'ulentin, weiter bekannt gemachit wurde.

Weiter zu crwähnen sind die Arbeiten ron Bickat, Blandin, E. II. Weber, dic sich zun Theil sogar schon mit der Regeneration beschäftigen. Die Grundideen über das Wachsthun uni dic Eigenschalten der Ejidermiszcllen, wie sie jetzt noch allgemein anerkannt werden, sind crst ron IIenle 1837 bekannt gemacht worden.

Dass natürlich auch Forscher wie Schwann. Schleiden, Berymam. Kiolliker, Kranse, Iutentin, J. Mieller, Remuli sich in den 40er Jahren nit dieser interessanten Frage beschäftigten, verstelıt sich ganz ron selbst. Lijlliker wies zuerst nach, dass ausgeschnittene Epilermisstückchen sich aus den eigenen Eleinenten regeneriren, während Tirehow den Bindegewebskörperchen cinen grossen Einfluss bei der pathologischen Neubildung zuschrieb. Señ entschieden trat dieser Lelure Tirchow's Remuk entgegen, dessen Theorieen hauptsïchliclı anf embryologischen Untersuchungen basirten, indem er für ummöglich crklärte, dass aus dem Fragmente eines Keimblattes sich später Gewebe lilden könnten, die ursprünglich aus einem anderen Keimblatte entstanden sind. Dennoch schlossen sich die berühnntesten Autoritäten der Lchre Kirchow's an, unter dessen Anhängern die Namen

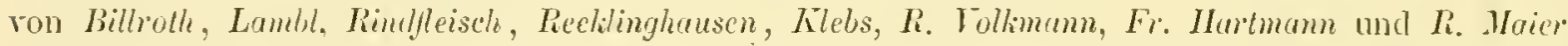
einen hervorragenden Platz einnehmen, und welche sïmmtlich darin miteinander übereinstimmen, dass sie den indifferenten Bindegewelszzellen die Fähigkeit zusehreilıen, sich in Epithelialzellen rcrïndern zu können.

Selır wichtig für die Aufrechterhaltung der Tirchow'schen Theorie war die Untersuchung ron (i. Burchlurd 1859, der schliesslich 7 dem Resultat kam, dic oberflichliche Schicht des Bindegewebes als die Matrix des Epithels anzusehen.

Die gegnerische Theorie (Remak) wurde ebenfalls heftig verfochten und IIenle, Iloger und Folliker, sowie dann anch Billrolle schienen simmtlich die Richtigkeit ihrer Ansicht durch ilıe Untersuchungen bewiesen zu haben.

Dic Entdeckung der Wanderzellen ist natürlich für die in Fragc stelıende Untersuchung ron ausserordentlicher. Wichtigkeit gewesen. 
Hier leuchten num besonders die Namen Recklinghausen, Cohnheim und Biesiudechi hervor, Rusticki und Visconti gringen sogar soweit zu behaupten, dass aus den weissen Blutkörperchen alle Gewebe entstehen könnten.

Ueber die Regenerationen arbeiteten fermer Thiersch, Waldeyer, Buh, Lücke, Bruck, IIasse und kamen sämmtlich zu dem Resultat, dass an den Rändern des alten Epithels eine glasartige homogene Hasse ausgeschieden würde, in der sich zuerst die Nucleoli differenzirten, um die herum sich dann die Kerne anlegten.

Arnold nannte die aufüngliche granulirte Substanz das Cythoblasthena, und betrachtete es als abgeschieden von dem darunter liegendem Bindegewebe.

Wiederum wurde dic Auffassung Anold's von vielen Seiten bestritten, bis man schliesslich einen Mittelweg cinschlug, weleher von den meisten Forschen betreten wurde. Es wurde jetzt als ziemlich sicher angenommen, dass das Epithel sich sowohl aus den alten Epithelzellen, wie auch aus cien Wanderzellen regeneriren köme.

Durch Reverdin wurde die 'Transplantation eingeführt und hierdurch kamen nun wieder verschiedene neue Gesichtspunkte in diese Untersuchung hincin. Man verpflanzte kleine Stückchen abgetrennten Epithels auf einen fremden Boden, z. B. auf die Torderkammer des Auges und fand nun, dass diese Stückchen auch hier anwuchsen und sich sogar vergrösserten. Ueber die Transplantation von Hautstückchen mit Haaren machte Scherenninger interessante Beobachtungen, welehe bereits mit ähnlichem Erfolge schon ron Dicffenbach ") im Jahre 182 g bei verschiedenen Thicren angestellt worden waren. Ueber den Bau der Epidermis war man nun so ziemlich ins Klare gekommen, jedoch konnte man sich noch keine rechte Torstellungr von der Ernährung dieses Organes machen. Da wurde die Verbindung der Kittsubstanz des Epithels mit den Safteanäichen des Bindegewebes durch Arnold, Thoma, Schrön und Andere machgeriesen und mun auch in diesen Punkt einiges Licht gebracht.

Schrön bildete sich über die Regeneration der Hornschicht die Ansicht, dass dieselbe ein Produkt der Talg- und wohl auch der Schweisszellen sei.

Am frischen Objekt beobachtete Klels die Regenerationserscheinungen an der Schwimmhaut des Frosches und sah das neue Epithel nur aus den Elcmenten des alten entstelien.

Dieselbe Ansicht wird in den neueren Arbeiten ron fiolliker, Ilis, $v$. Beneden, IIensen, IIaeckel, Frey, Lrause, Cohnhcim, Perls, Billroth, Unna und Anderen vertreten, so dass sie wohl als die augenblicklich allein herrschende angesehen werden kann. Bei weitem die wichtigste Arbeit über die Regenerationserscheinungen der Epithelien ist die leider in russischer Sprache geschriebene Abhandhung von $W^{\prime}$. M $\left(a_{y} \mathrm{el}^{2}\right)$, der schon vorher mehrfach thätig in den so heftig entbramnten Streit eingegriffen that.

Da mir der kurze im Jahresbericht ron Hoffmann und Schacalbe enthaltene Auszug aus diescr Arbeit nicht genügen konnte, so machte ich mich daran, den Originallext selbst zu studiren.

1) Noun. de regen. et trausplant. 182:. Diss. Mïnchen.

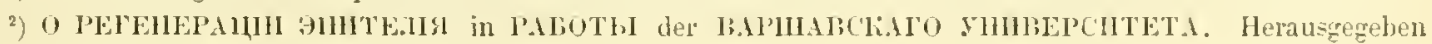

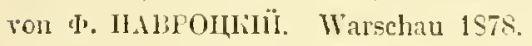


Unterstützt wurde ich hierbei durch Herrn stud. med. von Lucskiexics der nit besonderer Aufopferung mir über die Schwierigkeiten der Sprache hinweghalf. Es möge mir gestattet sein, Herrn von $L$. auch an dieser Stelle meinen wärmsten Dank auszusprechen.

$\mathrm{Zu}$ meiner grossen Freude sah ich nun, dass die Beobachtungen Muysl's mit den meinigen derart übereinstimmten, dass nur wenige Differenzen zu erörtern scin werden; ich stehe fast vollständig auf dem ron Mnyzel eingenommenen Standpunkte, den ich bereits auf der NaturforscherVersammlung in Baden-Baten ${ }^{1}$ ), als ich die Mayzel'sche Arbeit noch nicht kannte, in jeder Weise vertreten halıe.

Die meisten dieser soeben aufgefühten Arbeiten sind, wie schon die in del Medicin zum Theil hochberühmlen Namen der Autoren bezeugen, von Medicinern für bestimmte medicinische Zwecke angestellt worden, und es unterliegt heinem Zweifel, dass dieser Zweck wohl auch besonders durch die Vervollkonmnung del Transplantation in vollem Masse erreicht worden ist.

Es kam bei diesen Versuchen meistens auf den Erfolg und auf die el'sten Regenerationsstadien an und obgleich man gerade die vielseitigsten Experimente an den Batrachiern und Urodelen anstelite, setzte man die für die augenblicklichen Resultate nicht eben gerade notlurendigen feineren Untersuchungen über den Bau der Haut vielleicht zu sehr zurück.

So bekannt die änssere Bedeckung besondel's der Amphibien nun auch hente zu sein scheint, so wenig abgeschlossen sind die Untersuchungen der feineren Structur derselben, denn fortwährend erscheinen neue Beiträge zur Kenntniss des ïlusseren Integumentes dieser Thiere und der alte Streit Cuticula contra Verhornung scheint noch immer nicht beigelegt zu sein.

Es dürfte deshalb wohl angebracht sein, an dieser Stelle zunächst einmal den heutigen Standpunkt unserer kenntniss dieses Organes zu besprechen, wobei ich in der Lage sein werde, meine IIeinung und Stellung zu derselben kurz zu motiviren.

Die lienntniss des feineren Batues rer Amphihienhaut haben wir vor Allem Leydig zu verdanken, welcher uns zuerst mit den oft sehr metkwürdigen Verhälnnissen vertraut machte.

Zwar finden sich schon bei Curier ${ }^{2}$ ) und Blancharl ${ }^{3}$ ) ganz voltreffliche Beobachtungen über den gröberen Bau des äusseren Integumentes, doch blieb das Verstïndniss der feineren Structur Jjis in die neuere Zeit hinein verschlossen.

In einer grossen Anzahl ron Arbeiten legte Leyding seine Resultate nieder, so dass es schwer wird, jele einzelne kleinere Nittheilung sofor't aufzufinden, da sie zum Theil in Abhandlungen, die einen ganz heterogenen Gegenstand behandeln, verflochten sind. Ich beschränke mich daher darauf, diejenigen Arbeiten aufzufühen, welche sich hauptsïchlich mit der Amphibienlıat beschäftigen.

\footnotetext{
1) Amtlicher bericht f. 1879 Sitzung der zool. Section rom 19. Septenber.

${ }^{2}$ Lecons diatomie compare.e. Tom. II. parg. 62\%. Paris 1805.

$\left.{ }^{3}\right)$ Recherches anatomiques et physiologiques sur le systeme tegumentaite des reptiles in. Anu. des. sc. nat. fme serie Zool. T. XY. 1 S61.
} 
Unter diesen nimmt die Abhandlung: ,Ueber die allgemeinen Bedeckungen der Amphibien“" ${ }^{\text {) }}$ unstreitig den ersten Rang ein, da in derselben alle früheren Arbeiten desselben Autors genügend berücksichtiont wuden.

Leyclig rertheidigt nun wiederholt hierin die Ansicht, dass auch bei den erwachsenen Anphibien wahre Cuticularbildungen rorkommen und zwar sol] die Cuticula als eine, ,dünne homogene Grenzschicht, nan könnte sagen, als einseitig verdickte Membran der Zelle" den Epidermiszellen auflagern.

An einzehnen Stellen, zunächst an der Ilandfläche des Frosches odel an den Hauthöckern der Tritonen erfiebt sich jedoch die Cuticula zu einem kleinen Wulst oder IIöcker.

Den heftigston Widerspruch fanden die Ausführungen Leydiy's über die Cuticula bei F. E. Schulse $\left.{ }^{2}\right)$. In der ron mir an erster Stelle citirten Arbeit spricht sich F. E. Schulse dahin aus, „dass bei den erwachsenen Batrachiern, Salamandrinen und Coecilien der ganze Kö̈rper ebenfalls rou einer äusseren Hornschicht muschlossen wird, welehe indessen von der bei höheren Thieren gefundenen darin abweicht, dass sie nicht aus hochgeschichteten Zellenmassen, sondern aus einer einzigen oder aus zwei übereinanderliegenden Lagen verhornter Zełlen besteht. Nur an ganz bestimmten cireumseripten Stellen finden sich bei einigen Amphibien auch vielschichtige IornJagen, so z. B. in den IJornschwielen, welche an der Unterseite der Füsse mancher Batrachier, besonters entwickett bei Pelobates fuscus, aber auch bei Rama und anderen rorkommen."

Ton weiteren Arbeiten über die Amphibienhant sind mir zugänglich gewesen die Abhand-

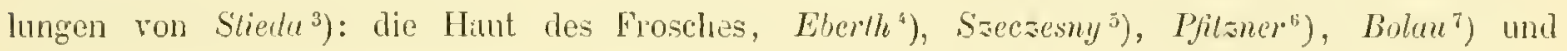

1) Arch. f. mikil. Anat. Bd. XII. p. 119. Norember 15\%. Man vergleiche ferner: Leydig: Iite fippenstacheln des Pleurodeles $W^{\circ}$ altlii in Arch. t. Naturgesch. 45. Jahrg. p. $2 t 1$ ff. - Anure Batrachier der deutschen Fauna. Bonn 1877. - Organe eines sechsten Simnes in Acta acal. Leop. Carol. Vol. XXXlY, Tal, III. Nene Beiträge zur anatomischen Kenntniss der Hantdecke und Haut:innesorgane der Fisclie. Sonderabdruck aus der Festschrift der naturforschenden Geseltschaft zu 11alte. 1879. - Dic Hautrlecke und llautsimnesorgane Jer Ulorlelell. Morphol. Jahthuch. Br. II. p. 9S7. - Anatomiseh-hist. Intersuchungen iber Fische und lieptilien. lherlin 1853. Ueher den Bau der Zehen mu die Berleutmug des Fersenlöckers, Morph. Jahrb 1876. 1'd. 11. p. I6.5. - Leber die Molche der Württemberge: Fauma. Berlin 1867. - Ceher die kopflrüsen einheimiseher Ophidier. Areh. f. mikrosk. Anatomie 1873. - Die in Deutschland lebenten Arten der Saurier. 1872. — Schwanzflosse, Tasthörperehen und Endorgane del Nerven bei Batrachiern. Arch. l: unikr. Anat Pal. Xll. - Zur Kenntniss der Sinnesorgane der Schlangen. Arch. f. mihr. Anat. Ijd. S. 1 72. - Ueber die ässeren Bedeckungen der Reptilien und Amphibien. Areh. f. mikr. Anatonie B3T. IX. - Vom Bau des thierischen Körper's - Lehrbuch der Histologie. - Hauldecke um] Schale der Gastropolen. Areh. f. Naturgesch. 1876. - Ueler die Haut einiger Süsswasserfische. Zeitschr. f. w. Zoologie. Bil. III Isjo. etc.

$\left.{ }^{2}\right)$ Ueber enticulare Bildungen und Verhornung von Epithelzellen lei den Wirhelthieren. Arol. t. mikrosk. Anat. Вл. V. P 996. 1839. - Ferner: Epithel- und Drüsenzellen. Arelı. l. 11. Anat. Bt. 1II. p. 167. 1864. Ueber die Nervenendigungen in den sogenanuten Schleinhanälen der Fische und über ents[rechenue Organe dej durch Kiemen athmenden Anphilien. Arch. f. Anat. u. Physiolog. 1861. - Lelrel die Simnesorgane der Snitenlinie lei Fischen und Amphibien. Arch, l, mikl. Anat. Bd. VI. - Die hecherförmigen Organe der Fische. Zeitschr. f. misk. Zoologie 入II. p IS (1863). - Untersuchnngen ïber den Bau der Nasenschleimhaut, namentlich lie Structur und Endigungsweise der Geruehsuerven bei den Mensehen und den Wirbelthieren. Ilalle 186z. ete.

s) Reichert und Dhe Bois Reymond, Alelı. f Auat. 18fij. p. ว2.

4) Untersuchungen zur normahen und pathologischen Anatomie der Frosehhaut. Leipzig 1869, 3. Taf.

5) Beiträge zur Kenntniss der Textur der Froschhant. Dorpat 1S67. I Taf. Dissertation.

${ }^{\circ}$ Die Sclıleimzelten in der Epidermis dej Larve ron Silanandra maculosi. Dissert. Kijel 1Si:) und: I)ie Epidermis der Amphibien. Ilorphol. Jahrbuch. Bal. VI. lleft 1V. 2 Tafeln.

7) Beitrag zur Kenntuiss del Amplibienhaut. Dissert. Göttiıgen 1866 mit Tafel. 
Anderen. In denselben sprachen sich die Autoren theils für die Leydiø'sehe, theils für die Schulse'sche Ansicht aus, jedoch scheint die letztere jetzt wohl die allein herrschende geworden zul sein.

Iel selbst habe bereits in meiner Abhandlung: „Beitrïge zur Anatomie von Pleurodeles Waltlii" ) darauf hingewiesen, dass bei Pleurodeles Cuticularbildungen nicht rorkommen, sondern dass die auf der Epidemis auftretenden Sculpturen alle nur aus rerschmolzenen verhornten Zellen entstanden seien. Ebenso betraclitete ich nur die äusserste Zelllage, welche allein bei der Häutung abgeworfen wird, als wirklich verhornt, und stimnte also anch in dieser Beziehung mit Schulse, Bolau und anderen völlig überein. Jetzt liegt mir nun auch die ausführliche zweite Arbeit ron Pfisner über die Epidermis der Amphibien ror, welehe etwas später wie meine Plenrodeles-Arbeit ersehien, die aber vom Verfasser nicht mehr benutzt werden konnte, da er seine Studien bercits jn März abgeschlossen hatte. Mit derselben ist nun wohl endlich ein definitiver Absehluss der Hauptfrage gegeben und ich kann mich ruhig auf den Boden der hier ausgeführten Thatsachen stellen und zwar umsomehr, als ich bereits vor dem Erscheinen dieser Arbeit die gleichen Grundsïtze rertheidigt habe. Wenngleich ich nun der Arbeit ron Pfisner im Grossen und Ganzen beistimme und seine Auffassungen theile, so muss ich mich in einzelnen nebensïehliehen Punkten dennoch zu anderer Meinung bekennen.

Es scheint mir jedoch zweckmüssiger zu sein, gelegentlich dic einzelnen Punkte zu besprechen, als an dieser Stelle eine längere Kritik der Arbeit zu liefern.

Ueber die sogemannten Organe des sechsten Simnes oder die Hautsinnesorgane bei den Amphibien vergleiche man vor Allem die bereits erwähnten Arbeiten ron Leydig, weleher de. Entdecker dieser merkwürdigen Geljilde war, und von Fr. E. Schulse; doch sind auch die Abhandlungen von Malbrane ${ }^{2}$ ) und Bumion ${ }^{3}$ ), da sie den Gegenstand ausführlich hehandeln, sehr wichtig. Ueber den feineren Bau hat man sich in der letzten Zeit woll im Allgemeinen geeinigt. Den ron F. E. Schulae beschriehenen Cuticnlarcylinder, weleher wie ein Sehornstein aus der Oeffnumg des Sinmesorganes bei Tritomenlarven hervorragen soltte, konnten weder Leydig noeh ieh auffinden, es sind im Allgemeinen nur kurze Färchen oder auclı nur Cutieularknöpfehen, welche den sogenannten Mautelzellen aufsitzen.

Da die Hantdrüsen im. späteren Leben der Thiere, obgleich sie ron Epridermiszellen abstammen, mit der Cutis im intimeren Zusammenhange stehen, so werden sie besser bei jenem Capitel abgehandelt.

Somit hätten wir nun die Uebersicht über die hervorragendsten Arbeiten über die Amphibienhaut geschlossen und können uns nun zur Haut der Reptilien wenden, welche in den letzten Decennien ebenfalls das Objekt der mannigfaltigsten Untersuchungen gewesen ist.

1) Arbeiten a. d. zool. Institut Würzhrg. Bd. V. Separat erschienen 1580.

2) Malbrenc in Zeitschrift t: w. Zuologie. Band XXVI.

3) Bugniou, Organes sensitifs dn protee et de liaxolotl; in Bulletin de la Societr vaudoise des sciences naturelles vol XII pag. 
Vor allen Dingen ist hiel zu erwïhnen die interessante und bahnbrechende Arbeit von Carlier ${ }^{1}$ ) über die Häutung der Reptilien.

Diese Arbeit muss unser Interesse in diesem Falle un so mehr in Anspruch nelmen, als in derselben ein Act der Regeneration und zwar der physiologischen Regeneration genau untersucht, darüber jedoch auch die Deutung und Klassificirung der einzelnen Gewebselemente durchaus nicht vernachlïssigt wurde.

Auch die Arbeiten Cartier"s hatten natürlich ihre Vorliufer, $\left.{ }^{2}\right)$ unter denen die Abhandlungen von Curier, Blainville, Heusinger, IIyrtl, Duméril et Bibron, F. de Filippi und besonders Leydig $\left.{ }^{3}\right)$ hervorragen.

Cartier fasst nun nit Leydig die oberste Schicht der Reptilienhant als wahre Cuticula auf in Gegensatze zu Fr. E. Sclulse, ${ }^{4}$ ) welcher behauptet, dass ,wahre Cuticularbildungen in der Epidermis der drei höheren Wirbelthierklassen nicht vorkommen.."

Cartier hält jedoch nicht die ganze oberste Schicht für eine echte Cuticula, sondern nur die Härchen, Leisten, Ringe und die verschiedenen anderen Ornamente, welche die Haut der meisten Reptilien zieren. Er denkt sich dieselben entstanden durch eine Verschmelzung der" bei der Häutung zuerst auftretenden und unbedingt zu den echten Cuticularbildungen zu zühlenden Häutungshärchen.

In der zweiten Abtheilung seiner Arbeit geht Cartier erst auf die Häutungserscheinungen ein, welche uns als ein Act der plysiologischen Regeneration ja gauz besonders interessiren müssen.

Da die Arbeit jedoch Jedermann leicht zugänglich ist, so beschränke ich mich daraut; hier mitzutheilen, dass Cartier die Hüutung bei Schlangen und Eidechsen auf reine Wachsthumserscheinungeu in der Epidems zurückführt, auf die Bildung der sogenannten Häutungshä̈rchen.

Weitere Arbeiten üher die Haut der Reptilien sind besonders ron Leydig zum Theil in grosse Abhandlungen eingeflochten worden, so z. B. ist die Epidermis der Eidechsen und Blindschleichen eingehend besprochen in: „Die in Deutschland lebenden Arten der Saurier, Tübingen 1872" und in mehrfachen anderen Arbeiten.

Leydig lasst im Grossen und Ganzen das Oberhäutchen der Epidermis, wetches sich leicht von den andern Schichten derselben trennen lässt, ats eine wahre, zusammenhängende Cuticula auf. In 13. Bande des „Archivs für Mikroskopische Anatomie“ befindet sich die vorher schon erwähnte Ablandlung von C, Kerbert: "Ueber die Haut der Reptilien und anderer Wirbettliere." Kerbert bezeichnet den obersten Theil der Hornschicht, das Oberhäutchen Leydig's, als Epitrichial-

1) Arbeiten aus dem zool. Institut d. Lniv. Würzburg. Bd. J. p. 83 'Taf. IIl u. IV und p. 930 ff. nit Tal: XVI.

$\left.{ }^{2}\right)$ Vergl. üher die historische Entwickelung der Arbeiten über die Reptilienhaut hesonders die unter der Leitung ron Dr. Leuckart ausgeführte Arbeit von Coenraud Terbert. Arch. f. mikr. Anatomie Bd. XIII. P. 205 If. Taf. XVIll bis XX, auf die zurückzugreifen ich später Gelegenheit baben werde.

ग) Ueber die äusseren Bedeckungen der Reptilien. Arel. f. mikr. Anat. Bd. IX. Is73; ferner: Ueher die Verbreitung der Ossificationen, 1857; Ueher Organe eines sechsten Sinnes, 1472; Zur Kenntniss der Simnesorgane der Schlangen, 1872 u. a. m. Bd. V. 1869 .

4) Ueber cuticulare Bildung und Verhornung vou Epithelzellen bei den Wirbelthieren. Arch. I. miki. Anat. 
schicht, und sagt hicrüber pag. 215: „Meiner Auffassung nach haben wir es bei dem Oberhäutchen sowohl auf der oberen und unteren Schuppenfläche als in den interstitiellen Partien nil einer wahren Zellschicht zu thun, die in Betreff ihrer Zellen merkwürdige Modificationen darbietet."

Kerber stützt seine Ansicht hauptsiichlich durch die Beobachtungen, welche er an Embryonen gemacht hat.

Unter der Epitrichialschicht liegt nun die „Körnerschicht", unter dieser das Stratum corncum, Stralum lucidum und zuletzt die Schleimschicht oder das Rete Malpighii.

liesbert stellt ganz richtig die stark verhärtete Epidermis bei den Reptilien als „Hornschuppe“ den eigentlichen Schuppen oder "Papillarkörpern" gegenüber. Auf die Beobachtungen, welche dieser Forscher über den feineren Bau und die Entwickelung der eigentlichen Schuppe gemacht hat, werde ich an gecigneter Stelle zurückkommen.

Dic kurz daraf elschienene umfangreiche Abhandlung von Todaro ${ }^{1}$ ) behandelt mit besonderem Fleisse die historische Entwickelung der Untersuchungen über das äussere Integument der Reptilien. In Bezug auf dic Häutungserscheinungen stellt er cine Theorie auf, die der Cartier'schen vollständig widerspricht. Nach Todaro verschnelzen bei der Häntung die obcrflächlichen Schichten des Rete Malpighii, später sondert sich diese Lage in zwei Schichten. Dic ,drüsigen Zellen", welche die ticfere Lage bilden, degeneriren zu einer schleimälnlichen Masse und hierdurch wird eben das Stratum Jucidum mit allen oberhalb desselben liegenden Schichten von dem Rete Malpighii abgetrennt, der Hïutungsprozess also vollendet. Bezüglich der zuerst von Kerbert so genannten Epitrichialschicht schliesst sich Todaro vollstïndig den Ausführungen seines Vorarbeiters an, indem er dieselbe nicht als eine Cuticularbildung betrachtel, sondern sie aus Zellen zusammengesetzt sein lässt. -

Kurz darauf erschien eine Abhandlung von Aulvea Batelli, ${ }^{2}$ ) welcher im anatomischen Institut zu Strassburg cinige Beobachtungen über den feineren Bau der Reptilienhaut gemacht hatte.

Nach Bulelli besteht die Reptilienhaut im Allgemeinen aus 5 Schichten:

1) Stratum epitrichiale (Kerbert), pellicola epidermica ('Todaro).

2) Stratum granulosum superius (herbert).

3) Stratum corneum compatum (Todaro).

4) Stratum corneum relaxatum (rilassato, Tolaro).

5) Stratum Malpighianum, s. mucosum.

a) Stratum densatum.

b) Stratun cylindricum.

Als intermediäl'e Schichten bezeichnet Batelli die von Lerbert und Todaro aufgeführten Lagen der sog. Stratum lucidum und granulosum inferius. Er konnte in der Epitrichialschicht miltelst Kalilauge (Moleschott'scher Lösung) elenfalls Zellen von stark abgeplatteter Form isoliren.

1) Sulla struttura intima della pelle dej Rettili, riclrerche tatte nel Lahoratorio di anatomia nomale della Reale universita di Roma. Vol. II. Fasc. I. Roma $187 \mathrm{~S}$.

$\left.{ }^{2}\right)$ Beitrïge zur Kenntniss des Baues der Reptilienlaut. Arch. f. mikr. Anat. Bd. XVIl. p. $343 \mathrm{fr}$. Taf. XXXIV und XXXV. 
Mit Todaro spricht sich Butelli dahin ans, „dass sïmmtliche Zollen des Rele Malpighi der Reptilien in die Kategorie der Rift- ınd Stachelzellen gehören; an den Cylinderzellen beschränkt sich die Zühnehung auf die der Culis zugewendeten Basis." Die Zähnelung tritt stets secundär auf; ,an den jung entstandenen Zellen velmisst man dieselbe."

Es gelang Batelli, an Goldpräparaten nachzuweisen, ,dlass an viclen Stellen eine Menge Nervenfasern zur Epidermis aufstreben, ihr Hark verlieren und in die Epidermis selbst eintreten." Man sieht aus diesen wenigen Notizen, dass Batelli sich fast vollstïndig auf den Standpunkl stell, welchen Kerbert in dieser Frage einnimmt; Nenes ist von ihm kaum hinzugefügt, dagegen ist die ohnedies schon zu umfangreiche Nomenklatur noch um einige schöne Worte bereichert worden.

Von bedentender Wichtigkeit für die Entscheidung der schwebenden Frage seheint mir dagegen die Beobachtung Braun's ') zu sein, nach welcher die Haftlappen der Geckotiden er'st nach der ersten Häutung mil den Cuticularborsten besetzt werden.

Dass es sich hier um echte Culicularbildungen handelt, wird von Niemandem bezweifell werden, der jemals einen guten Schnitt durch die Haftlappen unter dem Mikroskope betrachtet hat.

Braum hält demnach die Haftlappenhare für modifizirte Häutungshärchen, deren Function sie ja auch an ihrer Stelle übernehmen.

Da nun Braun ${ }^{2}$ ) bei dem Häulungsprozess des Flusskrebses constatirte, dass auch dort die Häutung durch eine Absonderung von Culicularhärehen eingeleltet wird, so scheint mir die Darstellung Cartier's mehr und mehr an Wahrscheinlichkeit zu gewinnen.

Was meine eigenen Beobachtungen über die Reptilienhaut anbelangt, so kann ich mich den Ausführungen Cartier's und Braun's nur anschliessen.

Dass eine geschlossene Cuticula die Hornschicht der Haut bedeckt, leugne ieh allerdings vollständig, dass aber gewisse Seulpturverhällnisse, Haare, Ringe, Leisten ete. nur als Guticularbildungen anzusehen sind, scheint mir zweifellos klar zn sein.

Bei der embryonalen Entwickehung der Epidermis kamn man diese Bildungen noch nicht erkennen, sie sind auch nicht vorhanden, eben weil sie aus der Verschmelzung der kleinen Härchen entstehen, welche sich erst bei der ersten Häutung auf den mittleren grossen Zellen bilden; die abweichende Mleinung Kerbert's ist wohl nul dem Umslande zuzuschreiben, dass lierbert zu viel Gewicht auf die embryonale Entwickelung gelegt hat und dem Hïutungsprozess selbst zu wenig Aufmerksamkeit widmete.

Die Darslellung der embryonalen Entwiekelung wurde jedoch von Kerbert in völlig correkter Weise dargestellt. Nur in einem Punkt bin ich etwas abweichender Ansicht, die erste Anlage der Schuppen scheint mir nicht die Erhebung einer Cutispapille, sondern viehmehr ein einfacher geschlossener Follikel zu sein, welcher sich in die Culis hineinsenkt.

Da die spälere Schuppenbildung jedoch hauptsäehlich von der Cutis ausgehł, so verschiebe ich die Discussion diesel Frage auf das nächste Capitel.

1) M. Braun: Zur Bedeutung der Cuticularborsten aul' den Haftlappen der Geckotiden, Arbeiten aus dem zool.-zoot. Institut Würzburg. Bd. IV. pag. 231 ff. Taf. XII.

3) Dieselben Arheiten, Bd. II. 
Ueber die Regenerationserscheinungen der Reptilien-Epidermis ist soviel wie gar nichts bekannt, die Reptilien wurden in dieser Beziehung in derselben Weise rernachlässigt, wie man die Amphibien bevorzugte.

So kommt es, dlass wir nur cinige wenige kurze Mittheilungen über den Bau der sehon wiedel ziemlich vollständig hergestellen Epidermis besitzen, dass aber die ersten Stadien der Regencration vollständig unbekannt sind.

Meine Untersuchungen über die Regeneration der Amphibienhaut begann ich sofort, als ich lebendes Material in die Hünde bekommen konnte.

Am meisten wurde experimentirt am Axolotl, von denen mir Professol Semper schon in Frühjalır 1879 sechs halbwüchsige Thiere zur Verfügung gestellt hatte und die in unserem Arbeitszimmel, ziemlich weit rom Fenster entlernt, in seichten mit Glasplatten bedeckten Gefässen ihl Dascin fristeten.

Sobald ich Larven von Tritonen erlangen konnle, benützte ich natürlich auch diese; später nahm ich noch die Larven des Wasserfrosches und einige erwachsene Triton cristatus zu Hülfe.

Von Pleurodeles Walthi habe ich leider nul ältere Regenerationsstadien der Epidermis crlıalten, ich wollte die doch immerhin werthrollen Thicre nicht zu oft beunruhigen, obgleich sich dieselben ja, wie bereits erwälnt, einer ausscrordentlich grossen Reproductionskraft crfieuen.

Es rerstcht sich von selbst, dass mir noch eine grosse Anzahl Stadien der regenerirten Haut anderer Amphibien durch die Hände gegangen ist, da ja jedes neugebildete Glied selbstverständlich auch von einer neugcbildeten Epidermis umgeben wird, allein ich beschränke mich darauf, diejenigen Thiere hervorzuhelen, an denen man den Regenerationsplozess meincr Erfahrung nach besonders gut beobachten kann.

Vol Allem ist hier nun Siredon pisciformis das günstigste Object, da bei diesem nicht nur die Elemente der Epidermis ausserordentlich gross sind, sondern auch, weil die äusserst apathischen Thiere sich oftmals hinter cinander zu Experimenten gebrauchen lassen.

In cler ersten Zeil kam es mir natürlich daranf an, überhampt Material ron regenerirten Theilen zu sammeln; ich liess daher stets gernume Zeit vergehen, ehe ich zur erneuten Amputation schritt, später mussten dic ersten Stadicn der neugebildeten Epidermis besonders gesammelt und conscrvirt werten. Da von ciner Schcere, mag sic auch noch so scharf scin, leicht Quetschungen zarterer' Theile verursacht werden können, so fing ich schliesslich ein Thier' aus dem Behälter heraus, wickelte es in ein nasses Tuch, so dass nur der Theil, den ich amputiren wollte, heraussah, und schnilt num mit einem schr scharfen Rasimmesser ein Stückchen rom Scliwanz odel vom Flossensaum ab.

Das Thier wurde darauf in ganz l'eines Wasser gebracht und nach bestimmter Zeit wiederum, und zwar diesmal mit einer Scheere in der Weise amputirt, dass die alte Wundfläche möglichst geschont wurde.

Sofort nach der ersten Amputation muss mun die Beobachtung des ersten Regenerationsprozesses beginnen. Die Blutung ist meistens minimal, hört in dem frischen Wasser anch sofort auf, wälırend sich ein leichler Ueberzug von einer lymphartigen Flüssigkeit über die Wunde legt. 
Schon nach Verlauf von einer halben Stunde bemerkt man das Bestreben der Wundränder, sich cinander zu nähern, sie biegen sich efwas um, so dass die Kanten nicht mehr scharl; sondern rundlich erscheinen und die Wundfläche etwas verkleinert wird. Einen activen Antheil an dieser Erscheinung kann ich jedoch der Epidernis nicht zuschreiben, da dieselbe, wie mir scheint, hauptsïchlich durch Resorptionsprozesse hervorgerufen wird, welche in den freiliegenden Geweben vor sich gehen. Nach Verlauf von $5-6$ Stunden hat sich eine Wunde von 2 mm Breite und beliebiger Länge völlig geschlossen und zwar sowohl durch active wie durch passive Bewegung der Epidermiszellen. Zweckmässiger für die Beobachtung der ersten Stadien sind grössere Wundẹ, welche sich nicht so bald schliessen können, namentlich wenn man Längsschnitte der regenerirten Theile anfertigen will.

Ungefähr nach einer. Stunde scheint die Neubildung von Epidermiszellen bei Siredon zu beginnen, wälrend rorher nur die verletzten und sonst unbrauchbaren Epideimiszellen entweder resorbirt oder abgestossen wurden, also eine Reinigung der Wunde stattfindet, die bei diesen Thieren jedoch durchaus nicht den Ciharakter eines entzündlichen Processes trïgt.

Will man diese ersten zarten und so ausserordentlich empfindlichen Regenerationsstadien unter dem Microscop untersuchen, so wird man wohl in allen Fällen die Betrachtung eines frisc̀ herausgeschnittenen Wundrandes vorziehen, da man so ein natürlicheres Bild erhalten muss, als es bei Anwendung der besten Conservirungsflüssigkeiten möglich ist.

Leider besteht nur wiederum eine der bedeutendsten Schwierigkeiten darin, dass es sehr selten gelingt, ein unverletztes und genügend dünnes Stückchen des Amputationsstump̣es mit dem Rasirmesser alozuheben, da man natürlich an dickeren Stücken rom eigentlichen Wundrand niclıts zu sehen bekommt. Allein nach mehrfach missrathenen Versuchen wird auch dies gelingen und man wird damn durch instructive Bilder für die aufgewendete Mühe entschädigt werden.

As Zusatuflüssigkeit benutzte ich theils reines Wasser (welches sich hier nicht so schüdlich lür die Gewebe erweist, wie bei anderen Untersuchungen, und ja auch das naturgemässeste Nedium in diesem Falle ist, da die Wunde von Anfang an von demselben umspült wird), tleils 1/2 procentige Salzlösung oder stark verdünntes Glycerin. Der Rand del Wunde ist glatt und regelmässig gerade, wenn man ein genügend scharfes Hesser anwandte; die Grenze del alten Epithelzellen lïsst sich leicht an der dunkleren Färbung erkennen. Allein von diesen Rande aus schicht sich nun eine dünne Schicht fast ‘lurchsichtiger, mit homogenem Proloplasma erfüllter Zellen nach der Mitte der. Wundfäche vor, hier und da Auslïufer, mitunter sogar Inseln bildend, welche nur durch eine schmale Brücke mit den Randzellen zusammenhängen.

Durch diese hellen Zellen hindurch sieht man deutlich durchschnittene Schleimdrüsen der Cutis - verletzte Musculatur und Blutgefïsse hindurchschimmern, deren Lumen von Blutkörperchen erfüllt ist.

Auch die obere Fläche der Wunde ist grossentheils, besonders aber an den Pä̈ndern mit Blutkörperchen bedeckt, welche oft zu Täuschungen Veranlassung geben können, da sie, wenigstens im conservirten Zustande, den ganz jungen, neugebildeten Epidermiszellen nicht unïhnlich sind. 
Die Zellgrenzen sind schwer zu erkennen, desto leichter abel die glänzenden, homogenen Kerne, so dass man glauben möchte, dieselben seien in einem gleichmässigen Plasma vertheilt; ron Kernfiguren oder sonstigen Theilungsbildern ist nichts wahrzunehmen.

Je älter das Regenerationsstadium ist, desto dicker wirt die Schichte der neugebildelen Epithelzellen, so dass man nach einiger Zeit zu anderen Hülismitteln der Untersuchung greifen muss, um die weiteren Vorgänge genauer studiren zı können.

Die Herkunft der neugebildeten Kerne und Zellen ist am frischen Object absolut nicht z.u erkennen; die rundlichen und glänzenden Kerne laben ein durchaus von denen del' alten Epithelzellen abweichendes Aussehen, die Zelgrenzen sind schwer wahrnehmbar und das ganze Bild ist, wie bereits erwähnt, getrült durclı eine Menge von Blutkürperchen, die in späteren Stadien durch Wanderzellen verdrängt werden. Dennoch geben frische Präparate einen rortrefflichen Ueberblick über die ganze Wundfläche, so dass man keinesfalls versäumen darf, sich solche anzufertigen.

Da ich leidel' am lebenden curarisirten 'Thier genaue Beobachtungen der heilenden IVundfläche in situ nicht machen konnte, so muss ich mich darauf beschrünken, hier nochmals auf die vortreffliche Abhandlung von Mayzel $^{1}$ ) zu verweisen, welcher den Regenerationsprozess an der Zunge des lebenden Frosches genau untersuchte.

Un dünne Schnitte durch die verschiedenen Gewebe der ersten Stadien anzufertigen, behandelte ich die in bestimmten Intervallen wiederholt amputirten Theile nit sehr dümer (hellweinfarbener) Chromsäure, die dieselben so vortreflich conservirte, dass z. B. die weissen Blutkörperchen ihre Gestalt vollstïndig behietten, wesshalb ich einige dieser Präparate noch heute zur Demonstration derselben rerwende.

Dies sclıeint mir ein Zeichen zu sein, dass in diesem Falle durch dieses Reagenz die Gewebe wirklich in ihrer natürlichen Gestalt und Lagerung tixirt und conservirt werden, wofür ausserdem noch die Aehnlichkeit der in dieser Weise angefertigten Präparate nit den frischen Ohjecten spricht.

Das jüngste Stadium, welches ich in der angegebenen Weise fixirte, ist eine halbe Stunde alt und zeigt noch nichts ron proliferirenden Epithelzellen. Der Rand ist ziemlich scharf, die durchschnittenen Zellen sind grösstentheils collabirt und über der ganzen freien Wundfläche liegt ein dünnel Saum von rothen Blutkörperchen, die sich gegen die Epidermis hin in mehrere Schichten zusammenlallen.

Diese Blutkörperchen zerfallen sehr bald, wie es scheint, und zu gleicher Zeit breitel sich eine homogene Schicht über die Wunde aus, die bei Anwendung von Reagentien leicht gerinnt; es ist eine Iymphartige Flüssigkeit, an deren Bildung die zerfallenden Bhutkörperchen wahrscheinlich Theil nelımen.

Durch Picrocarmin werden die Kerne der Blutkörperchen orangeroth, das Plasma gelblich gefürbt, während die Epidermiszellen einen karminrothen Kern und rosarothes Protoplasma zeigen, der Lymphsaum füıbt sich nicht.

\footnotetext{
y) loc. cit. pag. $27 \mathrm{fr}$.
} 
Allmählig trelen nu Elseheinungen in den den Wundrändern zunächst liegenden Epiderıiszellen auf, die auf eine baldig beginnende Proliferation hindeuten. In einem Prïparat von Triton cristatus ad., welehes mit Methylviolett tingirt war, das bekanntlich, nach der Born'schen Methode angewandt, nur die Kerne und die Grundsubstanzen färbt, zeigt sich zunächst eine Erweiterung des Lacunensystems zwischen den einzelnen Epidermiszellen. Die Riffzellen, welehe den Wundrändern anliegen, runden sich ab und zeigen bald ein gleichmässig gekörntes Protoplasma, der Kern wird ebenfalls homogener, wie in den übrigen Zellen - kurz, die Zellen nehmen einen embryonalen Charakter an.

Bald schiebt sich nun, dachartig sich gegen den Lymphsaum neigend, eine Reihe von neuen Zellen von allen Seiten vor, welche auf dem Quersehnitt das Taf. I Fig. 8 dargestellte Bild zeigen, welehes übrigens nu' zur Uebersicht dienen soll, da der Zeichner leider die feinen Details sehr vernachlässigte. Die Zellgrenzen sind überall deutlich zu erkennen ljis zum äussersten Wundrande, wo man sie nicht melır nachweisen kann. Die Zellen sind länglich oval und mit der kurzen Axe senkrecht zu. Lymphschicht gestellt, die Kerne nehmen den grössten Theil del' Zelle ein, die an den meisten Stellen nur einen ganz schwachen Saum von Protoplasma erkennen lïist, wodureh ein Bild hervorgerufen wird, welches leicht zu Täuschungen Veranlassung geben kann, da man wohl glauben könnte, es handle sichı hier un die dichtgedrängt stehenden Kerne in eine' plasmatischen Grundsubstanz, - wemn nicht durch die Behandlung mit den bekannten Reagentien und die Tinetion mit IIthylviolett eben die Zellgrenzen so dentlich hervorgehoben würden. An den älteren Zellagen sieht man bereits die obere Reihe etwas abgeplatlet und in directer Verbindung mit der einzelligen Hornlage de! alten Epidermis (Fig. 8 H.), deren Kerne sich dadurch auszeichınen, dass sie platter, homogener und viel stärker tingirt sind, als die Kerne der iibrigen Hant.

Von den Erseheinungen der Kernmetamorphose (Karyokinese) und anderen Theilungserscheinungen lässt sich auf der ganten Schnittserie nichts nachweisen.

Bei der angegebenen Behandlungsweise müsste dies aber geschehen können, denn die Kerntheilungsfiguren sind im alten Epithel derselben Präparate ausserordentlich klar, es liegt aber liein Grund rol, wesshalb sje in den zarten jungen Zellen nicht ebenso gut hätten conservin't werien sollen.

Diese und schr ähnliche Bilder erhielt ich stets bei den jüngsten Regenerationsstadien erwachsener Thiere, sowohl von Tritonen wie von Perennibranchiaten oder Anuren. Es würde viel zu weit führen, hier jede kleine Abweichung in den Lagerungsverhältnissen genau zu beschreiben. Die Hau,tsache bleibt stets, dass bei älteren Thieren die Zellgrenzen selhst bei den jüngsten Stadien der regenerirten Epidermis selı' deutlich zu erkennen sinc.

Ganz anders stellt sich dies nun bei jüngeren Thieren und besonder's bei den Larven von Triton taeniatus dar. Sehon bei meinen in Sommer 1879 angestellten Versuchen fiel mil auf, dass die Zellgrenzen bei den ersten Regenerationsstadien ganz junger Larven nicht zu erkenmen waren und ich theilte bereits auf der 52. Tersammlung deutscher Naturforseher und Aerzle in 
Baden-Baden ${ }^{1}$ ) mit, dass an den Stellen, an welchen die Regeneration am schnellsten und unter den grössten Druckverhältnissen vor sich geht, sich auch bei den Larven ron Triton taeniatus eine Art Wulst in der neuen Epidermis bildet, „in welchem man nach 24 Stunden keine Zellgrenzen unterscheiden kann, die Kerne liegen viehnehr in einem gleichmïssig körnigen, von dunklen kugeligen Elementen durchsetzten Plasma." Da diese Thatsache mit den Resultaten, welche man bei älteren Thieren erhïlt, durehaus nicht in Einklang zu bringen war, so machte ich wiederholt Experimente, um hierüber völlig ins Reine zu kommen. Zwar stellten sich den neven Versuchen zum Theil unerwartete Schwierigkeiten in den Weg, und meine inzwischen erfolgte Uebersiedelung nach Leipzig verzögerte dieselben in dem. Maasse, dass die Herausgabe der abgeschlossenen Arheit darunter zu leiden hatte, doch konnte ich durch die nerren Experimente nicht nur die früheren Beobachtungen bestailigen, sondern auch für einzelne mir damals noch unklare Punkte eine Erklärung finden, welche mich wenigstens in soweit hefriedigte, dass ich zur Publication schreiten konnte.

Inzwischen war nun neben anderen Albeiten auch die Abhandlung von Flemming ${ }^{2}$ ) erschienen, in welcher derselbe seine Ansichten über die Regenerationsfrage ausspricht.

Sein Wahrscheinlichkeitsschluss lautet: Die Regeneration der Epithelien, wie aller Gewebszellen, geschicht durch Zelltheilung in dentiefen Schichten, mit Kerntheilung unter den allerwege bekannt gerrordenen Elselıeinungen der Kernmetamorphose (Karyokinese). Es bestelıt kein Grund, Vorgänge andrer Art - wie z. B. „freie Zell- oder Kernbildung“ - bei der Epithelzellenvermebrung vorauszusetzen.

Was mich vor allem dazu veraulasst, gegen die Flemming'schen Ausführungen Front zu machen, sind die negativen Resultate, die ich in Betreff der Kernfiguren und der einfachen Kerntheilungen in den jüngsten Stadien erhalten habe, ferner abes auch positive Bilder, die ich nur als Beweise für eine anders vor sich gehende Kernbildung ansehen kann, wie der Taf. I. Fig. 5

- dargestellte Schnitt durch die 24. Stunden alte regenerirte Epidermis ron einer Tritonenlarve. ${ }^{3}$ ) Da es hier auf Priparation und Tinction besonders ankommt, so wiederhole ich hier nochmals genau den Gang der Conservirungsmethode.

Die Larve wurde amputint am 10. Juli 1879, am 11. Juli, genau nach 24 Stunden, in 2\% Chromsäure abgetödtet und darauf in schwachen Alkohol gebracht, der am selben Tage noch von Stufe zu Stufe mit stärkerem und schliesslich absolutem Alcohol vertauscht wurde. Nach vollständiger Entwässerung legte ich dieselbe am folgenden Tage 6 Stunden in einplocentige Salpetersäure, darauf erfolgte stundenlanges Auswasehen in langsam flicssenden Wasser und nun

3) Vergl. den Bericht über die Versammlung pag. 223.

$\left.{ }^{2}\right)$ Ueber Epithelregeneration und sogenamnte freie Kiernbildung von Walter Flemming im "Archiv fül microscopische Anatomie, Bd. 18, pag. 347 fi. und: dasselbe Archiv Bd. 16, pag. 397.

3) Dieses Bild ist entnommen von einem Schnitt durcl dic 21 Stunden alte regenerirte rechte hintere Extremität einer $20 \mathrm{~mm}$ langen Larve von Triton taeniatus. (Zciss, Ș̣st. E. oc. 11. Camera). Ein anderer Schnitt diesel Serie wurde hei schwïcherer Vergrösserung dargestellt in Taf. I Fig. 11, an dem man das Hineindringen der vielkerngen Wanderzellen zwischen die Epidermiszellen deutlich beolachtet. (Zeiss oc. II Syst. A. Camera.) 
Tinction mit Mcthylviolett (Methode ron Born) und abermalige allmähliche Entwässerung Terpentin - Paraffn mit Terpentingemischt und schliesslich reines Paraffm, in welches die kleine Extremität vermittelst heisser Nadein eingebetlet wurde. Ich schneide bei diesel Einbettungsmethode stets trocken und zwar auf dem grösseren Leyser'schen Mierotom mit den Lomy'schen Messer; nach einiger Uebung wird man leicht Schnitte von $1 / 8_{80}-1 / 100 \mathrm{~mm}$ Dicke erhalten und derartig arrangiren können, dass eine munterbrochene Schnittserie entsteht. In diesel hier in Betracht kommenden Serie sind die Schnitte sämmllich nicht dieker wie ${ }^{1 / 80} \mathrm{~mm}$; die Gewebe sind so vortrefflich erhalten, dass z. B. die Blutkörperchen wiederum ihre volle Praltheit behalten haben und dass überhaupt die subtilsten Nuancirungen in der Form der Kerne und Zellen zu erkennen sind. Kunstproducte kann man hier also wohl mit Sicherheit als ausqeschlossen betrachten.

Die verschiedenen Abstufungen in der Färbung erleichtern die Uebersicht ungemein. Wie bereits erwähnt, werden durch Methylviolett (Bornsehe Methode) nur die Intercelluharsubstanz und die Kerne gefürbt. Das Plasma der Blutkörperchen nimmt oft allerdings einen gelblichen Schein an, derselbe wird jedoch höchst wahrscheinlich nicht dureh die Tinction bedingt, sondern durch die vorhergegangene Behandlung mit Chromsäure. Fast schwarz erscheinen nun die Kene der Blutkörperchen und der Wanderzellen, während die übrigen Keme ntehr oder weniger violett gefürbt sind. Das lıomogene Protoplasma ist ungefärbt, wollt aber erscheinen die grösseren und kleineren Körrchen desselben heller oder dunkler lingirt. Die Intercellularsubstanz ist merkwürdigerweise diesmal nur schwach gefürbt, wie dies in Fig. 11 naturgetreu dargestent ist, doch hat dies seinen Grund darin, dass ieh die Farbe lïngere Zeit wie gewölnlich rluch Aleohol ausgezogen habe.

Sehr wiehtig für unsere Betrachlung ist unbedingt das Verhalten der Wanderzollen. Diese sind rundlich und lassen stets mehrere stark gefärbte lierne erkennen, die oftmals allerdings so dicht aneinander gedrängt sind, dass man sie nur mit staker Vergrösserung in mehrepe Theile zu zerlegen vermag. Man findet sie zerstreut in den oberflächlichen Bindegewelsstagen und besonders massig angehäuft am Wundrande - sie treten in bedeutender Anzalıt in das sieh regenerirende Epithel hinein, wo sie dann in ganz eigenthümlicher Weise zerfallen, mm sich in der protoplasmatischen Grundsubstanz zu vertheilen. Vielfach ziehen sich hier die kleinen Kerne zu einen grossen zusammen, welcher nun als grössere dunkle Kugel zwischen den Kernen des Epithels erseheint.

Diesen Uebertritt der Wanderzellen habe ich auch an frischen Object beobachten können, ja nicht altein am proliferirenden Epithel tritt dieser Fall ein, sondern auch in der normalen Epidermis vieler Amphibien finden sich Wanderzellen: so bei Proteus in grosser Anzaht und aueh bei Pleurodeles.

Für mich ist kein Zweifel vortanden, dass alle die in Fig. 5 dilrgestellten dunklen Puncte von Wanderzellen abstammen, die zur Emähung des Protoplasmas, in dem sie frei sich herumbewegen, beitragen. Dieselben zerfallen bald nach ihem Eintritl in das proliferirente Gewebe und bilden meiner Ansicht naeh das Blastem, in welehem dann wiederum später dic Kenne der neuen Epiderniszellen secundär dadurch entstehon, dass nach und rach die feineren körnchen zusammentreten, um dann allmählig zu riehtigen Kernen zu werden. 
Dafür sprechen ausserdem noch verschiedene Umstïnde: erstens liandelt es sich hiel' wirklich un ein echtes Syncytim, denn es ist mit den stärksten optischen Hülfsmitteln nicht möglich, Zellgrenzen aufufinden; es bildet sich zwar selu bald um dic ausgebildeten Kerne ein heller protoplasmatischer Saum, aher ohne deutliclıc Grenze nach dem umgebenden Protoplasma zu ein Unstand, der mehr lür als gegen meine Vermuthung sprichıt.

Zweitens howeist lür mich die verschietene Grösse der Kerne, dass dieselben sich allmählig aus dem umgebenden Protoplasma heraus differenziren, besonder's da ron Kerntheilungserscheinungen nichts whrzunehmen ist.

Ausserordentlich wichtig für meine Ansicht ist schon der Umstand, dass keine abgegrenzten Zellen vorhanden sind, sondern cin melır oder weniger homogenes Blastem, in welchem die Kerne unregelmïsiy zcrstreut licgen. Diese Thatsache widerspricht allen neueren Beobachtungen, ja sie steht in directen Widersprucli zu meinen eigenen Resultaten, die jeh bei älteren Thieren erhielt.

Der erste Widerspruch lässt sich jedoch leicht dadurch erk]ären, dass wohl alle neueren Experimentatoren an erwachsenen Thieren ihre Versuche anstellten, namentlich war es ja der Frosch, welche: vielfach zu denselben benutzt wurde. Haben aber nun die älteren For'scher. z. B. Henle, $\left.{ }^{1}\right)$ welche eine freic Kernbildung in einem Syncytium bei der Regeneration für wahrscheinlich Jielten, niclıt vielleicht auch Larven oder' junge Thiere unter den Händen gehabt, und erklären sich hierdurch auch dic abweichenden Resultate der jüngeren?

Was anch mich lange Zeit hinderte. die eben ausgesprochene Ansicht unbedingt anzunehmen, ist der Umstand, dass ich in den ersten Regencrationsstadien erwachsener Urodelen andere Bilder enhielt. Dies sind vor Allem das in Fig. 8 abgebildete Stadium, sowie die ersten Zellproliferationen bei Siredon, bei denen man deutlich das Vorschieben der einzchnen Zellen beobachten konnte. Hicr sind unzweifelhaft Zellgrenzen vorhanden, von einem Syncytium keine Spur zu entdecken - ja das Protoplasma ist so ausserordentlich gering, dass es nur einen sehr schmalen Rand um dic Kicrne herm bildet. Auch in älteren Stadien, die dem cben beschriebenen entsprechen wïrden, finden sich ganz andere Bilder: stets sind, wenn die Wunde sich einmal durch einen solchen Epidermisüberzug geschlossen hat, Zcllgrenzen deutlich zu erkennen. Auch sind die Kerne stets viel homogener und zeigen nichts von der unregelmässigen Kömclung der eben erwïhnten Kerıe.

Es war schwierig für mich, unter diesen Verhältnissen zu cinel cntscheidenden Ansicht zu gelangen, denn zwei siclı direct widersprechende Bilder standen siclı gegenüber: hier das Epithel des ausgewachsenen Thieres in den ersten Regenerationsstadien - dor't das Syncytium der Larve eines Angehörigen der'selben Gattung.

An den verschiedensten Urodelen wurden nun Versuche gemacht, die diese Verhältnisse völlig aulklïren sollten, doch gelang es mir nicht, beweisende Präparate für diese oder jene Ansiclıt zu crhalten; stets liessen sich in den älteren Stadien bei erwachsenen Thicren dic Zellgrenzen deutlich unterscheiden, während dies bei jüngeren Thieren und besonders Larven zur Unmöglich-

1, Henie, Hindbuch der Fingeweidelehre. ‥ Aufl. p. 3, Anmerkung. 
keit gehörte. Daraus bilde ich mir nun die Ansicht, dass bei Larren, besonders den Laven der Tritonen, neben der einfachen Kerntheilung: a ueh cine freiekernbildung in cinem gleiehmässig über die Wundfäche rertheilten Blastem bei der Epithelregeneration rorkommt, während bei erwals freie kernbildung wenigstens sehr beschräkt, wcnn nichtganzaufgehoben wird.

Ich bin gewiss, dass meine Ansicht über diesen Punct ganz besonders angefochten werden wird und zwar nicht nur von den Gernern der freien Kermbildung, sondern auch ron den Anlïngern derselhen, welche mir Inconsequenz in dor Beziehung vorwerfen künnen, dlass ich eine doppelte Artt der Kernbildung fül wahrseheinlich halte und danit die beiclen streitenden Parteien zu reteinigen suche, während dieselben noch fost an ihren eimmal ausgesprochencn Grundsätzen sich anklammern. Allein ich muss hice anf gewisse embryonale Vorginge verweisen, dic sich in den Eiern abspielen. Auch hier entsteht cin grosser mesoblastisclıe Theil des Blastoderns direct. aus den primälen Furehungskugehn uml bildet eine continuirliche Reihe von Zellen, die sich sehr bald in zwei Blätter spalten, wïhrend anderscits innelhalb des Dotters neuc Kerne entstehen, die sich illmählirr mit Zellprotoplasma und schliesslich mit eincr Zellhaut momeben; wenigstens kinn ich nur in dieser Theise die eigenthünlichen Bilder deuten, wclche in der Entwickelung des Pristiulus ron $B$ uffur aufgefunden und dargestellt wurlen.

Auch beim viel untersnchten Hühnchen finden sith wahrscheinlich ähnliche Verhältnisse, denn Koblliker) spricht sich dahin aus, dass noben den direct aus den Furchungsugohn abstanmenden Zellen auch noch nene Kerne und Zellen im Dotter enlstehen künnen.

Da wir nun entschieden in den Pegenerations-Erscheinungen in Allgemeinen ein Zurückgreifen auf embryonale Terhïltnisse constatiren künnen, so liegt fül mich nichts Wunclerluares: darin, dass auch bei der Regeneration der Epidermis eine doppelte Entstchung ler Kerne vorzukommen scheint, wie sie bisher nur bei der embryonalen Zellbildumg ronstatirt rurde.

Was nun die Rolle der Wanderzellen aublangt, über Welehe bis rol knzel Zeit so heterogene Ansichten im Streite mitcinander ligen, so nehme ich aueh in dicser Beziehung einc vermittelnde Stellung ein.

Heisst es auch seit Remak, dass nur aus den Elementen del Epritermis wicler neue Ejidermiszellen hervorgehen können, eiıe Ansicht, die selbst von den muthigsten Vertheidigern der freion Kernbildung, z. B. von Iraysel, unbedingt angenommen wird, so kann ich doch nicht unhin, auf die grosse Wiehtigkeit hinzuweisen, welche den Wanderzellen loci der Regeneration überhaupt zuzusprechen ist. Kcinesfalls gehen aus den Winderzellen direct nene Zellen des Epithels herror, denn soweit muss man den Beobachtungen so bedcutender Forselıer wie Köllitier und andercr unbedingt trauen - auch galsen mil meine eigenen Präparate nicmals Voranlassung: dies anzunchmen -, woh] aber tragen sie ganz entsehieden zur Ernähıung der proliferirenden Zollen bei, sowie zur Bildung des honogenen Blastems, in welehem bei den Larren die neuen Kerne entstehen. Indirect betheiligen sie sich abcr sehr bedeutend am Auf bau der neuen Epiłermis

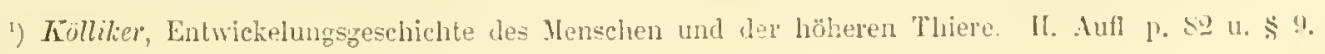


sie ernähren sie vor allen und befördern dadurch das Wachsthum. Höchst wahrscheinlich haben auch diejenigen Wanderzellen, welche sich in der normalen Epidermis ausgewachsener Urodelen vorfinden, denselben Zweck - unbrauchbare Elemente aufzunehmen und nach gescheliener Assimilation auf der anderen Seite als Nahrungsmaterial für die waclsenden Zellen zu dienen. Und hierdurch ist wiederum die grosse Uebereinstimmung nachgewiesen, unter del pathologische und physiologische Regenerationsvorgänge verlaufen. Dass die Vianderzellen in dem pathologisch sich neubildenden Epithe\} so bedentend häufger sind wie im normalen, darf uns nicht W'under nehmen, denn die Zellproliferation ist hier ja eine bedeutend intensirere und in Folge dessen das Nahrungsbedürfniss ein bedertend grösseres.

Dass ich die Wanderzellen direct als Träger der Ernährung ansche und nicht allein die umgebende lynphartige Flässigkeit, stellt mich wiederum in Gegensalz zu den Ansichten der meisten Histiologen. Allein da es mir gelang, die Wanderzellen in allen Stadien des Zerfalles im sich regenerirenden Elithel aufzufinden, da ich die Veränderungen derselben Schritt für Schritt verfolgen konnte, so liegt fïr mich kein Umstand ror, weleher mich ron der Annahme dieser Ansicht ahhalten könnte. Die oberen Schichten aller Gewebe werden ja, wie bekannt, wemn sie unbrauchbal gerrorden, einfach abgestossen, in den tieferen Lagen jedoch kann eine solche directe Abstossung nicht stattfincleu und nun sind eben die Wanderkörperchen dazu da, diese unbrauchbar gewordenen Gewebetheile aufzunehmen, quasi zu verdauen, um sie dann wieder als brauchbares Nahrungsmaterial an wachsende Zeilen abzugeben.

Ohne Wanderkörperchen würde sich ein verletzles Epithel ebensowenig regeneriren können, wie irgend ein Gewebe des mittleren Keimblattes. ${ }^{1}$ )

Was endlich die neue ron Lott ${ }^{2}$ ) und Drasch ${ }^{3}$, besonder's vertretene Hypothese der sogenannten „Rudimente“ und der darin auftretenden freien Kernbildung anbelangt. so kinn ich mich, gestützt auf meine Resultate, nur gegen dieselbe aussprechen. Zwar habe ich die Experimente der betreftenden Forscher nicht an demselben llateriale viederholen können, und hin insofern nicht im Stande, ihnen direct zu widersprechen, doch möchte ich eben vor eincr Verallgemeinerung ihrer Ansichten gewarnt haben. Bei der Epidermis erwachsener Amphibien, die hier für mich allein in Betracht kommen, kann ich dergleichen ,Rudimente" nirgends auffinden, die Zellen sind, wie bereits erwähnt, alle mit deutlichen und fast gleich grossen homogenen Kernen versehen.

1) Die Arbeit von Kielonko (Archiv f. mikl. Anat. Bd. X p. 35l) liefert insofern keine beweisenden Resultate, als das Vorkommen yon Wanderzellen in Lymphraum absolut nicht ausgeschlossen werden kann. Geht man auf die Entstehungsweise der Wanderzellen zurück, so sind ja ausserdem Wanderzellen, Leucoçthen und Lymplukörperchen nicht mehr zu tremnen - wodurch die Annahme Zielonko's von sellust hinfällig wird.

${ }^{2}$ ) Ueber den feineren Bau und die plỵsiologisclse Regeneration der Epithelien, inshesondere der geschichteten Pflasterepithelien in Untersuchungen aus tem Institute für Physiologie und Histologie in Graz. Herausgegeben von A. Rollet, 3. Heft, 1873 .

3) Die physiologische liegeneration des Flimmerepithels der Trachea. Sitzungsberichte d. Wiener Academie d. Wiss. Matlı. nat. (a. 13d. so. 14. October 1879. 
Gelse ich nun über zur Besprechung der älteren Regenerationsstadien der Epidermis der Amphibien, so muss ich vor allem voraufschicken, dass über die weiteren Verhältnisse bei der pathologischen Regeneration so gut wie gar nichts bekannt ist. Ich werde daher als Grundlage meiner folgenden Betrachtungen ein Thier vor allem zu berücksichtigen haben, dessen Epidermis nach einem ausserordentlich einfachen 'Typus gebant ist und welches mir, wie schon elwähnt, überhaupt für meine Untersuchungen von grösster Wiclutigkeit war - ich meine den Pleurodeles Waltlii.

Den Bau der normalen Epidermis labe ich pag. 6 ff. meiner Abhandlung über Pleurodeles genau besprochen, - das wichtigste hiebei ist die ausserordentliche Regelmässigkeit in der Anordnung der veschiedenen Zellagen - das Auftreten ron Pigmentkörnchen in den Fernen und das Vorhandensein von Hautsinnesorganen, welche darauf hinweisen, dass Pleurodeles wahrscheinlich ein ständiger Wasserbewolıner ist.

„Eine einzellige Hornschicht, in welcher jedoch durch geeionete Reagenzien die Keme meistens deutlich nachzuweisen sind, bedeckl ten ganzen Körper und wird nur an beslinmten Slelten, besonders an den von Lataste und Braun beschrichenen Begattungs-Hülfsorganen, mehrschichlig.

In Durchschnitt kanı man bei Pleurodeles etwa fünf übereinander liegende Zelllagen annehmen; die untersle hat cylinderförmige, die darüber liegende bereits cubische Zellen. „Die unterste Cylnderzellenschicht (l.c. Taf. XV, Fjg. 10 R., II.) scheint mis die allein proliferationsfühige zu sein, denu nur aus ihr entstehon, wie spätel besprochen wird, die Schleimdrüsen und die Hautsinnesorgane, ron ihr stammen auch alle übrigen Zellen der. Epidermis direct ab.

Durch die fortwïhrende Termehrung der Zellen werden diese mit ihren dichtgedränglen Kernen zum Theil nach oben aus dieser Schicht hinausgepresst, wodurch die Kerne cin lïngliches. rübenartiges Aussehen erhalten. (1. c. Taf. XV, Fig. I0 r.) Sie ruolen sich dann nach und nach ab nnd bilden die Zellen des nächstfolgenden Schichten."

„Gelangen num diese Zellen durch fortgesetztes Nachdrängen ron unten und durch ein zeitweises Abstossen der obersten Schicht in die dritte Lage, so werden sie platter und rerlieren das gekörnelle Aussehen, was jedenfalts von einer Verïndermng des Zellprotoplasmas lıcrührt, während die Kerne noch ihr granulirtes Aussehen behalten. In der vierten Reihe ist dic Umwandlung des Protoplasmas noch weiler volgeschritten, der Inhalt der Zelle noch homogener geworden und der Kern weniger granulirt. Die Zellen sind jetzt schon starrer, liegen nicht mehr so gedrängt und werden durch den Druck von unten und den Widerstand der obersten noch starreren Plattenschicht in ihrem senkrechten Durchmesser verkürzt, so dass auch sie an vielen Stellen schon rollständig plattenförmig crscheinen.

Jetat ist eine Veränderung durch Wachsthum der einzehen Zellen nicht mehr anzunehmen, es sind vielmeln rein mechanische Monente, die eine weitere Abplattung erzeugen. Schon die Zellen der vierten Schicht häıg̨en fester untereinander, als mit den Zellen der übrigen Lagen zusammen; bei der fünften und letzten Schicht ist dieser Zusammenhang noch inniger und die Trennung ron der vierten Lage so scharf, dass ein deutlicher Saum nach unten erkembar ist, während die seit- 
lichen Zellgrenzen kaum mehr wahrgenommen werden künnen. - Ist die seitliche Verschmelzung der obersten Zellen in dem Mlaasse vorgeschitten, so muss jeder Druck von unten die ganze Fläche. ausdehnen und in Folge dessen die einzelnen Theile, d. h. die Zellen, abplatten.

,Leydig ${ }^{1}$ ) sicht überall bei Amplibien die äusserste Schicht der Epidernis als Hornschicht an, ebenso F. E. Schulse2), nur ist ron Lcydiy nicht angegeben, ob er bei Pleurodeles nur die äusserste Plattenschicht oder auch noch die darunter liegenden Zetlen, deren Proloplasma ebcnlatls schon rerïndert ist, zu Homschicht rechnet; ich glaube jerloch aus anderen Stellen seiner Abhandlung über Pleurodeles zu ersehen, dass er nur die oberste Zelllage als verhornt aufasst.

Ueber den Prozess der Verhornung spricht sich Leydig ${ }^{3}$, dahin aus, ,dass die Terhornung, das heisst Erhärtung durch l, ebensthätigkeit, nicht die eigentliche Zellsubstanz oder das Protoplasma betreffenkanu, sondern nur dievon letzterem naclu aussen abgeschiedenen, also cuticularen Schichten. Wir können uns eine verhornle Zelle kaum anders rolstellen, denn als eine solche, deren eigentlicher Leib nach und nach ejnging, während die Membran-oder Kapselschichten einem Erhärtungsprocess verfielen.*

Meine Beobachtungen gehen nun dahin, dass eine solche hapsel hei dem Prozess der Verhornung nicht abgeschieden wird, dass viehnehr die Verhornung in einer Ietamorphose des Protoplasmas selbst besteht und dass sogar die Kerne olt eher verholnen, als das Protoplasna der übrigen Zelle. Letzteres behauptet Leyrlig auch pag. 226 seiner Arbeit ïher Pleurodeles im Widerspruclı zu sciner früberen Angabe, wenn er sich auch in Betreff der bramen Färbung nicht ganz in meinem Sinne auschrïckt. -- Ich stülze mich bei der Aufstellung meines soeben ausgesprochenen Satzes hauptsïchlich auf die deutlichen Bilder, wetche ich durch Picrocarmintärbung erhalten habe.

lch halte nur die oberste Ptattenschicht füı wirklich vollständig verhornt, die darunter liegende Zellschicht dagegen für noch im Process der Verhornming begriffen und nur an wenigen Körperstellen lür chenfalls völlig verhornt."

Eine ïhnliche Ansicht wic Loyling in Betrefí des Verhorungsprocesses und der Guticularbildungen scheint Pfitancr zu haben; dem es gelang ihm, nachzuweisen, , flass der Cuticularsaum (der Salamanderlarren) eine Hornbilkung ist.. - Und zwar sieht er den Culicularsaum ,als cine Rückbiklung eines früheren Flimmerljesatzes an."

Wie num ein Cuticularsaum rine Hornbildung sein kinn, ist mir nicht ganz klar, jedenfalls sind die ron I'fitzner angewandten Terdaungsversuche noch nicht genügend, die Fichtigkeit einer solchen Ansicht z.u beweisen. Eine Cuticularljildung ist eben unter allen Umstärden ein Alssonderungsproduct des Protoplasmas (welche ja mitunter in seiner chemischen Zusammensetzung eine gewisse Aelnulichkeit mit llom haben mag), wählurend der Process der Verlornung auf einer Mletanorphose des Protoplasmas selbst beruht.

i) leydig. Die Hulche det wâttemberegichen Fanna.

2) F. F. Échulse. Lelser cuticuline Billungen und Verhornungen von Epithelzellen bei den Wirhelthieten. Archiv für mikiosk. Anatomie. Bd. $T$, s $2 !$ i.

3) Leydig. Leber die allgeneinen Bedeckungen der Anphibien. Archiv für nikrosk. Anatomic. Bt. XIl, P. 136. 
Ferner glaubt Pftaner die Ansicht aufstellen zu müssen, dass die Kerne eine geringere Neigung zur Verhornung haben als die Zellleiber, wenigstens komml er bei der Besprechung der verschiedenen Tinctionsmethoden zu dem Resultat, „dass del' Verhornungsprocess sich nicht in gleicher Inłensität auf den Kern erstreckt (pag 503, Anm.)." Es handelt sich hier um dic Ergebnisse einer ron Ifitaner vielfach angewandten Safraninfüubung, welche alle ausgeprägte Hombildungen wie Haare und Nägel intensiv roth fürben soll, jedoch bei der Hornschicht der Epidermis des errachsenen Salananders, ,merkwürdigerweise uneistens den Kern und die Zellgrenzen ungefürbł lässt, während es den Zellleib intensiv roth fürbt." Ob dieser eine Unterschied der Färbung nun für diesen speziellen Fall beweisend ist, muss ich dahingestellt sein lassen, meine mit dem für die Diagnose der Itormmetamorphose wohl ebenso branchbaren Picrocarmin angestellten Versuche ergalon auch bei Salamandra dieselben Resultate wie bei Pleurodeles: "hat das Picrocarmin selur lange aut das Object cingewirkt, so is! wohl noch das Protoplasma der oberen Zellen roth gefürbt, nicht aber die Kerne, welche unter gewöhnlichen Umstïnden meistens gelb werden."

Wie bereits elwähnt, hatte ich leider versäumt, gerade bei Pleurodeles die ersten Regenerationsstadien etwas genauer anzusehen, später liess sich dieser Fehler nicht wieder repariren, da meine Pleurodeles während einer kurzen Abwesenheit meinerseits theils durch remachlässigte Pflege zu Grunde gegangen waren, theils das Theite gesucht hatten. Jch muss mich also gerade bei dieser interessanten Form auf die ïlteren Stadion heschränken. - Diese besitze ich nun in grosser Anzahl und zwar von 48 Stunden ab.

In dem jüngsten regenerirten Epithe] lassen sich bereits fünf bis sechs übereinanderliegende Zellschichlen erliennen, die jedoch insofern ron den ursprünglichen elwas abreichen, als sie mit Ausnahme der äussersten aus lauter eubischen Zellen zusammengesetat sind. Nicht einmal die unterstc Lage, das sogenannte Rete Malpighii, besteht ans cylinderförmigen Zellen, sondern besitzt ebenfalls cubische Elemente, wälırend die äusserste Sehicht aus deutlich abgeplatteten Zellen bestelat, die jedoch noch keine Hormmetamorphose durchlaufen haben - wenigstens lässt sich eine solche durch Tinctionsmittel (Picrocarmin) nicht nachweisen. Die Kerne sind gleichmässig gekömelt, das Protoplasma der Zellen jedoch ist homogen und rosa gefïrbt. - Kernfiguren sind nicht zu crkennen, dagegen ist ein interzelluläres Lacunensystem sehr deutlich als ziemlich stark lichtbrechendes Netzwerk erkennbar - ein Zeichen, dass dassclbe mit einer homogenen gerinnbaren Substanz erfüllt ist, welche diese physikalische Eigenschaft besitzt. -- Wanderzellen sind nur spürlich vorhanden, sie befinden sich slets in den Lacunen.

Die nächste wahrnehmbare Veräinderung besteht darin, dass die untersten Zellen cylinderförmig werden und zwar zuerst völlig regelmässig, dlann durch die fortwïhrende Proliferation unregelmässiger. Es treten wie bei der normal wachsenden Epidermis vielfach schmale Zellen mit rübenförmigen Kicrnen aus dieser Schicht heraus, um sich in die oberen Lagen zu begejen. Bahl darauf verhornt num anch die oberste Schicht und damit ist eigentlich der pathologisehe Regenerationsprocess vollendet - demn ron jetzt ab treten die Wachsthumserscheinungen ein, welche bej der normal wachsenden Epidermis bestündig in Thätigkeit sind. - Jedoch verlieren die mittleren 
Zellen nichıt so bald die Fähigkeit der Proliferation, da man in späteren Stadien häufig die bekannten Zelltjeilungsfiguren erkennen kann, was bei der normalen Epidermis nicht der Fall ist.

Schr auffallend war mir das häufige Vorkonmen ron Pigmentkömehen in den Kernen der neugebitdeten E\}ridermis. Es kommt zwar auch in den Kernen des normalen Integumentes Pigment ror, jedoch nicht in derselben Menge wie bei der regencrirten Haut ${ }^{1}$ ). Dass dasselbe spontan in den neugebildeten Kernen auftritt, ist mir jetzt wahrscheinlicher als frülser, da ich glaubte, die Pigmentkömchen rührten ron den durch die Verwundung zerstörten Pigmentzellen her'; nachtrigglich hatte ich jedoch beobachtet, dass diese zerstreuten Pigmentreste sehr bald zerfallen und resorbirt werden. -

Für meine Ansicht spricht ausscrdem noeh das Torkommen rerselben in der normalen Epiclermis. In Fig. 7 ist allerdings in schematischer Weise auf dem Uebersichtsbilde cines Schnittes clureh den 3 Nonate alten regenerirten Schwanz von Pleurodeles dic neugebildete Epidermis dargestellt.

Etwas complicirtcre Wachsthumsverhältnisse der Epidermis finden bei denjenigen Thicren statt, welche neben den einfachen Elementen noch complicirtere Organe besitzen wic z. B. die Leydig'schen Zellen.

Diese sind in der Epidermis der Tritonenlarven und der Larve des gefleckten Salamanders ausserordentlich hïufig.

In Bezug auf diese Zellen schliesse ich mich den Ansichten Leydig's und Ifitsner's an, welche ihmen cine bcsondere Wichtigkeit für das Larronleben der betreftenden Thiere zuschreiben, während Peremeschko sie nur als vorübergehende, rasch entstehende und rergehende Bildungen ansicht. - Für dic Richtigkeit unserer Ansicht spricht ror Allem, dass diese Zcllen sich durchaus nicht so schnell differenziren, wie ries Peremeschko annimmt. Die fast rollständig regenerirte Epidermis einer $95 \mathrm{~mm}$ langen Larve ron Triton taeniatus zeigt eine deutliche Plattenschicht jedoch ohne den normalen Guticularsaum und mehrere (2-3) darunterliegende Zelllagen mit grosscn Kernen und kaum erkembaren Zellgrenzen. (Taf. 1, Fig. IS). - In den unteren Lagen sicht man jetzt ausserordentlich häufig die bekannten Kernfiguren auftreten, welche übrigens hier öfter cine Eigenthümlichkeit zeigen, die meines Wissens bisher nicht beobachtet wurde. Gewöhnlich tritt die Kernspindel in der Weise auf, dass die Längsaxe derselben mit der Längsaxe des Kernes zusammenfällt, hicr jedoch sche ich häufig die Spindel scnkrecht auf der Längsaxe des Kerncs stehen. Die Kerne sind sämmtlich schr unregclmässig geformt und der Zellieib wie gesagt noch renig differenzilt. 'Trotzdem zeigt sich schon in dicscm Stadium der erste Anfang der Leydig'schen Zellen, denn um einzelne Kerne sammelt sich cin helleres, homogencres Protoplasma, in welchem dann bald die netzö̈mige Anordnung auffällt, wälırend sich in die einzelnen Masclıen dieses Netzes die Schlcimkügelchen einlagern. In ähnlicher Weise verlaufen dicse Vorgänge bei den Larren ron Salamandra, bei den erwachsenen Siredon, Proteus und anderen Urodelen, welche mit derartigen Organen versehen sind. -

') Plevrodeles loc. cit. jag. 9, Fig. 10. 
Eine Eigenthümlichkeit des Wachsthums, welche besonders deutlich bei den Froschlarren hervortritt, muss ieh noch kurz erwähnen, obgleich derselben wohl keine besondere Bedeutung zugeschrieben werden kann. Schon Bonnet war das kleine knopfartige Kü̈gelehen bekannt, welehes sich am Sehwanzstumpfe der Froschlarver etwa am zweiten Tage zu zeigen beginnt. Diese kleine kugelige Anschwellung liegt gewöhnlich in der Mitte der bereits geschlossenen Wundfläiche und zeigt auf dem Frontalschnitte das in Taf. 2, Fig. 1 dargestellte Bild.

Die Epidermis des Schwanzes der Froschlarven besteht aus I Lagen von Zellen, deren obere plattenförmige, die darunter liegenden dagegen cubische Elemente besitzt. -

Diese beiden Schichten verdicken sich nun an Wundrande kurz nachdem der Schnitt geführt wurde. Die Zellen fangen an, sich leblaft zu vermehsen, obgleieh auch hier keine Spur von Kernfiguren zu entlecken ist, und num bildet sich eine erst kleine, allmälılich jedoch grösser werdende Blase dadurch, dass das Epithel sich von der Cutis ablöst, oder vielmehr dadurch, dass das Epithel an bestimmten Stellen beteutend schmeller regenerirt, als die darunter befindlichen Gewebe. Diese Blase ist erfüllt mit einer lymphartigen Flüssigkeit, in der an einzehnen Punkten massenhafte Anhüufungen ron Wanderzellen zu erkennen sinc. -

Keinesfalls kamn man diese Blase mit der Braur'schen Schwanzblase ${ }^{1}$ ) vergleichen, welche bei einzelnen Vogelembryonen in bestimmten Stadien auftritt; denn es gehen weder Chorda noch Gefïsse in dieselbe hinein wie dies bei jener der Fall ist. Wir haben es hier nur mit einer einfachen Wachsthumserscheinung zu thun, welche keinen Bezug hat auf palingenetische Entwicklungsstufen, während sowohl ter Eckert'sche Sehwanzfaden wie die Graun'sche Schwanzblase cine ebenso grosse phylogenetische Bedeutung haben wie del eigenthümliche Knorpelstab, aus dem die letzten normalen Wirbel der Urodelen hervorgehen. - Doeh daron später!

Diese hlasenartige Erhebung der neugebildeten Epjidermis finclet sich, wenn auch nicht in dieser typischen Kugelgestalt, auch bei den Urodelen, besonders bei Siredon, bei den meisten Amphibien jedoeh bilket sich nur ein compacter Knopf aus dem äussersten Schwanzencie, aus dem nach Analogie des Vegetationspunctes bei den Pflanzen die weiteren Elenente der Epidermis hervorgehen - hier aber nur diese.

Ueber die Häutungsvorgänge bei den Amphibien hätte ich hier noch cine ganze Anzahł interessanter Thatsachen mitzutheilen, da die Häntung einen Act der physiologischen Regeneration repräsentirt, jeh will mich jedoch auf das Nothwendigste beschränken, da man in früheren Arbeiten, besonders bei Bolau, Leydig und anch in meinem Aufsatze über Pleurodeles weitere Auslührungeu funden kann.

Die Häutung gelıt bei den im Wasser lebenden Amphibien sehr häufig vor sich, und zwar besonders oft, wenn die Thiere an Körpergrösse stark zunehmen, also in den Larvenstadien bei guter Fütterung ${ }^{2}$ ) oder bei Eintritt der Fortpflanzungsperiode, in welcher z. B. die Flossen-

") Entwicklungsgeschichte des Wellensittichs. Arheit an dem zool. Institut Wrürburg.

$\left.{ }^{2}\right)$ In Gegensatz hierzu liemerkt Mallrane: .Um von einem und rlemselben Triton die Nauseldnat ölter zu erhalten und zu controliren, braucht man ilım nur das Futter zu entziehen, bei dem liungernden Thiere gelit die Häutung öfter vor sich.“ Zeitsch. f. w. Zool. Bd. 26. p. 40. Anm. 
säume der Tritonen zu enormer Grösse heranwachsen und auch der Gesammthabitus des Thieres sich völlig verändert.

Abgestossen wird nur die vallständig verhornte Schicht der Epidermis, welcher ja auch als harter und starer, durchaus nicht delinbarer Ueberzug ein weiteres Wachst]ium der darunterliegenden Gewebe, wenn nicht verhindern so doch beschrïnken würde.

Bei den meisten Amphibien wird wohl nur eine cinzige Zelllage abgestossen, welche sich nur an besonderen liörpertheilen, besonders zur Bildung eigenthümlicher Organe, verdoppelt und verdreifacht.

Dies ist z. B. del. Fall bei denjenigen Theilen, dic als Begattungshilfsorgane von Braun, Latuste und anderen beschrieben sind. Bei Pleurodeles finden sich mach meinen Beobachtungen an der abgestossenen Haut der vorderen Extremitäten des Mämmchens folgende besonders auffallende Structurverluälnisse.

„Legt man eine solche abgestossene Hant einer vorderen Extremität mit der Aussenseile nach oben unter das Mik'oscop, so sieht man bei oberflïchlicher Einstellung eine scharf facettirte Hembran. Die einzelnen Facetten sind grau pigmentirt und ron einander durch breitere unpigmentirle Lagen getrenut, so dass das Bild eines groben Netzwerkes entstelot. Bei etwas tieferer Einstelhng erscheint ein zweites vicl feineres mpjigmentirtes Netzwerck, dessen Facelten aber nicht die des darüber gelegenen decken, sonderı dieselben ganz unregehnässig kreuzen.

Schon daturch wird der muthmassliche Zusammenhang beider illusorisch: deutlicher tritt die Trennumg auf Biddern, welche die Unschlagfalten bieten, hervor. Hier sieht man auf dem optischen Querschnitt, dass die mpigmentirten Stellen der oberen Membran Vertiefungen sind, welche die einzelnen Facetten rinnenförmig umgeben.

Betrachtet man die abgestossene Haut ron der iuneren Seite, so finciet man hier auf dem optischen Querschnitt ebenfalls Vorsprünge der zweiten Membran, die von oben gesehen Vertiefungen darstellen. würden. Es lassen sich sowohl in der unteren wie auch in der oberen Lage, in letzterer allerdings seltener, noch Reste ron Zellkernen erkennen, so dass man sagen kann, es sind hier zwei Schicliten ron Zellen abgestossen worden, eine pigmentirte und eine umpigmentirte.

Die Zellgrenzen sind sehr schwierig darzustellen, doch scheint es mir, als wenn die einzelnen Zellen jumer in den Vertiefungen endeten. Dic untere Membran geht in die gewöhnliche einschichtige abgestossene Zelllage über. Es finden sich demnach hier zwei Zelllagen über cinander abgestossen, von denen die äussere zum bessern Haften mit einel ganz besonderen Architehtonik versehen ist $\left.{ }^{1}\right) .6$

Del Process der Häutung selbst ist bei den Ampluibien ein sehr einfacher und ebenfalls auf rein mechanische Vorgünge zurückzuführen. Es werden durchaus keine besonderen Organe hierfür gebildel wie z. B. heim Flusskrebs und bei den Reptilien dic Häutungshärchen, es wirch

1) Das ron mir in del lläutung untersuchte Thier war ein Hïnnchen; es handelt sich bier also um die ron Lutaste in seinen Memoire sur les brosses copulatrices des batraciens anoures in Ann. sc. nat. 1s76 T. III, 6me série

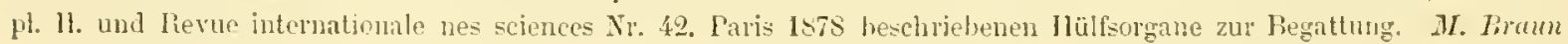
hat ähntiche Organe hei Triton virilescens gesehen. Zoolog. Anzeiger Isis, Nr. 6, pag. 125. 
dieselbe vielmehr hier eingeleitet durch eine ganz eigenthümliche Verklebung der obersten Zellschicht. Bereits pag. 61 habe ich auf die Wachsthumsverhältnisse der einfachen Amphibienhaut hingewiesen und erwähnt, dass ich nur die oberste Zelllage als völlig verhornt ansehe. Mlit dem Process der mehr und mehr um sich greifenden Verhornung geht bei den Zellen der oberen Sehichten eine seilliche Verklebung derselben Hand in Hant, so dass schliesslich die Zellen der obersten Lage nur noch im Zusammenlang isolirt werden können.

Der Häutungsprocess wird ganz einfich dadurch eingeleitet, dass die Zellen der näclisten Schicht nun ebenfalls stïrker verhornen, wodurch der Zusammenhang mit der immer starrer und bäıter werdenlen obersten Lage mehr und mehr gelockert wird, bis dicselle dann durch forgeselztes Wachsthum der unteren Schichten gespannt, an irgend cinel Stelle einreisst und nun von Thiere selbst als unbequener Mantel abgestreift und meistens auch gleich darauf verzehrt wird. -

Soviel über die Amphibienhaut und deren Regeneration geschrieben und bekannt ist, so wenis wissen wir über die Wiedererneuerung der Reptilienhaut.

Ueber dic jüngsten Regeneratioustadien ist sogar gar nichts bekannt und nur einige wenige ältere Autoren berichten über die Zahl und Stelhung der regenerinten Schuppen bei der Eidechse und-Blintschleiche; so zühlte Rankin ${ }^{1}$ ) die Schuppen des regenerirten Schwanzes bei Blindschleichen (vergl. par. 30) und find stets mehr, aber kleinere regenerirte Schuppen als au normalen Schwanze vorhauden waren.

Diese Vernachlässigung der Reptilienhaut ist übrigens leicht zu erklären, demn die crsten Anfänge der Regeneration sind der directen Beobachtung meistens durch einen dicken und spröden Schorf entzogen, so dass am lebenclen Material nichts, am conservirten nur selur sehwer genaue Untersuchungen genacht werden können.

Da diese Verhältuisse übrigens weniger allgemeines hteresse auclu fül unsere Abhandlung erwecken, so verweise ich auf die einschlügige Arbeit in der pathologisch-anatomischen Literatur, unter andern auf die letzte Darstellung ron Murcuse über Heilung unter dem Schorfe in der ,,deutsehen Zeilschrift für" Chirurgie"* und auf die betreffenden Lehrbücher, besonder's auf die höehst exact durchgeführten und geistreich interpretilten Untersuchungen ron Thiersch. ${ }^{2}$ )

„Es tritt hiernach zuerst regelmässig eine die Wundränder rerklebende Substanz auf. Dieselle erscheint schon wenige Stunden nach der Verinderung und erweist sich zunächst und bei genauer Untersuchung als das mit Blutkörperchen nud Serum stark infiltrirle und in lelzterem anfgequollene Bindegewebe der Wrunḍäche selbst. In zweiter Linie stellt sich dann die Auswanderung farbloser Blutkörperehen aus den stark erweilerten Gefässen der Nachbarsehaft ein. Die ganze Kiltsubstanz, sowie das anstossende Bindgewebe werden von ihnen durehselzt, so dass 7uletzt eine continuirliche Schicht embryonalen Bindegewebes die getremnten Theile vereinigt..3) Während

1) R. Runkin: on the structure and labits of the slowworm (Anguis frayilis) in Edinburght new philosophical Journal Vol. V. Kew Series 1857.

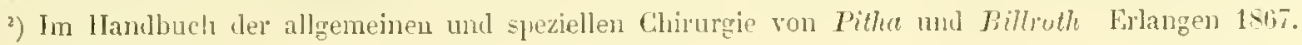

3) Rindleisch, lohrburch der pathologischen Gerrerluelehre, 5. Aullare. Ists 
wir bei clen Amphibien noch eine Art der Wundheilung vorfinden, welche der einfachen Verkłebung (die ja bei höheren Thieren, wemn anch schr selten, noch volkonmt) etwa zu rergleichen wäre, finden wir bei den Reptilien bereits einen Process, der an älınliche Vorgänge bei den Warmblütern erinmert. Was bewirkt nun diesen doch immcrhin bedeutenden Unterschied zwischen den beiden in Frage stehenden Thierklassen?

Die höhcre Differenzirung der Gewebe dürfte es kaum sein, ebensowenig die anders beschaffene Hautbedeckung, wohl aber wird ein bedeutender Einfluss den anders gestalteten Lebensbedingungon zugeschrieben werden müssen.

Wir sahen, dass die Heilung bei den Amphibien besonders dann rasche Fortschritte macht, wemn dieselben in frischem Wasser gelialten werden, dass das Landleben für den Regenerationsprozess ungünstigere Bedingungen mit sich loringt und dass die Wunden während des Landaul'enthałtes, wonn sie auch nicht mit einem Schorfe sich bedecken, doch schlechter und langsamer heilen wie in Wasser. Num sind aber die hier in Frage stehenden Reptilien die Eidechsen und Ascalaboten echte Landbewohner und hieraus folgt schon nach dem rorher Gesagten, dass die Mcilung langsamer und unter schwierigern Verhältuissen vol sich grchen muss, wie bei den Amphibien.

Wic wunderbar zweckmässig die Natur in allen Punkten arbeitet, sieht man auch hieraus wieder, denn, olne cin teleologisches Moment hincintragen zu wollen, der frische, blutende Sclıwanzstumpf, der gewiss fül ein so kleines Thier wie die Eidechse cine ganz bedeutende Wunde repräsentirt, wird nun geschützt gegen die Insulten der ungünstigen Umgebung durch einen harten und starren Schorl, unter dem die Heilung ungestört und unter glcichen Verhältnissen ror sich gehen kann, wie bei den im Wasser lebenden Amphibien.

Dass aber die Bildung des Schorfes eine rein mechanische ist, wird sofort daraus ersichtlich, dass derselbe eben nu aus rertrockneten Bhtzellen und weniger Lymphe, sowie vielleiclıt aus einzehnen abgestossenen Bindegewebselementen besteht.

In Wasser kann sich gar kein Schorf bilden, in del Luft wird or bei grösseren Munden und ohne Verband stets entstehen.

Der Selwwanzsumpf wird bei den Veränderungen, welche das Thier in der Freiheit ethält, niemals völlig glatt scin, sondern ausgezackt und zwar derartig, dass die einzelnen alogerissenen Muskelbündel l’ings etwas hervorstehen. Wie bereits erwïhnt, bricht der Eidechsenschwanz hauptsächlich in der Gegend des siebenten Schwanzwirbels leicht ab, an welchem sich der locus minoris resistentiae des Schwanzes befindet, da hier die Quertheilung der Schwanzwirbel beginnt.

Wir gehen also am besten von denjenigen Wunden ans, die sich an dieser Stelle befinden und die durch Zugo oder Druck entstanden sind, nicht aber durch dic glatte Schneide eines Messer's oder einer Scheere, da die Verbältnisse hierbei etwas anders sich gestalten. Am zweiten Tage trocknet del Stumpf gewöhnlich ab, das spärliche Blut vorschwindet, und num beginnt das letzte Segment sich zusammenzuzichen, wolurch der Stumpf hercits am vierten Tage stark konisch zugespitzt erscheint. 
Hierdureh wird die Wundfläche bedeutend rerkleinert und die Heilung bereits eingeleitet.

Etwa 9 Tage nach der Abnahme des Schwanzes fällt der Schorf ab und es erscheint nun der Stumpf mit einer glatten Flïche rersehen, schön rosenroth mit neugebildeten zartem Ejpithel, das vollstïndig durchscheinend ist, so dass man einen Theil der neugebildeten Blutgefïsse durch dasselbe beoluachten kann. Die obersten Zellen sind auch hier schon elwas verhornt, denn durch das Starrerwerden der obersten Lage wird eben der Schorf alogehoben.

Allmählich bildet sich nun ein kleiner liegel, der sich in demsellsen Maasse, in welchem el wächst, dunkler fürbt, bis er besonders bei Lacerta muralis fast schwarz geworden ist.

Die analomische Untersuchung eines derartigen Stadiums lehrt uns, dass die Epidermis hei einem ca. $3 \mathrm{~mm}$ langen Stumpfe noch hüchst einfach gebildet ist. Nan ist jedoch schon an denjenigen Stadien, welche kurz rol her noch rom Schorfe bedeckt waren, in Stande, eine Schleimund eine Hornschicht zu unterscheiden. Die Hornmetamorphose trift also sehr früh ein. In der uṇregehmässigsten Weise blittern sich nun bald die obersten Hornzellenschichten ab und werden abgestreift, ohne dass eine reguläre Häutung stattfïnde, während ron der Schleinschicht aus stets nene Zellen in die oberen Lagen gedrïngt werden.

Sehr auffallend ist der äusserst geringe Zusanmenbang zwischen Cutis und Epidermis, denn auf sonst rortrefflich erhaltenen Schnitten wird meistentheils die Epidermis in ihrer Lage rerschoben oder ganz abgehoben. Erst wenn die Bilkung der Schuppen beginnt, tritt eine festere Verbindung ein.

Trotzdem finden sich eine Anzahl von Elementen in der Ejpidemis, welche nur aus der Cutis in dieselbe eingewandert sein künnen, vor allem in grosser Henge Pigmentzellen, die entweder sternförnig und rerïstelt äusserst zierliche Bildungen darstellen oder als schwarze kiümpchen erscheinen. Da die Pigmentzellen auch bei den Reptilien ausserordentlich contractil sind, so sehe ich die letztere Form einfach als contrahirte Zelle an, besonders desshalb, reil Uebergänge zur Sternform mitunter vorhanden sind.

Die Epidermis der Jemidactyhus frenatus und anderer Ascalaboten zeigt die schönsten sternförmigen Pigmentzellen, bei den Eidechsen kommen mehr fadenförmige Ausläufer ror, wodureh an die gleichen Bildungen der Amphibien erinnert wird. Die Pigmentzellen oder Chromatophoren befinden sich jedoch nur im Bereich der Schleimschichl, zwischen den Hornzellen habe ich keine gefunden. Es ist demnach selır wahrseheinlich, dass bei den Reptilien ein ähnliches lymphatisches Canalnetz besteht wie bei den Amphibien, da auch Wanderzellen. wenn auch seltener, neben den Epidermiszellen gefunden werden.

Almählich erreicht die Hant eine gewisse Dicke. so dass S-10 Kerneilıen über einander liegen und num beginnt die Regeneration der Schuppen.

Nicht eine Pajille bildet nun, wie man erwarten könute, den ersten Anfang einer Scluuppe, sondern ein langer geschlossener Follikel, wie ich solche in Figur 1, Tafel III im Querschnitt ajogebildet habe. 
Im ganzen Lmkreis der Epidermis stülpen sich die Zellen der Schleimschiclit in bestimmten Abständen in die Cutis ein, welche in diesen Stadium noch sehr locker ist und embryonalen Cilıarakter trägt und bilden auf diese 17 cise lange solide Sträinge, die in gleicher Dislanz rerlaulen.

Die rreitere Entwickelung geht dann allerdings durch Bildung einer sich segmentweise zwischen je zwei Follikeh erhebenden Papille ror sich.

Hierdurch wird eine bedeutende Abweichung von der Bildung der embryonalen Schuppe documentirt, denn nach den neueren Beobachtern dieses Entwickelungsvorganges, besonders nach Kerbert ${ }^{1}$ ) wird das Entstehen der embryonalen Schuppe auf das primäre Herrorwachsen einer Cutispapille zurückgeführt, wie die erste Anlage der Haare und Federn.

Mir selbst gelang es leider nicht, Enbryonen ron Reptilien in diesen Stadium zu erbalten, alle in meinen Hünden befindlichen Embryonen waren für diese Untersuchung bereits zu alt, doch habe ich keinen Grund, an der Richtigkeit der Beobachtungen von herbert zu zweileln, da sie ja auch ron anderen Forschern lyereits bestätigt wurden und andererseits Argumente genug vorliegen, durch welche man eine andersartige Entwickelung der regenerirıen scluppe erklüren kants.

Würde die sielı regenerirende Schuppe in der embryonalen Art angelegt, so müsste ohne Zweifel eine noclı bedeutend grüssere Anzalhl von Schuppen ant dem regenerirten Schwanze auftreten, als dies ohnehin schon der Fall ist, denn die embryonalen Papillen stehen seh" dicht bei einander. Andererseits ist der embryonale Schwanz bedeutend kleiner und dünner als der regenerirte Theil eines exwachsenen Thieres, besonders an der Stelle, die wir hier im Auge haben und es stehen die einzelnen Schuppen an ihm in viel gleichmässigerem Verhältniss zu der Ausluildung der anderen Oloane. Würden nun die Schuppen an regenerirten Schwanze in derselben Weise nngelegt, so müsste sehr bald ein Missverlältniss zwischen diesen Bildungen und den übrigen Organen entslehen. So wird dem die regenerirte Schuppe, um einigermassen den nommalen Schuppen an Grösse und Geslalt in der kürzesten Zeit ähnlich zu werden, auf breiterer Basis angelegt und dies geschieht eben durch die Einsenkung mehrfacher langer Follikelrimnen zwiselıen denen dann segmentweise eine breite Cutispapille sich erhebt. So wird der Process der Bildung in gewisser Weise rereinfacht, denn die sonst secundär auftretenden Falten werden lier gleich primäl angelegt und dadurch der secundär anftretenden Cutispapille bereits eine bestimmte Grösse vorgeschrieben.

An dem Querschnitte eines Schwauzes von $3 \mathrm{~mm}$. Durchmesscr zïhlte ich 30 Einstülpungen.

Es seheint nir, als ob wir hier eins der treffichsten Beispicle der speziellen Anpassung (Anpassung sui generis) oder der functionelleu Anpassung vor uns hïtten. Vererbt ist jedenlalls die Anlage zur Schuppenbilung. neu angepasst iep abweichende Entrickelungsmodus dieser Organe.

Die weitere Ausbildung der Schuppe geht dann ron der Cutis aus, wie bei dem Embryo, weshahb bei den luetreffenden Capitel das Nühere milgelheilt werden soll.

Ton der Regeneration der Epidermis ist weiter nicht viel zu sagen. Sind die Schuppen zu bedeutender Grösse angewachsen, so dass sie den normalen fast gleichen, so schwindet all-

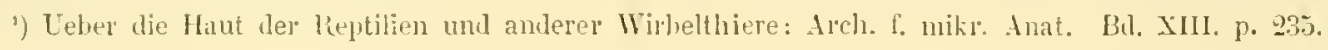


mählig das dunkle Pigment in der Epidermis, wie sich dassellye ja anch beim jungen Thier aus der normalen Epidermis langsam in die Cutis zurückzieht.

Wie beim Schwanze der Amphibien, kann man auch bein neugebildeten Reptilienschwanze. auf einer Schnittserie fast alle Entwickelungssladien der Haul studieren, da natürlicherweise die proximalen Stellen die älteren und vollendeleren, die distalen die jüngeren und meln embryonalen Verhältnisse zeigen werden. Es lassen sich denmach mit Ausnahme der allerjüngsten ziemlich alle Entwickelungsphasen an demselben Lüngsschnitte durch einen ca. Q cm. lang regenerirten Eidechsenschwanz verfolgen.

\section{Regeneration der Cutis.}

Ueber die Cutis, resp. die Entwickelung derselben, liegen fasl gar keine speziellen Arbeiten vor, es sind die Mittheilungen über dieselbe stets in die Abhandlungen über die Epidermis über' Haar, Feder, und Scluppenbildung etc. rerflochten. Trolzdem die Cutis oder das Corium aus einem anderen Keimblatte bei den Wirbelthieren entsteht, wie die Epidermis, trilt sie doch in eine so innige und unzertrennbare Verbindung nit dieser, dass eine Trennung auch bei embryologischen Arbeiten wenig gerechtfertigt erscheint. Dennoch habe ich gerade bei dieser Abhandlung über die Regeneration es als eine Nothwendigkeit empfunden, diese beiden, sonst so eng verknü]pten Organe zu trennen, denn es regeneriren sich dieselben nicht simultan, sondern succedan. Lange nachdem die Epidermis schon wieder einen dichten Veberzug über die rerletzten Gewelsstheile gebildet hat, differenzirt sich erst die Culis, bis dahin ist sie ron dem allgemeinen Bindegewebe weder bei Amphibien noch bei den Reptilien zu trennen.

Ich unterlasse es, hier eine lïngere Schilderung der normalen Gutis unserer 'Thiere zu geben, und rerweise desshalb auf die einschlïgigen Arbeiten besonders ron Leydiy und herberl; nur wenn die Gutis nicht wieder in der normalen Weise hergestellt wird durch den Regeneralionsprocess, werde ich auch auf die Structur der normalen Lederhaut näher eingehen müsscı.

Wie bereits erwähnt, wird die Cutis bedeutend späler differenzirt als die Epidernis, was eben seinen Grund darin lat, dass bei der Regeneration in ten jüngeren Stadien die Epidermis schneller und rollständiger sich neubildel wie die Cutis. Dies geschieht aber nach dem bekannten Grundsalze, dass Gewebe, deren Zusammenhang ein lockerer ist, deren einzelne Elemente also eine bedeutendere Selbstïndigkeit behallen, sich schneller and rollständiger regeneriren, wie Gewebe mit complicirteren Verschmelzungen.

Die Zellen der Epidermis stehen ja in einem gewissen Zusammenhange, sind aber nie derartig verschmolzen und metamorphosirt wie die Elemente der Cutis, die ja bei ausgewachsenen Thieren kaum noch embryonale Zellen enthält. So wird sich, wähnend die Epidermis sehon wieder voilständig neugebildet ist und den typischen Charakler trägt, an Stelle der Cutis erst ein zelliges Blastem bilden nüssen, aus dessen embryonalen Bindegewebszellen nun durch secundäre Wachsthumsvorgänge die Fasern, Fibrillen etc. der Cutis herrorgehen. 
Da die Cutis ausserordentlich rerschiedenartig gebaut ist, da neben den einfachsten auch die complicirtesten Structurverhältnisse sich vorfinden, so werden wir naturgenäss mit der Betrachtung der einfacheren beginnen. Diese finden sich nun eigenthümlicher Weise nicht bei den Amphibien, sondem bei einzelnen Reptilienformen. Die Cutis ron Hemidactylus und Phyllodactylus ist fast ganz aus zelligen Elementen zusanmengeselzt, welche wenig oder gar nicht mit einander verschmelzen.

So sagt Leydig' ${ }^{1}$ ) von der Cutis des Phyllodactylus europaeus: ,.Umgekehrt ist bei dem weichhäutigen Ph. eur. dieser Theil der Lederhaut (d. fibrilläre) sehr zurückgewichen, während das weiche, blasig-zellige Bindegewebe in weit grösserer Menge sich entwickelt hat."

Es ist hier im Schwanze eine Trennung der unter der Epidermis liegenden Bindegewebeschichten in Cutis und Unterhautzellgewebe nicht möglich, da man sich aber daran gewölnnt hat, die direct unter der Epidermis liegende Schicht, soweit sie sich mit der ersteren zusammen abheben lïsst, als Cutis zu bezeichnen, so wollen wil diesen Namen hier beibehalten.

Viel auffilliger wie bei Phyllodactylus europ. sind die Verhältnisse bei Hemidactylus frenatus und platyurus, da hier die blasige Cutis eine bedentende Stärke erreicht.

Bekanntlich besitzen die in Rede stehenden Hemidactylusarten einen dorsoventral comprimirten Schwanz, so dass der Quersehnitt die Gestalt einer Spindel erhält.

Diese eigentlü̈nliche breite Form des Schwanzes wird hauptsïchlich durch seitliche Wucherung der Cutis hervorgerufen, denn Muskulatur und Skelet werden nur sehr wenig comprimirt. Dicht unter der Epidermis liegt nun ein ganz dünnel Streifen fibritlären Bindegewebes, woranf eine blasige Zellmasse folgt, die etwa wie leere Fettzellen aussehen und dann abermals eine fibrilläre Schicht die der Muskułatur, dem Nuskelschlauche, wie man sich hier auscirücken könnte. dicht anliegt. Die blasige Zeltschicht ist an der Ventral- und Cardialflïche sehr düm, an den Seiten sehr stark entwickelt. Zellkerne kann man in ihr au normalen Schwanze nicht nachweisen.

Sehr interessant sind nun die Verhältnisse an regenerirten Schwanze, denn bei jüngeren Stadien lässt sich deutlich erkennen, dass die Cutis hier wilklich aus einer grossen Anzahl blasiger Zełlen besteht, die mit Kernen versehen sind und bald eine ausserordentlich starke Zellhaut absondern.

Die ohersten Schichten werden wie die dem Muskelschlauch anliegenden jedoch nicht in dieser Weise erhalten, sondern es bildet sich an diesen Stellen ein wenig fibrilläres Gewebes aus.

Ich habe versucht, diese Verhältnisse in Fig. 6 Taf. 1 darzustellen, es sind jedoch die Kerne in Wirkichkeit dentlicher als sie dort der Zeichner angegeben.

Der regenerirte Schwanz von Hemidactylus frenatus, durch dessen mitteren Theil etwa der Schnitt gelegt ist, wal ron ziemlich bedeutender Länge (ca. $3 \mathrm{~cm}$ ) und an der Schnittstelle $7 \mathrm{~mm}$ breit, wir haben es also mit einem ziemlich ausgewachsenen Schwanze zu thun.

Sogleich in die Augen fallend ist die Aehnlichkeit der Cutiszellen mit den Fettzellen, welche im Imnern des Muskelschlauches die Knorpelröhre umgeben, und es handelt sich wahr-

1) Ceber die allgen. Bedeckungen der Amphibien. Arch f. mik. Anat. Bd. XII. p. 223. 
seheinlieh anch nm eine Fetmetamorphose in diesen Zellen, obgleieh dieselbe später eintritt, als bei dem imneren Fettkörper.

Zwischen den blasigen Zellen, deren Inhalt dureh die Behandlungsweise mit Alkohol, Terpentinöl ete. längst ausgezogen ist, liegen nun einzelne Fasern und mehrfach kleine Blutgefässe, die ein, wie es seheint, ziemlich unfangreiches Capillametz naeh den oberen Schiehten der Cutis senden. Von Nerven konnte ieh dagegen in der Cutis nichts erkennen. Die jüngsten Stadien standen mir von Ilemidactylus leider nicht zur Verfügung, doch kam man anelı bei diesem Object beliebig jüngere wie ältere Entwickelungsstufen erhalten, indem man entweder Längssehnitte dureh den regenerirten Schwanz anfertigt oder eine Querschnittserie. Einige Zellen aus dem Fettgewebe der Cutis habe ich Fig. 17. Taf. III. abgebildet. Das Protoplasma ist fast ganz geschwunden und der Kern an die Zellwand gedrängt worden, nur selten sielıt man den Kern noch in der Uitte der Zelle dureh Protoplasmastränge mit der Zellwand verlunden. Da mir lebendes Material nicht zur Verfügung stand, so kann ich leider nicht mit Bestimmtheit behaupten, dass in diesen blasigen Zellen der Cutis eine F'ettmetamorphose stattindet, die Wahrseheinlichkeit spricht jedoch dafiur, denn erstens sind diese Zellen später nicht zu unterscheiden von den das Knnorpelrohr umgebenden Zellen und zweitens ist der Kern hier wie dort in älteren Stadien an die Zellwand gedrizckt worden, ein Zeichen, dass eine Protoplasmametamorphose stattgefunden hat. Sehr wohl könnte man auch an eine Metamorphose in Zcllwasser denken, allein da bei den ïbrigen Asealaboten und Eideehsen ein riehtiger Fettkörper im Sehwanze vorhanden und $n \mathrm{~m}$ die Wirbelsäule herumgelagert ist, sn werden bei Hemidaetylus die Verhältnisse wahrseheinlich ähnliche sein.

Bei Phyllodactylus findet sieh weder beim normalen noch beim regenerirten sehwanze Fett in der Cntis, hier nimmt der Kern in grossen blasigen Zellen meistens die Mitte ein, während das Protoplasma selbst äusserst durehsichtig und schwer zu fürben ist.

Auffallend ist bei Ph. eur. der grosse Reichthum an Blutgefïssen in der Cutis in verhältnissmässig noch jungen Regenerationsstadien. Die erste Bildung der Schuppe gebt wie bei den Eideehsen durch eine Einstiilpung der Epidermiszellen vor sich, wïhrend das Pigment ein fein rerzweigtes eontinuirliches Netzwerk in der Cutis bildet, welehes zuweilen in die Schleinsehicht der Epidermis hinïber zieht. Die grossen braunen Pigmentzellen des normalen Schwanzes fehlen in diesem Stadium nneh vollständig. Im normalen Sehwanze des Platydactylus facetamus findet wahrscheinlieh bereits eine Fetmetamorphose in den blasigen Zellen der Cutis statt; die Kene fehlen oder sind wandstïndig und der lest des bildungsfähigen Protoplasmas ist sehr gering. Im Ganzen sind die Verhältnisse denen sehr ähnlich, die wir bei Hemidactylus vonfanden, nur ist die obere fibrilläre Schicht sehr dicht und innerhalb derselben finden sich die bekannten Knochenkugehn, die als Rudimente der bei Anguis und anderen Reptilien vorkommenden Knochenschrppen gedeutet werden kïmen.

Bei Platydaetylus verus ist im Gegensatz zu den iibrigen Ascalaboten die blasige Sehicht sehr schmal, dagegen sind die tibrillären Lagen sehr stark ansgebillet unł melıfache Verbindungsstränge ziehen sich zwischen den beiden primären Schichten hin, besmders ansgebildet an deu Einsenkungen der Schuppen. Bei beiden Thieren tritt nu im regenerirten Schwanze das blasige Gewebe sehr hinter dem fibrillären zurïck, so dass im Gegensatz zu Hemidactylus die Cutis krïftiger und widerstantsfähiger wird dureh den bedentenderen Unfang der Faserziige. Dafür fehlen aber 
anch noch in den ältesten regenerirten Schwänzen die normalen Kunchenkugehn: es scheint mir, als wenn dieselben bei den genannten Geckonen iiberhaupt nicht regenerirt wiirden.

Die Anordnung der normalen Cntis bei Lacerta und Anguis ist besonders von Leydig und Kerbert in mustergiiltiger. Weise geschildert worden, ich brauche deshalb nur anf die betreffenden Arbeiten zu verweisen. Die Regeneration geht in den ersten Stadien in gleicher Weise ror sich, wie bei den Ascalaboten und, wie wir später schen werden, anch bei den Amplibien.

In der ersten Zeit ist, wie bereits erwähnt, die Cutis durchaus noch nicht von dem allgemeinen Bindegewebe zu trenncn, selbst wenn die erste Bildung der Schuppen durch Einstiilpung beginnt, kann man von einer Differenzirung in der Lederhant noch nichts erkennen.

Jetzt erst erhebt sich in der Mitte zwischen zwei Schuppenturchen eine kleine Papille, an deren beiden Seiten sich blasige Zellen ansammeln. Vielfache Ausläufer der Zellen des Rete Malpighii ragen in dieses Blastem himein, in welchem sich ausser wenigen Pigmentzellen eine Menge von IVauderzellen nachweisen lassen.

Allmählig wächst die Papille nun und treibt die Epidermis papillenartig auf, jedoch nie in gerader Richtung, sondern mit sofortiger Biegung nach hinten. Das spongiöse Gewebe wuchert sehr stark, es bilden sich massenhafte Ansammlungen ron Pigment, besonders in den Spitzen der Schuppen und zwischen dem lockeren Gewebe legen sich eine grosse Anzahl ron Blutgefïssen an. (rergl. Taf. III, Fig. 2). Damit ist wiedermm ein bedentender Unterschied zwischen dem Wachsthum der normalen und der Bildung der regenerirten Schuppe documentirt.

Wihluend die embryonale Schuppe zuerst radiär symmetriseh nach aussen wảchst, wird die breite Cutispapille der regenerirten Schuppe sogleich in der Richtung angelegt, in welcher die Schuppe im späteren Entwickelungsstadium sich ansdehnt. Die regenerirte Schuppe wächst von Anfang an bilateral-symmetrisch und die Cutispapille derselben ist nach hinten gebogen. Auch hierdurch wird, wie leicht verständlich, eine bedeutende Abkiurzung des Bildungsvorganges bewirkt.

Das fibrilläre Gewebe ist bei Lacerta besonders in den unteren Lagen sehr stark: wegen der normalen Entwickelung derselben rerweise ich auf die vorzügliche Arbeit von Boll, deren Ergebnisse ich bei der Vergleichung zu Grunde lege. ${ }^{1}$ ) Die Entwickelung des Bindgewebes der Cutis wird speziell ron Kusnetzoff'?) behandelt, welcher die ron Schwann und MI. Schultze anfgestellten Theorien etwas modificirt, jedoch durch Boll widerlegt wird.

Anch bei der Regeneration verlaufen die Entrickelungsphasen in fast gleicher Weise wie beim Embryo.

Wir finden zuerst cin zelliges Blastem, dessen einzelne Zellen protoplasmareich und hiülenlos so dicht gedrängt stehen, dass sie miteinander zu verschmelzen scheinen. Die Kerne dieser Zellen sind länglich und mit der schmalen Achse zur Längsachse des Schwanzes senkrecht gestellt. Ans diesem Blastem entrickelt sich nun nicht nur dic Cutis mit ihren blasigen Zellen und den Fibrillen, sondern, wie wir später schen werden, noch eine ganze Anzalıl von anderen Geweben.

Nun sondert sich die obere, der Epidermis zunächst liegende Schicht rom ülırigen Blastem ab, dadurch, dass die Zellen derselben sich vergrössern und dentlichere Wandungen zeigen, während

1) Untersuchungen über den Bau und die Entwickelung der Gewebe 1. Arch. f. mikr. Anat. Bd. 7, p. 276, Taf. 15-17 und 2. dasselbe Arch. Bd. 8, p. 28, Taf. II.

^) Beitrag zur Entwickelungsgeschichte der Cutis. Wiener acad. Sitzungsber. LVJ. I867. 
die nun folgenden Zellen dureh Bildung von vieltaehen Ausläufern die Fibrillen und Fibrillenbündel lieferu. Auch bei den Reptilien scheint es mir, als wenn aus einer Zelle viele Fibrillen hervorgingen, da man oft sternförmige Zellen in der Cutis beobachtet, welche ihre Ausläufer naeh allen Riehtungen hin versenden.

Zwischen den Fibrillenbïndeh bleiben dan einzelne Zellen als Bindegewebskürperehen oder Zellplatten zuriick. Eiu bedentender Unterschied zwischen diesem Bildungsvorgange und der embryonalen Entwiekelung tindet also nicht statt, wenn ieh anch behaupten möehte, dass imnerhalb des regenerirten fibrillären Gewebes sieh wenigstens in der ersten Zeit melı Embryonalzellen erhalten, als in dem normalen. Sehr wiehtig sind die zwisehen den Fibrillen sich erhaltenden Embryonalzellen, die dann in keinem Falle vorher Fibrillen gebildet haben, für die Regeneration der Knochenplatten in der Cutis von Anguis fragilis, Senira bieolor ete., dem sie sind es, welche sich zu Osteoblasten umbilden und aus denen also die Kunohenkörperchen der späteren Knochensehuppe werden.

Für die normale Bilchng rler Fautknochen liegen so gut wie gar keine speciellen beobaehtumgen vor, nur Kerbert gibt pag. 225 cine kurze Darstchung ihres gröberen anatomischen Baues. „Das Bindegewebe umhiillt nicht nur die Knochenschuppen rollkommen, es steht auch das der oberen Seite mit dem der unteren seite in Verbindung und zwar durch die sogenannten Ifarkkanäle oder Havers'sehen Kanäle. Die Kanäle dienen zur Emährung, sie belıerbergen daher die Blutgefässe, welche damn weiter von Bindegewebe nielıt blos, sondern auch von Nerven und Pigment begleitet werden künnen." Die Zahl dieser Kanäle is: jedoeh sehr versehieden, bei Pseudopus liegt sogar eine Art spongiösen Knochens ïber einer als Substanzia dura bezeiehneten sehicht.

Ueber die histogenetisehe Entwiekelung ertalmen wir leider weiter nichts; ich denke jedoch, dass embryonale und regenerative Verhältnisse hier im wesentliehen übereinstimmen werden.

Die Osteoblasten bilden sich wie hereits erwiihnt, aus Embryonalzellen herans und behalten lange Zeit ihren Charakter als lebensfähige, protoplasmareiche Zellen. In den ersten Stadien der Verknöcherung sind sie häufiger, allmählig jedoch scheint ein grosser Theil derselben entweder resorbirt zu werden oder direet in die Knochensubstanz überzugehen, wodurch die von Waldeger ${ }^{1}$ ) vertretene Ansicht iiber die Knochenbildung eine weitere Stiitze erhielte. Wie die Enbryonalzellen sich zu Osteoblasten umbilden, konnte ich nicht genan beobachten, genug, in Bercieh der späteren Knochemplatte treten gleichzeitig eine ganze Anzahl derselben anf, indem die Verkalkung sofort um dieselben beginnt. Die Ansläufer der Knochenkörperehen sind ron Anfang an selı kurz und in geringer Anzahl vorhanden, spätes sthwinden sie fast ganz, so dass die llautknochen bei Anguis in späteren stadien äusserst lomogen und eonsistent erseheinen. Die llarkräume seheinen sich von der oberen Partie der Cntis abzuschniuren, wodurch anch das massenhafte Vorkmmen von P'igmentzellen in denselben erklärt wird. Die Osteoklasten oder Myeloplaxen besitzen cine ganz belentende Anzahl von Kernen und sind wohl 12 mal griossel wie die Knochenkürperehen.

Die Schuppentasche bestelıt aus fibrillärem Gewebe, das keine Verkalkung erkennen lässt, clagegen ausserordentlich stark und widerstandstähig ist.

1) Ueber den Ossificationsprocess $\unlhd$ ırch, f. mikr. Anat. I. p. 3504.1865 und: Untersuchungen über die Entwickelung der Zähne. 2. Abh. Ztsch. f. rationelle Melizin. III. Reihe. Bd XTIV. p. 169. 
Uelurgens sind die regenerirten Knochensehuppen bei Anguis zuerst durchaus nielit regelmässig angelegt, es scheint vielmehr, als wenn die ganze nittlere Partie der Cutis urspriunglieh verknöcherte und dass die spaitere Regelmässigkeit erst dureh die Thätigkeit der Mýloplaxen hergestellt wïrde. Diese Resorptionserscheinungen sind jedoch am conservirten Material so ausserordentlich sehwierig zu beobachten, dass ieh es für nothwendig erachte, über dieselben noch genauere Studien anzustellen und an anderem Orte dariiber zu berichten.

Bei den Geckotiden, welehe normalerweise die bekannten Knochenkiigelehen in der Cutis fiiluren, konnte ich auch an älteren regenerirten Schwänzen eine Regeneration derselben nicht Jeobachten. Wie bereits erwihnt, wird hier nur die fibrilläre Lage der Cutis ansserordentlich derb und zeigt jene feine lockige Anordnung, die in fibrillären Bindegewebe der hüheren Thiere so liäufig auftritt.

Während bei den Reptilien die geschilderten Verhältnisse recht unangenehm und schwer zu beolsachten sind wegen der Kleinheit der Gewebselemente, lïsst sich bei den Amphibien aueh der Regenerationsprozess der Cutis leiehter rerfolgen. Die normale Entwickelung der Cutis der Amphibien wurde von mehreren Forsehern in grindliehster Weise untersucht. Die Arbeit von Eberth ') soll mir bei der Tergleichmg der regenerativen Vorgänge mit del normalen Bildung als Grundlage dienen, wenn wir die correct beschriebenen Thatsachen heute auch zum Theil anders deuten müssen. Aus Elerth's Darstellung entnehme ich Folgendes: „Der flossenartige Schwanz junger Froselılarven bestelit in der ersten Zeit aus einer zelligen Achse und einer homogenen, gallertigen, dieselbe deckenden Platte mit ilnèm Epithel. Diese homogene Substanz ist nach Hensen anfangs zellenlos, aber der äusserste Saum derselben ist immer homogen, wemn anch später in der Peripherie des Sehwanzes Zellen auftreten. Da die erste Bildung dieser Gallerte ohne Vermittelung in derselben eingeschlossener Zellen erfolgt, ist sie wohl nach Hensen als ein von der Epidernis geliefertes Secret zu betrachten, in welches von der zelligen Achse des Sehwanzes Zellen einwandern. Etwas abweiehend ist die Ansicht Remak's, naeh weleher die Gallerte mehr ein Secret der zelligen Elemente der Achse wïre. Diese homogene Substanz verdichtet sich nach Remali an der Oberfläche nicht nur an Schwanze, sondern am ganzen Körper zu einer festeren, glashellen Membran, die jedoch Hensen niclıt als eine für sich bestehende anffassen kann, da ihm die Isolirung nie gelungen ist." Eberth vermutlet, dass Hensen nur ganz junge Larven untersuchte, bei denen allerdings der" Saum noeh sehr zart ist, „später ist, wenigstens bei Bombinator igneus dieser homogene Saum als eine ziemlich feste Membran in kleinen Stiicken zu isoliren"... .

Die Bezeichnung derselben als homogene oder glashelle Membran ist jedoch nur fur die früheste Larvenperiode zulässig, indem die betreffende Selicht, wie das schon längst bekannt ist, später Quer- und Lïngsstreifen erhält, die Remali als Andeutung der mit Kernen besetzten einander durchkreuzenden Bindegewebsbïndel betrachtet, welehe im entwickelten Zustande den derberen Hauptbestandtheil der Cutis bilden und wie der genannte Embryologe rermuthet, aus ciner Verschmelzung der Zellen hervorgehen“.... „Die besprochene Sehieht ist in der That die junge Cutis, und es ist merkwiirdig, wie aus ilur, die anfangs ganz zellenlos ist, später die zellenreiche

1) Zur Entwickelung der Gewebe im Schwanze der Froschlarven. Arch. f. milir. Anat. Bd. IJ, 1866. p. 490. Taf. XXIV. Fig. 1 und 2 und Taf. XXV. Fig. 1-2, 7-25. 
Cutis sich entwickelt".... „Bei jungen Larven besteht diese Schicht aus feinen, steifen, unter rechtem Winkel sich kreuzenden Fasern, wie man diese leicht an Rissstellen sieht. Die ganze Lamelle gleicht einem Gitterwerk mit selı feinen puntförmigen Liicken. Nirgends trifit man um diese Zeit kernhaltiges Protoplasma in derselben, wohl aber zahlreiche feine Protoplasmafäden, die als Ansläufer der darunter gelegenen Zellen senkrecht die Cutis durehsetzen und bei Flächenansichten als feine Punkte erscheinen. Da diese Protoplasmafïden meist in Reihen gruppirt sind, die siel mit einander verbinden, entsteht an der Oberfläche clas Bild eines feinen, durel Punkte angedeuteten Mosaiks."... "Verfolgt man die Entwickelung der" Cutis bis zum Schluss der Larvenperiode und dariber hinaus, so sieht man, dass die feiren, staren, sie zusammensetzenden Fasern sieh leieht kräuseln, mehr das Ansehen lockiger Bindegewebsfibrillen annehmen und sich zu feineren und gröberen Bündeh ordnen, wïhrend zugleich die Zwischenräume sieh vergrössern. In die erweiterten Liicken schiebt sich fon den untenliegenden Zellen Protoplasma vor, welches da und dort sehon Kene führt. Diese Protoplasmaklumpen bilden rundlielıe und längliche mit Ausläufern versehene Zellen - die jungen Bindegewebszellen der Cutis."

Unmittelbar unter der Cutis ier Froschlaren findet sich ein Netz mit einander verbundener Spindelzellen, die bahl neben dem Kém wasserhelle Bläschen, bald Pigment führen. Dieses Gitter steht in einer besonderen beziehung zu den Hautnerven. Innerhall, des homogenen Saunes komnte E. keine Nerven entdecken.

In diesen Darstelhngen begegnen wir, wie bereits erwïhnt, einigen veralteten Anschauungen. Wir werden heute natiolich den homogenen Saum der embryonalen Cutis nicht als ein Secret der Epidermiszellen sondern mit Remak als Secret der zelligen Elemente der Achse ansehen. Die dureh die Beobachtung ron Eberth dargestellten Thatsachen bleiben hierdurch umberihhrt und sind, wie ich mich an eigenen Präparaten abcrzengen kann, wohl anch zweifelsolne richtig.

In der normalen Cutis von Proteus unterscheiden wir nach Bugnion 3 Lagen; eine obere compacte, die nur unterbrochen ist durch die aus ihr aufsteigenden Bindegewebsbündel und allein das Pigment führt bei Exemplaren, welehe in der Gefangenschaft schleeht vor dem Lichte behütet wurden. Die mittlere Schicht ist die dickste, sie besitzt Lagen von verticalen und sehrägen Fasern, welche die ubere nit der unteren compacten Schicht verbinden und zwischen sieh grosse durch ein gallertiges Gewebe ausgefillte Lacunen lassen. Man bemerlit in diesen wellige Fasem und helle Zellen, welche sich zu sehr zarten Filamenten vereinigen, und so ein Netz von ausserordentlieher' Feinheit bilden. In dieser Schicht befinden sich die Hautdriisen, welche grossentheils von Gefässen und Nerven der Haut begleitet werden. Ilure Dieke variirt sehr; an gewissen Regionen des Körpers verschwindet sie fast vollständig und die beiden compacten änsseren Schichten nähern sich einander so, dass zwisehen ihnen kaum ein Raum für die Hautdriisen übrig bleibt. Die untere compacte Selicht ist gebildet ron horizontalen Fibrillen, die eine venig regulüre Gestalt besitzen; unterhalb derselben liegt das Unterhautzellgewebe, (paniculus adiposus), welehes mitunter grössere Dimensionen einnimmt, als Epidermis und Cutis zusammen, und das selbst bei Individnen, welche mehrere Monate gefastet haben. Bei in Alkohol conservirten Exemplaren versehwindet das Fett, und es bleilst an dessen Stelle ein Gewebe, welches Alveolen won rantenfïmiger Gestalt erkemnen lässt.

Nach Leyclig hat die Haut der Kanlquappe an Stelle der mittleren Schicht des erwachsenen 
Frosches eine schlaffe und gelatinöse Schicht. ${ }^{1 j}$ Oberflächlich liegt wie beim Protets, der längere Zeit in Gefangenschaft gelebt hat, ein \etz von verzweigten Pigmentzellen, aber die Ausdehnung ler oberen schicht ist viel geringer, als bei letzterem. Papillen existiren nicht.

Bei der Regeneration der Cutis von Proteus sehen wir nur diese 3 Sehichten wiederum entstehen, und zwar gehen die feineren Verhältnisse bei der Bildung der Fibrillen in der Art vor sich, lass zuerst bestimmte Lagen von Bindegewebszellen näher zusammenricken. In den allerersten Stadien finden wir auf den Querschnitt ein Bild, wie ich es in Taf. III Fig. 14 f. Bg. dargestellt habe. Die Epidermis busteht aus vollstänlig gleichmässigen Zellen; die Cutis aus einem ebenso gleichmässigen Blastem, in welehem keinerlei Differencirungen zu erkennen sind.

Nicht wie in der Beschreibung der embryonalen Entwickelung dargestellt wurde, geht die Neubildung der Cutis bei erwachsenen Amplibien vor sich, sondern in ähnlicher Weise, wie bei den Reptilien. Selhst bei den Larven tinclet eine Regeneration des homogenen Gallertgewebes nicht statt, es tritt vielmchr an Stelle desselben, wie bei den erwachsenen Amphibien, ein Blastem von dichtgedräingt stehenden embryonalen Bindegewelszellen, Zellen, die denen seh» ähnlich sind, welche beim Embryo die Achse des Śchwanzes zusammensetzen. Ausnahmen tinden allerdings hierbei ebentalls statt. Wie bereits erwähnt bildet sich in einem sehr frühen Stadium der Regeneration des Froschschwanzes an Ende desselben ein knopfartiges Gebilde, das rollstindig hohl ist. Hier fehlt die Cutis noch gainzlich wenn man nicht die wenigen Embryonalzellen, welehe in der lymphartigen Fliissigkeit cliescs Hohlraumes flottiren, als erste Cutiszellen ansehen will. Erst allmählich wird das nene Blastem auch in diese Kugel hineintreten und nun nach und nach an den älteren Stellen eine Unwandlung in Fibrillen etc. vor sich gehten. Die Neubildung der stärkeren Faserzüge des Bindegewebes ler Cutis lïsst sich an besten bei Proteus studiren, weil hier wie eljen aus der Bugnion'schen Arbeit erwähnt wurde, ein isolirter Fibrillenstrang in einiger Entfernung von der Epidermis auftritt, und weil bei diesen Thiere die Chromatophoren nicht so störend wirken, wie bei den anderen Amphibien. Auch bei dieser. Untersuchnng hatte ich wiedel'um Gelegenheit, die Boll'schen Befinde zu bestätigen; es kommen die Fibrillen nur dureh die Umwandlung von Zellen zu Stande, nicht etwa durch die Umlagerung der Moleküle der Grundsubstanz. Ueberhaupt wird die Ansicht, dass das fibrillïre Gewebe dureh Umwandhung der Grundsubstanz entstehe, wohl mehr mud melur verlassen werden, obgleich ein so bedentender Vertreter der Histologic wie Ranvier, bestrebt ist aut alle mögliche Weise diese Theorie zu stiitzen; hat doch fïr die wirbellosen Thiere Brock nenerdings die Entstehung der Fibrillen bei dem Bindegewele der Mollusken aus Bindegewebskörperchen naehguriesen. Es seheint mir, als ob Runvier sich durch Kunstprodukte vielfach hat täuschen lassen. Ieh glaube aut die Entwickelung der Fibrillen nicht näher eingehen zu miissen und will nur mittheilen, dass an einem ziemlich vollständig regenerirten Schwanze von Proteus am oberen und unteren Flossensaum die Fibrillen aufhören, und dass an ihre Stelle Zellen treten, die zuerst mit einen oder vielen Ausläufern versehen sind, bis sie zuletzt den Charakter rollständig embryonaler Zellen tragen. Auch die Basalmembran der Epidermis ist aus Zellen entstanden, die sich am oberen und unteren Theil noch vorfinden, in der Mitte jedoch verschwinden, da sie vollständig mit einander verschmelzen. In diesen Zellen verändern sich die Kerne allmählig: sie werden mit der Zelle länger

1) Leydig: Nora acta Leopold. Carol. 1868. p. 44. 
und sehlanker, und gehen zum grössten Theil zuletzt zu Grunde, wenn die Fibrillen- und Membranenbildung die höchste Stufe erreicht hat. Dazwischen bleiben jedoch stets mehrere Zellen mit embryonalem Charakter bestehen, die sogenannten Bindegewebskörperchen, deren Funktion mir eine complicirtere zn sein scheint, als bisher angenommen wurde. Dureh die Beobachtung regenerirter Theile wird man unwillkürlich darauf hingeführt, diese Bindegewebsküperchen als diejenigen Elemente anzusehen, aus denen eventuell bei Verletzungen oder beim unbrauchbar werden einzelner Faserzüge nene Fibrillen sich bilden. Wahrseheinlich kommt ilmen daneben auch eine ernährende Funktion zu.

Ueber die Bildung der Pigmentzellen besitzen wir die ausführlichen Untersuchungen von Bruch ${ }^{1}$, welcher die versehiedenartige Form, in weleher die Pigmentzellen im thierisehen Körper anftreten, genauer studirte. Wichtiger für unsere Untersuchungen sind die Beobachtungen, welche von Kerbert bei Reptilien gemacht worden sind 2), da dersellye die Einwanderung farbloser, "stark liehtbrechender" Elemente aus der Cutis in die Epidermis nachweisen konnte. Erst in der Epidermis metamorphosiren diese Zellen ihren Inhalt danı derart, dass sie zu Pigmentzellen werden, und wandern später in einem bestimmten Stadium der Embryonalentwickelung aus der Epidermis in die Cutis zuriick. Bei der Regeneration findet man nun ähnliche Verhältnisse in einem sehr fribhen Stadium auftreten; man sieht helle Bindegewebszellen an Samm in der Epidermis hinwandern, sie in die Epidermis eindringen und dort zu Pigmentzellen werden. Aber nicht blos hier, sondern auch in dem gesammten Unterhantzellgewebe tinden sich derartige Umwandhungen von Bindegewebszellen in l'igmentzellen und es kann meiner Beobachtung nach jede nuch nicht fixirte Bindegewebszelle ebenso zur Pigmentzelle werden, wie sie zur Fettzelle werden kann. Aber während die Fettzellen gewöhnlich ein besonderes fixes Gewebe bilden, welches ron Told sogar als Fettgewebe oder als besonderer Fettköper der Wirbethiere angesprochen wurde, bilden die Pigmentzellen niemals einen bestimmten Plexus, sondern wandern, ähnlich wie die Leukocyten umher, bald hier, bald dort sich anhäiffend, bis sie dam später allerdings zu bestimmten Netzen sich zusammenlegen, um die typischen Farbenerseheinumgen der Haut hervorzurufen. Oftmals lagern sich mehrere Schichten ïber einander, und zwar versehieden gefürbte, wie dies vom Frosch schon lange bekannt ist; es werden dann, durch die den Zellen selbst innewohnende Contractilitit und höehst wahrseheinlich chu'ch besondere Innervationscentren veranlasst, die versehiedenen Färbungen der äusseren Haut hervorgebracht. Dem das Pigment ist nicht in allen Theilen gleichartig, sondern wir haben bei den Amphibien ror allen Dingen ein gelbliches, und ein, dunkelbrames oder schwarzes Pigment zu unterscheiden, und zwar liegen die helleren Zellen iiber den dunkleren. Somit werlen, wemn sich die hellen Zellen contrahiren, die dunkleren Töne der darunter gelegenen sehwarzen Zellen die Ueberhand gewinnon und das ganze Thier dunkler erscheinen: anch wird durch die Misehung der beiden Farben das bekannte Grỉn und Braun der Frösche hervorgerufen. Die schönen Zeichnungen, welehe den erwachsenen Salamander auszeichnen, rühren davon her, dass die gelben Pigmentzellen sich beim erwachsenen Thicr auch noch in der Epidernis betinden an denjenigen Stellen, an

1) Untersnchungen zur Kenntniss des körnigen Pigmentes der Wirbelthiere in physiologiseber und pathologischer Hinsicht vou Karl Bruch. Zürich 1814.

2) Archiv f. mikr. Anat. Bd. XIII. pag. 213 ff. Taf. 18-20. 
welchen die gelben Flecke wahrzunehmen sind ${ }^{1}$ ), so dass hier ein Durchscheinen des sehwarzen Pigmentes unmöglich wird. Uebrigens scheinen auch die dunklen Pigmentzellen bei weitem leichtel' contractil zu sein, als die gelben; man sieht bei conservirten Präparaten diese noch völlig ausgebreitet, während sich die dunklen zu einfachen Flecken zusammengezogen haben. Dass sich l'igment auch in den Epidermiszellen selbst vorfindet, wurde zuerst von Leydig bei Menopoma nachgewiesen und zwar fand derselbe, dass es siclı hier hauptsächlich ${ }_{1}$ in den Kermen anhänft; dann machte Schöbl dieselbe Beobachtung bei der Fhughant der Fledermäuse und ich fand, bei Plenrodeles, dass die Hauthöckerchen, welche zerstrent in der Epidemis sich vorfinden, anch dureh die I'igmentinung der Kerne eine dumklere Farbe crhalten. Hier ist das Pigment kein körniges, sondern ein diffuses; durch die liegenerationserscheinumgen werden wir jedoch daranf hingeführt, dass das diffuse Pigment aus dem körnigen entsteht, wahrscheinlich dadurch, dass die Körnchen mit der Zeit eine minimale Grösse annehmen, die durch unsere hentigen Hilfsmittel nicht mehr aufgelöst werden kann. Wodureh die verschiedene Färbung der Pigmentkürnchen in den verschiedenen Zellen bedingt wird, wage ich nicht zu cntscheiden; es scheinen hier bestimmte Vererbungserscheinungen in Kraft zu treten, die jedoch so schwer zu definiren sind, dass wir es lieber einer späteren Zeit vorbchalten wollen, hierauf näher cinzugehen. Jedenfalls ist das in der Epidermis der Eidechsen auftretende Pigment stets dunkelbraun bis schwarz, und es ist kein Unterschied in der Färbung zwischen diesem und den am Ende des Embryonallebens in der Cutis vorhandenen Pigmentzellen zu entdecken. Auch auf die Bildung der Pigmentzellen in der Epidermis md das Vorhandensein derselben in der Epidermis zeitlebens habe ich bereits a. a. O. aufmerksam gemacht, und werde die Theorien, welche sich hieranf aufloanen lassen, noch im Schlusstheil näher erörtern.

Die Hanptbildungsstätte ler Pigmentzellen bleibt die Cutis, und hier liabe ich beobachtet, dass einzehne der Cutiszellen, wenn sie noch einen embryonalen Charakter tragen, sich beliebig in Pigmentzellen umwandeln können: wenigstens kïnnen wir eine Pigmentzelle, die erst wenige Körnchen Pigment gebildet hat, nicht von einer anderen Cutiszelle mnterscheiden. Die Ansammlung des Pigmentes beginnt um den Kern herum, und dieser wird zuerst vollständig von den Pigmentkörnchen eingehiillt, dann vermehrt sich das Pigment und es tritt in die Ansläufer der Zelle hinein und dicsc Auslänfex" sind oft in der schönsten Weise zweigförmig verästelt, wie das von Salamanderlarven und anderen bereits längst bekannt ist. Alle diese Anslänfer behalten ihre Contractilität bis in's späteste Alter hinein, während der Kern der eigentlichen Pigmentzellen fast unver:indert bleibt, und meist um sich herum in nächster Nähe einen Hof noch mveränderten Protoplasmas erhält. Die Kö̈nchen kömnen zuerst minimal klein scin, sie werden jedoch später so gross, dass man sie schon mit geringen Vergrösserungen anfl̈sen kann. Ist die Pigmentzelle vollständig ansgebildet, hat sie ihr sämmtliches Protoplasma also der Pigmentmetamorphose unterworfen, so wird sie höchst wahrscheinlich ihren Ort nicht mehr wechseln kümnen und es werden dadurch dam die fixen Zeichnungen auf der äusseren Haut hervorgernfen. Eigene Muskeln kommen nach meinen Beobachtungen den Pigmentzellen der Amphibien nicht zu, sondern sie sind, wie bereits erwälnt, per se contractil.

1) Pfitzner, 1. c. 
Zum Schluss möchte ich noch erwähnen, dass der Schilchrö̈tenpanzer physiologiseh in anderer Weise wächst, wie die Haut der übrigen Reptilien. Es tritt eine Häutung bei den Sehildkrüten niemals ein, sondern es legen sich die sich neu bildenden nu durch Opposition wachsenden Hornlamellen in so eigenthumlicher Weise anemander, dass durch die Furchensysteme, welche die einzelnen Hornschuppen von emander trennen, ein stetiges Wachsthun der Epidermis vor sich gehen kamn, ohne dass eben eine Abstossung der äusseren, härter gewordenen Schiehten nothwendig geworden wäre. Diese Abstossung findet vielmehr nu in den Furehen statt. Jedermann kann sich leicht von dieser Art des Wachsthums an einem Schildkriitenpanzer iiberzengen. Dagegen tritt bei Verletzungen der äusseren Schale ein sehr intensiver Regenerationsprocess auf, durch welchen selhst in kurzer Zeit grössere Verletzungen ausgebessert werden. Dann ist freilich der Hornpanzer oftmals nicht mehr so regelmässig geformt, wie früher, sondern wir finden die mannicfaltigsten Unregelmässigkeiten, Buckel, Löcher n. s. w. in ihm auftreten.

\section{Hautdriisen und Hantsinnesorgane.}

Die Regeneration dieser beiden Organe hätte eigentlich bereits in den vrigen Capiteln abgehandelt werden kömen, jedoch schien es mir insofern zweckmässiger, sje gesondert zu betrachten als die Entstehmng dieser Organe mu damn verständlich wird, wemn man über die Entwickelung der Epidermis und Cutis, sowolıl beim Embryo, wie bei der Regeneration vollständig in Klaren ist. Ich hoffe nun in den vorhergehenden Capitehn zur Genïge die Entwiekelnngsgeschichte dieser beiden Lagen der Haut klargestellt zu haben, so dass ich zur Betrachtung der Regeneration dieser Organe ibergehen kamn.

Ueber die Entwickelung der Hautdrisen finden wir nur ganz vereinzelte Angaben in der Litteratur; vor Allem sind es die Arbeiten ron $v$. Török, welehe hier beriicksichtigt werden miissen. Bei den höheren Thieren war bereits durch Johannes Mïler, Pflïger, Leydig und Andere nachgewiesen, dass die Schweissdrüsen, die Talgdü̈sen und andere Dritsenarten sich dureh Einstïlpungen rom Epithel herausbilden. Die Kemntniss dieser Vurgänge bei den Auphibien war bisher in Dunkel gehiullt, wenn man anch vermuthen konnte, dass dieselbe in ähnlicher. Weise ror sich gehen wiirde, wie bei den Säugethieren. $v$. Türök machte num im Centralblatt fü die medieinischen Wis sensehaften 1874, No. 17 daranf aufmerksam, dass Cutisdruisen und Hautsinnesorgane bei den Amphibien in derselben Weise entstünden, wie bei len Süngethieren. Verfertigt man Durehschnitte durch die Hant, so kann man an der freien Oberfläche der obersten Zellenlage von Stelle zu Stelle knospenartige Hervorragungen bemerken, die als einzelne, unffallend vergrösserte Zellen sich erweisen. (Sic enthalten als active Bildungscentra 2-3 Dotterplättchengruppen). lhre sjütere Entwickelungsgeschichte liefert den Beweis, dass diese Zellen die ersten Organanlagen - Drḯsen. 
Organe des 6. Simmes - ler Ilaut sind, weshalb er sie als "Wrganoblasten" der Haut bezeichnen möchte. Theils während die Intterplittchengrupjen dir Iletanorphose (Schnelzung orler Aufquellung) eingelen, theils späiter, zeigt die rergrösserte Ilutterzelle - Organublast - die Neigung zur Vermehrung: dic 'Theihngsproducte werden selbstständiger. Weiter wurde diu Entstehung dieser. Organe nur nuch ron Leydig beolanclitet, der sie innerhalh der Fihiille an $3-4$ mm langen Larven von Tritun alpestris schon als gut abgegrenzte Epiderunisbildungen erkannte. Jedenfalls ist danit eine selır friihe Anlage der Cutisdrisen und Hautsimnesorgane constatirt.

In Gegensatz zum Axolotl, den Salamandrinen und Fribschen hat der Proteus nur cine einzige Art von IIautdriisen, die Schleimdrisen, welche den kleineren Driisen nit transparentem Inhalt der ïbrigen Amphilsien lomolog sind, Sie bieten den Anblick einer letorte, und setzen sich aus einem liörper zusammen, welcher in die breite bchicht der Cutis eingelettet ist, und aus einem Excretionsgang, welcher direct die Epridemis durchbricht, mu sich an der Oberfläthe zu ïffnen. Oft ist er verengt an der Stelle, an weleher er die compacte obere Schicht an der Cutis durchbricht, und so entsteht die Form einer Calabasse, 0,15-0,10 mm im Durehmesser, auch 0,25-0,30 an cinzehen Stellen. Die Tunica propria ist eine homogene Membran, welche namentlich in der Nachbarschaft der Oefinmog besäet ist mit einer grossen Anzahl von Kernen. Dazu treten Muskelfasern, von denen Bugnion meln als 70 an einer einzigen Driise gezihlt hat. Das inmere Epithel setzt sich aus grossen konixchen Zellen zusammen, deren Spitze abgermulet ist und sieh gegen die Seite der Oeffunng neigt. Sie haben einen excentrischen runden Kern von 0,12 mm Durchnesser, seheinen mit einer schleinigen Masse erfüllt, und lassen sich nit der grö̈sten Leichtigkeit isoliren. Mlit Ueberosmiumsäure treten die Schleimk̈̈rperchen schr deutlich hervor. Bei jüngeren Drüsen findet man diese Zellen nach Art eines Ejithels an die Wand der Drüsen angelagert.

Axolotl, Salamander, Kröte und der grïsste Theil der iibrigen Amphibien besitzen ansser diesen transpurenten Drïsen eine grosse Zahl viel whminöserer Drïsen, deren lnhalt von einer Anzahl runder stark lichtbrechender Körnchen erfüllt ist und ron grossen wenig grinzenden Tröpfehen. Diese Kömchen lïsen sich weder in Aether, noch in Alkohol, noch in Sïuren. Es sint dies diejenigen Driisen, welche, wem man das Thier reizt, eine Art giftigen, milchigen sceretes hervortreten lassen. D S Schleim des Proteus, welehem diese Driisen fehlen, besitzt keine giftigen Eigenselaften; man kann denselben auf die Zunge oder die Cunjunctiva bringen, olne die mindeste Irritation zu verspiiren.

Ich selbst labe bei Pleurodeles Waltlii folgendes beobachten können. Die Cutisdruisen nahmen an normalen Schwanze gegen das Ende hin allmählig an Grösse ab; es liegen jedreh zwischen den grossen Driisen auch kleinere, die nur als Ersatzdriisen gedentet werden können. Nach den Schwanzende zu werden die Drüsen kleiner und kleiner, bis znletzt gar keine mehr walngenonmen werden können, sondern nur noch Verdickungen in der Schicht des Rete Malpighii. "Bei Pleurodeles weicht die Entstehung der Cutisdrïsen in snfurn von der bei anderen Urodelen gefundenen ab, als sich bei diesem Thiere nur anschliesshich die Zellen des Rete Malpighii an ier Bildung betheiligen, nicht auch die Zullen der nächstfolgenden Schichten, wie ich Jei TiitonenLarven und b. i Perennibranchiaten beobachten konnte.

An bestimnten Stellen findet eine so bedentende Proliferation der Zellen des Rete statt, dass die neugebildeten Zellen in der Epidermis keinen Platz melır haben, sie drüngen siel daher zusammen und durchbrechen die darunter liegende Sehicht der Cutis. In den emmal gebildeten 
Ram dringen dam nach wmd wich mehr Zellen hinein und grupliren sich so, hass ihre Kerio wandständig werden.

Dieser Process scheint seln schnell zu verlaufen, dem die allerjingsten Stadien sind schwer aufzutinden, häutiger sieht man das von mir Pleurodeles, Taf. XV Fig. 10 dargestellte Bild.

Dass ein Zusammenhang der jungen Driisenzellen mit den Zellen des Rete besteht, sieht man sofort aus der Stellung der Kerne, die übrigens auch noch zum Ueberfluss etwas ron dem eigenthimlichen Pigment behalten haben, welches die Epithelzellen der Epidermis auszeichmet.

Ist die Einstiilpung in dieser Weise vor sich gegangen, so treten Pindegewebskijperchen hinzu und ungeben die neue Drïse als bindegewebige Scheide, in welcher sich später glatte Ituskelu differenziren. Nun beginnt auch lie Absondernng von seeret und die seemrlire Bildung eines Austïhrungsganges, während die Chromatophoren die Drïse zu umspamnen suchen und die obersten Sehichten des Bindegewebes den Hals der Driise einschnïren.

Solehe Driisen kïnnen meiner Ansicht nach nicht llas ganze Leben eines Thieres hindureh fungiren, es muss eine gewisse Erschöpfung und mit ih eine Riickbildung statthaben; auch kiun ich manche Bilder nicht anders, als aut die eben angegebene Weise denten. Ein Ersatz muss geschafft werlen und so bilden sich zwischen den grossen noch funktionirenden aber am Ende ihrer Thätigkeit stehenden Driisen neue kleine Driisen, welehe spuäter dieselbe Grösse wie die ałten erreichen kïmnen."

Es ist klar, dass diese Einstül ${ }^{\prime \prime u n g ~ d e r ~ D r i i s e n ~ a u f ~ e i n e n ~ S t a d i u m ~ e r f o l g e n ~ m u s s, ~ a u f ~ w e l e h e m ~}$ die Cutis noch nicht den grössten Widerstand entgegensetzt, und deshalb wirl, wie oben erwähnt, anch der grösste Theil tler Einstiilpungen am Schwanzende vor sich gehen, wo die Cutis noch eine embryonale, weiche Beschaffenheit hat.

Uebej die Entstehung der Hantsimnesorgane ist alusser den kurzen Angaben von $v$. Türök und Leydig nichts bekannt geworden. Auch Pfitsner, von dem die nenesten Untersuehungen ïber die Amphibienhaut rorliegen, und der sich hauptsächlich mit einigen specialfragen besehäftigt, konnte iiber die Bildung dieser Hautsimnesorgane nichts berichten. Ich selbst habe iiber die embryonale Entwickelung dieser Hautsimnesorgane keine besonderen Studien maehen kömen und muss mich deshalb darauf beschränken, den Regenerationsprocess lerselben zu beschreiben. Ueber die Struetur der ausgebildeten Hautsinnesorgane liegen vor allem die schönen Beobachtungen von Leydig, Franz Eilhardt Schulae, Bugnion und Malbrane vor. Mullmane boschreibt die Scitenorgane ausserordentlich eingehend. Er fiihrt atus, dass dieselben specich fiit das Wasserleben bestimute Organe sind (ef. meine Bemerkungen bei Pleurodeles), hauptsächlich studirt er die Anordnung der Sinnesorgane auf lem Kïrper, und es geht aus seinen Mittheilungen lucrur, dass sie in bestimnt verlanfenden Zeiehnungen gelegen sind, und zwar entlang den Vertatufe aller is den genannten Thieren zukommenden Rami laterales nervi vagi. Bei der Dentung dieser sutenoryane sehliesst er sich mehr Franz E. Sclulze an, inden er meint, dass die Natur diescr l3ihlungen nehr für eine Function als Wellensinnesuryane spräche. Die ursprüngliehe Anlage der Seitenurgane scheint bei den Amphibien und Fischen eine segmentale zu sein. Bei ïlteren Thieren sind naw Nulbane die Seitenorgane viel zahlreicher, als bei den jingeren, und es ist ihm damach wahrscheinlich, dass diese herrorgegangen sind aus einer activen Theilung der urspringlichen Seitenorgane wihlhend des Wachsthums des Thieres, indem diese .imnerhalb ihrer engen Wolnung cine new: Gruppirung ihrer Bestandtheile vornehmen". Es zerfallen zunïchst die inneren Zellen in melueve 
Bündel, di von den später duenfalls anseinanterweichenden Jantelzellen umgeben werden: erst in zweiter Linie seheinen die Tuchterorgane durch die zwischeneinwachsende Epidermis getrennt zu werden. Anfangs existirt anch noch eine gemeinsame Ausfïhrungs-Ceffinung; dann wird dieselbe jeduch lappig ausgezogen und zerfällt endlich in vollständig getrennte, den nengebildeten Organen entsprechende Einzehnündmugen. Von jungen Drisen sind lie Anlagen der Seitenorgane nur dadurch zu unterscheiden, dass das Pigment um erstere sich vollständig herumzieht, während es bei letzteren nur eine nach oben offene Grube bildet Ueber die Degeneration weiss Mallurane nicht riel anzufihren: er glaubt dass dieselbe sehr sehncll vor sich gehen miisse. "Wie Scitenorgane der Amplibien gehen mit dem detinitiven Uebertritt ihrer Eigenthümer zum Luftleben spurlos verloren. Das Wann, Wohin und Wie ihres Scheidens, die Momente der liiickljildung des gesammten Urgansystems sind aber noeh ein Riathsel."

Bereits in meiner Pleurodelesarbeit habe ich, wit oben eitirt, darauf hingewiesen, dass die Bildung der Cutisdrisen am Schwanzende nur dureh die Einstiilpung der untersten Zellsehichten zu Stande kommt. Auch bei der Regeneration finden wir, wie das voranszusetzen war, diese Verhältnisse wieder. Ich konnte niemals beobachten, dass bei Pleurndeles sich Zelien der mittleren Sehiehten sieh an der Bildung der Cutisdrisen betheiligten; dagegen war dies sehr wohl wahrzunehmen bei der Bildung der Hautsinnesorgane. In Folge dessen kann man bei Pleurodeles auf einem sehr frühen Regenerationsstadium die Anlage eines llantsinnesorganes und einer Cutisdrise ron einander unterscheiden, da das Hantsinnesorgan sich in ähnlicher Weise zusammensetzt, wie es vou den $v$. Töröli'sehen Organoblasten bekannt ist. Zu den Hautdriisen treten selrr bald Elemente ans der Cutis hinzu, wie ich das von der normalen Bildung anf Tafel IV, Figur 10 meiner Pleurodelesarbeit abgebildet habe, und bilden ilann die Tunica propria der Driise, und die Muskelelemente, welehe sich der Längsaxe der Driise entsprechend anordnen. Aueh bei den Regenerationsstadien konnte ich nur eine Art ron Cutisdrüsen nachweisen; es bleiben allerdings einige derselben in der Entwiekelung sehr zurück und sind deshalb kleiner, wie die anderen, aber ich denke mir, dass hier dieselben Verhäilnisse vorherrschen werden, wie im normalen Sehwanzende; dass eben die kleineren Driisen dann zur vollen Ausbildung gelangen, wenn die :ilteren sich ersehöpft haben und einer Resorption anhein fallen. Was die Hautsimnesorgane ron Pleurodeles anlangt, so sehen wir jedoch in dem unteren Theile der Epidermis mehrere Zellen sich zusammenballen, ohne dass irgend eine Einstïlpung in die Cutis bemerkbar wäre. Von diesen Zellen werden die äusseren zu den Mantelzellen, indem sie sehr bald sich strecken und ausserordentlich sehlank werden, während die Kerne sich stets am Grunde befinden; die mittleren Zellen dagegen verändern sich derartiğ, dass die Kerne sieh bedentend vergrössern und bald den ganzen Raum der Zelle einnelnmen, das Protoplasma der mittleren Zellen ist fast gïnzlieh geschwunden, dagegen sehen wir feine Ausläufer von diesen Zellen nach oben gehen und ans der Oeffnung herausragen, welehe sehr bald an der freien Seite entstcht. Den Zutritt von Nerven zu den Hautsinnesorganen konnte ich leider bei der Regeneration nicht beobachten; es mïssen jedoeh unbedingt feinste Nevenästehen an diese mittleren Zellen herantreten, denn nur diese können als Träger einer Sinnesfunction angesehen werden; nich ảer dic Mantelzellen, welchen höehstens eine sehützende Funetion zukommt. Diese feinsten Nervenästchen sind deshalb so schwer nachzuweisen, weil eine ausserordentliche Ansammlung ron Pigmentzellen die Beobachtung sehr erschwert. Anch die Mantelzellen sind an ihrem oberen Ende mit kleinen Fortsätzen und Ḱnöpfehen versehen, wie dies von Leydig in seinen neueren Untersuchungen 
iiber die Sinnesorgane der Fisehe weitläufig dargestellt ist. Das Hinzutreten grösserer Nervenäste unuss ieh hier entschieden in Abrede stellen; dagegen ist auffallend, wie ieh es schon bei den normalen Sinnesorganen beschrieben habe, dass stets anch unterhalb des normalen Simnesorganes eine ziemlich grosse Blutgefïsssehlinge zu bemerken ist. Bei Pleurodeles labe ich nur ältere Stadien der Regeneration von Hautsimnesorganen zu Gesicht bekommen, und ein solehes, fast vollständig ausgebildetes Organ in Tafel I, Fig. 4 alggebildet. Wenn man an der ganzen Anordnung der Epiderniszellen, der Mantelzellen und der inneren birnförmigen Zellen anch noch Anklänge an embryonale Verhïlnisse findet, so ist doeh in Allgemeinen der Typus des Hautsinnesorganes hier sehon so dentlieh ansgedriekt, dass er von dem vom mir in meiner Plenrodelesarbeit abgebildeten Hautsinnesorgan kaum untersehieden werden kann. Auch bei Larven von Tritonen habe ich die Regeneration von llautdriisen und Hautsimnesorganen geman verfolgen kïnen. Es ist dies um so leichter, als sieh auf einer einzigen Längsschnitserie dureh einen etwa $S$ Tage alten regenerirten Schwanz von Triton taenatus oder eristatus simmtiehe Stadien auf's Schönste verfolgen lassen. Bei einer $23 \mathrm{~mm}$ langen Larve von Triton taeniatus finden wir am 12. Regenerationstage, dass der Schwanz wiederum fast vollstïndig die normale Länge erreicht hat. Die Epidermis ist am hinteren Theile etwas kolbenartig vorgewölbt, und besteht ans 2 Zelllagen, von denen die obere bestimmt ist, zur Hornsehicht zu werden, wälırend ans der unteren sehr bald dureh Umwandlung die Leydigsehen Zellen der Epidermis hervorgehen. Diese Leydig'schen Zellen sieht man sehon in sehr kurzer Entfernung vom Sehwanzende anftreten. Inzwischen vermeht sich die Schichtung der Epiderunis nach vorn zu, wir halen es sehr bald mit 3, dann mit 4 Lagen von Zellen zu thun, und nun beginnt auch die Organoblastenbildung, indem sich die Zellen zusammenballen und zum Theil in die Cutis eindringen. Das jingste Hantsimnesorgan, welches ich als solches muterseheiden komnte, fand ich im Abstand ron $0,5 \mathrm{~mm}$ rom Schwanzende. In demselJen haben sieh die Zellen in eigenthümlicher Weise gruppirt, so dass man bereits den Unterschied zwischen den Mantelzellen und den inneren Zellen erkennen kam. Die Mantelzellen bestehen in 2 Lagen; die untere derselben hat längliehe Kerne, wälrend sie in der oberen, dariberliegenden rundlich sind. Alle Zellen sind länglich und erstreeken sieh von der Basis der Epidermis, die hier etwa \pm Lagen aufzuweisen hat, bis zur Aussenseite. Zu den späteren centralen oder Nervenzellen numgewandelt selıe ieh mit Uentliehkeit nur zwei, aber diese haben im Gegensatz zu den Mantelzellen eine grössere Achnlichkeit mit den Epidermiszellen bewahrt. Schon in diesem jıngen Stadinm, in welehem auf dem Längsschnitt 8 untere und 7 obere Kerne von Mantelzellen zu erkennen sind, scheint eine Bildung ron Cuticularsubstanz an der Oberfäche der Mantelzellen vor sich gegangen zu sein, da der obere Theil derselben stärker liehtbrechend wirkt, als der iibrige. Auffallend ist, dass in der Umgelıng dieses Simnesorganes die Ansammlung von gewömliehen Epidermiszellen eine bedeutende zu nennen ist; anch fehlt bereits hier die Capillarschlinge nicht. Die weitere Ausbildung, sowohl der Hantsinnesorgane, wie der Hatdrüsen geht nach dem volher beschriebenen Typus ror sich.

Bei Proteus sind die hier besproehenon Verhïlnisse insofern etwas abreichend, als wir hiel erst in späteren Regenerationsstadien die Hautdrisen und Hantsinnesorgane in Bildung legriffen vorfinden. Beim rollständig regenerirten Śchwanz, der etwa 1 cm lang abgeschnitten war, tinden sich in der Entfernung ron $3 \mathrm{~mm}$ ror dem Schwanzende nuch keine Organoblasten, dagegen trifft man dieselben ausserordentlich häufig an der Uebergangsstelle vom regenerirten zum unverletzten Theile und zwar kann man hier ebenfalls fast alte Stadien an einem giinstig gefihhrten sehnitt 
benbachten. Es finden sich nänlich die Organoblasten in dem Flossensaum in bedentender Anzalıl vor, während sie in der Witte des Körpers bereits alle zu Drüsen oder Hautsinnesorganen umgebildet sind. Bei Proteus wäre es nun noch schwieriger', wie bei Triton oder den T'ritonenlarven, von vornherein zu sagen, was aus einer solchen Zellanhiufung werden wird: ob eine Hantdrüse, uder ein Hantsinnesorgan entsteht, wenn wir nicht durch Bugnion und Mallrane ïber die genane Vertheilung der Hautsinnesorgane unterrichtet wären. Diese beiden Forscher wiesen nach, dass die Hautsimmesorgane nu in ganz bestimnten Linien auf (tem Körper angeordnet sind und su lamm man, wenn man diesen Linien folgt, fast mit Gewissheit behaupten, dass dieser oder jener Organoblast nicht zu einer ('utishruse, sondern zu einem Hautsinnesorgan werden muss. Ursprïnglich sind die Anlagen einander sn vollknnmen :ihnlich, lass eine Trennung nicht möglich ist. Später jednch lässt sich die Anlage der beiden Organe schon tadurch ziemlixh deutlich unterscheiden, dass man bei den IFautsinnesorganen sehr bald im Stande ist, eine Gruppirung von mittlen birnfönigen und äusseren Mantelzellen zu erkennen. In Fig. 14 T'af. IIl scheinen mir zweifellos die nit S. und $S_{1}$ bezeichneten Centron die Anlagen ron Sinnesorganen zu sein, von denen ss die iiltere repräsentirt während das nit I2r. bezeichnete Organoblast whl die erste Anlage einer Drise renräsentiren dürfte. Besonders instructiv wird die Vergleichung mit der nomalen Entwickelung auch in diesem Falle sein, weshalb ich ein noch nicht vollkommen ausgebildetes Simnesorgan eines numalen Schwanzes in Tat: III. Fig. 13 mit aufgenommen habe. Aus dieser Vergleichung wird hervorgehen, dass das mit $S_{1}$ hezeichnete (Trgan wohl schon mit Sicherheit als Hautsimnesorgan zu bezuichnen ist, während man bei dem anderen immerhin noch zweifelhaft sein kiinnte, wenn es nicht in den Bereiche der Vaguslinie läge.

Nienals konnte ich beobachten, weter bei Plemodeles, nuch bei Protens, noch bei den Tritonenlarven, dass die vollständig regenerirten Sinnesorgane nun etwa durch Theilung sieh vermehrten; ich vermuthe vichnuln, dass dieser Vorgang, der von Mallranc ja besonders hervorgehoben wurde, sich num an denjenigen Theilen des Thieres vollzieht, welche mit sinnesurganen mehr bedeckt sind, als die hier in Frage konmenden; also z. B. an Kopf, oder am Ursprung der Seitenlinien.

Ueber die physiologische Function dieser eigenthiimlichen sinnesorgane will ich zum schluss nur wenige Worte hinzufigen. Uebergangssimesorgane sind es wohl auf jeden Fall, denn es lassen sich zwischen ihnen und den Geschmacksbecliern, welche sich am Rande des Mundes, und in Munde selbst vortinden, keine irgendwie erheblichen Unterscheidungsmerkmale auftinden; ja es sind selbst in (ter Naseuhöhle einzelner Urodelen, wie dies z. B. von neinem Sehüler Blaue ${ }^{1}$ ) nachgewiesen wurde, bei Proteus, ferner bei verschiedenen Fischen, Organe aufgetunden worden, welche mit den Hantsinnesorganen in ter typischsten Weise ïbereinstimmen. Es werden also diese Organe'nicht nur als allgemeine Empfindungsorgane anfzufassen sein, soudern es wird ihnen höchst wahrscheinlich anch eine Function zukommen, welche unserem Geschnacks- und Geruchssinn ungefăhr entsprechen könnte. Die Innervation thut hierbei nichts zur Sache; denn wenn auch diese sinnesorgane, wie bisher augenommen wird, von Verzweigungen des Vagus innervirt werden, und eventuell sogar ron Spinahnerven, so liat doch Semper nachgewiesen, dass die Riickenaugen der Onchidien, die doch

1) J. Blaue: Zool. Anzeiger 1882. S. 657. Ueber den Bau der Nasenschleimhaut bei Fischen und Amphibien. 
gewiss als Sehorgane aufgefasst werden miissen, ebenfalls ihre Inmervation nicht von einem Nerven des oberen Schlundganglions, sondern vom Visceralganglion erhalten 1). Die Gefässschlinge, welche sich stets unterhalb des Sinnesorgans vorfindet, brachte mich auf den Gedanken, dass wir es hier nicht nur mit einem Sinnesorgan zu thun haben, sondern mit einem Organ, welches eventuell anch die Regulirıng des Wassergehaltes in Körper der wasserlebenden Thiere zu versehen hat. Sehr bemerkenswerth ist dabei der Umstand, dass diese Organe überhaupt nur, wic aus allen Beobachtungen hervorgeht, bei im Wasser lebenden Thieren vorkommen.

1) C. Semper: Ueber Seborgane vom Typus der Wirbelthieraugen auf dem Rücken von Scbnecken. Wiesbaden 1877. pag. 30: Die Koptaugennerven entspringen wie gewöhnlich vom sogenannten Cerebralganglion; die Rückenaugennerven sind aber nichts weiter, als dnhängsel der Pallialnerven, welche mit 3 getrennten Wurzeln jederseits vom sogenanten Visceralganglion ausgeheu. 


\section{Das Skeletsystem.}

Es wiirde mich viel zu weit führen, wollte ich auf alle über das nurmale Skeletsystem der Amphibien und Reptilien ersehienenen Arbeiten eingehen; es ist ja die Aufgabe der vergleichenden Anatomie, diese Arbeiten zu sichten und das bleibencle herauszuheben, und somit können wir uns ruhig darauf besehränken, neben den neneren Lehrbiichern der vergleichenden Anatomie, unter denen das von Wiedersheim wohl das herrorragendste ist, nur die hauptsäehliehsten Arbeiten in Betracht zu ziehen, in denen besonders von denjenigen Theilen die Rede ist, welehe reprodnetionsfähig sind. Diese Reproduetionsfähigkeit des Skeletes erstreekt sieh nun allerdings bei den Tritonen und namentlieh bei den Larven derselben so ausserordentlich weit, dass eigentlich jeder Theil des Skeletsystemes regenerirt werden kann, dass demmach also dennoch das ganze Skeletsystem in Betracht käme. Da das aber die Ausdehnung der Arbeit unendlich vergrössern würde, und sieh meine Beobrehtungen nur auf die Regeneration des Schwanzskeletes und der Extremitäten beziehen, so werde ich also nur Gelegenheit haben die einschlägigen Arbeiten von Gegenbaur, Leydig, Wriedersheim, Götte, Philippeaux, Claus, Strasser und einigen Anderen zu citiren; abgesehen natiirlieh von denjenigen Aufsätzen, in denen sich Untersuchungen oder Andeutungen iiber Regenerationsverhältnisse vorfinden.

Die normale Wirbelsäule der Reptilien ist besonders ron Gegenbaur und Laydig genan nntersucht worden. Ich habe die betreffenden Arbeiten bereits im ersten Theil weitlinfig besproehen und namentlich erwähnt, dass Leydig vor Allem aufmerksam macht auf die Quertheilung der Wirbel des Eidechsensehwanzes. Vorher hatte allerdings Brïh ${ }^{1}$ ) auf diese interessanten Verhältnisse aufmerksam gemacht, nhne zu wissen, dass bereits Cuvier an derselben Stelie, an welcher er iiber die Regeneration der Schwanzwirbelsäule der Eideehsen sich verbreitet, anch die normale Quertheilnng derselben genau bespricht; aber Leydig gebührt unbedingt das Verdienst, zuerst nachgewiesen zu haben, dass gerade in rler Gegend des 7 . Candalwirbels, an welehem die Quertheilung beginnt, naturgemäss der loeus minoris resistentiae zn suchen ist, und er fïhrt uns so unwillkirlich darauf

1) Sitzungsver. d. Wiener Academie. 1853 Bd. XI. pag. 318. 
hin, in dieser Quertheilung der Schwanzwirbel bereits eine eigenthiimliche Anpassung an die Regenerationserseheinungen zu suchen. In wie fern die Schwanzwirbel der Ascalaboten in ähnlieher Weise schon Verhältnisse zeigen, welche ebenfalls eine diesbeziigliche Auffassung reehtfertigen können, lehrt uns Gegenbaur in seinem mehrfach citirten grossen Werke ${ }^{1}$ ) kennen. Aueh bei den Ascalaboten findet sich, wie sehon Hyrtl nachwies, die normale Quertheilung der Schwanzwirbel. vor. "Diese Uebereinstimmung mit anderen Reptilien seheint jedoch weder auf den Bau der Wirbelkörper, noch auch auf die Verbindungsweise derselben sieh auszudehnen, und es lehrt schon die einfache Zergliederung der Wirbelsäule, dass die einzelnen Wirbel nicht dureh Gelenke unter einander verbunden sind. Jeder Wirbelkürper besteht aus einer äusseren Knoehenscheide, die aus eontimuirliehen Lamellen von Faserknochen zusammengesetzt ist, und bildet so einen Doppelkegel, der in der Mitte von Markkanïlen durchsetzt ist. Der Intervertebralknorpel ist ausserordentlich stark entwiekelt, speciell bei Platydaetylus; im Schwanz von Phyllodaetylus ist die Chorda sogar von einer ansehnlichen Lage von Knorpel umgeben. Bei Phyllodaetylus meint Gegenzanr, misste ein ganzes, eontinuirliches Rohr um die Chorda gebildet werden, aus dem sich die knüchernen Wirbel differenciren. Die Chorda muss cin ansehnliehes intervertebrales 15 achsthum besitzen, denn sie hat, abgesehen von der ausserordentlichen Verlängerung, die sie nit dem Längswachsthum der gesammten Wirbelsäule eingehen muss, einen intervertebralen Querdurchmesser, der gerade um das Doppelte so gross ist, als der vertebrale, an dem die urspriingliche Dicke der Chorda erhalten bleibt." Aus alle diesen von Gegenbaur ausführlich dargestellten Verhältnissen geht hervor, dass bei den Ascalaboten eine total versehiedene Wachsthumsrichtung, und in Folge dessen eine bedentende Abweichung von den ïbrigen Reptilien stattfindet.

Die Thatsachen, wie sie Gegenbaur beschreibt, sind für die Regeneration von änsserster Wichtigkeit. Wenn wir ein regenerirtes Rückenmarksrohr einer Lacertide oder eines Ascalaboten betrachten, so werden wir da zum Theil ähnlichen Verhältnissen begegnen, wie sie von Gegenbaur von der normalen Wirbelsäule der Ascalaboten dargestellt wurden. Es wird die Aehnliehkeit sofort in clie Augen fallen, wenn ich zur Besprechung des regenerirten Sehwanzes iibergehe, doeh will ich vorauf sehicken, dass es sich hier nur um Analogieen, nicht um Homologieen handelt. Ueber das äusserste Schwanzende der Wirbelsäule der Reptilien besitzen wir leider fast gar keine Mittleilung; ich habe im zool. Anzeiger vom Jahre 1850, pag. 12 nur ausgesproehen, dass der bei den Amphibien so leieht nachweisbare Knorpelstab anch ,sehr klein, aber naelweisbar, bei Lacerta“ sich vorfinde. Braun ${ }^{2}$ ) hat mir darauf erwidert: „Nach einer Andeutung von Fraisse kommt dies aueh bei Lacerta vor" (Zool. Anz. III. Jahrg. No. 46) doch ist dieser Knorpelstab sehr kurz; vielleicht liegt jedoeh hier eine Verweehselung mit dem hintersten, auf embryonalem Typus stehen bleibenden Chordaende vor." leh kann jedoch nicht umlin, noch hente meine Ansicht in betreff der Lacertiden wenigstens aufreeht zu erhalten, denn es findet sich namentlich bei Lacerta muralis, die sich ja bekanntlich durch die

Jena 1862.

1) Gegenbaur: Untersuchungen zur vergleichenden Anatomie der Wirbelsäule der Amphibien und Reptilieน

2) Braun: Aus der Entwickelungsgeschichte der Papageien. Verhandlungen d. Würzb. physical.-medicin. Gesellsch. B. XV. pag. 175. 
ansserordentliche Länge ihres Schwanzes auszeichnet, ein deutlich nachweisbares knorpeliges Ende der Wirbelsäule. Bei den Ascalaboten dagegen sind die Wirbel bis zun letzten stark rerknöchert und ron eincr Knorpelkappe ist nicht die Spur zu crkennen.

Nehmen wir als Beispiel für die Amphibien wiederum ans der grossen Menge der Arten ein Thicr heraus, an dem ich hauptsächlich experimentiren konnte, so finden wir, dass die Schwanzwirbel bei Pleurodeles je naeh ihrer Lage eine recht rerschiedene Form haben. ,.Man kann, ohne eine scharfe Grenze ziehen zu wollen, sie am besten in der Weise beschreiben, dass man den ganzen Schwanz in 3 Theile theilt, und nun die Wirlel derselben mit einander vergleicht. Wie die Wirbel anderer Urodelew sind sie opistuevel, wenn anch gleich zu besprechende Abweichungen hiervon vorkommen können, langgestreckt und in der Hitte, besonders im rorderen Drittel durch querhindurchgehende Harkiänme getheilt. Betrachten wir zuerst diejenigen Wirbel, welche am Ende des vorderen und am Anfang des mittleren Drittels rorkommen und rou denen ich einige im sagittalen Längsschnitt auf Taf. XV. Fig. $3^{1}$ ) largestellt labe. Am meisten faillt hierbei auf, dass die von einem $14 \mathrm{~cm}$ langen Thier genommenen Wirbel nur wenig rerknöchert und dass die Gelenke sehr schwach ansgebillet sind. Man findet statt dessen, dass das rordere und hintere Ende eines Wirbelkörpers aus grosszelligen schönen Hyalinknorpel hesteht, während die Mitte ein ziemlieh bedeutender Markraum einnimmt. Umgeben sind diese Bildungen von einer dïnnen Lamelle bindegewebigen Faserknochens, der nach Aussen die verschiedensten unregelnässigen Answïehse und Torspriinge bilden kann, die sich meistens an den Seiten befinden, auf Fig. 3 also nicht wahrgenommen werden kömnen. Der aus senkrechten, dicht gedrängten kinorpelzellen bestehende Intervertebralknorpel hat sich noch nicht durch Bildung einer Gelenkhühle zu einem Gelenk differencirt, nur am allervordersten Ende der Schwanzwirbelsänle treffen wir Verbindungen durch Gclenkpfanne und Gelenkkopf.

Hinter dem Intervertebralknorpel liegt in jedem Wirbelkörper ein 0,15 mm breiter Chordarest, dessen blasige Zellen stark comprimirt zu sein scheinen. Der Chordarest liegt in der Mitte des hyalinen Knorpels, ist birnförmig von Gestalt, so dass die breitere Basis nach vorne steht und nach hinten in einen langen Sticl ansgeht, welcher ron dem Ueberrest der die Chorda anch jetzt noch rmgebenden Scheide herriilırt.

Eine Verbindumg der einzelnen Chordareste untereinander ist hier nicht mehr wahrzmehmen.

Die Markräume nehmen etwa die Hälfte der Wirbelkörper ein und zwar die beiden mittleren Viertheile. Sie sind erfüllt rom einem grossmaschigen luckeren Gewebe, das ungemein fettreich ist und von kleineren Blutgefässen durelizogen wird.

Gegen den Knorpel sind die Markräume scharf abgesetzt, es entstehen dort ausgezaekte Rïnder, an denen der Knorpel mitunter verkalkt. Nach aussen sind sie nur begrenzt ron der diimnen Knochenlage; es findet sich also auch hier der locus minoris resistentiae des Wirbelkïrpers, was fiir die Regeneration ron grosser Wichtigkeit ist.

Der Durehmesser der Wirbelkärper am Intervertebralknorpel betrigt ea. 1-1,5 mm: an der dïnnsten Stelle des Markraumes etwa $0,17 \mathrm{~mm}$. Der Faserknochen ist $0,044 \mathrm{~mm}$ breit.

1) ef. Pleurodeles I, c. 
Ueber die Wirbel länft, ihren Einsenkungen und Erlöhnngen wellenförmig folgend, das Rïekenmark, umgeben von den oberen oder Neuralbögen, welche ebenfalls stark rerknöchert, in der Mitte einen Markraum besitzen. Fig. 3. N. B.

Unter den Wirbelkörpern liegt erst die Arteria eandalis mit engem Lumen und stark muskulöser Wandung und dann die Vena candalis, welche dïnnwandig und sehr weit ist und ron brannem Pigment völlig eingehïllt wird.

Senkrecht unter dem Intervertebralknorpel zeigen sich dann Querschnitte der unteren oder Haemalbögen, die ebenfalls in der Mitte einen Markraum haben. Fig. 3. HB.

Die einzelnen Bägen sind dureh Muskelbündel mit einander verbunden.

Am Ende des zweiten Drittels nehmen die Wirbel sehon eine etwas andere Gestalt an.

Der birnförmige Chordarest liegt wenigstens zur Hälfte mitten im Intervertebralknorpel, muterbricht diesen somit und hängt dureh die Chordascheide mit dem Chordarest des nächstfolgenden Wirbels zusammen. (Taf. XV. Fig. 4. Ch. S.) Ton Markrämmen ist hier keine Spur mehr wahzunehmen; die Stelle, an der sie sich bei den vorderen Wirbuh finden, wird dureh Knorpel ansgefüllt, weleher innerhalb der weiten Chordascheide liegt mol ron Gegenbaur Chordaknorpel genannt wurde.

An den Intervertebralstellen ist die knöeherne Bekleidung der Wirbel an den Seiten durehbrochen, so dass anf Fig. 4, an den Stellen, die mit Iv L bezeichnet sind, ein Gewebe dafür eintritt, welches Gegenbaur als Intervertebralligament bezeichnete und das sich contimuilich in den Intervertebralknorpel und durch diesen in den Knorpel der Wirbelkürper iibersetzt. Wo man dies Gewebe noch als Bindegewebe und wo man es schon als Knorpel bezeichnen kam, ist nicht dentlich anzugeben da der ans ihm entstehende Intervertebralknorpel anch nur sehr wenig Zwischensubstanz enthält.

Die hier dargestellten Verhältnisse erimern sehr an diejenigen, welche dureh Geyenbaur ${ }^{2}$ ) ron einem jungen Triton eristatus besehrieben und abgebildet wurden, nur mit dem Untersehiede, dass der rertebrale Chordarest hier vollständig verknorpelt ist und nur der intervertebrale bestehen bleibt; dies geschieht in der Weise, dass der birnförmige Theil mit breiter Basis im vorderen, der spitz zulanfende dagegen im, nächstfolgenden Wirbel liegt. Denkt man sich den in der gleich darauffolgenden Erweiterung der Chordascheide gelegenen Theil des Chordaknorpels noch als echte Chorda, und nur den an der sehmalsten Stelle befindlichen Theil verknorpelt, so hat man das ron Gegenbaur dargestellte Bild.

Die von dem den Wirbelkörper umgebenden Faserknochen abgehenden zahlieichen Vorsprünge und Fortsätze mit theilweise grossen Markkanälen und Markrämnen erimern an die bei Siredon vorkommenden gleichen Gebilde.

Aus diesen auf einem horizontalen Längsschnitte abgebildeten Terhältnissen die Gestalt der vorhergehenden Wirbel abzuleiten, hält nicht schwer, denn man brancht nur anzunehmen, dass der immer mehr zunehmende Chordaknorpel die Chorda bis ïber den Intervertebralknorpel hinans vorlpingt $n$ I dass dieser damn selbst degenerirt und die von ihm eingenommene Stelle zu

1) Untersuchungen zur vergleichenden Anatomie der Wirbelsäule bei Amphibien und Reptilien. Leipzig 1862. 
einen Markraum wird, wälnend der Knorpel des Wirbelkïrpers am hinteren Ende zu einer becleutenden Måchtigkeit gelangt.

Diese Wirbel gehen gegen das Sehwanzende allmälılich in noch anders gestaltete iiber, welche ieh in Figur 5 alsgebildet habe.

Sie sind hier noch ganz knorpelig, nur umgeben von einer festen bindegewebigen Membran. Der grössere $0,15 \mathrm{~mm}$ im Querdurehmesser haltende Chordarest liegt intervertebral, ein kleinerer rautenfürmiger vertebral; der letztere ist umgeben ron Chordaknorpel. -

Die Wirbel werden naturgemäss inmer sehmäler und endigen zuletzt in einen Krnorpelstab von selır versehiedener Länge, in welchem sieh keine Spur von Chorda melu erkennen lässt.

Den längsten, welehen ich beobaehtete, habe ieh in Fig. 5 abgebildet und mit $\mathrm{K}$. St. bezeiehnet: er misst $3,5 \mathrm{~mm}$. Es finden sich anfangs noch einzelne Segmente in ihm deutlieh ausgeprägt, gegen das Ende zu verliert sieh dies vollstindig. Nit der Chorda liängt dies Gebilde durehaus nieht zusammen, denn es sitzt dem letzten Chordarest, der mit spitz zulaufender Chordascheide endigt, kajpenartig auf.

Schon Heinrich Mïller ${ }^{1}$ ) kannte diese Thatsaehe bei den Tritonen, Flesch ${ }^{2}$ ) kam neuerdings auf diesen interessanten Punkt zuriick.

Der Knorpelstoek geht am äussersten Schwanzende (Tafel XV Figur 7) allmählich in ein zelliges Blastem olne Grundsubstanz iiber, welehes vielfach die ron Strasser als dunkle prochondrale Elemente bezeichneten Gebilde erkennen lässt.

Was die Bilder anbelangt, welehe man auf Quersehnitten durch die Wirbelsäule erlıält, so sind diese natiirlich ebenfalls von einander verschieden, je nach der Region, dureh welehe der Sehnitt geführt wurde.

Stets ist die linorpelige Consistenz des Wirbelkörpers sehr in die Augen springend: in Fig. 1 und 2 habe ieh solche Selnitte abgebildet, welche in Fig. 4 durch Striehe markirt sind.

Ueber die Wirbelkürper etwas Weiteres hinzuzufügen, dürfte überflïssig sein; die Fortsätze, welehe sich an ihnen finden, mögen jedoeh kurz besprochen werden.

An oberen Bogen, der sich continuirlieh aus dem Faserknoehen des Wirbelkörpers fortsetzt, finden sich ein oberer Dornfortsatz und zwei seitliehe Fortsätze in den Vertebralstellen.

In Fig. 1, die einen Selmitt dureh eine Intervertebralstelle darstellt, ist der obere Theil des Neuralbogens bedentend verdickt, mit einem Markraum rersehen und mit den Anfängen des näehstfolgenden Bugens dureh Gelenke verbunden.

Der Wirbelkürper besitzt Querfortsätze.

Die unteren Bögen ähneln in jeder Beziehung den oberen, nur sind sie etwas kleiner. -

Fig. 6 stellt einen senkrechten Querschnitt durch das letzte Ende des Selwranzes dar. Der Wirbelkörper ist noch vollständig lnorpelig, ohne eine Spur von Chorda zu zeigen und ebenso die beiden Bögen. Umgeben sind alle Knorpelcentren ron einer mit längliehen Zellen durehsetzten bindegewebigen Sehieht. Betrachtet man mehrere Sehnitte einer Selmittserie hintereinander, so sieht

1) Ǔeber die Riegeneration der Wirbelsäule und des Rückenmarkes bei Tritonen und Eidechsen. pag. 21 Frankfurt a, M, 1864.

s) Flesch, Sitzungsberichte der physikal.-medic. Gesellschaft zu Würzburg. 1. Juni 1878. 
man dentlich den Zusammenhang der Bögen mit dem Wirbelkïper - ein ebenfalls wichtiger Befund, da man bisher nach Götte annahm, die Bügen stammten ron der Chordascheide ab.

Wir haben aber eben gesehen, dass Wirbelkörper und Bögen anch olne Chorda entstehen können - eine Thatsache, deren Tragweite noch nicht abzusehen ist."

Begimmen wir bei der Betrachtung der Regenerationserseheinungen der Wirbelsäule mit der Besprechnng desjenigen Gebildes, welehes iiberall als der Vorläufer der knöchernen Wirbelkörper angesehen wird, mit der Chorda. Die Chorda entsteht, wie wir jetzt durch die neneren Untersuchungen bewährter Embryologen wissen, bei niederen Wirbelthieren allgemein aus dem Entodern. Namentlich bei den hier in Frage kommenden Thieren, den Amphibien und Reptilien ist wol clie bisher streitige Frage zu Gunsten der eben clargestellten Ansicht entschieden. Auf die Structur der normalen Chorda kann ieh hier natülicherweise nicht weiter eingehen; ich muss nur erwähnen, dass ich ein Chordaepithel als iiljerall vorhanden ansehe, und class ich gerade dieses Chordaepithel, welches der inneren Chordascheide dicht anliegt und aus platten Zellen besteht, als dasjenige Element betrachte, ans welchem sich die Chordazellen beim normalen Wachsthm hervorbilden. Es sind diese Epithelzellen allerdings mitunter nicht gerade seln dentlich, so dass man sie leicht übersehen kann. Die Chordazellen sind schon in jungen Stadien derartig modificirt, dass eine Proliferation derselben nieht mehr angenommen werden kann, dem wo einmal in den Zellen eine so bedentende Metamorphise des Protoplasmas stattgefunden hat, wie hier, in Zellwasser, wird niemals die Zelle selbst noch im Stande sein, sich weiter zu theilen. So finden wir denn auch am Sehwanzende stets einen kleinen embryonalen Rest ron protoplasmareichen Zellen der eigentliehen Chorda aufsitzen, aber demnoch mit ihr zusanmenhängen, nicht etwa getrennt von ihr, wie der bereits erwähnte, morphologisch rollständig rersehiedene Konorpelstab. Diese Chordaenden sind ausfïhlich besehrieben worden ron Braun, Iupffer und anderen, und ieh kann deshalb hieriber wol hinweggehen, da sie bei der Regeneration keine Rolle zu spielen scheinen.

Die Chorda regenerirt sich ïberhaupt nur bei den Anuren, und zwar bei den Larven derselhen: anch bei den jüngsten Urodelenlarven, die ich zu diesem Zwecke amputirte, komnte ich niemals eine Regeneration der Chorda constatiren. Allerdings sitzt bei diesen kleinen Larven, die eine Grösse ron 6-10 mm haben, der neugebildete axiale Stal nicht so kappenartig den letzten Chordazellen, die unverletzt geblieben sind, anf, wie das bei den älteren Larven und den erwachsenen Thieren der Fall ist, sondern es scheint sogar mitunter, als ob die Elemente der Chordazellen direct in den regenerirten Knorpelstab iibergingen. Ich komte jedoch niemals beobachten, dass die hintersten unverletzten Chordazellen sich in irgend einer Weise modifieirten oder gar zn embryonalen Zellen sich umwandelten, vielmehr ging eine lebhafte Proliferation von den seitlichen, die Chorda umgebenden Gerreben ans, also von dem skeletogenen Gewebe, aus them anch die regenerirte Wirbelsänle der älteren Thiere entsteht.

Aus der grossen Menge ron Versuchsobjecten unter den Amphibien will ich ror allen Dingen wieder eimmal den Pleurodeles hervorhelsen, bei dem ich die Regeneration um so genaner rerfolgen konnte, als ich mich ja auch eingehender mit dem Studium des normalen Thieres beschäftigt hatte. Ausserdem sind, wie bereits mehrfach erwähnt, die Gewebselemente dieses Molehes besonders gross und deutlich, so dass hierdurch die Untersuchnng wesentlich erleichtert wird. Alle meine Exemplare wuden im Wasser gehalten, welches sie wihrend der Regeneration nicht verliessen; alle waren sie wohlgenährt und frassen begierig Würmer und klein geschnittene Muscheln. Ton 
den verschiedensten Regenerationsstadien habe ich mir nun Schnitserien angefertigt, und zwar sagittale und frontale Längsschnitte, sowie aueh Quersehnitte. Am instructirsten sind nnbedingt die Sagrittalschnitte, aber auch am schwierigsten anzufertigen, da man selten im Stande sein wird, den betreffenden 'Theil so auf dem Mikrotom zu befestigen, dass die Medianlinie des Thieres getrofien wird; denn es kommt ja eigentlich nur auf einen einzigen, riehtig geführten Medianschnitt an Später sind deshalb zum Vergleich stets die anderen Schnittserien heranzuziehen, und so habe ieh vor allen Dingen einmal Querschnittserien zu diesem Zweeke benutzt. Bei einem 5 Monate alten regenerirten Schwanze von Pleurodeles ist die Uebergangsstelle des normalen in den regenerirten Theil besonders interessant. Es beginnt die erste Andeutung des neugebildeten Wirbelsystemes in der Mitte von Knnochenlanellen, in denen sieh noch die alten Markräume befinden. Die Knorpelanlage geht damn unmittelbar vom alten Wirbelköper aus, und zwar setzen sich segmentweise an die neugebildeten knorpeligen Wirbel Haemal- oder, Neuralbögen an, in welehe die Knorpelmasse des Wirbelkörpers direet iibergeht. Ringsherum hat sieh bereits in älnhlieher Weise, wie beim normalen Thier, nur bedeutend unregelmässiger, Faserknochen gelsildet, weleher sowohl die Bögen, wie den W'irbelkörper überzieht. Die Bögen setzen sieh an den Intervertebralstellen an; in Fig. 11, Tafel I1, habe ich einen Querschnitt durch eine derartige Intervertebralstelle, in Fig. 12 einen Querschnitt durch die Vertebralstelle abgebildet. Figur 5 zeigt einen Frontalsehnitt dureh den Uebergang des normalen in den regenerirten Theil; die Schnittfläche ist mit SF bezeichnet, und von hier aus setzt sich nach links der neugebildete Ḱnorpel an das alte Skeletsystem an. Der letzte Chordarest befindet sieh dicht vor der Sehnittfläehe. Man sieht nun, dass von dem Intervertebralknorpel aus bereits eine Differenzirung von Spindelzellknorpel nach dem neugebildeten Theile sich hinzieht. Der Spindelzellknorpel nmfasst kalbkreisförmig den älteren Knorpel und läuft dann, was anf dem Bilde nicht mehr zu sehen ist, in ein'axiales Blastem aus. Bei den jüngsten Regenerationsstadien sieht man stets, mag der Sehnitt nun durch eine Vertebral- oder Intervertebralstelle greführt sein, zuerst gewisse Veränderungen an dem Knorpel anftreten. Vor allen Dingen werden ja einmal eine ganze Anzahl von Ḱnorpelkapsehn geöfhnet und deren Zellen verletzt, so dass sie zum Theil zu Grunde gehen mïssen. Andernfalls wird aber eine Knorpelzelle, welche nicht direet vom Schnitt gretroffen ist, sondern nur in der Nähe der Schnittfläche gelegen ist, num dureh den Reiz der Verwundung zur Proliferation getrieben; sie wird sich theilen und so bald eine bedentende Anzahl ron embryonalen Knorpelzellen am Rande des unverletzten Kinorpels entstehen. Ob noeh besondere Resorptionserseheinungen, wie wohl zu vermuthen wäre, stattfinden, ist schwer nachznweisen, da diese sich ja der direeten Beobachtung entziehen, und man nur aus Analogiesehliissen solehe folgern kann. Ich glaube wohl, dass einzelne Ḱnochenspitzen resorbirt, oder wenigstens abgerundet werden, da man niemals am vollständig regenerirten Schwanze im Stande ist, scharfe Kanten nnd Eeken an den Krnochen, welehe die alte Sehnittfäche berihren, nachzuweisen; aber es seheint mir, wemn wir nach der Herkunft der nenen knorpelzellen forsehen, als ob ein Theil dieser Krnorpelzellen wirklich aus den alten, embryonal gewordenen und aus ihren Kapseh befreiten Zellen hervorginge. Doch ist das Wachsthum des regenerirten Sehwanzes ein so intensives, dass aneh bei der schnellsten Vermehrung diese Zellen nicht im Stande sein wïrden, allein den Vorlänfer des regenerirten Skeletes, den Knorpelstab zu bilden; wir sehen vielmehr an einzehnen Exemplaren, denen ein grosses Stiick des Schwanzes, ca. $5 \mathrm{~cm}$, amputirt war, dass das linorpelgewebe, welches man wirklich direct als solches bezeichnen kam, sehr bald aufhört, und dass an dessen Stelle ein embryonales Blastem 
tritt, dass demjenigen ganz gleich ist, welches am Ende des normalen Schwanzes die Spitze der Wiabelsäule bildet. Das Wachsthum des axialen Blastemes hält nicht genau gleichen Schritt mit der Entwickelung der ïbrigen Bindesubstanzen und del Epidermis, vielmehr finde ich oftmals das Ende des regenerirten Schwanzes angefuillt yon einem ganz gleichmässigen embryonalen Bindegewebe, welehes sich an den axialen Stab ansetzt, und ohne bosondere Grenzen in die Gewebeschichten ibbergeht, aus denen später die Cutis mit ihren Gefissen u. s. w. sich hervorbildet. Was die Lmwandlung des Knorpelstabes zu echten Wirbeln anbelangt, so geht dieselbe zuerst in ähnlicher Weise vor sich, wie das rom Ende des normalen Schwanzes bereits beschrieben ist. Später tritt dann die Bildung von Bögen auf, die mit dem axialen Blastem zusammenhängen, und hierauf folgt eine vou aussen nach imen fortschreitende Verknöchermg.

Auch bei Siredon pisciformis finden ganz ähnliche Verhältnisse bei der Regeneration der Wirbelsäule statt. Ich rerweise auf meine Abbildung Fig. 4 Taf. II, in weleher eine regenerinte Wirbelsäule dargestellt ist; hier haben sich bereits 8 oder 9 dentlich abgegrenzte Wirbel difterencirt, wähend das Ende wiederum in das ungegliederte Knorpelblastem ansläuft. An diesem medianen Sagittalschnitt sieht man den letzten Chordarest $\left(\mathrm{Ch}_{1}\right)$ vor dem ersten regenerirten Wirbel liegen, der mit Kst bezeichnet ist. Betrachten wir das Schwanzende eines normalen, 6 cm langen Siredon, dem niemals die geringste Verletzung zngefïgt war, - das betreffende Thier wurde vollständig isolirt aufgezogen, - so treffen wir auf Verhältnisse, welche den eben beschriebenen zum Verwechseln ähnlich sind. So kommen wir zu einem Schluss, zu dem schon Heinrich Mïllcr dureh seine Beobachtungen zum Theil gelangte, dass die Bildung der regenerirten Wirbel in derselben Weise vor sich geht, wie im normal waehsenden Sehwanzende desselben Thieres. Hieraus werden wir einen weiteren Schluss zichen können, der vielleieht für die gesammte ILorphologie ron einer gewissen Wichtigkeit sein diurfte, dass nïmlieh für die Bildung der Wirbel die Segmentation ein bedeutungsvolleres Moment sei, als das Vorhandensein der Chorda.

Der Bau des regenerirten Schwanzes der Eidechsen und verwander Thiere wurde so ausfuihrlich von den frïheren Forschern studirt, dass darïber kaum mehr nene Beobachtungen gemacht werden können. Ich finde ebenso, wie die älteren Autoren, dass sich in einem ziemlieh $12 \mathrm{~cm}$ langen, regenerirten Schwanze von Lacerta Lilfordi ein continuirliches Ḱnorpelrohr hinzieht, welches an seinem vorderen Theile mit dem Reste des 7. Sehwanzwirbels verwaehsen ist, und naturgemäss schmïler und dünner werdend, dureh den ganzen Schwanz bis zum letzten Ende verlïuft. Ab und zu sehe ich auch Liicken in dem Rohre, nirgends aber eine Andeutung wirklicher Segmentirung oder gar einen Zusammenhang dieser Segmentation mit den Muskel- und Hautsegmenten. Die feinen Kanälchen, welche die Wände des Rolıres durchbreehen, lassen Blutgefíisse hindurehtreten, wie man das besonders sehön bei den Ascalaboten sehen kann; niemals jeduch treten Nervenfasern heraus oder hinein, und das ist ja ziemlieh leicht erklärlich, wenn man die Structur des regeneriten Riuckenmarksrohres, welches in dem Knorpelrohr verliuft, in Betracht zieht. Allerdings lassen sich ringförmige Verdickungen in der äusseren Wand dieses Rohres nachweisen, aber dieselben sind vollständig unregelmässig, und hängen von einer später zu besprechenden Kalkablagerung in der Knorpelınasse des Rolures ab. Gachet hatte bereits die Frage aufgeworfen, ob die starke Verknöcherung vom Kilima abhängig sei, und will benerkt haben, dass bei einzelnen Formen ausländiseher Eidechsen sich aus dem Knorpehohr mit der Zeit dennoch wirklieh Wirbel herausbilden. Dass diese Annahme auf Täuschung beruht, ergiebt die einfache anatomiseh 
Untersuchung des Wirbehohres, dessen einzelne verdickte Ringe Gachet wahrseheinlich für Wirbel gehalten hat. Vor Allem muss uns interessiren die Ansatzstelle des Linorpelrohres: ich habe bereits erwähnt, dass bei diesen offenbar physiologisch-regenerirten Schwanze, den ich im Ange habe, der vordcre Theil des 7 . Schwanzwirbels noch vollständig unverletzt ist. Dort, wo sonst im normalen Riickgrat die Quertheilung beginnt, setzt sich nun, wie auf einem Liingssclmitt sehr dentlich zu sehen ist, an dem halben Wirbel, und zwar an dem Wirbelkürper sowoll, wie an dem oberen Bogen das Rohr derartig an, dass es von dem Wirbel absolut nicht getrennt werden kann, so dass auch bei einer späiteren Verletzung eine Trennung an derselben Stelle ganz undenkbar crscheint. Querschnitte, die wir durch das Wirtselrohr machen, belehren uns, dass wir, wie schon Heinrich Mïller es gesehen hat, es hier mit einem eigenthümlichen linurpel zu thun haben, der ursprïnglich rein zelliger Natur und dessen Intercellularsubstanz ausserordentlich gering ist, so dass die einzelnen Knorpelzellen fast das Bild darbieten, wie wir es ron den Chordazellen kennen. Dieser Umstand hat vielleicht anch dic älteren Forscher veranlasst, unser Knorpelrohr als eine Chorda oder ein chordaähnliches Gebilde anzusehen. Heinrieh Mïler hat in seinem mehrfach eitirten Werke ïber die Regeneration uns pag. 12 mitgetheilt, dass das Knorpelrohr rorn ctwa den Durchmesser der S'chwanzwirbel hat und sich gegen das hintere Ende alhmählich verjiungt. Er untersuchte hauptsächlich an Querschnitten, die mir durch die Liberalität des Hern Geheimrath von Külliker, meines verchrten Lehrers, sämmtlich zur Durehsicht ïberlassen wurden, und so konnte ich denn constatiren, dass seine Darstellung nach den Präparaten, die H. Mïller angefertigt hatte, vollständig zutreffend ist. Ich bin demmach im Stande anf die ferneren Ausführungen Mïller's pag. 13-15, zu verweisen. Nur cines ist mir, weun auch nicht an den Mïller'schen Praeparaten, so doch an einer zur Controle angefertigten Schnittserie aufgefallen, lass der ron IIïller zuerst erkannte. Hyalinknorpel durchans nicht diesen Namen verdient. Betrachten wir die Genese des Knorpelrohres etwas genauer, so sehen wir in den allerjungsten Stadien der Regeneration ebenfalls, wie es bei den Salamandriden der Fall ist, ein zelliges Blastem auftreten, das eventuell der häutigen Skeletanlage im normalen Theil rerglichen werden kann. Aus diesem zelligen Blastem entwickelt sich aber nicht, wie Müller meint und es beschreibt, eine Art ron Hyalinknorpel, ,mit grösseren meist scharf polygonalen Knorpelhöhlen, mit hyaliner Zwischensubstanz und einer von dieser scharf zu trennenten Grenzschicht,“ sondern es geht aus demselben durch Umwandlung der einzelnen Embryonalzellen ein ganz eigenthiimlicher hrnorpel hervor, der iiberall, sowohl in der mittleren Zone, als auch an den Randschichten eive ausserordentlich geringe IIenge von Zwischensubstanz absondert. Die Bilder, wie sie Mïller, Traf. II. Figg. 6 und T darstellt, sind nach meinen Beobachtungen nicht ganz richtig, da die Intercelhuarubstanz ron Müller umbedingt viel zu stark angegeben ist. Wir finden vielmehr anch bei den jüngeren Stadien Verhältnisse, wie er sie von älteren regenerinten Schwiinzen darstellt, nämlich eine ansserordentlich dichte Schichtung der zelligen Elemente, wie ich das anf meiner Tafel 11. Fig. 9 rom Ende eines regenerirten Knorpelrohres von Platydactylus mauritanicus abgebildet habe. Niemals erreicht die Zwisehensubstanz anch nur annälnernd die Mächtigkeit, wie wir das bei den Urodelen beobachten kömnen. Interessant ist num vor allem, dass sich, wie ebenfalls schon von Mïller und den älteren Autoren gesehen worden ist, zwei Ringe in dem linorpelrohr unterscheiden lassen, ein äusserer und ein innerer, welche beide verkalken. Auch Miuller hat dieselben Taf. II. Fig. 7 abgebildet, jedoch dabei ansser Acht gelassen, dass durch die Terkalkung, welche in diesen kingen eintritt, nun die Kinorpelzellen in ganz 
eigenthïmlicher Weise verdringt werten. Vun den älteren Forschem ist also beschrieben worden, dass sich der Knorpel znerst dadurch metamorphosirt, dass er Elemente ron kohlensaurem Kralk absondert, die sich in 2 Lagen, als änssere md innere Lamelle, selı dentlich unterscheiden lassen. Später, wurde gesagt, kommt es zu einer Knochenbildmg, namentlich an der äusseren Fläche. Ich habe nun die Bildung dieses Knochens etwas genauer verfolgt, und kann behampten, dass er mit der Verkalkung des Knorpéls in keinem Znsammenhange steht, dass viehmehr der Knochen ein Product der Bindegewebszellen ist, welche an der ånsseren und inneren Seite das Knorpehrohr umgeben. An der äusseren Lamelle ist der Faserknochen, dessen zellige Elemente sich noch dentlich als Knochenkörperchen erkennen lassen, oftmals viel starker, als an der inneren; jedoch finde ich auch eime Knochenbildung in der inneren Lamelle, wo man auf einzehnen Stellen den Uebergang in das die Rïhre ausfitlende lockere Bindegewebe genau constatiren kam. Ein Auftreten von Ostenklasten. wie bei der Knochenentwickelung der hïheren Wirbelthiere, komute ich niemals benbachten. Was den Knorpel anbelangt, so finde ich, dass bei den Ascalaboten das ganze Gewebe des Rückenrohres fast ans reinem Zellkmorpel besteht, dessen Elemente ausserordentlich dicht an einander liegen, so dass won der Bildung einer Zwischensubstanz kamm die Rede sein kann, wie es auf's Dentlichste die vortreffliche Färbung mit Nethylviolett ergiebt, vermöge deren bekanntlich die geringsten Mengen von Knolpelgrundsubstanz nachgewiesen werden kömnen. Die Kinorpelelemente platten sich gegenseitig ab, und zwar von vorn nach hinten, so dass oftmals einzelne Zellen namentlich am hinteren Ende, die ganze Breite der Lamelle durchsetzen. Bei Hemidactylus sahen die Knorpelzellen fäst wie Chordazellen ans; es kommt gar nicht selten zum Schwund der Kerne, die sich in späteren Stadien ansserordentlich schwer nachweisen lassen, und anstatt der Bildung der Grmndsubstanz findet gleich eine Ablagerung ron Kalk an den Rändern statt; nnd zwar zwischen den Zellen, wodurch ausserordentlich viele Knorpelelemente verdrängt werden. Sn kann es oftmals anssehen, als wüude der Kalk in den Zellen selbst deponirt. Letztere Ansielst ist natiirlicherweise vollständig hinfällig, denn es handelt sich hier, wie man schrittweise rerfolgen kam, nur um eine Verdrångnng der nicht secemirenden Elemente. Bei Anguis fragilis findet schon mehr Kapselbildung statt, aber die Knorpelzellen sind in änsserst mregelmässigen Gruppen angeordnet, und die Zwischensubstanz ist hier bedentend mehr ausgebildet, als bei den Ascalaboten. Bei den Eidechsen, namentlich bei Lacerta ocellata, tritt zuerst, wie das schon Heinrich Mïller bei anderen Formen gesehen hat, ein Zellknorpel auf, der von dem gewöhnlichen Zellknorpel der Reptilien nicht unterschieden werden kann: alluählich wird dann eine ziemlich bedentende Menge von Grundsubstanz abgesondert. wodurch der Knorpel zum Hyalinknorpel wird, und erst später findet dann eine Einlagerung ron Kalkeoncrementen in die Grundsubstanz der beiden Lamellen statt. Auch hier wird der Knochen nicht in den Elementen des Korpels sondern aus dem ungebenden Bindegewebe, dem Perichondrimm, gebildet. Doch sehe ich, z. B. bei Senira licolor, dass eine innere Lamelle stark verkalkt, und sogar verknöchert vorhanden war, während von einer Terkalkung und Verknöcherung der äusseren Lamelle nichts entdeckt werden konnte, trotzdem der Schwanz äusserlich fast vollständig das Anssehen des normalen hatte. Vergleichen wir cliese Verluältnisse mit den normalen Bildungen der Selwanzwirbelsäule, so finden wir, dass der Knorpel an den Intervertebralstellen bei den Ascalaboten oft sehr ähnlich ist demjenigen des Knorpelrohres; anch hier ist fast reiner Zellknorpel vorhanden, ohne jede Intercellularsubstanz, ein Torhältniss, welches daranf schlicsscn lässt. dass clie Regenerationsvorgänge auch hier noch, trotz der functionellen Anpassung, einen bestimmten 
Entwickulungsgang durchlaufen, der dem embryonalen oder normalen Entwiekelungsgange gleicht. Ueber das Ende des Knorpelrohres sagt Mïller, dass dasselbe nieht immer gleich ist, in der Regel geht der Schwanz in ein kleines Höckerchen aus, das über die allmählich kleiner gewordene Schuppenreihe etwas vorstelıt. Bis an oder in dasselbe erstreckt sich das Inorpelrohr, naehdem anch bei den älteren Exemplaren die Verkalkung desselben anfgehört hat. Meist geht dann der diinn und kleinzellig gewordene Knorpel in das itbrige pigmentlose Gewebe über. Der hohle Rückennarksstrang aber, oder wenn man licber will, das filum terminale, tritt auch in dieses wenig differencirtc Gewebe ein, und ist deshalb auf Quer- wie auf Längsschnitten bis ganz nahe unter die Epidermis zu verfolgen. Ieh habe nun fast regehmässig constatiren kümen, dass das Knorpelrohn nicht in der Weise, wie es Mïller beschreibt, mit dem ibbrigen Gewebe, wenigstens bei dem vollständig regenerirten Schwanz zusammenhängt, sondern dass es immerhin doch scharf von demselben zn trennen ist. Vor allen Dingen ist dasselbe nicht an der hinteren Seite offen, um das Riickenmark durchzulassen, welches dann noch eine Strecke weit bis dicht unter die Ejidermis verläuft, sondem ich fand dassclbe verschlossen, namentlieh bei den Ascalaboten, und oftmals sogar noch durch einen besonderen knorpeligen Pfropf, der den Verschhuss vervollständigte. Einen allerdings nicht ganz frontalen Längssehnitt habe ich Taf. II Fig. 9 abgebildet, und ebenso ist in Taf. II Fig. 3 von derselben Species das Ende des Rüekenmarkes im Knorpehrohr angegeben. Eine Tänschung ist kaum möglieh, da es sich hierum vollständige Längsschnittserien handelte. Was die Umwandlung des Knorpelruhres anbelangt, so stimme ieh darm mit Mïller iilserein, wenn er behauptet dass im späteren Leben eine fast vollständige und Verkalkung Verknöchermg desselben stattzızutinden pflegt; namentlich an den vorderen Theilen. Die Hypothese Gachet's, dass die Verknöcherung eventuell rom Klima abhängig sei, wird durch meine Beobachtungen durchans nicht unterstiitzt.

Wenn ich kurz noch einmal auf die Ansicht zurickkomme, die auch schliesslich sogar noch von Leydig vertreten wurde, dass das nengebildete Knorpelrohr vielleicht doch einer Chorda zu homologisiren wäre, so muss ich nu daran erimnern, dass die Regeneration der Chorda schon bei den Urodelen, und zwar, wie wir gesehen haben, selbst bei den jünsten Larven derselben nicht mehr eintritt. Dass sich eventnell später wieder Wirbel ans dem Rohr bilden könnten, glanbe ich vollständig verneinen zu diiufen; denn ieh habe eine sehr grosse Anzahl von regenerirten Schwänzen durchmustert, und niemals auch nur den geringsten Hinweis daranf gefunden.

Was die interessante Thatsache anbelangt, dass sich der Schwanz der Eidechsen of tmals micht einfach, sondern doppelt oder gar mehrfach regenerirt, wie man das wohl an Exemplaren eines jeden grösseren Musemms beobachten kann, so rerweise ich auf die älteren Darstellungen. In unserem zoologischen Institut befinden sich 2 höchst interessante doppelschwänzige Exemplare. Das eine von Podinema teguixin (Wag.), besitzt 3 Gabeln, von denen die beiden oberen dureh eine Epidermiswucherung zusammengehalten werden, während der untere frei ist und eine bei weitem deutlichere Segmentirung zeigt wie die oberen, so dass wahrseheinlieh in ihm das Ende der geknickten normalen Wirbelsäule verläuft. Das zweite Exemplar von Platydactylus guttatns besitzt ein gabeliges Sehwanzende mit einem $4 \mathrm{em}$ und einem $1 \mathrm{~cm}$ langen Ast. In der Würzburger zootomischen sammlung befinden sich ebenfalls 2 Exemplare von Hemidactylus, von welchen der eine sogar 7 stummelförmige Fortsïtze am Schwanzende besitzt, die allerdings zum grossen Theil nur durch häutige Wiilste gebildet zu sein seheinen.

Auch ieh komme bei der Betrachtung dieser Objecte zu dem Schluss, dass es stets; 
nur eigenthiimliche durch unvollkommene Ruptur des Schwanzes entstandene Missbildungen sind: gewöhnlich ist, wenn zwei Schwänzc vorhanden sind, der eine noch der normale, nicht vollständig abgeworfenc, der andere dagegen ein durch den Reiz der Verwundnng hervorgerufener regenerirter Schwanz. Ueber das Verhalten des Knorpelrohres bei diesen Almormitäten haben sich bereits ältere Forscher mehrfach ausgesprochen. Diss man solehe Missbildungen anch künstlich hervorrufen kann, ist ebenfalls längst bekannt. Genauer beobachtet habe ich dic Regeneration des Knorpehohres bei den ein- heimisehen Eidechsen; ferner loei Lacerta ocellata, Lacerta viridis, Platydactylus facettanus, Platydactylus muilatus, Platydactylus verus, Phyllodactylus curopaens, Hemidactylus frenatus, Hemidactylus platyurus und Senira bicolor. I Ueberall fand ich in den Sammlungen, wo ich danach snchte, eine grosse Anzah\} schon äısserlich erkennlıarer, regenerirter Schwänze der betreffenden Arten, und auch unter den selbstgefangenen Exemplaren von Lacerta muralis war der Procentsatz derselben ansserorlentlich hoch; und zwar merkwürdigerweise in der Nähe von Stäcten und Dörfern am höchsten; in Einöden dagegen, in welche sich selten ein menschlicher Fuss verirt, am geringsten. So erklärt sich die Bemerkung, die schon früher von einem Reisenden Needham gemacht wurde, und die ich schon pag. 15 erwähnt habe; derselbe stellt als Ursache von dem häufigen Verhuste des Schwanzes bei den Eidechsen in Portugal dic Kinder hin, welche mit den Eidechsen spielten und sie geflissentlich verstiimmelten.

Fiir die Regeneration der Gliedmassen ist die von Plitippeaux zuerst gemachte Benbachtung von der grössten Wiehtigkeit, dass bei älteren Amphibien nur dann die Extremitäten rollständig wieder nachwachsen, wenn ein oder melırere Knochen bei der Amputation verletzt waren, dlass dagegen nach einer vollständigen Exstirpation niemals eine Neubildung des Skeletes constatirt werden konnte.

Ebenso wird kcine Regeneration eintreten, wenn der Schulter-orler Bcekengiirtel verletzt waren.

Sonit werden wir hier dic Richtigkeit des Satzes beweisen kïnnen, dass der pathologisehe Reiz einen bedeutenden Einfluss auf die Regenerationsprocesse ausïbt und dass die Neubildung nicht allein dadurch zu erklären ist, dass nun an dem Amputationsstumpf einfach dureh das Fehlen des vorher vorhanden gewesenen Geweberluckes ein locus minoris resistentiae sich befindet. Dazu werden naturgemäss Vererlungserseheinungen ontogenetischer und vielleicht anch phylogenetischer Art kommen, wenn dieselben bei den immerhin doch schon lıch organisirten Salamandrinen gewiss oftmals anch nur in abgekiurzter und unklarer Form bei der Regeneration ihren Ausdruck finden. Dass gerade bei dem skelet der Extremitäten und weniger bei dem des Stammes so viel darauf ankommt, dass die betreffenden Theile nicht in den Gelenken exstirpirt waren, hat seinen Grund wohl darin, dass bei den Extremitäten der Salamandrinen die Gelenke besser ausgebildet und die Knochen unabhängiger von einander sind, als dies namentlich im letzten Theil des Schwanzskelets derselben Thiere der Fall ist.

Auch bei den Reptilien sind, als bereits oben erwïhnt, die Selnwanzwirbel in eigenthuimlieher Weise angepasst, ja es kommt luäufig zu gar keiner abgesehlossenen Gelenkbildung, wie bei den Ascalaboten. Bei jeder Amputation des Schwanzes muss also auch eine Verletzung der Knochen stattfinden, und eine reine Exstirpation ist eben unmöglich.

Dies ist der Grund, weshalb anch bei jüngeren salamandrinen und besonders bei deren Larven fast stets cine Regeneration der Extremitäten eintritt, wenn nieht, wie erwilhnt, der Schulteroder Beckengiirtel mit verletzt wurde, denn hier sind die Gelenke noch nicht derartig ausgebildet 
wie im röllig erwachsenen Thicr, weshalb auch bei der saubersten Präparation eine Verletzung der am Stumpf stehenbleibenden Knochen kaum zu umgehen ist.

Bei älteren Thieren wird man sogar einzelne Finger exstirpiren kïmen und hier ebenso wie hei der Exstirpation im Knie- oder Ellenbogengelenk sich stets iiberzengen künnen, dass rum eincr liegencration des Skeletes in diesem Falle keine Rede mehr ișt.

Ton einem Simnesorgan, dem Auge, waren diese Thatsachen schon Blumentach bekannt, "r. fand bei seinen Experimenten, dass ein viollig exstirpirter Bulbus bei einzelnen Amphibien sich niemals nenbildete, dass dagegen ein halb ansgeschnittenes Auge sehr bald wieder völlig die Gestalt und Structur des alten angenommen hatte. Ueber diese Verhältnisse spricht sich Lotze ${ }^{1}$ ) folgendermassen aus: „Die Regenerationen rerloren gegangener Glieder erfolgen, wie es wenigstens scheint, in ähnlicher Treise, wie rlie ersten Bildungen; Ablagerung formlosen Blastems, Zerfall desselben in versehiedene differente Theile, die erst spät die friilıere Gestalt wieder erreichen, kommen anch hier ror. Nun sind aber im ansgebildeten Körper nicht nur die Lagen und Functionsrerhältnisse des Ganzen ïberhaupt, sondern namentlich die derjenigen Theile, in deren Ungebung sich das wiederentstehende Glier bildet, häufig beträchtlich ander's, als sie zur Zeit der ersten Bildung waren. Wenn daher der gegenwärtige Bestand eines ausgebildeten Kö̈rpers zwar durch eine morphotische Formel ausgedriickt werden kann, die einen verloren gegangeneu Theil mit einschliesst und ihu postulirt, so ist doch damit keineswegs die II ethode der Bildung erklärt, durch welche der abgelagerte Ersatzstoff aus 'vorläufigen Gestalten, die dem Postulat der Formel zuerst gar nieht entsprechen, nach und nach in die rerlangte Anordnung übergefïhrt wird. Man wiirde nach jener Hỵpothese allenfalls eine Neubildung der Krystalllinse begreifen: denn man würde sich rorstellen kiinnen, dass die Kapsel derselben auch im gewöhnlichen Zustand eine Art bildender und den Stoffwechsel regulirender Matrix sei, die daher den Verlust der Linse durch eine Erhöhung ihrer gewöhnlichen Thätigkeit, olne dabei doch zu anderen Methoden ihres Wirkens genöthigt zu sein, auszugleichen vermöchte; aber man kam nicht anf gleiche Weise die Regeneration eines Krebsschwanzes erklären, für welche der zuriekgebliebene stumpf mmöglich dieselbe Funktion iibernehmen künnte. Gerade diese Phänomene der Regeneration entlıalten ein schwierigeres Räthsel, als die vollkommene Neubildung eines ganzen O rga $\mathrm{n}$ ism us. In der Pflanze, die keinen umfänglicheren Theil wiedererzeugt, sondern nach dem Verlust des einen ihren Saftreichthum nur zu iippigeren Nachwuehs iiberall gleichgebauter Bildungen benutzt, kommt diese Schwierigkeit nicht ror. Bei ihr ist die Blattknospe weder eine schon fertige Miniatu des Blattes, noch ist sie an einen bereits innerhalb des Stengels organisirten Keim als Ansatzpunkt ihrer Bildung gebunden; sie entsteht vielmehr ans einem anscheinend chaotischen Zellenhaufen, und gestaltet sich erst durch seine regetirende Thätigkeit, und zwar nicht in allen ihren Theilen zugleich, sondern die Spitze roranschiebend, während die Basis noch ziemlich mausgebildet ist. Hier liegt es daher nahe, die Entrickelung ganz an die qualitatire chemische Natur des Saftes und an die eigenthimliche Gestalt der einzelnen Primitirzellen gebunden zu denken. Dies kam bei Thieren nicht so sein. Soll aus dem abgelagerten Plasma hier ein rerlorenes bein dort cin verlorener Schwanz regenerirt werden. so muss allerdings die organisirte 
Umgebung, oder die Loealität der Neubildung anf die speeifisehe Gestaltung des Nachwuchses einen bestimmenden Einfluss ansüben. Aber es bleibt uns niehts ib rig, als die Art, in weleher dieser Einfluss wirksam ist, und die Quellen, von denen er ausgeht, für rorlä ufig vollkommen unbekannt zn erklären."

Nehmen wir nach dem stande der hentigen Wissenschaft die functionellen Anpassungen und die Reize, welehe die versehiedenen Gewebe auf einander ausiiben, zur Erklärung dieser so merkwïrdigen Thatsache zu Hïlfe, wie das von Roux in seinem melırfach citirten Werke bereits in der ausgiebigsten Weise für andere Theile gesehehen ist, so sehen wir vor allen Dingen ein Gewebe der grössten. Variabilität fähig, das Bindegewebe, und dies spielt anch bei der Regeneration die grösste Rolle. Es wird also unter allen Unständen wiedererzeugt. Es bilden sieh die verletzten Bindegewebszellen zu Embryonalzellen um und liedureh ist der Austoss gegeben zu ernenertem Wachsthum. Obgleich nun allerdings das primordiale Skelet bein Embryo auch aus dem embryonalen Bindegewebe hervorgeht, so seheint es doch, als ob bei älteren Thieren, bei denen eine Exstirpation in Gelenk vorgenommen wurde, num die Regenerationsfähigkeit sieh nicht so weit erstreckte, dass erst ein prinordiales Skelet angelegt wiirde, aus dem sich durch weitere Differencirnng ein knöehernes Skelet entwiekelt. Es seheint viehmehr darauf anznknmmen, dass dieser Reiz ausgehen muss von den verletzten Periostzellen. Roux sagt: Zu welcher Zeit nun fïr jedes Gewebe, und in jedem Organe die Periode des embryonalen Lebens aufhört und die des Reizlebens beginut, ist wahrseheinlich für jeden Theil verschieden. Sn hört denn hier die Regenerationsfähigkeit anf, wenn die Reizaffection nieht mehr das skeletogene Gewebe erreicht; wenn auch nach der Boll'sehen Ansicht, nach welcher die versehiedenen Gewebe in der Riehtung des geringsten zu ïberwindenden Druekes waehsen, immerhin die Möglichkeit geboten ist, dass eine völlige Reproduction der Gliednassen stattfinden könnte. Auch naelı den Gesetzen der correlativen Entwickelung iniisste eine solehe sogar unbedingt postulint werden. In die praetische Chirurgie sind diese Thatsaehen bereits seit länger als einem Jahrhundert übergegangen; denn man weiss, dass ein einfacher Amputationsstumpf leiehter heilt, als die durch Exarticulation von Gliedmassen lerrngerufenen Wunden. Es wird dureh die verletzten Periostzellen eine Neubildung ron Callus angeregt, durch welehen vor allem auch ein festerer Absehluss der Röhrenknochen herbeigeführt wird.

Nehmen wir vor Allem die normale Entwickelung ter Gliedmassen der höheren Wirbelthiere als Basis an, so finden wir, dass leider die Beobachtungen iiber diesen Gregenstand noch ziemlieh dürftig sind. Für unsere Zweeke kommen hier in erster Linie in Betraeht die Arbeiten von Götte und Strasser, da dieselben sieh mit der Entwiekelung des Extremitiitenskeletes der Amphibien besehäftigen. Die Gliermassen entstehen zuerst als einfache Auswiichse aus den Seiten des Körpers, und sind ans Ektodern und Mesoderm zusammengesetzt. Bei den Amnioten erseheinen sie als Vorspriinge einer besonderen Längsleiste, welehe als Wolff'sche Leiste bekannt ist. Am distalen Rande besitzen sie eine verdiekte Lktodermkappe (Küllikr). | Beide Gliedmassen verlanfen anfangs parallel der Körperobertäehe und sind beide nach hinten geriehtet. Innerhalb des Mesoderms der Gliedmassen bildet sich nun ein zusammenhïngendes Blastem aus, aus welehem durch Differeneirung bestimmter Knorpelcentren dann das primordiale Knorpelskelet hervorgeht, welehes späterhin verknöehert. Der Entwickehungsworgang ist für Hand und Fuss beinahe derselbe. Die beiden vorderen Finger (anf der radialen, resp. tibialen Seite) bilden sieh in erster Reihe, dann der dritte, vierte und fünfte nach einander. Nach Strasser entwiekeln sich aus der entinuirliehen 
Gewebeplatte zuerst die Kerne des Humems, sowie der LIna mit dem Radius, gleichzeitig die entsprechenden Theile der hinteren Gliedmassen. Etwas später erscheint dann an der Basis des ersten und zweiten Fingers ein knorpeliges Centrum (das bereits in Form einer Hervorragung am Ende der Extrenität sichtbar war) an der Stelle des bleibenden zweiten Carpale der distalen Carpalreihe, und ron diesem Centrum ans breitet sich dann der Vorgang der Verknorpehng nnch in dem ganzen ïbrigen Carpus und nach ren Fingern ans. Anf diese W'eise entsteht eine continuirliche knorpelige Carpalplatte, welche einerseits nit dem Knorpel der beiden Metacarpalia, andererseits mit dem Radius und der Ulna zusanmenhängt. Der dritte und rierte Finger und an Fusse anch die fuinfte Zehe wachsen allmählich an der Ulnarseite der zusammenhängenden Carpalplatte hervor, während diese selbst sich gliedert und in die Carpalknochen zerfällt, nachdem sie sich rom Radius und der Uha getrennt hat. Ton dem urspringlichen radialen Knorpelstrang entwickelt sich ein proximales Radiale, ferner das erste Carpale, und an der distalen Seite das zweite Carpale. ..Das erste Carpale kommt so zwischen den Basalknorpel des zweiten Fingers und das Radiale zu liegen und scheint daher eine mittlere Reihe ron Carpalknochen zu vertreten, während das Centrale einen andern Vertreter derselben darstellt. Das C'entrale und das Intermedium sind das mittlere und das proximale Product der Abgliederung des uharen Knorpelstranges von dem ursprïnglichen Carpus, während das zweite Carpale diesem und dem radialen Knorpelstrang gemeinsam ist. Die uluare oder fibulare Seite des Carpus oder Tarsus theilt sich in ein proximales Element, das Ulnare oder Fibulare, wobei jedoch das Unare theilweise mit dem lntermedium verbunden bleibt. Ans dieser Platte entstehen auch 2 Carpalia, welche mit dem dritten und vierten Finger articuliren, während am Fusse die entsprechenden Elemente mit der dritten Zehe einer-, und der vierten und fünften Zelme andererseits articuliren. Nach Götte besteht das primitive Gliedmassenskelet ans einem basalen Abschnitt, dem Humerus, welcher sich in einen radialen und einen ulnaren Strang fortsetzt, die wiederum in die beiden ersten Finger auslaufen. Die beiden Strahlen verschmelzen an der Basis der Finger, um den Carpus zu bilden, und anf diese Weise ist damn die Gliederung der Gliedmasse in Oberarm, Unterarm und Hand durchgeführt. Die Ulna, welche sich ursprünglich in den zweiten Finger fortsetzt, trennt sich später davon ab, und läuft in den dritten Finger ans. Von der Seite des die Ulna mit dem dritten Finger verbindenden Theiles des Carpus sprosst damn der vierte Finger hervor, und am Fuss entsteht dann in clieser Gegend die vierte und fünte Zehe. Jede der drei mit lem ersten, zweiten und dritten Finger ver)undenen Knorpelsäulen zerfällt in 3 hinter einander gelegene Carpalknochen, so dass das skelet der Hand oder des Fusses sich nach Götte aus einer proximalen, einer mittleren und einer distalen Reihe ron Carpalknochen herausbildet, von denen jeder wiederum potentiell 3 Elemente enthält. Die proximale Reihe besteht hiernach aus dem Radiale, dem Intermedium und dem Ulnare, die mittlere aus Carpale 1, dem Centrale und Carpale 4, die distale Reihe endlich und Carpale 2 (das nach Götte aus zwei verschmolzenen Elementen zusammengesetzt ist,) und aus Carpale 3.

Bevor noch Götte seine ausführliche Arbeit publicirt hatte, war ich bereits zu Resultaten gekommen, welche in mir dieselbe Ueberzengung wach riefen, wie sie auch Götte hatte, dass nämlicl die Regeneration nur Processe recapitulirt, welche in der ontogenetischen Entwickelung der G'liermassen vorhergegangen waren. Ich hatte mich damals genau an die Untersuchungen Strasser's gehalten, uml am regenerirten Theile das nachuntersucht, was er für den normalen angegeben hatte. Da nun inzwischen das grosse und schön ausgestattete Werk von Götte vorliegt, so will ich 
es unterlassen, hier noch eimmal auf die genauere Beschreibung der verschiedenen Regenerationsstadien einzugehen, ich habe mich darauf beschränkt, nu 2 ausfülıliche Abbildungen zu geben, um in betreff dieser Frage hier keine Lücke zu lassen; ausserdem bin ich dem Vorgange Strasser's gefolgt, und habe in Tafel 2 Figur 13 und 14 die verschiedenen åusserlich sichtbaren Phasen der Regeneration der Gliedmassen schematisch dargestellt. Vor allem muss ich rorausschicken, dass ich etwas mehr Werth auf die prochondrale Centrirung lege, wie sie Strasser nennt, als Götte; dem durch sie scheint mir doch angedeutet zu werden, dass wir hier die ältesten Centren des späteren Kunchensystemes der Gliedmassen zu suchen haben. Es wird sich naturgemäss der phylogenetisch älteste Knochen auch zuerst ontogenetisch differenciren, wenigstens wenn wir hiel das biogenetische Grundgesetz gelten lassen wollen. So wird es vor Allem auffallen, dass die radialen Gliedmassen sich sowohl in der primären Entwickelung, als auch bei der Regeneration zuerst wiedererzengen. Götte hat bekanntlich an diese Thatsache eine Hypothese gekniipft, dic ihn zu einer etwas reränderten Auffassung des Gegenbaur'schen Archipterygiums führte, und ich glaube mich seinen Ansfülırumgen auch in Betreft dieser Hรpothese anschliessen zu können, umsomehr, als es noch an weiteren Untersuchungen iiber die ontogenetische Entwickelung der Extremitäten bei den niederen Wirbelthieren mangclt. Wir müssen erst, um auf weitere Vergleichungen eingehen zu können, eine genaue Entwickelungsgeschichte der Elasmobranchierextremitäten besitzen, die hoffentlich wohl in kurzem einmal einen Forscher interessiren dürfte. Bisher ist nur bekannt, dass sich die Skelettheile der Elasmobranchierextremität entwickeln, bevor noch cin Schulter- oder Beckengiirtel angelegt ist, und das ist unzweifelhaft fuir die Bildungsweise der gesammten Gliedmassen der Wirbelthiere ausserordentlich wichtig. Es handelt sich vor allem um eine Unterstiitzung, welche dem Flossensaum, der Wolff"schen Leiste, an bestimmten Stellen zu Theil werden soll und es ist wohl zu erklären, dass uun diese Stütze nicht von Innen nach Aussen, sondern von Aussen nach Imnen sich entwickelt. Deshalb lege ich auch so grosses Gewicht auf die distal auftretenden Knorpelcentren in den regenerirten Gliedmassen der Salamandrinen, weil hieraus sich eventuell später eine Vergleichung mit den ähnlichen Terhältnissen bei den Selachiern ergeben könnte, und wir dadurch erst zu einem wirklichen Terständniss der bisher beobachteten Thatsachen kommen wiuden. Bevor das geschehen ist, kann ich mich auch den Ausfïhrungen, welche Balfour an die Götte'schen und Strasser'schen Arbeiten ankniipft, nicht vollständig anschliessen: denn wenn wir anch annelmen, dass der Radius urspriuglich ventral, und die Ulna dorsal liegt, so lässt sich doch daraus olme Wreiteres nicht fulgern, dass beicle mehrere verschmolzene Strahlen der Elasmobranchierflosse repräsentiren, welche ,an ihren distalen Enden noch zahlreiche Flossenstrahlen stiitzen, aus denen sich die Reihen der Carpal- und Tarsalknochen bilden."

Zum Schluss sei kurz bemerkt, dass ich nicht nur an Tritonen und deren Larven experimentirte, wie das Götte gethan, sondern, dass ichauch andere Thiere zur Vergleichung heranzog. Vortreftlich passend zu dieser Untersuchung warwieder eimmal Siredon, und dann Pleurodeles, doch ging bei letzterem die Neubildung der Extremitäten nicht in derselben rapiden Weise vor siclı, wie die des Schwanzes. Bei Siredon dagegen lässt sich ein Unterschied in del Wachsthumsenergie bei diesen beiden Theilen nicht bemerken, und in der günstigsten Jahreszeit dauerte es etwa 6 Wochen bis eine am Humerus oder Femur amputirte Extremität rollkommen nachgerachsen war. Ein vollst:̈ndig negatives Resultat erhielt ich dagegen bei den Larven unserer einheimischen Frösche und Kröten, auch wenn sie noch in sehr jugendlichem Alter standen. Stets wuchs auch unter den 
grimstigsten Lebensbedingungen ein kleiner Conus an der verstimmelten Extremität nach, den ich jedoch niemals zu weiteren Ausbildung gelangen sah. Diese Thatsaelıe ist $\mathrm{nm}$ so anfälliger, als us ja bekannt ist, dass Frösehe mit 3 Hinterbeinen vorkommen, und solehe zuerst wohl ron $J$. ran der Hoeven und anch in verschiedenen populären Werken abgebildet sind. Mir selbst ist ein derartiges Exemplar leider niemals in die Hände gekommen, und so kann ich mich auch iiber die Ursaehen dieser Missbildung hier nicht weiter anssprechen.

Auch die zu demselben Zweck ihrer Gliedmassen beraubten Reptilien zeigten kein hüheres Regenerationsvermögen, als die Säugethiere und Vögel, so dass niemals beobachtet werden konnte, dass eine wirkliche Neubildung einer Extremität stattgefunden luätte.

Fassen wir die Ergebnisse, welehe durch die Untersuchungen ïber das normale und regenerirte Schwanzende zu Tage gefürdert wurken, kurz zusammen, so finden wir vor Allem, in der Reihe der Wirbelthiere die hochinteressante Thatsaehe, dass einmal bei der Bildung der letzten Schwanzwirbel die Chorda unzureiehend ist, wie bei den Urodelen des näheren erörtert wurde, und dass an Stelle der normal gebildeten Wirbel dann ein Knorpelstab tritt, aus welehem sich in späterer Zeit Virbelkörper differenciren, die jedoch nicht immer genau den vorhergehenden entspreehen. Wir sehen, dass ähmlich, wie bei den Cheloniern durch functionelle Anpassung dies bedingt ist, ans dem Knorpelstabe procoele, opischotoele, amphieoele und biconvexe Wirbel entstehen, doch wird man hier, namentlieh da diese versehiedenen Typen ganz unregelmässig mit einander abwechseln, an eine funetionelle Anpassung nicht denken können. Dagegen beruht die Bildung des Ǩnorpelstabes selbst allerdings auf einer functionellen Anpassung, denn es kann eonstatirt werden, wie ich das auch an anderen Orten erwälnt habe, dass eine Turgescenz des ganzen Schwanzendes zu bestimmten Zeiten, und zwar zur Brunstperiode der Urodelen eintritt, und dass höchst wahrscheinliels dam beim Landaufenthalt der Thiere wiederm eine wenn auch geringe Reduetion der su gebildeten Wirbel stattfindet. Aneh bei der so ausserordentlich langschwänzigen Laeerta muralis finden wir ein Ḱnorpelstäbchen, und die Bedeutung desselben ist für die Regeneration eine äusserst wiehtige; denn die regenerirten Wirbel werden nicht, wie es bei der embryonalen Bildung der Fall ist, von dem skeletogenen Gewebe der Chorda differeneirt, sie entwiekeln sich vielmehr in ähnlieher Weise aus einem axialen Gewebe, einem Knorpelstabe, wie das vorher weitläufig beselurieben worden ist; also nach dem Typus der normalen Wirbelbildnng im Schwanzende. Auf der anderen Seite sehen wir, dass bei vielen Thieren die Chorda für die Bildung der Wirbel zu lang ist, oder wenigstens bedentend länger, als die später um sie hermm entstehende Wirbelsäule. Das ist vor Allem beobachtet worden bei den Entwiekelungsrorgängen an cler Sehwanzspitze der Vügel und Säugethiere vou $\operatorname{Braun~}^{1}$ ). Derselue hatte beim Papagei ein kleines gestieltes Knöpfehen gefunden, das sich nur auf bestimnten Stadien, und zwar zur Zeit der Entwickelung der Federpapillen, zeigte. In dieses Knöpfchen ragt Chorda, wie Rückenmark hinein; allmählich nimmt es jedoch an Masse immermehr ab, und besteht sehliesslich nur noch aus einem Häufehen von Ektodermzellen, welche der IIaut an der Schwanzspitze aufsitzen. Aehnliche Verhältnisse wurden dann bei Tauben-, Sperlings-, Enten- und Sehleiereulenembryonen nachgewiesen. Interessant ist es vor allem, dass die Chorda hier an ihrem Ende auf einem jüngeren Entwiekelungsstadium stehen bleibt, und dass man ein besonderes Chordastäbchen, wie es Braun genannt hat, unterscheiden kann. Beim Menschen 
hatte bereits Rosenberg ähnliche Thatsaehen gefunden, die später von Braun dahin ergänzt wnrden, dass er bei Schweins-, Katzen-, Sehafs-, Kaninchen-, Maus- und Hundeembryonen analoge Verhältnisse eonstatirte. Um das hinterste Chordaende, sagt Braun, bilden sich keine IVirbel; es ragt jenseits der Wirbelsäule herans, ist mitunter getheilt, gewunden oder geschlängelt, und oftmals kommt es sogar zur Bildung eines dem Sehwanzknöpfehen der Vögel homologen Theiles, den Braun seiner Gestalt wegen Schwanzfaden nennen möchte. Er fand nämlich am hinteren Selnwanzende einen versehieden langen Faden, der sich dureh seine Dünne seharf vom ïbrigen Schwanze absetzt; in ihm liegt in jüngeren Stadien das gewundene oder getheilte Chordaende; später besteht es nur ans Epidermiszellen und sehwindet endlich ganz. S'chon vor längerer Zeit hat Marshall ${ }^{1}$ ) in seiner so hochinteressanten und leider doch so wenig bericksichtigten Arbeit ïber das Schwanzende der Ente nachgewiesen, dass der Endkürper der Wirbelsäule urspriinglich ans vielen Wirbeln besteht, die erst allmählich mit eineinander verschmelzen, dass also anch bei Vögeh anfangs eine bedentend grössere Anzahl von Wirbeln existirt hat. So finden sich hier beim Embryo Verhältnisse vor, welche an die Bildnng der Sehwanzwirbelsäule des Archaeopteryx erimnern. Nicht minder interessant, als bei diesem ältesten Vogel, ist auch der Sehwanz von Hesperomis, wie Wiedersheim ${ }^{2}$ ) in seiner nenesten Arbeit besehreibt. „Er besteht ans 12 starkknochigen Wirbeh, eine grosse Zahl, die vielleicht, abgesehen von der nahezu ausgestorbenen Alca impennis bei keinem jetzigen Vogel mehr zur Beobachtung kommt." Noch heute findet sich bei den Ratiden, wie Wiedershcim in derselben Arbeit angiebt, ein Verhältniss, welches auf die gleich zu bespreehende Hypothese hindeutet, indem bei diesen Vögeln die einzelnen Wirbel bis zur Schwanzspitze hinaus abgegliedert bleiben. So können wir jetzt wohl mit Sieherheit annehmen, dass unseren sämmtlichen Vögeh friiher ein längerer Schwanz zugekommen ist, der erst almählieh dureh Anpassungsverhïlnisse reducirt wurde; dass in ähnlicher Weise, so lehrt uns wenigstens die Entwickelungsgesehichte, die Amphibien in früherer Zeit einen kiirzeren Sehwanz besessen haben, als die hente lebenden. Auch palacontologisch ist del Nachweis zu liefern, dass die Sehwanzwirbel der ältesten Amplibien und Reptilien nie in der bedeutenden Anzahl und Länge vorhanden gewesen sind, in der sie jetzt anftreten. Das bestätigen vor allem anch die nenesten Arbeiten von Credner ïber die Stegocephalen ${ }^{3}$ ). Für die Regenerationsverhältnisse ist dies insofern von grüsserer Wichtigkeit, als sieh naturgenäss bei denjenigen Thieren, bei welehen sehon im embryonalen Leben eine Reduction der schwanzwirbel vorkomnt, nicht besondere Regenerationsfähigkeit vortinden wird; dass dagegen diejenigen Schwänze, in denen schon normaler Weise zu bestimmten Perioden eine Verlängerung eintritt, anch eine bedentend grössere Reproduetionskraft besitzen werden. Dementsprechend finden wir attch, dass der abgestutzte Sehwanz des Hundes niemals wiederwächst; auch bei Viigeln wiirden wir vergeblieh Versnche in dieser Richtung anstellen; dagegen tinden wir, dass namentlich die Schwänze der Urodelen in fast unbegrenzter Weise sich ernenern. Sehon bei den Reptilien ist die Regenerationsfähigkeit des Schwanzes nicht mehr eine so unbegrenzte wie bei den Urodelen; es regenerirt sich der einmal abgesehnittene Schwanz ja fast rollständig bei den Eidechsen und Ascalaboten, so dass man sehliesslich, wemn das Thier gut genähnt wurde, das Neugebildete vom Alten änsserlich kaum

1) Marshall, Niederländisches Archiv f. Zoologie.

2) Wiedersheim, Biolog. Centralbl. Bd. 111. No. 24.

3) Credner, Zeitschr. d. deutsch. Geolog. Gesellsch. 1881-83. 
unterscheiden kann, hingegen lïsst die Reproductionsfähigkeit in rapider Wreise nach, wemn man ein Thier melnefach zu verstimmeln sucht.

Leider besitzen wir, soviel ich wenigstens weiss, keine palaeontologischen Funde, welche uns einen Anfschluss darïber greben kümnten, wann zum ersten Mal, und leei welcher Form die so hïehst wunderbare Umbildung der regenerirten Wirbelsäule in ein Knorpelrohr aufgetreten ist. Es miisste sich hier unbedingt das Knon elrohr, da es durchans kein so vergängliches Gebilde ist, und im Alter sogar, wie erwähnt, an der äusseren und inneren Oberfl̈̈che stark verknöchert, ebensogut erhalten haben, wie die iibrigen Slieletthcile. Betrachten wir die Ascalaboten als die niedrigst stehenden jetzt lebenden Reptilien, so tinden wir bei ihnen keine anderen Verhältnisse, als bei den Eidechsen; dagegen besitzen weder Krokodile, noch Chelonier, noch Schlangen das Vermögen, al)geschnittene Schwanzstiicke wieder zu erzengen. Wo die Regenerationsfähigkeit des Skeletsystems in der phylogenetischen Reilıe beginnt, und wo sie endigt, das zu entscheiden, muss späteren palaenntrlogischen Aufschlüssen iiberlassen lleilucn.

Im ersten Theile habe ich auf die histnrische Entwickelung der Lehre von den Regenerationsrorgängen weitläutig hingewiesen, und es wird jeden dabei autgefallen sein, dass ror Allem die Schwanzwirbelsäule es gewesen ist, deren Wichererzengung schon in frühester Zeit die Forscher beschäftigte. Ich kam deshalb der allgemeinen Gesichtspunkte halber anf diesen Theil verweisen und möchte nur noch einmal herworheben, dass es nicht etwa Heinrich Mhïler gewesen ist, der zuerst die abweichende Strutur des nengebildeten Riickenmarksrohres bei den Reptilien erkannte, noch auch Dugés, sondern dass Pervaut der Ruhm gebiilurt, zuerst diese complicirten Verhältnisse und zwar bereits im Jahre 1688, erkannt zu haben.

Auch auf eine Theorie muss ich noch zuritckkommen, nänlich die von Leydig. Leydig will -elbst bei normalen Exemplaren von Lacerta viridis, muralis und vivipara im Inneren des Schwanzes ein Knorpelrohr ron 2-3 Zoll Länge gefunden haben, das sich ganz so rerhielt, wie das Ḱnorpelroln des regenerirten Schwanzes. Schon pag. 36 habe ich erwähnt, dass meiner Ansicht nach ein Knorpelrohr stets das Product eines regenerativen Processes ist. Das Aeussere eimes ziemlich lange Zeit regenerirten Schwanzes, namentlich der langschwiinzigen Eidechsenarten, kann allerdings so täuschend dem normalen ähnlich werden, dass man es rou demselben bei obertächlicher Betrachtung nicht unterscheiden kann. Ich selbst habe mehrfach normale Schwänze untersuchen wollen, und schliesslich doch gefunden, dass die betreffenden Theile, die ich zur Untersuchung heranzog, regenerirt waren. Erst nachdem ich mich überzeugt hatte, dass bei jüngeren Eidechsen, die lange Zeit in der Gefangenschaft gehalten waren, und bedeutend an Grösse zugenommen hatten, bei welchen auch jegliche Verletzung des schwanzes vermierlen war, ein solches Ĺnorpelrohr niemals vorkam, konnte die von mir schon friiler gefasste Vermuthung bestätigt werden. Es wäre wenigstens wunderbar, wenu unter den vielen Exemplaren, die ich in der Gefangenschaft gehalten habe, und unter deneu sich Arten ron den verschiedensten Fundorten befanden, niebt einmal der Fall eingetreten wäre, dass ein oder das andere Exemplar uns den von Leydig vermutheten abweichenden Ban der nomalen W'irbelsäule gezeigt hätte. Ich muss demnach Leydig's Darstellung zuriickweisen: wahrscheinlich wird der beriihmte Histologe selbst seine frihere Ansicht nicht weiter festhalten.

Tersuchen wir nun, den eigenthümlichen Ban des Ḱnorpelrohres morphologisch zu erklären, so begegnen wir da bedeutenden Schwicrigkeiten, denn ein ähnliches Gebilde, wie der Knorpelstab des regenerirten Reptilienschwanzes tindet sich wohl nirgends in der gesammten Thierreihe mehr 
vor. Man kümnte ihn, wenigstens in den ersten Stadien, vergleichen mit dem $\bigcup_{s}$ coceygis der anuren Amphibien. Aber dieser Vergleich wird sofort dadurch wieder hinfällig, dass der betreffende Knochen der Anuren vollständig solide ist, und wie Schuegmann ${ }^{1}$ ) nachgewiesen hat aus einer. Verschmelzung mehrerer Wirbel hervorgeht. Ausserdem würde, wemn man diesen Vergleich weiter festhalten wollte, anf eine nähere Verwandtschaftsbeziehung zwischen Anuren und Reptilien hingedeutet werden, die nach den neneren Ansichten wohl unbedingt gelengnet werden muss; lem trotzdem sich verschiedene Vergleichungspunkte bei der Wirbelbildung auffinden lassen, hat man doch die Anuren als eine aberrante Form anzusehen. Schon das Verhalten der Chorda bietet bei ihnen insofern einen Gegensatz zu den Urodelen dar, als diese intravertebral länger persistirt, als intervertebral, - „ein Verhalten, das allerdings zu den Reptilien hiniibertühnt“2) Wir werden so zu der Frage geführt, ob nicht etwa in dem Knorpelroh ein Rïekschlag nach den Anmen oder den den Anuren ähnlichen Vorfahren der Reptilien zu erkennen sei. Freilich werden, wie schon gesagt, die Anuren heute als eine aberrante Form augesehen, welche sich seitlich von der geraden phylogenetischen Reile abgezweigt hat.

Ebenfalls könnte man einen Vergleich wagen mit dem Krnorpelstabe, wie er sich bei den Urodelen im normalen Schwanze vortindet, und wie er sich bildet bei der Regeneration des Lrodelenschwanzes. Anch dieser Vergleich kann nicht durchgefüh't werden, da das Rückenmarkspohr sich in typischer Weise bei den Urodelen regenerirt, und oberhah des neu gebihleten Wirbelsystems verläuft, während das regenerirte Nervensystem der Reptilien im Innern des Knorpehrohres als ein physiologisch fast vollständig werthloses Gebilde sich hinzieht. Nehmen wir allerdings an, dass das Knorpelrohr homolog sei einer Bildung, die durch Verschmelzung der oberen und unteren Bögen mit Ausfall der Wirbclkörper zu stande gekommen, so kann dem der eben angंezogene Vergleich vielleicht mit einer Berechtigung durchgefiihnt werden. Leydig hat dies zu thun versucht; aber wir stossen dabei doch auf bedentende sehwierigkeiten: wir sehen, wie später erörtert werden wird, vor allem eimmal eime vollständig veränderte Structur des Rückenmarkes vor uns: es sind keine Ueffnungen für die Spinalganglien rorhanden, Spinalganglien existiren ïberhaupt nicht, und an stelle des centralen Nervensystems tritt ein anderes in Function, welches nicht an die Skeletverhältnisse gebunden ist.

So sehen wir uns demn genüthigt dieses Knorvehrohr als ein morphologiseh rollständig anderes Gebilde anzusehen, als die ursprïnglich vorhanden gerresene Wirbelsänle; als ein Gebilde, dem sowohl plylogenetisch, als ontogenetisch jele Verwandtschaftsbeziehung zu anderen skelettheilen fehlt, und welches nur entstancen gedacht werden kann durch eine functionelle Anpassung des leichtblechbaren Eidechsenschwanzes, die im Kampfe um's Dasein von den heute lebenden Lacertiden und Ascalaboten erworben wurde. Die Fähigkeit, diese einmal erworbene Anpassung auf alle Mitglieder der Sippe zu vererben, scheint allen Individuen der besprochenen Arten zuzukommen: denn niemals fand ich ein solches, das nicht im Stande gewesen wäre, den verforenen Schwanz in der besprochenen Weise zu regenerien. Tch glaube jedoch nicht, dass die Vererbung dieser specifischen Anjassung bereits soweit gegangen ist, lass nun, wie es nach del Leydigisehen Angabe scheinen könnte, auch bereits Exemplare mit nomalem Schwanze die souben besprochenen specitischen $A_{b}$

1) Schiegmann, Entstehung und Metamorphose der Wirbelsäule von Rana temporania. Halle $18 s 1$.

2) Wiedersheim, Vergl. Anatomie, pag. 58 . 
änderumgen zeigen könnten. Wären allerdings die Leydig'schen Befunde richtig, so würden sic eine gnte Stiitze sein für die Theorie, die Geoffroy St. Hilaire aufstellte, dass neue Arten durch günstige Missbildungen entstainden. Wir hätten dann freilich Eidechsen oder ihnen ähuliche Reptilien, die jene so ansserordentlich vortheilhafte Aupassung des regenerirten Selwwazes direct auf ihre Nachkommen vererbt, als Ausgangspunkt neuer Arten zu betrachten.

Ueber die Grinde, durch welche eine derartige functionelle Anpassung der Wirbel rerursacht sein diurfte, werde ich im letzten Abschnitte einige knrze Bemerkungen machen.

\section{Regeneration des Riickemmarkes.}

Vom Centralnervensystem kommt für unsere Untersuchungen nur derjenige Theil des Rïickenmarkes in Betracht, welcher im Schwanze verläuft. Ieh will jedoch nur ganz kurz auf die histologischen Detailfragen des normalen Riickenmarkes eingehen, da wir sowohl bei den Amplibien, wie bei den Reptilien rortreffliche Arbeiten besitzen, die bei der Betrachtung der Regenerationsrerhältnisse zn Gmunde gelegt werden kömnen. Vor allem sind es die Arbeiten ron Stieda: Ueber den Bau des Centralnervensystems des Axolotl, ${ }^{1}$ ) und die rou Klaussner: das Rïckemmark des Proteus \{nguinens ${ }^{2}$ ), welche für die Amphibien, und die von Giuliani: Sulla struttura del midollo spinale, e sulla riproduzione della coda della Lacerta viridis ${ }^{3}$ ), welehe für die Reptilien in Betracht kommt. Ausserdem werden naturgemäss die neuesten Arbeiten ïber das Rïckenmark anderer Thiere am geeigneten Orte Beriicksiehtigung finden.

Bevor ich zur Besprechung der uns hier interessirenden Fragen iibergehe, möclite ich einen kurzen Blick auf die als Filum terminale des Riickenmarkes beschriebene Bildung werfen. Es wird dies um so nothwendiger sein, als wir hauptsïchlich mit dem letzten Ende des Rïckenmarkes zu thun haben, welches ja, wie bekannt, bei vielen Thieren normalerweise in einen einfachen Faden ausläuft. Noch heute besteht eine rerschiedenartige Anffassung der Elemente, welche dieses Fihm zusammensetzen. Manche Forscher sprechen demselben jede nervöse Natur ab, während andere es als eine directe Fortsetzung des Riickenmarkes betrachten, welche allerdings auf embryonaler Stufe stehen geblicben ist. Beim Menschen bildet sich dadurch, dass die Wurzeln der Spinalnerven eine immer schiefere Richtung anuehmen, schliesslich die cauda eqnina, die „dura and arachnoidea betheiligen sich ebenfalls an diesem Wachsthume und anch die pia bleibt nicht zurick und bildet das filum terminale". (Köllilier.) Rauber ${ }^{4}$ ) hat nun vor allem nachgewiesen, dass

1) Zeitschr. f. wiss. Zool. Bd. XXV. pag. 285. Taf. XIX.

2) Abhandl. d. kgl. bayr. Acad. d. Wissensch. If. Klasse. XIV. Bd. II. Abth.

3) Poma. Salviucci 1878 .

3) A. Rauber. Die letzten spinalen Nerven und Ganglien. Morphol. Jahrb. III. pag. 603. Taf. XXXI. 
in dem Filum terninale des Mensehen auch nerröse Elemente rorhanden sind. Hauptsächlich interessaut sind anch die Angaben dieses Forschers ïber die caudalen Anschwellungen des Fischmarkes. Es war aus der älteren Litteratur bekannt, dass das Riickenmark von Petromyzon 11/2 mm rom Rande der Schwanzflosse noch zu bemerken war, wo es blind endigt. "Aehnlich verhält es sich mit dem Ende des Rückenmarkes von Raja Torpedo, bei der Barbe dagegen und beim Heclit latte schon Stilling nachgewiesen, dass das Riickenmark in einem eigenthiumlichen Knoten endigte, der anch schon frïher beim Karpfen ron $E$. H. Weber beschrieben und richtig abgebildet wurde. Auch bei der Aalraupe und beim Wels hatte Weber den Endknoten gesehen und ebenso Quatrefarges beim Amphioxus lanceolatus." Tauber findet nu bei einem Amphioxus von 3 cm Länge diesc Anschwelhng nicht; er meint aber, dass der Knoten sich vielleicht bei allen Fischen mit heterocerker Schwanzwirbelsäule vortinde, ,er liegt in dem nach oben offenen Einknickungswinkel der Wirbelsäule." Jedoch schliesst das Nark auch bei der Barbe nach Rauler mit diesem Knnoten nicht ab, „sondern entwickelt ein vollständiges Filum terminale, welches die Anfwärtskriummm des Endes der Wirbelsäule mitmacht, un erst in längerem Verlauf auf's Höchste verdiimnt zı endigen." „Das Filım terminale endigt als ein corsoventralwärts abgeplatteter Epithelcylinder"; eine nervöse Natur kommt diesem Filum terminale nach Rauber nicht zu.

Bei den Amphibien habe ich die normalen Verhältnisse des Schwanzendes, und demgemäss auch die normale Endigungsweise des Rückemmarkes näher bei Pleurodeles Walthi untersucht.

„Je weiter man bei Betrachtung von Querschnittserien nach hinten kommt, desto meln verliert die weisse Substanz an Mächtigkeit, endlich verringert sich anch die Zahl der Nervenzellen und es finden sich im letzten Viertheil mur noch die länglichen Zellen des den Centraleanal umgebendeu Epithels und renige randständige Nerwenfasern. Mit dieser Veränderung der Structur geht eine Abnahme des Tohmens Hand in Hand, so dass das Riickemnark sehliesslich mur noch einen Durchmesser von $0,13 \mathrm{~mm}$ hat.1 Der Centralcanal ist melı in die Mitte geritekt und hat jetzt ein Lumen von $0,036 \mathrm{~mm}$. Die Gestalt rariirt hier etwas, denn die Basis ist meln oder weniger abgeplattet und ebenso die Seitenfläelıen, so dass das Riiekenmark an diesen Stellen auf dem Quersehnitt die Form eines gleichsehenkeligen Dreiecks annehmen kann, dessen Hypothenuse nach unten liegt. Die bindegewebige Seheide ist einfach geworden und liisst sich zuletzt gar nicht meln nachweisen.

Allmählich versehwindet die weisse Substanz vollständig; es bleibt nur noch das Epithel des Centralcanals iibrig, welehes in einschichtiger Lage den immer enger werdenden Canal umgibt. Am äussersten Ende ist das Rückenmark gewöhnlich etwas nach aufwärts gebogen und endet, nachilem der Centralcanal sich geschlossen hat, in einer knopfartigen Ansehwellung, welehe chrch Termehrung der Epithelzellen entsteht. Diese Ansehwellung am Ende des Riickemmarkes ist ron rerschiedenen Embryonen bekannt und fiudet sich auch mach ten Nlittheilungen von Braun besonders ausgeprägt bei einzelnen Vogelembryonen.

Wie das Ende des Riickenmarkes einen vollständig embryonalen Charakter sich bewahrt hat, so kam man bei der Betrachtung der won hinten nach vorn durch dieses Organ gelegten Querschnittserien einen allmählichen Lebergang zu dem rorderen hoehorganisirten Theil desselben wahrnelumen, der genau alle Stufen der normalen Entwickelung zeitlebens dargestellt enthält; denn anch der vordere Theil des Rïckenmarkes ist erst durch allmähliche in derselben Weise verlaufeude Umwandlung aus einem einfachen Rohr zu einer so complicirten Struktur grelangt. 
Die Spinalganglien haben stets etwa den vicrten Theil der Grösse des Rückenmarkdurchmessers, wenn man diesen von der Stelle nimmt, an der die Sjpinalganglien abgehen. Sie finden sich bis weit nach hinten mit dem Durchmesser des Rïekenmarkes kleiner und kleiner werdend und liegen zuletzt innerhalb der oberen Bögen.

Von der Stelle ab, wo las Riickenmark uur aus dem von einfachen Epithelzellen umgebenen C'entraleanal besteht, sind sie nicht mehr nachzuweisen."

Aus dieser Beobachtung geht hervor, dass ein eigentlicher Endfaden bei Plemrodeles nicht existirt, und dass man wohl die Eudanschwellung des Rïckenmarkes derjenigen der Fische vergleichen kann. Auch bei den anderen Amphibien ist wohl ein eigentliches Filum terminale nicht deutlich ansgeprägt, dagegen kann man vielleicht stets den letzten $A$ bschnitt des Riickenmarkes mit diesem homologisiren, denn man kann wohl mit Recht vermuthen, dass von der Stelle ab, an welcher die weisse substanz auflü̈rt und typische Ganglienzellen nicht mchr nachgewiesen werden können, auch eine nerröse Funetion nicht mehr vorhanden ist. Jedenfalls sind aber die sämmtlichen Zellen, welche das Ende des Riickemmarkes bei len Amphibien zusammensetzen, nervöser Natur; ein Hinzutreten ron Bindegewebselementen konnte ich nirgends beobachten, nicht einmal bei dem so alusserordentlich verlängerten Schwanzspitze von Triton helveticus.

Bei den Reptilien beobachtete, wie erwähnt, Giuliani ein Filım terminale speciell bei Lacerta viridis: "Il tilo terminale dei rettili è molto corto, dappoiclı̀ il midollo spinale in questi animali percorni la massima parte del canale vertebrale della coda."

An stelle des Ueberganges endigt nach Giuliuni das Riiekemmark in einem kleinen Conus, der also der C'audalanschwellung des Fische und der Amphibien zn vergleichen wäre. Der Centralkanal behïlt die runde Form, aber er wird weiter und endigt blind mter der Cntis. „Nei tagli longitudinali si vede chiaramente la continuazione del canale centrale e del tessuto ehe lo circonda non che della pia madre, con il canale centrale e la pia madre del midollo spinale; nei tagli trasversali e longiturlinali non si scorge nessuna traceia nè di tibre nervose, nè molto meno di cellule nervose."

Da Giuliumi die Epithelzellen des Centralcanales nicht für nervöse Elemente ansieht, hält er das ganze Filum terminale für ein Gebilcle bindegewebiger Natur.

Aus den angeführten Citaten wird zur Genïge hervorgehen, dass der Begriff des Filum terminale hente nicht mehr so streng abgegrenzt ist wie zur Zeit Bidder's oder Stilling's.

Ich kann mich nicht entschliessen, einen Theil des Rïckenmarkes selbst, und wäre er noch so stark in seinen Elementen reducirt, mit diesem Namen zu bezeichmen.

So lange der Centralcanal mit seinen Epithelzellen vorhanden ist, so lange ist auch die Möglichkeit gegeben, wie wir später sehen werden, dass nuch weitere nervöse Elemente hierans entstehen. Deshalb möchte ich vorschlagen, nur diejenigen Gebilde mit diesem Ansdruck zu bezeichnen, welche nach dem Authören des Centralcanals nud der Epithelzellen nun entweder aus den Häuten des Pitickemmarkes oder anderen bindegewebigen Elementen hervorgehen und dem völlig abgeschlossenen Centralorgan kappenartig aufsitzen, wie das bei den Fischen und einigen Säugethieren der Fall ist. Ich werde wenigstens in meinel folgenden Darstellung den Ansdruck „Filum terminale" nur in diesem Sinne gebranchen.

Ln die Regenerationsvorgänge am Rückenmarke der Amphibien zu studiren, wählte ich vor 
allem Larven von Tritonen, ferner Siredon, Proteus und Pleurodeles, da die Structur des Ritickenmarkes bei diesen am besten bisher untersueht worden ist. Mehrfach habe ich darauf hingewiesen, dass die Regeneration im Wasser unter anderen und giinstigeren Bedingungen verläuft, als bei den Landthieren, und dass so namentlich die dabei auftretenden Verhältnisse leichter unter dem Mikroskop studirt werden kïnnen. Bei Siredon num habe ich die allerjïngsten Stadien der Neubildung des Riickenmarkes rerfolgen kïnnen, leider allerdings nicht am lebenden Thier, da ja die Untersuchung dieser Verhältnisse mit den grössten Sehwierigkeiten rerknipft ist. Tohl aber konnte ich an vortrefflichen Längsschnittserien doch so manches erkennen, was für die Neubilumg der Gewebe im Allgemeinen von grossem Interesse sein diirfte.

Durch einen scharfen Sehnitt, mag er nun mit der Scheere oder mit dem Rasirmesser geführt sein, muss natïrlich, wie sofort einzusehen ist, der Centralcanal des Riickenmarkes mit dem umgebenden Medium in directe Verbindung treten. Während bei den Epithelzellen, wie das bereits weitläufig auseinandergesetzt wurde, eine Quelhung der Elemente im Wasser nicht erfolgt, tritt nun an den Elementen des Riickenmarkes insofern eine Veränderung auf, als dessenEpithelzellen, deren Kerne bis dahin ein etwas meln granulirtes Aussehen hatten, jetzt ebenfalls ihren Lerninhalt mollständig homogen erseheinen lassen, so dass sie etwa 2 Stunden nach der Verwundung von den kugeligen Elementen und den sogenannten Uebergangszellen nicht melı getrennt werden kïnnen; wohl aber erscheinen die Ganglienzellen noch scharf ron den iibrigen Elementen gesundert, an ihnen ist noch keine bedentende Quellung zu constatiren, obgleich bei den verletzten Zellen natiirlicherweise eine Resorption eintreten muss. Bereits frïher machte ich darauf anfmerksam, dass am Wundrande eine starke Auswanderung von Lenkocyten stattfindet, und dass diese es sind, welchen vor allen Dingen die Bildung des homogenen, lyuphartigen Saumes, welcher zuerst die Wunde bedeckt, zuzuschreiben ist. Das Riickenmark geht nun an meinen Schnitten bis dicht an diesen homogenen Saum heran, und die Elemente, welche es zusammensetzen, lassen sich immerhin noch nach 24 Stunden auch an diesem Saum ron einander tremen, dann aber tritt eine bedeutende Wneherung ron Kernen auf, und zwar scheint dieselbe auszugehen von den sogenannten Körnern, deren Inhalt röllig homogen und stark lichtbrechend erscheint. Durch Picrocarmin werden diese Elemente ebenfalls stark tingirt, und nun sieht man an diesen nahezı gleich grossen Könnern Kerntheilungen, ohne dass jemals eine Spur von karyokinetischen Figuren constatirt werden konnte, in der Weise auftreten, dass der Kern oder die Kü̈rner sich in der bekannten Weise schulısohlenförmig einschuiiren, und dass danm aus beiden Hälften Elemente gleicher Art hervorgehen. Nicht nur eine einmalige Einschnitung glaube ich beobachten zu künnen, sondern anch eine mehrfache, so dass der Kern sich bei diesem Process nicht mu in 2, sondern auch in mehrere Stiucke theilen kann, Es wïrde dies ïbereinstimmen mit eivigen Theilungsvorgingen im Pollensehlauch der Pflanzen, obgleich bei dieser Theilung meist karyokinetische Figuren benbachtet wurden. Es werden also die Elemente des Rückenmarkes am Wundrande, wie es scheint, wirklich zu Embryonalkernen umgebildet, welche nur einen schmalen protoplasmatischen Saum um sich herum besitzen: gerade das scheint mir ein nenes Licht aut die Regenerationsverhältnisse des Rückenmarkes zu werfen, denn wir künnen diesen hellen Protoplasmasaum, welcher die Kerne ungielıt, als das ernährende Plasma der noch embryonalen Zelle auffissen. Der Kiern ist noch nicht im Stande gewesen, Reservenahrungsstoffe in grösserer Menge anzuhüufen und in Folge dessen fehlen die trpischen Kerntheilungsfiguren, der Kern bietet uns noch ein homogenes, glänzendes Aussehen dar. Auch in den 
Spinalganglien kam man, wenn dieselben auf dem Schnitte getroffen sind, eine V'ermehrung der sogenannten Kürner beobachten, zwischen denen nur vereinzelte Ganglienzellen noch persistiren.

Die grosse Frage ist mu ror allem die, ob sich an der Bildung der nenen Elemente des Riickenmarkes etwa noch andere Zellen betheiligen, als die Elemente des Riickenmarkes selbst. Zuerst konnte ich mich der Ansicht nicht verschliessen, dass auch die weissen Blutkürperchen, die in Allgemeinen ziemlich schwer von diesen embryonalen Kugehn des Riickenmarkes zn unterscheiden sind, an der Bildung der neuen Elemente theihnehmen. Als mir aber namentlieh bei Siredon die bedentende Proliferation, die in diesen Kömern stattfindet, besonders anffiel, habe ich mieh vollständig zu der Ansicht bekehrt, dass die Elemente des neugebildeten Riickenmarkes wiederum aus embryonalen Zellen desselben Organes hervorgehen. Es bleibt nun noelı ïlrig, einige ältere Stadien einer nïheren Betrachtung zu unterziehen.

Die W'eiterentwickelung des Rïckenmarkes habe ich ror Allem an einer Larve ron Salamandra maculata seh" dentlich verfolgen kömnen. Es entsteht zunächst aus den kugeligen Elementen, die zuerst den Abschlnss des rerwundeten Theiles bilden, und die in ihrer Färbung den Leukneyten so mgemein ähnlich sind, ein blastema'tiges Gebilde, in welchem die einzelnen Elemente vollkommen gleichartig erscheinen. Sehr bald jedoch tritt eine Differeneirung in den den Centralcanal ungebenden Zellen ein: welche sich vor allem dadurch anszeichnen, dass ihre Gestalt liinglicher wird, und dass mu auch ein sehmaler, protoplasmatiseher Theil m sie herum gebildet wird. Somit wird also ein Theil dieser Zellen zn exhten Epithelzellen des Centralcanales, während aus den ibrigen, wie mir scheint, nur wiederum könige Elemente hervorgehen, die nicht direct als Epithelzellen betrachtet werden kömnen. Die Bildung der spinalganglien wird ebenfalls durch eine Proliferation dieser körnigen Elemente eingeleitet: da ich jeloch diesen Torgang an den älteren Regenerationsstadien von Pleurodeles besser beobachten konnte, soll derselbe dort beschrieben werden. Ans dem Epithel des Centralcanales selbst gehen num Elemente hervor, welche man oftmals nicht direct als nervöse Elemente bezuichnen kam. So werden z. B. die Ausläufer, welche sich zuerst von den Epithelzellen zur Peripherie des Riickemmarkes hinziehen, nicht als Nervenfasern gedeutet werden kïmnen, sie bilden viehmehr ein Stiitzgewebe, welches in versehiedener Beziehung grösste Aehnlichkeit mit dem Bindegewebe hat, so dass hervorragende Forseher keinen Anstand nahmen, es direct den Bindesubstanzen zuzurechen. Ein direetes Einwandern von Bindegewebskörperehen in das Riickemmark konnte ich weder bei den Larven ron Salamandra, noch sonst wo constatiren.

Bei einem ذ̀ Monate alten regenerirten Seluwanze ron Plenrodeles ist an dem unverletzten Theile das Rüickenmark noch ziemlich complicirt gebaut. Ansser dem den Centraleanal umgebenden Ephithel, welches ans mehreren Schichten besteht. sieht man dentlich eine Sonderung zwischen graner und weisser Sulstanz, und zwar ist die Weisse Substanz noch einmal su stark, als die grane. Diese letztere wird gebildet durch die Ausläufer der Epithelzellen, zwischen welchen num bipolare und multipolare Ganglienzellen in grösserer Menge eingebettet liegen, deren Auslïufer ebenfalls zur Perijherie hinstreben. Die Spinalganglien haben an diesen Stellen die Hälfte des Durchmesser's vom Rïickenmark. An der Uebergangsstelle von dem unverletzten in den regenerirten Theil treten num in Riickenmark neben den normalen, grösseren, stark granulirten Kernen die etwas kleineren stark lichtbrechenden mit homngenem lnhalt auf, wie sie für das regenerirte Riickemmark der Amphibien so characteristisch sind. Der Centralcanal ist mmgeben ron den bekannten, längliehovalen Zellen: er hat noch seine normale Weite, ist rund, und liegt ebenso excentrisch, wie weiter 
oben. Abgehende Fasern kann man deutlich noch ron den oberen, länglichen Epithelzellen erkennen, die bindegewebige Umgrenzung des Riickemmarkes ist jedoch nicht mehr scharf, sondem die Fasern endigen an freien Rande. Von dieser. Stelle hale ich das Riuckenmark abgebildet Taf. II Fig. 1. Auch hier ist, wie man sieht, die weisse substanz noch ausserordentlich michtig, unl ïbertrifft die graue bedeutend an IIasse.

Verfolgen wir die Querschnittserie ron der Ansatzstelle des regenerirten Schwanzstickes weiter nach hinten, so erseheint las Riickenmark bald etwas seitlich comprimirt, in Folge dessen der grösste Durehmesser jetzt ron oben nach unten liegt; sonst zeigt sich lieine berleutende Veränderung, die weisse Sulsstanz nimmt jedoch von Schnitt zu Schnitt ab. An dieser Stelle sind die Wirbel vertebral sehr unregelmässig, mit vielen Knochenblättern und Platten; die Bügen sind ebenfalls vollständig knö̈chern. Während das jetzt beginnende knorpelige regenerirte Skelet ziemlich scharf von den alten Wirbeln sich abhelst, ist das beim Riiekenmark nicht der Fall, vielnelı geht dasselbe, ganz allmählich kleiner und diinner werdend, in den regenerirten Theil iiber. Die länglichen Ep,ithelzellen des Riickemarkes besitzen namentlich nach oben noelı deutliche Fortsätze; ausserdem kann man ab und zu anch noch unipolare Ganglienzellen erkennen und kleine Spinalganglien mit grossen Zellen, welche noch immerhalb des Bogens am Riickenmark liegen. Die körnigen Zellen drängen sich immer mehr nach dem Centralcanal und ihre Zahl wird goringer. Nicht immer befinden sicl die spiualganglien in gleicher Entfernung vom liickenmark, oftmals steht das eine näher, das andere weiter ab. Die Höhle, in welcher das Riickemmark liegt, wirl immer enger, das Riickenmark selbst dagegen behält ziemlich genau seine Dimensionen bei, und fiillt die frïhel viel zu grosse Höhle jetzt beinahe vollständig ans. Dieses Stadium wurde mit den spinalganglien aut Tat. II Fig. 2 abgebildet. Hier sieht man die kugeligen Elemente bereits derartig rermehrt, dass sie die immer noch vorhandenen uni- und bipnlaren Ganglienzellen fiast vollständig verhiillen und sich namentlich an der Oberseite des C'entralcanales derartig ansammeln, dass anch die von den Epithelzellen des Canales amsgehenten Faserzüge ganz verdeckt werden. Allmählich nimmt mu die weisse Substanz immer mehr an Masse ab; es treten dann die kugeligen Elemente in den Hintergrund und zuletzt, kurz vor dem Ende des Ritickenmarkes ist nichts weiter zu unterscheiden, als ein einfacher Centralcanal mit dem anskleidenden Epithel.

Bei einem anderen, jïngeren regenerirten schwanze reicht das Riickemmark nicht ganz bis an das Ende des Schwanzes, sondern tritt erst im 20. Sclunitte ron hinten auf. Von einem axialen Knorpelgewebe ist hier noch nichts zu erkennen, wohl aber sind die Blutgefässe bereits differenzirt. Das Riickenroh! ist ausserordentlich regehmässig ruurlich, der Centraleanal liegt mehr nach unten und ist umgeben von grossen platten Zellen; etwas weiter rom sehen wir die letzten Endigungen der weissen Substanz, die hier viel weiter nach hinten reitht, als dies beim normalen Schwanze beobachtet wurde.

Ueber die Regeneration des Rïickenmarkes bei den Eidechsen und den tidechscnartigen Reptilien sind nur wenige Beobahtungen gemacht worden, da ron den älteren Forschern der feine Strang, welcher sich im Innern les regenerinten Knorpelrohres vurfindet, meist iibersehen wurde. Die erste Andeutung, dass eine Regeneration des Riickenmarkes anch bei den Reptilien statt lat, finden wir bei Heinrich Ifïller. Pay. 33 habe ich bereits hieranf hingewiesen und besonders betont, dass es Müllev gelungen war, im regenerirten Riitekenmark nerröse Elemente zu erkennen und zwar feine markhaltige Nerenfasern sicherer, als Ganglienzellen. Auch rlass die sppinalganglien fohlen, 
hatte Miiller bereits sehr richtig bemerkt, so das bei Lacerta, Geeko und Anguis niemals das Knorpelrohr durelı heraustretende Nervenfasern unterbrochen ist.

In Gegensatz zu Mïller sprieht Gegenbau ${ }^{*}$ ) dem neugebildeten Rïckenmarke jede nerväse Function ab, vor allen Dingen weil er niemals regelmiissige Communieationen rom Canal des Knnmpelrohres nach Aussen durchgehen sieht. Dass Gegenbaur sieh Heinrich Miiller gegenüber im Unrecht befindet, geht schon, wie erwälnt, daraus hervor, dass er nur grübere Pråparationsmethoden anwandte, vermöge deren so zarte Verhältnisse nicht genau zu erkennen sind. Eine Arbeit ist es noelı, auf die ielı jetzt verweisen muss: nümlieh die von Giuliani.2) Gruliani hat, elonfalls nicht erkannt, dass das regenerirte Riiekenmark dem Ende des normalen morphologisch gleichwerthig ist, denn da auch er keine Spinalganglien von ihm abgehen sah, sehloss er sich der Ansicht Gegenbaur's an. Seine Abbildung Taf. 13, Fig. 11 giebt ein ungefihhres Bild dieser Verhältuisse auf dem Quersehnitt, ist aber doch anch wiederum zu schematisch gehalten, als dass man weitere Folgerungen daraus ziehen könnte.

Ich habe deshalb versucht, möglichst viele Regenerationsstadien des Reptilienritickemmarkes zu untersuehen, und vor allen Dingen auch verschiedene Arten. So habe ich dem gefunden, dass bei Hemidactylus frenatus, allerding bei einem Exemplar, welehes nicht melı so ganz tadellos erhalten war, (wie aueh schon aus der genau naeh der Natur gezeiehneten Abbildung zu erkennen ist), dass sieh hier nur der Centralcanal des Rüekemmarkes mit dem Epithel regenerirt hat; und zwar besteht dieses Epithel nur ans einer einfachen Lage ron langgestreckten Zellen, deren Kerme sich distal und kranzförmig anordnen, so dass sie das umgebende Bindegewebe fast beriihren.

Diese einfache Zellenlage findet sieh auch in den ersten Regenerationsstadien bei Eidechsen vor. Hier ist also von nerrösen Elementen noch gar keine Spur zu entdecken, weder Ganglienzellen, nuch Nervenfasem. Dieses Rückenmark habe ieh in Tafel III, Figur 8 möglichst naturgetreu darzustellen versucht.

Ein weiteres Präparat, von Lacerta muralis genommen, zeigt mir in regenerirten Rïckenmark ebenfalls nur den Centralcanal, der sogar auffällig weit ist, und $n$ m ihn herum die einschichtige Epithellage, deren Kerne jedoch hier dem eentralen Rande fast angelagert sind. Ausserdem lassen sich einige feine Pünktehen, welche zwischen den Epithelzellen erscheinen, vielleicht schon als Querschnitte blasser, zwischen den Epithelzellen verlaufender Nervenfasem deuten. Fon weiteren nervöseu Elementen ist auch lıier noch keine Rede. (Taf. III, Fig’. 3).

Bei Phyllodactylus europaeus sind die Verhältnisse in einem zienlich vollständig regenerirten Selnwanze folgende: Der Centraleanal hat kein besonders grosses Lumen, und ist anch von keinem eigentliehen, scharf abgegrenzten Epithel umgeben. Vielmeln finden sich die Keme der Epithelzellen in verschiedene Lagen zerstreut, bald birnförmig ausgezogen, bald rundlich, grösser und kleiner und ziemlich dicht gedrängt stehend vor. Das Rïckemmark ist ungeben von einem fibrillären Bindegewebe, das öfter blasige Auftreibungen bildet; auch finden sich hier bereits zwischen den einzelnen Zellen des Rüickemmarks Vacuolen, wie sie in grösserer Menge bei den später zu beschreibenden lieptilienarten auftreten. Der ganze Schnitt, den ich Taf. III, Fig. 7 abgebildet habe, macht den Eindruck, als ob eine rege Proliferation an den dort getroffenen Stellen stattfinde; man kann

1) 1. c. pag. 31 .

3) $1 . c$. 
jedoch von speeifischen Theilungsfiguren nichts erkennen, obgleich einige der Kierne eine nierenförmige Einschürung zeigen. Auch hier sind wieder stark lichtbrechende Punkte, wemn auch in geringer Anzahl vorhanden, die nur als Querselnnitte von Nervenfasern gedeutet werden kimnen; Ihre Lage ist meist eine periphere. Kernkürperchen kann ieh in den Zellen nicht naehweisen; dagegen ist allen eine feine Körnelung eigen, weshalb die Mehrzalıl dureh Picrocarmin stark tingirt wird.

Wieder anders zeigen sich die Verhältnisse in einem alten, vollkommen regenerirten Schwanze von Platydactylus verus. Einen Quersehnitt durch das Knorpelrohr mit den Geweben, die es umsehliesst, habe ich Tafel I, Figur 2 abgebildet. Dasselbe Rüickenmark, welches lier als kleines rundliches Körperehen mit RII bezeichnet erscheint, ist nun auf Tafel III, Figur 6 bei stärkerer Vergrösserung gezeichnet. Bei diesem Rückenmark fällt vor allem auf die grosse IIenge der Vacuolen, die kaum als secundär dureh die Präparationsmethode entstanden gedacht werden kömmen, da der betreffende Schwanz sonst gut erhalten war. Die Zellen des Epithels umgeben den Centraleanal nicht in der typischen Weise, wie das von Ilemidaetylus beschrieben wurde, sondern ordnen sich derartig an, dass sie mehr nach der einen Seite hin gedrängt erseheinen, und zwar nach oben. Vor allen Dingen aber liegt der Centraleanal nieht mehr in der Mitte, sondern erscheint bedentend nach unten gerïckt. Eine feine Punktsubstanz lässt sich ïberall zwisehen den Epithelzellen und den andern aus ihnen hervorgehenden und gleich zu besprechenden Zellen erkennen. Anch hier haben wir es wohl mit quergeselmittenen blassen Nervenfasern zu thum. Dass eine rege Proliferation der Epithelzellen stattgefunden hat, zeigen die häufig rorhandenen randständigen Kerue, die oftmals noch eine birnfürmige Gestalt haben. Ferner sieht man von den einzelnen Zellen, die mehr distal gelegen sind, unzweifelhaft Fasern ausgehen, die sich am Rande des Rückenmarkes umzubiegen scheinen. Der Centraleanal ist ebenfalls ausserordentlich klein; viel kleiner, als einzelne der besproehenen Vacuolen. Das Bindegewebe, welches das Riickenmark als Seheide umgiebt, besteht nur aus einer feinen Lage von Zellen, in denen Kerne nicht nachgewiesen werden künnen.

Bei Lacerta ocellata sehe ich ebenfalls die Zellen, welehe den Centraleanal umgeben, mit ziemlich stark tingirten Ausläufern versehen, daneben sind am distalen Rande viele stark liehtbrechende Körnehen rorhanden, wie sie anch bei den Urodelen vorkommen und daselbst beschrieben sind. Während die Kerne der Epithelzellen stets ein oder zwei, hier selır deutlieh hervortretende Kémkürperclıen aufweisen, ist bei diesen Kernen, die dazu noch eine sehr verschiedene Grösse besitzen, nichts von denselben zu bemerken. Gerade an diesem Präparat nun glaube ich den Uebergang der oft besprochenen, stark lichtbreehenden Kömer $(Z)$ in die Kerne der späteren Ganglienzellen nachweisen zu können: Es zeigen sich nämlich an dem distalen Rande auch einige Kerne, die im übrigen noch stark lichtbrechend, doch bereits ein Kernkörperchen besitzen und sich mit einem Protoplasmahof ungeben haben. (Taf. III, Fig. 9). Ausserdem zeigt sich auf diesem Querselnitt ein starkes Iaschennetz, zwischen welehem sich Vacuolen in grosser Anzahl vorfinden; ferner anch jene feinen Pïnktehen, die den ebenfalls bereits geschilderten Querschnitten entsprechen. Noch deutlicher als an diesem Präparat, sieht man an dem in Taf. III, Fig. 10 abgebildeten Quersehnitt des regenerirten Rückenmarkes von Anguis fragilis, dass das Epithel, welches den hier seh. weiten Centraleanal ungiebt, nicht continuirlich dieselben Zellen zeigt, sondern dass zwiselıen den einzelnen Epithelzellen mit länglichen Kernen sich nun bereits solche eingesehoben, die einen reichen Protoplasmahof um sich gesammelt lıaben. Während auch die Kerne der Epithelzellen noch kein 
Lemküperchen besitzen, haben diese letzteren eigentlich sehon als Ganglienzellen zu bezeieluenden Gelsilde ein Kernkïrperchen differencirt.

Das Maschenwerk. wchleses then iibrigen Theil des Riickemmarksrohres erfïllt, ist nicht so deutlich, wie bei Lacerta ucellata: dagegen findet sich hicr eine Menge von feinen Piinktehen, die den optischen Austruck yuergeschnittener Nervenfasern darstellen, namentlich an der Peripherie vor. Das nugelsende Bindegewebe ist so stark nit Pigment infiltrirt, dass man kaum im Stande ist, die Kerne des ausserordentlich mäelıtig entwiekelten Gewebes zu erkennen.

Aus allen diesen Befunden selıeint mir unzweifelhaft hervorzugehen. dass die frühere Ansicht, welche in dem regenerirten liiickemmarke mu die Fortsetzung des filum terminale sal, und die namentlich anch noch ron Ginliuni vertreten wird, nicht ganz richtig ist. Wir halen es hier vielmely mit einem Gebilde zu thun, das unzweifelhaft nerviser Natur ist, da nicht nur Nerrenfasern, sondern anch schon vollständig ausgeljildete Ganglienzellen in demselben nachgewiesen werden kömnen. Dass mun dieses Gebilde auf einer so ausserordentlich niedrigen Stufe der Entwickelung stehen bleibt, dass es nicht einmal zur Weiterentwickelung der Nervenelemente lsommt, wie dies bei den Salamandrinen der Fall ist, hat seinen Hauptgrund wohl darin, dass es ron clem Körperfarenchym vollstindig durch das immerhin sehr widerstandsfähige Knorpelmoh abgeschlossen ist: denn niemals habe ich auch nu eine Andeutung ron einer Bildung der Spinalganglien gesehen. Es sind hier Wachsthmsvorgänge nur nach einer Richtung hin möglich, die der Längsaxe des Thieres entspricht: von einer seitlichen Abzreigung von Nervenfasern ist keine Spur zu erkennen.

Trotz alleclem aber miissen wir dieses Organ doch als ein nerröses Centralorgan ansehen, wenigstens morphologisch: dem fhysiologisch ist allerdings dieser Vergleich nicht mehr durchzuführen. Obgleich also die Tendenz zur Regeneration dem Ruickenmark der besprochenen Reptilien noch zukommt, ist doch die Regenerationsfähigkeit dieses Urganes nieht mehr so gross, wie bei den Salamandrinen und lchthyoden, die ein dem normalen vollständig ähnlich gebautes Rüickenmark wiederzucrzeugen im Stande sind. Trotz der eintretenden Regeneration haben wir es schon mit einem in der Degeneration begrifienen organe zu thun, und die structurverhältnisse. welche wil kennen lernten, passen vortrefflich zu der von Dawin ansgesprochenen Ansicht, dass degenerirende Urgane schr wandelbar in ihrer Structur sind, da ihre einzelnen Theile nicht meln dureh den Zwang einer ununterbrochenen Functionirung in strenger gegenseitiger Abhängigkeit von einander stehen.

Diese Wandelbarkeit des regenerirten Ritickemmarkes der Reptilien ist so gross, dass num in einen Knorpelrohr nicht nur ein Rïckenmark wiedererzengt werden kam, sondern dass oftmals melnere Centralcanäle sich nebeneinander rortinden, ganz ähnlich wie bereits die Bildung ron doppelten Schwïnzen und ïberzähligen Fingern beschrieben worden ist. Solche Divertikel des Centralcanales, die selu liäufig sich am Ende des Sehwanzes vorfinden, habe ich Taf. III, Fig. 5 ron Lacerta agilis abgebildet.

Die Cardinalfrage bei der Regreneration des Riickenmarkes ist nun folgende: Worans regeneriren sich die lilemente des nengebildeten Centralorganes? Wir wollen sehen, ob wir zur Lösung dieser Frage, die an die schwierigsten histogenetischen Probleme streift, aus unseren Präparaten einiges Material herbeibringen kïmnen.

Vor allem muss festgehalten werden, dass eine Neubildung des Rïckenmadses nach embryonalem Typus für nicht gut nüglich anzuschen ist, dem niemals wird man einen directen 
Zusammenhang der Elemente des Centralorganes mit der neugebildeten Epidermis erkennen künnen. Diese letztere ist viclmehr, wie bereits friiher erwälnt, oftmals schon in fast völlig normaler Weise regenerirt, wenn aus dem Rückenmark erst ein kurzer Kegel hervorgewachsen ist. Nicht selten treten auclı gerade in der Verlängerungsaxe des Ruickenmarkes in der Epidermis die bekannten Blasenbildungen auf, wie bei den Frosehlarven und Siredon beschrieben wurde.

Der zweite denkbare Fall wäre der, dass die Rïckenmarkselemente sich aus dem am Wundrande auftretenden embryonalen und undifferencirten Blastem entwickelten. Daun wären also embryonale Bindegewebszellen und Lenkocyten als die Bildner des nenen Organes zu betrachten.

Der dritte und plausibelste Fall wäre der, dass die Elemente des durehsehnittenen Riickenmarkes am Wundrande sich zu Embryonalzellen umwandelten, und dass durch eine intensive Proliferation nun die Neubildung vor sich ginge. IIier stossen wir jedoch sofort anf eine andere Frage: Wie verhalten sich dem die verseliedenen Elemente des Centralorganes zu einander? wie verhält sich das Epithel des Centraleanales zu den embryonalen Ganglienkugeh und zu dem bindegewebigen Geriist, dass die spiiter auftretende weisse Substanz durehsetzt? Diese Frage zu entscheiden, diuffe nicht so leicht sein, die Lösung wiirden wir nur in den allerfrïhesten Stadien der Regreneration finden, und diese sind bekanntlich sehr schwer zu fixiren; besonders muss man sich ron Kunstproducten, die durch die Präparationsmethoulen häufig hervorgerufen werden, niclıt täuschen lassen. Am frischen Object ist von diesem Regenerationsworgang so viel wie nichts zu erkennen, da die darïber liegenden Epidermiszellen den Einblick unmöglich machen; man muss also conserviren, und dann anf Quer- oder besser Längsschnitten untersuchen. Mir stehen von Tritonen und Siredon wenigstens die allerjügsten Stadien in solchen Serien zur Vorfügung, so dass ich es wohl unternehmen kann, auch diese so schwierigen Punkte hier einer Erörterung zu unterziehen.

Was die Wachsthumsverbïlmisse des normalen Rückenmarkes bei den Amphibien anbelangt. so hat man bisher allgemein angenommen, dass aus dem Epithel des Centralcanales bei der Weiterentwickelung nur wiederum Epithelzellen hervorgehen, und dass die Ganglienzellen, welche sich in friihen Stadien bereits vom Epithel gesondert haben, nun ebenfalls durch Proliferation neue Ganglienzellen erzengten, wie die Bindegerebskörper nene Bindegewebszellen. Ist es nun schon bei den normalen Rückenmark schwierig, Ganglienzellen und Bindegewebskörper von einander zu trennen, so erfordert die Scheidung der Elemente bei der Regeneration, wo diese sämmtlich noch embryonal sind, noeh viel mehr Vorsicht. Das Epithel wird embryonal, die Ganglienzellen werden embryonal, und ebenso die Bindegewebszellen; es kann ron einer scharfen Grenze zwischen diesen Elementen, wie mir jerler zugestehen wird, keine Rerle mehr sein. Nach der ebenerwälnten 'Thatsache seheint es. als ob die Frage nach der Herkunft der neuen Zellen durch Untersuchung von Regenerationsstadien nicht entschieden werden kïmnte: wir wollen sehen, ob dem so ist.

Bereits bei den Reptilien ist erwähnt worden, dass der Centraleanal mit seinem Epithel sich ror allen anderen Geweben des Riickenmarkes regenerirt. Anch bei den Amphibien finden wir ähnliche Verhältnisse.

Der Punctus saliens, auf den es bei der Regeneration des Rückenmarkes ankommt, ist unbedingt die Frage, ob aus dem Epithel des Centralcanales, das, wie wir ja gesehen haben, sich bei allen Formen zuerst regenerirt, nun anch später die iubrigen Elemente des Rückenmarkes herror- 
gehen künnen. Klaussner ${ }^{1}$ ) geht bei der Betrachtung des normalen Ritckenmarkes von Proteus anguineus so weit, dass er pag. 30 seiner Arbeit ausspricht: „Es lïsst sich nieht bezweifeln, dass dem mächtigen Epithel um den Centralcanal des Proteus dic Bedentung eines centralen Nervenapparates zukommt," und so weist er denn anch mit ziemlicher Sieherheit nach, dass aus dem Epithel die sämmtlichen ïbrigen Theile der granen Substanz des Rïekemmarkes sich herausbilden; ein Befund, der zu den frülıeren Anschanumgen in directem Widerspruch steht.

Betrachten wir jedoch die embryonalen Verhältnisse des Riickemmarkes, wie sie ron Hensen ${ }^{2}$ ) und His ${ }^{3}$ ) angegeben sind, so tinden wir, dass allmählich doch diese von Klaussner weiter ausgeführte Ansicht das Uebergewicht zu erlangen scheint; dem auch His bildet in Fig. 4 und 5 Präparate ab, welche keinen Zweifel darïber aufkommen lassen, lass urspringlich, bevor noch die Seheidung der Medullarplatte eingetreten ist, sämmtliche Embryonalzellen des Rïekenmarkes im Stancle sind, Ausläufer zu entsenden, welche sich an peripheren Rande in ein protoplasmatisches, vacuolenreiches Netzwerk aufl̈sen. Gerade diese ersten Stadien, welche His alıbildet, stimmen so ausserordentlich gut ïberein mit den Verhältnissen, wie ich sie am Rïckenmark in regenerirten Schwänzen von Eidechsen constatiren konnte, dass man an der Identität beider Bilder nieht zweifeln kamn.

Was das Auftreten der weissen Substanz anbelangt, so kam dieselbe bei den Lacertiden und Ascalaboten auf keinem bestimmten Stadium entstanden gedacht werden. Es tritt viehmehr mitunter bei der einen Species, sogar bei dem einen Exemplar schon sehr frïh ein wirklicher Nervenfaden auf, während bei anderen noch in späten Regenerationsperioden keine Spur vou weisser Substanz nachgewiesen werden kam, wie z. B. bei Phyllodactylus emropaeus. Während bei der normalen Bilc.ung des Riickenmarkes kaum ein Zweifel äber die Herkunft der Nervenelemente bestehen kamn, mögen sie num aus dem Epithel des Centralcanales oder dureh Vermehrung der abgespaltenen Aussenfäche des Medullarohres herrorgehen, so tritt bei der Regeneration noch die fernere Schwierigkeit hinzu, zu entscheiden, ob die betreffenden Nervenelemente nun nicht weiter durch Wachsthum in der longitudinalen Richtung sich vermehren künnten, ob also die an der Schnittfläche vorhandenen ausgebildeten und typisehen Ganglienzellen in Stande sind, sieh dureh Umwandlung in Embryonalzellen wiederum zu theilen und in die neugebildete Riickemmarkssubstanz hineinzuwachsen oder rasch ihre Abkümmlinge dort hineinwachsen zu lassen. Diese Frage zu entscheiden, ist natugemäss ansserordentlich schwer; jedoch kümen wir bei der Regeneration des Ritckemmarkes bei den Amphibien constatiren, dass oftmals ein melurere Hillimeter langer Centralcanal mit dem Epithel im regenerirten Schwanztheil sich neugebildet hat, der sich scharf vom dem vorher vorhandenen Theil des Rïekemmarkes abhebt, so scharf, class oftmals an der Ansatzstelle eine Art von Knoten entsteht, während von weisser Substanz und von eigentliehen typischen Granglienzellen noch keine Rede ist. Dann sehen wir am proximalen Rande allmählich die Epitluelzellen sich vermehren, und sich erst in mehrere Lagen übereinander häufen; es treten kugelige Elemente auf und schliesslich typische Ganglienzellen.

\footnotetext{
1) F. Klaussner: Das Fückenmark des Proteus anguineus. München 1853. Separatabdruck.

2) Hensen: Betrachtungeu über Befruchtung und Entwickelung des Kaninchens und Meerschweinchens. Zeitschrift f. Anat. u. Entw. Gesch. r. His und Braune. Bd. I. 1876.

s) His: Ueber das Auftreten der weissen Substanz nud der Turzelfasern am Rückenmark menschlicher Embryonen. Archiv f. Anat. u. Physiol. Jahrg. 1883. pag. 163, ff.
} 
Ich glaube zu dem Sehluss berechtigt zu sein, namentlich, wenn wir die Verhältnisse im normalen Rückemmarke des Proteus im Ange behalten, wie sie ron K7aussner geschildert worden sind, dass hier das Epithel als Matrix für clie sämmtlichen Nervenelemente der grauen Substanz anzusehen ist, und dass eine Einwanderung von Ganglienzellen aus dem normalen Theile des Rïckenmarkes als ausgeschlossen zu betrachten ist. Ich verweise vor allem auf die rorher beselıriebenen Längssehnitte dureh das Riiekenmark ron Pleurndeles und Siredon,

\section{Peripherisches Nervensystem.}

Ich begime bei der Betrachtung der Regeneration des peripherischen Nerrensystems mit der Schilderung der Verhältnisse bei den Reptilien. Wie oben bereits gesagt wurde, regenerirt sich das Rückenmark nicht rollständig, und vor allen Dingen fehlen einmal die Spinalganglien ganz. Dafür muss eine gewisse Compensation eintreten, da der neugebildete Schwanz doch inmerhin ein bedentendes Stiick des Körpers reprïisentirt, und auf diese oder jene Wrise mit Nerven versorgt werden muss.

Schon den älteren Experimentatoren ist es aufgefallen, dass Stiicke eines regenerirten Sehwanzes, die unterhalb der ersten Bruchstelle wiederum amputirt wuden, nicht mehr die antomatischen Bewegungen machten, wic sie am zuerst verloren gegangenen normalen Theile stets beobachtet werden kïnnen. Diese nutomatisehen Bewegungen sind wohl einem Jeden bekamnt, der jemals eine Eidechse gefangen hat; dem es kommt ja gar zu häufigr vor, dass auch bei der grössten Vorsicht einzelne dieser zierlichen Thierchen beim Ergriffenwerden ihren Schwanz einbiissen. Forschen wir num naeh dem Grunde dieser eigenthuimliehen Beweglichlseit des verlorenen Theiles, so werden wir beim normalen Schwanze histologisch wenig nachweisen können, nur wird die starke Innervation sofort in die Augen fallen.

Die Spinalganglien mit den von ilmen abgehenden Nervensind zu verfolgen l,is fast an das. letzte Stuiek des normalen Riickemmarkes, von wo aus damn das sogenannte filum terminale Giuliani's ausgeht. Ton jedem dieser Spinalganglien gehen starke und reieh verzweigte Nerven nach den Muskeln, der Cutis und zur Hant. Damit ist jedoeh noch durchaus nicht erklït, weshall, die automatischen Bewegungen nael der Tremnung vom Thierkürper eintreten, denn ganz ebenso stark innervirte Partieen von anderen Thieren besitzen diese Fähigkeit nielıt in demselben Masse, wie man sich leicht an dem aljgesehnittenen Schwanze der Salamandrinen und Ichthyorlen iiljerzengen kam. Es muss also ein besonderes Centrum für diese Bewegungen, die ja wolıl hamptsächlich Reflexbewegungen sind, im Rüickenmark selbst vorhanden sein: listologisch dasselbe nachzuweisen, gehört vor der Hand jedoch zu den Unmöglichkeiten.

Betrachten wir die Verhälnisse des regenerirten Schwanzes, so sehen wir hier an Stelle des ausgebildeten und hochorganisirten Rïckenmarkes einen einfichen, nit Epithel ausgeklei- 
deten Centraleanal, versehwindend geringe weisse Substanz, und ab und zu sporadisch eimmal eine Ganglienzelle auftreten. Jeder Querschnitt durch den regenerinten Schwanz einer Eideehse oder eines Ascalaboten belehrt uns aber, dass nun die peripherischen Nerven in ausserordentlicher Stärke vorhanden und anch numerisch beträchtlich vermehrt sind. Diese peripherischen Nerven liegen ausserhalb des regenerirten Wirbehrohres und sind in der Nïhe des normalen Theiles am stïrsten, um damn nach hinten verlaufend allmählich sehwächer zu werden. Vill man diese Verhältnisse genaner studiren, so muss man Querschnittserien anfertigen, die am besten von hinten nach rorn zu betrachten sind.

Bekamntlich liegt um das regenerirte Wirbehroh herum, gerade wie um das normale Wirbelsystem, ein Fettkörper, und in diesem Fettkörper sehen wir bei Platydactylus facettanus 20 grosse Nervenstimme um das Knorpelrohr herumliegend, die auf dem Querschnitte fast alle eine rundliche Gestalt zeigen. Sämmtliche Nerrenstämme sind dicker, als das regenerirte Riickenmark, einzelne sogar noch einmal so gross. Auch bei Platydactylus rems finden sich dieselben Verhältnisse, die ich hier an einer unterbrochenen Schnittserie bis zum Uebergang in den normalen Theil verfolgen kann. Der regenerirte Schwanz, von dem ich diese Schnitte angefertigt habe, war $15 \mathrm{~cm}$ lang; es war deshalb unmöglich, ihn ganz in Sehnitte zu zerlegen; deshall, habe ich von Centimeter zu Centimeter einige Schnitte herausgenommen, und nur den letzten Centimeter vollständig benutzt, so dass der Zusammenhang mit dem normalen 'Theil studirt werden konnte. Lassen wir das Schwanzende vorläufig ausser Acht, und betrachten wir die Uebergangsstelle, so finden wir hier das Rïckenmark noch fast normal gebaut; obgleich die grane Substanz hier schon etwas reducirt ist und die Ganglienzellen unregelmässiger angeordnet liegen, als im vollständig normalen Theil. Der Wirluelkörper ist an dieser Stelle dureh Markhöhlen bereits etwas verüindert, jedoch von dem Auftreten des Wirbelrohres noch keine Spur zu erkennen. Die oberen Bögen, welche das Rïckemmark umgeben, sind häutig; rom Riickenmark hat sich die Pia abgehoben, wie es schon von der Uebergangsstelle von Pleurodeles Waltlii geschildert wurde; auch die Dura hat sich gelockert und ist nur noch an der Basis des Riuckenmarkes in innigem Zusammenhang mit der Pia. An dieser Stelle finden sich nun jederseits drei grosse Nervenstämme ausserhalb der Dura liegend; Nervenstämme, welche den normalen Theilen vollständig fehlen; ̄́ clavon liegen ausserhalb der Dura, sich dieser dicht anschmiegend, der linke oberste jedoch befindet sich zwischen Pia und Dura. Ausserlialb der oberen Bögen liegen jederseits noch 3-4 grosse und dicke Nervenstränge, in denen namentlich die Kerne der Schwann'schen Scheide stark ansgeprägt sind, und durch die Hethylviolettfärbung besonders hervorgehoben werden. Die Axencylinder sind stark lichtbrechend, die Marksubstanz gering, aber dureh die Praeparation ganz ausgezogen, so dass an ihrer Stelle ein Hohlraum sich befindet.

Leider konnte ich die Frage nach der Herkunft dieser starken Nervenstränge, welche ja unbedingt hier anfgeworfen werden muss, an diesem Prïparate nicht entscheiden, da ich zu wenig von dem normalen 'Theil mit in den Bereich meiner Beobachtungen gezogen hatte und mir das Exemplar selbst leider nicht mehr zur Verfitgung steht, um weitere Studien daran zu machen. Dagegen will ich nun die Verhältnisse bei Phyllodactylus europaeus schildern, von dem ich vollstiindig den Uebergang in allen Stadien auf meinen Schnitten verfolgen komnte.

Bei einem ca. 1 em langen, regenerirten Schwanze ron Phyllodactylus europaens finden sich am letzten Theile noch vollständig embryonale Verhältnisse, die weiter oben zum 'Theil ihre Besprechung 
gefunden haben. Dam treten neben dem Wirbelrohre, das noch durchweg knorpelig ist, die Anlager des Fettkürpers, der Muskulatur der Cutis und der bindegewebigen Stränge auf; innerhalb des Fettkürpers, der noch vollkommen embryonalen Typus hat, und dessen Zellen noch grosse protoplasmareiche Kerme besitzen, liegen dann die letzten Endigungen der peripher rerlaufenden grossen Nervenstämme. Diese riicken, je weiter sie nach rorn verlanfen, immer näher an den Wirbelcanal heran, einzelne derselben" vereinigen sich, so dass sie ron einer gemeinsamen Scheide umgeben werden, oftmals 3-4, und zuletzt liegen sie an der Uebergangsstelle des regenerirten in den normalen Theil fast dem Wirbelsystem an. Sie endigen in den letzten spinalganghien des stehengebliebenen Schwanztheiles, die sich durch eine ganz besondere Grösse auszeiehnen. Nicht nu die von diesen Spinalganglien ansgehenden Nerren sind bedentend stïrker, wie das im normalen Theile der Fall ist, sondern auch die Wurzeln, welche aus dem lezten Theile des Ritekenmarkes in diese Spinalganglien hineinstrahlen. Die einzelnen Faserziige der Wurzeln sind nicht nur verdickt, sondern auch an Zahl vermehrt, so dass es oftmals den Ansehein hat, als ob starke Nerven direct aus dem Riickenmark heranstreten. Diese Wurzehn verlaufen zuerst der dorsalen und ventralen Seite des Rückemmarkes parallel, ihre Endigungen sind zu suchen an der tissura superior und inferior; zu bemerken ist dabei, dass die fissura superior bei den Reptilien fast noch sehwäeher ausgebildet ist, als bei den Amphibien. Nachdem diese Wurzeh die Hänte des Rückenmarkes durchlrochen haben, veremigen sie sich und gehen durch die foramina der neuralen Bögen hindureh, um mit einer bindegewebigen Scheide umgeben in die Spinalganglien einzutreten. Ein Uebersichtsbild über die gesammten hier geschilderten Verhältnisse habe ich auf Taf. III in Fig. 4 abgebildet.

Werfen wir num einen Blick anf die physiologischen Erscheinungen, die eventuell hierdurch eine Erklärung finden könnten. Ebenso bekannt, wie die früher erwähnten Eigenthümlichkeiten am regenerirten Schwanz war bereits die Thatsache, dass die autonatischen Bewegungen des amputirten regenerirten Theiles nicht anfhörten, wemn noch ein kleines Stïck des normalen Schwanzes demselben anhing. Bereits Hcinvich Müller hat dies beschrieben, aber nicht zu erklären gewusst, und anch II. Giuliani, dem wir die letzte Arbeit iiber das regenerirte Riickenmark der Eidechsen verdanken, schliesst mit den Worten:

$\dot{\mathrm{E}}$ orrio il fatto che staceando la coda ad una lncertola, questa presenta in modo esagerato i movimenti riflessi. Ora staceando rarie code riprodotte, alcume delle quali avevano la lunghezza di dieci centimetri, io non mi sono potuto accorgere mai di alcun movimento, anche doppo forte irritazione con un ago; però quando insieme alla parte riprodotta ho portato via una porzione anche piccolissima della coda primitiva, i morimenti riflessi erano sensibili come nelle code normali, e cii perchè allora trovavasi ancorn in questa porzione staceata l'ultima parte del midollo spinale, nel quale si trova il centro dei movimenti riflessi della coda riprodotta.

Eine Erklärung dieser Thatsache weiss er ebenso wenig zu geben, wie Heimich Müller, obgleich ilnm schon die grossen peripherischen Nervenstränge aufgefallen waren, welehe IIcinrich Nüller vollständig iibersehen zu haben scheint.

Es findet sich also nach Guliani das Centrum der Reflexbewegmingen in dem letzten Theile des Riickenmarkes; warum aber, und aus welchen morphologisehen Grinden, das hat anch dieser Forseher nicht erkannt. Nach den von mir eben dargestelten Verhältnissen, wie ich sie bei den Asealaboten ganz besonders, in ähnlicher Weise auch bei Lacerta agilis, Anguis fragilis und Senira bicolor anftreten salı, wird es uns jedoch nicht schwer werden, aus den gefundenen morphologischen 
Verhälnissen auf die physiologische Function zu schliessen, welche die letzten Spinalganglien für den regenerirten Schwanz zu übernehmen haben.

Sie sind die einzigen Gamglien, repröisentiren die einzigen Relais, welche wir in Verlaufe der starken und vielfach verzweigten Nerven in regenerirten Schwanze antreffen, und deshalb kam es nicht wunderbar erscheinen, wenn hier eine besondere Hyperplasie der Gewebe eintritt, durelı welche sowohl eine Vermehrung der Gauglienzellen als auch der Nerrenfisem hedingt wird. Diese letzten Spinalganglien wïrden demnach auch physiologisch für die Centren der antomatischen Bewegungen aufzutiihren sein, und nicht eigentlich das Rï̈ckeumark selbst.

Wie entstehen nun die Spinalganglien bei den Amphibien? Unmöglich können sie sich in derselben Weise bilden, wie beim Embryo das gesehieht. Denn hier sehen wir, dass nach den neneren Beobachtungen von His, Hensen, Balfour, Marshall, Külliker und Sagemehl, wenn wir den Darstellungen von Ilis folgen wollen, als erste Andentung der Spinalganglien ein sogenannter Zwischenstrang entsteht, der aus den an das Medullarrohr angrenzenden Theilen des Hornblattes herrorwuchert. Dieser Zwischenstrang ist nach His anfänglich eine zusammenhängende Leiste, jedoch ron Stelle zu Stelle mit stärker entwickelten, tiefer zwischen Urmark und Wirbel herabragenden Theilen; gliedert sich aber später, während el rom Hornblatt sich löst, in einzelne Stiicke, die Spinalganglien, ab, die erst nachträglieh dann sich mit dem Marke verbinden. In seinem Aufsatze ïlyer das peripherische Nerrensystem ${ }^{1}$ ) and in der Anatomie menschlicher Embryonen ${ }^{2}$ ) ist His noch entschieden dafür eingetreten, dass die Nerrenfasern aus den Zellen des ursprïnglich faserfreien Medullarohres, beziehungsweise aus den Ganglienzellenanlagen hervorwachsen. His wendet sich anch in seiner neuesten Publication: Ueber das Auftreten der weissen Substanz und Wru'zelfasern am Rückenmark mensclilichè. Embryonen ${ }^{3}$ ) besonders gegen die ron Balfour und seinem Sehüler Marshall aufgestellte Ansicht, dass die Nervenfascm direct aus Zellcomplexen entstehen sollten. Auch Sagcmehl ${ }^{4}$ ) hat im Sime von His die Hypothese Balfour's und Marshall's zurickgewiesen.

Mag num die Platte, aus welcher die Spinalganglien später hervorgehen, aus dem bereits differencirten Theile des Medullarrohres, oder mag sie ans dem Hornblatt direct ihren Ursprung nehmen, immer ist sie so gelagert, dass ihre urspriingliche Entstehung an der Stelle zu suchen ist. an der das Medullarohr in das Hornblatt iibergeht.

In dieser Weise können num ummöglich die Spinalganglien des regenerirten Rïckenmarkes entstehen, da ein Zusammenhang mit dem Hornblatt hier absolnt nicht nachzuweisen ist. Es muss also eine andere Bildungsweise stattfinden, und auf diese wollen wir jetzt einen kurzen Blick werfen. Schon in normalen Schwanze ist es bei den langsehwänzigen Salanandrinen und anch Perennibranchiaten nicht möglich, dass die ganze Reihe der Spinalganglien bis zum letzten Ende des Schwanzes in der eben beschriebenen Weise angelegt wird, denn es wäichst der Schwanz nach Alıschluss des embryonalen Lebens, nachdem also längst eine Trennung der verschiedenen Organsysteme stattgefunden hat, in ansgiebiger Weise noch weiter, un seine definitive Lünge zu erreiehen.

Ich habe bereits erwähnt, dass bei dem nomalen Rïckenmark sowohl, wie bei dem rege-

\footnotetext{
1) Archiv f, Anat. ย. Physiol. 1880. pag. 474.

2) 1. Theil, pag. 40 .

3) Archiv f. Auat. u. Physiol. 1883, pag. 163.

4) Untersuchungen über die Entwickelung der Spivaluersen. Dissert. Durpat. 1852. pag. 20.
} 
nerirten. die letzten Spinalganglien sich stets imerhalb der neuralen Bügen rortinden, und noch nicht ans denselben hinausgeriickt sind. Terfolgen wir nun die Spinalganglien bis zum Ende des Schwanzes, so finden wir sie schliesslich in direetem Zusammenhang mit den Zellen des Rïickenmarkes, bis endlich die allerletzten mu als kleine Auswiichse der Epithelzellen des Centraleanales sich erweisen. Ton diesem stammen sie mzweitelhaft ab, und soweit wird auch die ontogenetische Entwickelung bei der Regeneration wie im normal wachsenden Schwanzende reeapitulirt. Aber die erste Bildung der Spinalganglien wird nun nicht mehr dureh das Auftreten einer ungegliederten Platte eingeleitet, welche am oberen Theile des Rückenmarkrohres sich anlegt, sondern gerade an der entgegengesetzten oder doch fast gegeniiberliegenden Seite des Riïckenmarkes tinden sich segmentweise, d. h. den Wirbelsegmenten entsprechend, Vermehrungen der Epithelzellen, ans denen die nervösen Elemente der Spinalganglien hervorgehen.

$\mathrm{Da}_{\mathrm{a}}$ in der Litteratur meines Wissens niehts bekannt ist, so will ich die von mir am normalen Schmanze ron Protens gefundenen Verhältnisse hier kurz darstellen. Das Nervensystem ron Proteus besitzt anch, wemn man von hinten nach rom eine Quersehnittserie betrachtet, die Gestalt (rines einfachen Centralcanales wit durch Picroearmin ausserordentlich stark tingirtem Epithel, der nicht bis an das Ende des Schwanzes reicht. Die einzehnen Sehnitte sind ungefär ein Vierzigstel Millimeter dick; im 36. von hinten findet sich die erste Andentung des Rïickemmarkes. Die Epithelzellen sehliessen hier den Centralcanal ab, aber nur in einfaeher Lage, so dass kein geschlossener Strang dem Riiiekemmarke anhängt, wie das von Klaussner beschrieben wird.

Hier beginnt der Centralcanal also in 37. Sclmitt; man sieht da bereits das Lumen des Centralcanales, dessen Durehmesser der Länge der etwas gestreckten Epithelzellen gleich ist. Der Centralcanal liegt vollständig in der Mitte, und ist ringsherum kranzfürmig umgeben von einer einfachen Lage ron Epithelzellen, die sich allmählich in mehrere Lagen differenciren. In dieser Gestalt verlüuft das Rïekemmark eine Strecke und behïlt dieselbe anch noch, wenn die oberen Bïgen schon rollständig gebildet sind und sngar schon ans Faserknochen bestehen.

Genau nachweisen lässt sich eine neben dem Epithel auftretende weisse Substanz erst im 210 . Schnitte, und von da bleiben die Terhältnisse sich wieder gleich, bis einzelne ebenfalls stark tingirte und stark lichthrechende kugelige Elentente neben dem Epithel sieh erkennen lassen. Die weisse Substanz nimmt an Dicke zu, aber von einer Membran ist auch im 299. Sclnitte noch nichts zu erkennen; nu werden die Dimensionen grösser, die Nervenelemente vermelnen sich, bis endlich die von Klaussner weitläntig geschilderten Structurverhältnisse sich Schritt für Schritt nachweisen lassen.

Lange ror dem Anftreten der weissen Substanz, und zwar schon im 110. Sehnitte, also 2,5 $\mathrm{mm}$ vorher, findet sich die erste Anlage von Spinalganglien (Taf. 1II. Fig. 11). Die Epithelzellen haben sich hier bereits in mehrere Lagen gesondert; nach oben zu sehen wir $3-4$ ineinander geschichtete Zellgruppen, an den Seiten 3, und unten an der Basis des Iiiickenmarkes hüchstens 2. Nur die Kerne sind selu dentlich, von Zellleibern ist kaum etwas zu erkennen, der Centraleanal ist fast rund, nur etwas seitlich comprimirt; er wird duch eine dentliche Membrana limitans ansgekleidet. Nun tritt zuerst an der linken untern Seite eine Vermehung der Zellen in 4-5 Lagen auf, so dass hier die Wand des Centralcanales auf das Doppelte verdickt ist. Durch vier Sichnitte lässt sieh diese Verdiekung genau beubachten, dann tritt an der rechten Seite dieselbe Erscheinung anf, und lisst somit keinen Zweifel entstehen, dass wir hier die ersten Anfänge, oder viehmehr die letzten 
Anlagen der Spinalganglien vor uns haben. Im 169. Schnitte, also genau ein Virbelsegment weite! vorn, finden wir dieselbe Verdickung wieder an der unteren Seite des Centraleanales (Taf. III. Figr.12). und ron Wirbelsegment zu Wirbelsegment weiter nach rom dam eine fortgesehrittene Differeneirumg.

Genau in derselben Weise entstehen die Spinalganglien am regenerirten Ruickenmark, wie jeh das namentlich an einer Schnittserie von Pleurodeles Waltlii beobachten konnte.

\section{\%. Muskulatur.}

Trie das bereits melirfach im Laufe der Arbeit aufgefallen sein wird, sind die Reptilien anch in Bezug auf die Untersuchungen iiber die Neubildung dieses Gewebes ansserordentlich vernachlässigt, die Amphibien dagegen umverhälnissmässig bevorzugt worden. Auf den ersten Bliek scheint dies nicht mit Umeeht geschehen zu sein, da ja die histologischen Elemente der Amphibien ein bedeutend klareres und sehärferes Bild darbieten, als die der Reptilien. Forsehen wir jedoch genauer, so wird sich vielleicht das Gegentheil behaupten lassen; man wird erkennen, dass man die Reptilien mit Unrecht zurỉekgesetzt hat, da bei ihnen cinzelne Entwiekelungsphasen sieh viel sehärfer and prägnanter ausdriicken, als dies bei den Amphibien jemals der Fall ist.

In der normalen Inskulatur eines Eidechsensehwanzes tinden wir ausser einer selr schart ausgeprägten Querstreifung noch, dass dieselben sich sehr leicht in Längsfibrillen zerlegen lassen. Ebenso ist es bei Sehnitten sowohl, als an Zupfpräparaten auffällig, dass die Muskelkörperehen fast ganz gesehwunden sind; nur ab und zu sieht man anf Quersehnitten em stark lichtbrechendes und stark gefärbtes Körnehen, das als letzter Rest des Muskelkernes gedeutet werden kann; zuweilen besitzt es noch einen kleinen Protoplasmahof, der den Rest des MIuskelkürperehens bildet. (Taf. IIl. Fig. 21.) Diese Elemente finden sich nieht, wie bei den meisten Amphibien, an der äusseren Peripherie der Faser, sondern sie sind mitten in die contractile Substanz cingebettet, und deshalb auf Zupfpräparaten nur sehwer zu erkennen. Die Muskelfasern sind verhältuissmässig sehr stark; sie verlaufen in Bündeln urd werden, nachdem sie immer sehmäler und feiner geworden, ron einer Sehne umfasst, die sich in ähnlicher Wreise, wie das bei den höheren Wirbelthieren dureh die Beobachtungen Froriep's und Anderer nachgewiesen wurde, direct in die Zellen des Perimysiums iibergeht.

Getrennt sind die einzelnen Muskelfasern stets auch beim rollstindig ausgewachsenen Thiere durch eine bindegewebige Iembran, das Perimysimm internum, in weleher beim jugendliehen Individum noch viele und ziemlieh grosse Kerne anftreten. Fassen wir eimmal, ehe wir anf die Genese der regenerirten Muskelfasem eingehen. das Bild in's Auge, welehes dieselben uns in den verschiedenen Stadien der Regeneration dabieten. so sehen wir, dass bei Senira bicolor die Selmen der Muskeln sieh im regenerirten Schwanze nun nieht etwa an das Wirbelrohr ansetzen, sondern 
dass, wie gerade an diesem Präparate sehr deutlich zu bemerken ist (vergl. Tafel II, Figur 3), die einzelnen Muskeln in einandergeschachtelt sind; es wird ein vollständig geschlossener randständig angeordneter Muskelschlauch gebilclet, bei welchen die Sehnen der vorhergehenden proximalen Muskelbindel stets in der Muskelsubstanz der distalen verlanfen. Die einzelnen Segmente der Muskeln, oder die grossen Muskelbimdel sind umgeben von einem starken, bindegewebigen Faserzuge, und zwisehen den einzelnen Absehnitten der Muskeln verlaufen dann von dem änsseren Ringe des Wirbehrohres ans nach der Peripherie ebenfalls feste Bindegewebsziige. In der Mitte zwisehen Muskulatur und Knorpelrohr liegt der Fettkörper mit Gefässen und Nerven; ausserordentlich deutlich sieht man bei stärkerer Vergrösserung in den einzelnen Muskelfasern die Colnheimisehen Felder; die Kerne sind bei diesem älteren regenerirten Schwanze aussergewöhnlich klein und selten, liegen nicht am Rande, sondern im Innern der Fasern, anf deren Querschnitt sich als Ausdruek der durehsehnittenen Fibrillen dem Auge eine feine Punktirung darbietet.

Das Sarcolemma ist hier entsehieden noch nicht vorhanden, denn am Rande der contractilen Substanz ist niehts von irgend einer liehtbrechenden Scheide zu erkennen, dagegen wird jedes Muskelprimitiviundel oder jede Muskelfaser von einem bindegewebigen Netz, einer bindewebigen Scheide, dem Perimysium internum, nmzogen, dessen Entstehung bei jüngeren Stadien besehrieben werden soll.

Anch bei Hemidaetylus freettanus sind diese Verhältnisse sehr ähnlich, nur findet sich die Einsehachtehng der Muskeln in einander nieht so dentlich ausgeprägt, wie vorher.

Bei Platydaetylus verus sind die Muskelfasern sehr gross und stark, sie zeigen am alten regenerirten Schwanz $(15 \mathrm{~cm})$ eine prächtige Querstreifung. Von einem Sarcolemma ist nichts zu erkennen, ebensowenig sind Muskelkörperchen irgendwie nachweisbar; anch das Perimysium internum ist sehr sehwach entwiekelt. Beim Zerzupfen zerfällt der Muskel leichter noch als der der Eidechsen in feinste Fibrillen, da hier die Cuticularhïlle fehlt und das Bindegewebe sehr leicht zerreissbar ist. Auch hier sind im Perimysium die Kerne nieht mehr ganz dentlich. Weder bei Platydactylus noeh bei den vorher beschriebenen älteren Regenerationsstadien füllt auf dem Quersehnitte die contraetile Substauz die bindegeweljigen Selieiden ganz aus, vielmelı bleibt immer ein Zwischenraum.

Die Umwandlung des Bildungsgewebes zu quergestreiften Mnskeln kann man am besten verfolgen, wemn man eine Schnittserie von hinten nach rorn betrachtet; allerdings wird man hier die Entstehung der ersten contractilen Elemente nicht nachweisen können, da diese nur auf Längsschnitten oder Zerzupfungsurn̊paraten deutlich werden. Die erste gröbere Anlage der Muskelbiindel gesehieht stets in der Weise, dass dieselben einen randständigen Kranz bilden, der an die Cutis sieh anlegt und aus einzelnen rundlichen Muskelpacketen zusammengesetzt ist. Nehmen wir als Beispiel einen Querschnitt dureh den hinteren Theil des regenerirten Sehwanzes von Phyllodactylns europaeus, bei welehem der Fettkörper noch sehr gross und mit embryonalen Zellen und Kernen durehsetzt ist (Taf. III, Fig. 22), so schen wir die Muskulatur an der Peripherie ringförmig angeordnet und in ungefähr 30 Bündel getheilt, welche alle etwa den Durehmesser des Wirbehohres haben. Nur wenige Fasern bindegewebiger Natur verlaufen vom Wirbelroh zu diesem Muskelkranz dureh den Fettkörper, sonst jedoch sind die bindegewebigen Umhïllungsmembranen, wenn auch noch von embryonaler Struetur, deutlich zu erkemen.

Diese einzelnen rundliehen Muskelpackete entsprechen nun den Fortsätzen der alten Muskeln, sie stammen ron diesen, wie wir sogleich sehen werden, ab und wuchern, so zu sagen, in das 
undiffereneirte Blastem linein. Auf dem angeführten Durchschnitt fehlt den jungen Muskelfasern das Sarcolemma vollkommen, dagegen ist ihre Substanz deutlich in eine contractile Rinclenschicht, welche als Ausdruek der schon bestehenden Längsfibrillen eine feine Punctirung und Strichelung zeigt, und in eine protoplasmatische Markschicht geordnet, welche die Kerne enthält.

Verfolgen wir die Quersehnittserie nach vorn, so treffen wir schliesslich auf den Uebergang der neuen Muskelfasern in die alten, und können hier besonders den Zerfall einzelner alter MIuskelprimitivbündel eonstatiren.

Ich lege bei der Betrachtung der Querschnittserien durch die neugebildete Muskulatur hauptsäehlich Gewicht darauf, dass die neugebilkete Muskelzelle, denn ein jeder kleiner Ring entspricht, wie wir gleich sehen werden, thatsächlich einer Zelle, ihren Inhalt in randständige contractile Substanz und in eine fast homogene Marksubstanz gesondert hat. Dies erinnert an das Verhalten der embryonalen Muskelfasern von Vögeln und Sängethieren und auch bei Embryonen von Coronella laevis konnte ich einige Stadien der normalen IIuskelentwickelung beobachten, welche dem eben angeführten Bilde auf ein Haar gleichen.

Versuchen wir nun nachzuweisen wie die Regeneration der Muskelfasern urspringlich vor sieh geht und aus welehen Elementen sich die neuen Theile bilden.

Verliert eine Eidechse oder ein Gecko auf normale Weise seinen Schwanz, das heisst, wird er demselben durch Druck oder Zug ausgerissen, so steht ein ganzer Kranz ron zugespitzten Muskelbündeln über die Wundfäehe vor, zwischen denen ebensoviel Vertiefungen ebenfalls koniseher Natur sichtbar werden. Dies ist begründet dureh die eigenthimliche Anordnung der Schwanzmuskulatur dieser Thiere, indem, anch bei dem normalen Schwanze, nieht alle Muskelbiindel sich an die Skelettheile anheften, sondern viele in einander gesehachtelt liegen, so dass die Spitzen der vorderen Muskelsegmente in den hinteren Segmenten eingebettet erscheinen. Auch bei höheren Wirbelthieren ist es bereits seit Rollett bekannt, dass einzelne Muskelfasern im Innern des Muskels frei endigen ohne mit der Selne in Berïhrung zu treten; hier endigen nun ganze Muskelbindel in älnlicher Weise frei, nur umgeben von einem mitunter bei den Ascalaboten allerdings ziemlich festen Perimysimm, das aus fibrillïrem Bindegewebe besteht.

Bei einem mit der Scheere oder einem scharfen Messer gefuhrten Schnitt bekommt man naturgemäss aneh eine glatte Schnittläehe dureh die Muskulatur, aber diese Art der Verstimmelung wird in der freien Natu selten vorkommen, so dass die hierdureh herrorgerufenen Regenerationserscheinungen gewissermassen als abnorm zu betrachten sind.

Ist der Schwanz einer Lacerta nun auf die erwälnnte Weise ausgerissen, so vertrocknen die hervorstehenden Muskelbündel sehr schnell und bilden mit dem geronmenen Blut und abgestossenen Bindegewebszellen bald einen mehr oder minder dicken Schorf. Längere Zeit jedoch sieht man die kegelförmigen Spitzen noch dureh diesen hervorragen bis sie endlich ganz vertrocknen und völlig in den Sehorf mit übergehen.

Die histologischen Vorgänge sind dabei sehr einfacher Natur; es werden die Enden der Muskelbindel dureh den directen Einfluss der Luft nekrotisch, die Enden der Muskelfasern selurumpfen zusammen und das umgebende Perinysium sowie das oft sehr zarte Sareolemma folgt der Contraction und bildet rundliche Ansehwellumgen.

Alle diese Theile, welche direct getroffen werden, gehen anch direet zu Grunde, während der übrige Theil der Muskelbindel Veränderungen erfihrt, die complicirterer Natur sind. Oft wird 
das ganze Biindel anfgelöst, indem die contraetilen Elenente desselben Seheiben oder Schollen gleich im Bindegewebe zu finden sind. Oft zieht sieh aber das Sarcolemma zurüek und bildet ringfürmige Einsehniirungen, die dann ganze Stiieke der Muskelfasern.absehniiren. Der abgesehnürte Theil geht dann ebenfalls mit in den Sehorf iiber.

Hat sich nun die nekrotische Substanz der Bïndel von der noch lebensfähigen getrennt, so treten naeh dem 4. bis S. Tage, je nach der Jahreszeit, in dem letzteren wiederum Verüinderungen anf, welche auf eine vitale Reaetion schliessen lassen.

Inden dureh das Vertrocknen des Schorfes die Epidermis und die Cutis mit den stehengebliebenen Schuppen ringförmig zusammengezogen werden, bildet sich zwisehen Sehorf und Muskelenden eine Schicht ron Bindegewebszellen, die zuerst rundlieher Natur mit grossen Kernen und einem geringen P’rotoplasmahof, später zu Spindelzellen werden, deren Längsaxe quer zur Längsaxe des Körpers steht.

In dieses Blastem, welches oftmals nusserordentlich dieht ist, ragen nun die rerletzteu MLnskelfasern hinein. Die Bïndel haben sieh meistens stark gelockert oder ganz aufgelöst, so dass man auf Längssehnitten nur unregelmässig gelagerte Muskelfasern sieht, die keulen- oder kolbenförmig endigen. Diese Anselwwellungen bestelıen nur aus quergestreifter eontraetiler Substanz, deren Fibrillen bis zum letzten Ende vollkommen deutlich sind. Das Sareolemma fehlt am unteren Theil und auch das Perimysimm erseheint stark gelockert. Oft treten die Spindelzellen zienlieh hoeh zwisehen die einzelnen Faseru linanf, besonders dann, wenn bereits Gefässlaeunen gebildet sind. So liegen die Verhältnisse am normaler Weise rerlorenen Schwanze von Laeerta etwa am aehten Tage unch der Verletzung. Fïhrt man dagegen die Amputation durch Messer oder Seheere aus, so wird die entzindliehe Reaetion heftiger sein als oben dargestellt wurde. Vor Allem werden im letzteren Falle die Mnskelprimitiviindel selbst verletzt, die contraetile Substanz dringt aus dem Sareolemmasehlanch, der sich vermöge seiner Elasticität zuriekzieht, hervor und in Folge dessen rerödet ein grösserer Theil der Muskulatur als dies sonst der Fall ist. Fast immer sah ich gerade Schnittwunden durch den Reptilienschwanz sehwerer heilen als die dureh Abreissen entstandenen und führe dies hauptsächlieh auf das Verhalten der Muskulatur zuriiek.

In Folge der Nekrotisirung grosser Muskelpartieen, dem fast das ganze rom Scluitte getroffene Muskelsegment degenerirt, wird die Narbe vertieft und es dauert geraume Zeit bis sieh ein zelliges Blastem iiber den Muskelenden und den ebenfalls zum Theil absterbenden und der Resorption anheimfallenden Skelettheil gebildet hat.

Von diesem Zeitpunkte an sind die num eintretenden Entwiekelungsrorgänge jedoch identisch, so dass man bald nicht mehr unterscheiden kann, ob ein Sehwanz dureh Sehnitt oder durch Riss amputirt wurde.

Auch bei den Sehnittwunden durch die Muskulatur der Säugethiere wurde sehon von Neumann ${ }^{1}$ ) betont, dass erst nach dem dritten bis vierten Tage eine vitale Reaetion eintritt, während in der vorliergehenden Zeit einzehe Theile abgestossen werden und umhergestrent im umgebenden Gewebe erscheinen, indem sie alle Spuren des Zerfalls an sich tragen. Ist die Zeit der Degeneration voriber, so tritt bei unsern Eidechsen sowohl wie bei den Säugethieren eine eigenthiimliche Wincherung ron Fernen anf, lie den ersten Anstoss zur Neubildung gibt. (Taf. III, Fig. 2う̌).

1) Ueber den Heilungsprocess nach Muskelrerletzungen. Arch. f. mikr. Anat. Bd. 1F. pag. 323 ff. 
Diese Kernwucherung kamn bei manchen Muskelprimitiviundeln so stark sein, dass die contractile Substanz vollständig verdrängt wird und der Sarcolemmaschlaneh nur mit reihenförmig hintereinander liegenden Kernen erfüllt ist.

Dieses Verhalten der Muskulatur fiel mir besonders bei Lacerta agilis auf, bei anderen Formen mit dickeren Prinitivbündeln trat eine ganze Reihe von Kernen an der einen Seite der contraetilen Substanz auf, welche, wie es selien, hierdureh nicht verändert wurde.

Neben diesen mit Kermen vollgepfropften Sareolemmaschläuchen, neben den Rudera der verletzten Primitivbündel, sah ich nun zwischen den geloekerten Bündeln noch Zellen anderer Art, die ich nur mit den von Bremer und anderen beschriebenen Muskelspindeln vergleiehen kann. Es sind dies helle spindelförmige Zellen mit ovalem Kern und feinkörnigem Protoplasma, die gewöhnlieh so stark zwischen den einzelnen contractilen Fasern eingeklemmt sind, dass man sie nur schwer dureh Maceration von ihnen trennen kann. Thr ganzer Bau und ilure Genese stimmt, wie wir gleieh selıen werden, vollkommen mit dem der Sareoplasten von Töröli's ïberein.

So liegen die Verlältnisse bei den Reptilien in dem Stadium, in welchem die Regeneration beginnt, es wird daher am Platz sein, bevor wir uns den allgemeinen Bespreehungen zuwenden, einen Blick auf die gleichen Verhältnisse der Amphibien zu werfen.

Nach der Amputation des Schwanzes oder der Gliedmassen, die hier stets mit Scheere oder Messer ansgeführt wurde, tritt ebenfalls in der Mnskulatur der Amphibien ein Zerfall ein, der die getroffenen Stellen in melır oder minder grosser Ausdehnung affieirt.

Höher organisirte Formen reagiren heftiger gegen die Verletzung als niedere, und in Verhältniss hierzu tritt damm in kürzerer oder längerer Zeit die vitale Reaction und mit iln die Regeneration ein. Sehr lıeftig reagirt Pleurodeles gegen die Verletzung der Muskulatur. Bei diesem Urodelen ist die Selrwanzmuskulatur ausserordentlich stark ausgebildet, die Kerne sind fast ganz geschwunden, oder minimal geworden und das gamze Gefüge des einzelnen Muskels macht einen festen, krïftigen Eindruek. Dureh den mechanischen Eingriff werden die festgefïgten Elemente nun gelockert, grosse Particen des verletzten Muskels lösen sieh ab, liegen zerstrent in dem sich bereits neubildenden bindegewebigen Blastem und zeigen noeh lange nach der Vernarbung der Wunde, wie die gleichen Elemente von Siredon, dureh ilure intensiv rothe Färbung (besonders bei Anwendung von Pierocarmin), dass sie sich im Stadinm der Resorption befinden.

Ziemlich spät, nachdem bereits ein gutes Stück des Schwanzes sich regenerirt hat, nachclem sogar der Vorläufer des Skeletes, der ungegliederte Knorpelstab aufgetreten ist, finden wir deun auch, dass es in der Muskulatur sich regt und sehen MInskelfasern hervorknospen. Die Kerne der stehenbleibenden, nieht resorbirten Muskeln sind jetzt merkwïrdig homogen und stark glänzend, dass man sie fast für Fetttropfen halten könnte.

Bei den Larven von Triton, bei Siredon ete. gelst die Regeneration der Muskulatur schneller vor sicl, die Vorgïnge der Resorption nelımen nieht so lange Zeit in Anspruch, aber immer ist doeh ein gutes Stück des Schwanzes regenerirt, welehes Epithel, Bindegewebe, Blntgefảsse und Knorpel enthält, elıe eimmal die Muskulatur zur Proliferation sich ansehiekt.

Jedenfalls hïngt dies mit der Bildung der Spiudeln zusammen, von welehen die Neubildung wie wir sehen werden, ausgeht, und die sich erst von den unverletzten Fasern abspalten müssen. Dazu gehört eine Resorption von quergestreifter Substanz, dam eine Neubildung von Protoplasma 
und sehliesslieh die Bildung einer selbständigen Zelle - Alles das bedarf naturgemäss eines gewissen Zeitraumes.

Die Spindeln sehe ieh bei erwachsenen Tritonen immer erst nach der Verletzung auftreten, bei den Larven, die die Längo von $1 \mathrm{em}$ noeh nicht übersehritten haben, findet man sie überall zerstrent zwisehen den Primitivbindeln und alle Umwandlungsphasen zwischen der einzelnen Spindelzelle und dem Primitivbiindel.

Die juingsten Spindeln sind bei erwaehsenen Tritonen sehr lang und besitzen nur einen längliehen Kern, ihr Protoplasma ist fast homogen. Bei jüngeren Thieren findet man oftmals eine Kö̈rnelung im Protoplasma.

Andere Elemente, z. B. die bei Reptilien so häufigen mit Kernen erfülten Sareolemmasehlänehe habe ich bei den Amphibien nicht beobachten können.

Somit hätten wir nun die Elemente der Muskulatur der Amphibien und Reptilien in dem Stadium kennen gelernt, in welehem die Regeneration beginnt und es wird jetzt vor Allem unsere Aufgabe sein nachzuweisen, auf welehe Art und aus welehen Elementen die Nenbildung des Iuskulatur vor sich geht.

Sehon in den sechziger Jahren sind bahnbrechende Arbeiten iiber diesen Gegenstand erschienen, so die von Waldeyer, 1) C. O. Weber, ${ }^{2}$ ) Mlaslowshy, ${ }^{3}$ ) Deitcrs, ${ }^{4}$ ) Yeumann, $\left.{ }^{5}\right)$ Peremeschlio, $\left.{ }^{5}\right\rangle$ Billioth ${ }^{7}$ ) und Anderen.

Wiahrend Webcr, Waldeyer und die iibrigen Forseher eine Neubihng der Muskulatur naeh embryonalem Typus, wie sie wenigstens glanbten, annahmen, das heisst aus einem zelligen Blastem ohne dass die alten Muskelfasern dabei in's Spiel kamen, trat Teumann gegen diese Ansieht auf und behanptete, dass die Muskulatu nur aus den Elementen der alten verletzten Muskelfasern sieh wieder regeneriren könne.

$N$. salı die alten Faserenden, nachdem die „vitale Reaetion" eingetreten war, vollgepfropft von Kernen, die allmählieh an Grösse zunehmen. Am 5.-7. Tag kommt es zu einer „Lnospenbildung", die von Billroth und "leber ebenfalls gesehen, aber anders gedeutet wurde.

"Am häufigsten und leichtesten zu sehen ist ein sehmalev Fortsatz, der sieh gegen den alten, breiten Theil der Fasern mehr oder weniger abgrenzt und dessen Ende bald stumpf abgebroehen erseheint, bald kolbig verdiekt, balı spitz zugesehä rft ist, oder aneh wohl in einen fadenförmigen Anhang ausläuft."

Auch kann eine Spaltung oder seitliehe Knospung auftreten, welehe mitunter wirkliehe Aehnlichkeit mit den Knospen eines Baumes besitzt. In der weiteren Entwiekelungsperiode unterseheidet $N$. einmal die des unregelmässigen Waehsthums und zweitens die des stationäi n.

Jedenfalls hat $N$. die Spindelzellen nieht gekannt, welehe wahrseheinlich auch ron Heluer $^{2}$ und Waldeyor zwar gesehen, aber falseh gedeutet wurden, denn die neugebildeten Elemente, aus

1) Virchow's Archiv Bu. XXXIV. Heft 4.

2) Centralblatt f. d. med. Wisseusch. 1863. No. 31 and Virchow's Arch. Bd. XXXIV. Heft 2.

s) Wiener med. Wochenschr. 1868 No. 12.

4) Arch. f. A wat. u. Physiol. 1861.

5) Ueber den Heilungsprocess nach Muskelverletzungen. Arch. f. mikr. Anat. Bd. IV. pag. 323 ff.

6) Virchow's Arch, Bd, XXVI. Heft I.

7) Allgem. chirurg. Yathol, n. Therajic. 2. Aufl. Irg. 113. 
denen sieh nach lezzteren die Muskulatu nach embryonalem Typus regeneriren sollte, sind woh! olne \%weifel als Spindeln, die von der alten, verletzten Muskulatur abstammen, zu deuten; daher rührt dann auch das absprechende Urtheil, welelıes $N$. liber die Arbeiten von Waldeyer; Weber und Billroth lillt. Erst Fraske ${ }^{2}$ war es rorbehalten, auf die Wiehtigkeit der Spindeln bei der Regeneration linzudeuten, dessen Arbcit woll als die ausfihrlichste und gründlichste zu gelten hat. Die Resultate, welche er erzielte, sind kurz folgende: 1. Junge Muskeln stammen ausschliessliels von den alten ab. 2. Die wesentlichen Plısen sind Vermehrung der Kerne, Gruppirung des veränderten Protoplasmas, der contraetilen Substanz um dieselbe als Umhüllung, Abspaltung der so entstandenen „Mnskelzcllen“ von der Substanz der Faser, Auswaclssen der einzelnen Muskelzellen je zu einer quergestreiften Muskelfaser; ein Zusammenwachsen melirerer Muskelzellen zu einem jungen, quergestreiften Muskel tindet nicht statt. 3. Die sogenannten bandförmigen Elemente, kernreiche Platten, Iuskelknospen der Autoren, sind nicht Entwickelungsformen junger, sondern Theile älterer Fasern.

Kraske fusste bei seinen Untersuchungen hauptsäehlich auf den Beobachtungen ron Weismann 2, und findet in neuester Zeit eine Stütze in (len Sehilderungen von Bremer ${ }^{3}$ ). In Gegensatz zu diesen Forseliern behauptet vor Allen Er(blamm 4), dass die Regeneration der Muskulatur bedingt wird dureh das Einwandem von Lenkoeyten. Ferner spalten sich kleine Spindelfasem ab und die Nenbilkungr greht aus diesen Elementen vor sieh, welehe nichts, als moditieirte Wanderzellen sind: die alte Musknlatur wird als Nahrnng für die nene benutzt. Diesen Ansichten schliesst sich unter anderen Rachmaninow ${ }^{5}$ ) an, welcher mit Kaninchen experimentirte, und eine Gummischlauchunterbindung vornahm, welche er (i-10 Stunden liegen liess. Die Regeneration der quergestreiften Muskulatur erfolgt nach ihm, ihhnlich wie die der Nerven, dureh Auswachsen von alten Fasern ohne Vermittelung vou „Muskelzellen“, „Muskelplatten“, „Muskelsehlänchen“, welche letztere mit Wanderzellen urfüllte Sarcolemmaschlïnche sind. Auch betrachtet Rachmaninow die Muskelkene nieht als Zellen. Anch die Untersuelungen von Soliolow b) schliessen sich an die Ausführungen ron Rachmaninow in gewisser Beziehmng an, obgleich er doch eine Betheiligung proliferirender Muskelkerne, welche Zellen repräsentiren, amnimmt. Die Kerne rïcken nach ihm in Reihen an einauder, weiterhin bei der Bildung quergestreifter Substanz zwisehen den Kernen entfernen sich letztere von einander.

Hie Welf - Hic Waibling! Während man auf der einen Seite also immer wieder den Lenkocyten die Hauptrolle bei der Regeneration zuschiebt, vertheidigt die andere Schule die Nenbildung ans den vorhandenen Elenenten. Und letztere wird wohl Recht behalten, den nach den neneren Ergebnissen der Entwickelungsgeschichte und nach meinen eigenen Befunden kam ieh Niemeyer 187 s.

1) Kraske. P. Experimentelle Untersuchungen über die Regeneration der quergestreiften Muskeln. Halle. M

2) Ueber das Wachsen der quergestreiften Jluskelfaser nach Beobachtungen am Froscb. Zeitschr. f. rat. Med. 3. Peilhe X. Bd. 1861. pag. $263 \mathrm{ff}$.

3) Ueber die Huskelspindel, sowie Bemerkungen über die Structur nnd Neubildung del quergestreiften Muskelfaser. Arch. f. mikr. Anat. XXIl. Bd. Heft 2. pag. $318 \mathrm{ff}$.

4) Beiträge zur Kenntniss der Degeneration und Regeneration der quergestreiften Muskeln nach Quetschung. Virchow's Archiv, Bd. LXXlX. pag. 49-74.

5) Ueber die Regeneration der quergestreiften MI uskelfaser, Dissertat. Moskau 1881.

6) Kicwer Unirersitätsnachrichten 1881. October. pag. 147-18?. 
mich nur denjenigen Forschern auschliessen, welehe den neuen Muskel aus dem alten entstehen lassen. Manche Forscher sind dadureh verleitet worden eine directe Theilnahme der Leukocyten an dem Neuaufban der quergestreiften Mnskelfaser anzunehmen, weil rielfach ein Uebergang zwischen Bindegewebe und glatter Muskulatur beobachtet werden konute. Spricht sich doch unter Andern Flcmming ${ }^{1}$ ) in seinem Aufsatz über Form und Bedentung der organischen Muskelzellen dahin aus, dass er auf Grund seiner Beobachtungen an den glatten Muskelfasem der Harnblase des Salananders, unter welehen er Uebergangsformen zu dem Bindegewebe gefunden hat, geneigt sei, anzunehmen, dass eine Neubildung von Muskelgewebe anf Kosten von Bindegewebszellen in pathologischen Fällen müglich sei. So dachten auch ältere Forseher, wie von Wittich, und ihnen schlossen manche jiingere sich an.

Seit wir nun aber durch die bahnbrechende Arbeit der Gebr. Ilertwig ${ }^{2}$ ) darauf hingewiesen wurden, dass die quergestreifte Muskulatur genetisch etwas ganz anderes sei, als die sogenannte glatte Inskelzelle, seit man weiss, dass die Primitivbündel ihren Ursprung ans dem Epithelgewebe nehmen, kann man wohl keinen Augenblick mehr zweifeln, dass eine Entstehung nener quergestreifter Muskulatur aus Bindegewebselementen anch bei entzündlicher Reaction rollkommen auszuschliessen sei.

Ich betone also nochmals den Grundsatz, dass die ne ue quergestreifte II uskulatur nur aus den Elementenderalten quergestreiften Muskutur liervorgeht, und hervorgehen kann.

Nun tritt aber dic weitere Frage an uns heran, auf welche Weise sich die neue Mnskelfaser aus den alten Elementen entwiekelt und welche Elemente es speciell sind, die als die Träger der Entwickelung zu bezeichnen sind, denn wie wir gesehen laben ist eine ganze Menge verschiedenartiger Elemente im Muskel enthalten, wenn er sich zur Proliferation anschickt.

Schon frïher habe ich darauf aufmerksam gemacht, dass eine Regeneration nur da möglich ist, wo entweder embryonale Gewebe noch in bestimmter Anzahl vorhanden sind, oder wo wenigstens das ansgebildete Gerebe sich die Fähigkeit bewalırt lat, sich zu cmbryonalen Elementen umzuwandeln. Aus den alten Stümpfen und vernarbten Primitirschläuchen wird sich nun wohl kaum die neue Faser bilden kümnen, wenn anch Neumann uns die übcrzeugendste Schilderung von dem Knospungsprocess macht, ebensowenig von den abgestossenen, lose im Bindegewebe liegenden ILuskelpartikelchen.

So bleiben nur noch die erwähnten zarten Spindelzellen. - Diese sind, betrachten wir sie jetzt näher, nichts als embryonale Zellen, Zellen, deren Inlalt protoplasmareich, deren Kern mit feinem Kerngerust und deren Nembran kam nachweisbar erscheint.

Die Herkunft dieser Spindeln ist von Bremer wohl so genau gesehildert worden, dass ein Zweifel daran, dass sich diese Elemente von den Primitivbindeln einfach alsplalten, nicht mehr gehegt werden kanm.

Was Bremer nnn am normalen Muskel erkannte, indem er sogar fü die Frühjahrszeit, als die Hauptperiode der physiologischen Regeneration der Gewebe, eine vermehrte Abspaltung

1) Zeitschrift f. w. Zool. Bd. XXX. pag. $466-75$.

2) Coelomtheorie: Jenaische Zeitschr. f. Naturw. 188?. Bd. XV. N. F. Bd. VIIf. p. 95 if. 
dieser Spindeln nachwies, glaube ich für die pathologisehe Neubildung ebenfalls beweisen zu kïnnen.

Anch lier treten die Spindeln, die ïbrigens bei Amphibien fast immer in geringer Anzalıl vorhanden sind, durch den Reiz des pathologisehen Zustandes in grösserer Anzahl auf. Die Reizreactionsfähigkeit des Muskels geht nach der Verletzung ror allem dahin embryonales Gewebe zu erzeugen und als Product erhalten wir die Embryonalzelle, die ïbrigens ihre eharakteristisehe Spindelform nur ihrer Abkunft und dem Druck der ungebenden Fasern rerdankt.

Aus dieser Spindelzelle geht nun einzig und allein das neue Muskelprimitiviundel hervor, und zwar ganz in der Art wie das sehon ror Jahren in elassischer Weise ron Fr. E. Schulze ${ }^{1}$ ) von der embryonalen Muskelzelle geschildert wurde.

Hinzufügen muss ieh noch, dass bei den Reptilien wie bei den 2 anderen höheren Thierelassen die Sonderung des Inhaltes der Muskelzelle in eontraetile Rindenschieht md innere, kernhaltige Markschieht deutlicher ausgeprägt ist wie bei den Amphibien. Bei letzteren geht die Bildung der Fibrillen zuerst an einer Seite vor sich, von da aus über den ganzen Körper des Primitivbündels, denn inzwischen hat sich die ursprünglich einkernige Zelle durch Vermehrung ihrer Kerne zn einem Syncytinm umgewandelt.

Bei den Reptilien dagegen tritt zuerst ein feiner Kranz ron randständigen Fibrillen auf, die sich nach der Mitte zu allmählich vermehren, und so die Rindensehieht rerdieken.

Die mit Kernen prall gefülten Sarcolemmasehläuche der Reptilien endlich lıalte auch ich nicht für Vorläufer neuer Inskeln, sondern glaube in dieser aussergewöhnlichen Kernvermehrung eher einen Zerfall erblieken zu dürfen. Vielleicht lıandelt es sich wirklieh um eine Einwanderung ron Lenkoeyten - aber mit der Bildung nener Muskelfasem hat es nichts zu thun.

Bisher habe ich einzig und allein iiber die Skeletmuskulatur gesprochen und der glatten Muskelfaser nur nebenbei Erwähnung gethan. Fïr unsere Beobachtung kommt sie ja auch wenig ocker fast garnicht in Betracht, doeh glanbe ieh hier mittheilen zu miissen, dass ieh an regenerirten Theilen des Auges, woriber ieh später zu berichten gedenke, gesehen habe, dass aueh hier eine ähnliche Zellproliferation eintritt, wie bei der quergestreiften Muskulatur.

Die neuen glatten Muskelfasern unterseheiden sieh allerdings in kaum einer Beziehung rou dem embryonalen Bindegewebe, doeh glaube ich ihrer Abkunft von den alten Muskelzellen sicher zn sein.

Eine zweite Frage, welche bei der Betraehtung der Regenerationsvorgänge ihre Erledigung finden könnte, ist die nach der Merkunft des Sarcolemma's. Das Sarcolemma wird ron versehiedenen namhaften Forsehern als eine Zellmembran anfgefasst, welehe sieh in späterer Zeit an der Oberfläche des Primitivbindels absondert. Dagegen spreehen sieh Reichert, Leydig, Margo, Waldcyer, His, Ecliard, Deiters und Andere dahin aus, dass das Sareolemma eine umgewandelte Lage des Zwischengewebes sei und bei der Entwickelung erst nachträglieh dureh Erhärten der Grenzschicht gebildet werde; als Vertreter der ersteren Ansieht müssen besonders Weismann, Kühne, von Hessling, Kölliker, W. Krause und Ranvicr genannt werden. In den letzten 5 Jahren sind nun wiederum riele Arbeiten iiber dieses Thema erschienen, von denen ich nur einige hervorheben will.

1) Beitrag zur Entwickelungsgeschichte der quergestrciften Muskelfaser im Arch. f': Anat. u. Physiol, etc, ron Reichert u. Du Bois-Reymond 1862 l'ag. $385 \mathrm{ff}, \mathrm{m}$. Taf. 'IX. 
So hat Froriep ${ }^{1)}$ unter Anderem gesehen, dass die Sehne des Iuskelprimitirbiindels direct in das Sarcolemma ïbergeht, welches, wie durch verschiedene Experimente constatirt werden komnte namentlich durch Trypsinverdaumgsversuche) die Reaction des Bindegewebes zeigt. Während Froriep fand, dass das Sarcolemma durch die Trypsinverdaumg nicht zerstört wird, dagegen bei Säurebehandlung sehr schnell sich auflost, wies Chittenden ${ }^{2}$ ) nach, dass das Sarenlemma im Gegensatz zu den Beobachtungen von Froviep, dureh Trypsinverdaumg gänzlich zerstört wird, und zwar leichter, als der Muskelfaserinhalt; dasselbe war friher von Waldeyer und Kühne gefunden worden. Am isolirten Sarcolemma waren nach Chittenden niemals Kerne naebzuweisen. Gleichzeitig mit Chittenden spricht sich auch ein anderer Forscher, Sasse (in derselben Zeitsehrift) gegen die Froricp'sehe Ansicht aus. Auch Tamhofer ${ }^{3}$ ) hat gesehen, dass die quergestreifte Muskulatur der Käfer zwei durch Verdaumgsmethoden isolirbare Hembranen besitzt. ,Die äussere Hülse des Inskelsarcolemms verwächst mit der äusseren hyalinen Iiilse der mit diesem zusammenhängenden Sehne, Saftkanälchen wachsen ron der Sehne in den Mnskel hinein." Ueberhaupt sind bei vielen wirbellosen Thieren Kerne im Sarcolemma nachgewiesen worden, so z. B. ron Chironomus- und Corethralarven, auch fand Thering, dass die Fibrillenbündel von Chiton von einem kernhaltigen Sarcolemma umgeben sind. Dass das Sarcolemma dagegen oftmals fehlt, hat neuerdings unter Anileren Ciacrio bei den Flïgelmuskeln der Insekten nachgewiesen, während die ibbrigen Muskelfasern in dem Kürper derselben Thiere ein solches besitzen.

Somit ist die Frage, ob das Sarcolemma ein bindegerrebeatiges Product, oder ein Prouluct der Muskelzellen selbst sei, also eine cuticulare Abscheidung derselben, immer noch als cine offene zu betrachten, und wir werden anch hierauf unser Augenmerk besonders zu richten haben.

Obgleich ich weder Thrypsinverdaumg noch sonstige mikrochemische Spielereien anwendete, glaube ich doch dureh meine morphologischen Befunde berechtigt zu sein, etwas zur Lüsung dieser Frage beizutragen.

An mehreren Stellen habe ich erwähnt, dass sehr junge Mnskelprimitirbindel bei Reptilien kein Sarcolemma besitzen, obgleich das Perimysium internum bereits sehr gut ansgebildet war. (ef. Taf. III, Fig. 22.)

Elsenso finde ich an sehr jungen Muskelzellen ron Siredon und Triton, dass dieselben membranlos sind und erst später ein ganz dünnes, kernloses Sarcolemma erhalten.

Wo ich ïberhaupt das Sarcolemma deutlich erkennen konnte, war es stets structurlos und ohne jerlen Kern.

Alle oben erwähnten Forscher, welehe die bindegerebige Natur des Sarcolemma behaupten, scheinen meiner Ansicht nach dadurch getiuseht zu sein, dass sie das oftmals äusserst feine, kernhaltige und der contractilen Substanz eng anliegende Perinysium internum für das Sarcolemma hielten. (ef. Taf. III, Fig. 20.)

Nach meinen Beobachtungen ist das Sarcolemma nichts weiter als eine Zellmembran; in der

1) Ueber das Sareolemma nnd die Muskelkerne. Arch. f. Anat. u. Entwickelungsgeseh. Jalurg. 18is. Anat. Abth. pag. $416 \mathrm{ff}$,

2) Histochenische Untersuchungen über das Sarcolemma und einige rerwandte Jembranen. L'ntersueh. a. d. physiol. Inst. d. Univ. Heidelberg. Bd. IIl. pag. 171-93.

3) Beiträge zur Histologie des quergestreiften Muskels und der Vervenendigungen in demselben. Berichte d. kgl. ungar. Acad. d. Wissensch. Mathem.-naturw. Klasse. Bd. XI, Nr. 13 u. Biolog. Centralbl. pag. $349-351$. 
einkernigen cmbryonalen Muskelspindel noch äusserst dïmn und zart, später aber sich in verschiedener Weise bei den verschiedenen Thieren verdickend, wenn aus der einfachen IIuskelzelle das Primitivbindel geworden ist.

Die Reptilien zeichnen sich besouders dadurch aus, dass ihre Primitiviundel, anch wenn die Rindenschicht bereits eine bedeutende Stärke erreicht hat, noch immer ohne Sarcolemma sind und dass dasselbe auch später beim vollkommen ausgebildeten Muskel ron ansserordentlicher Zartheit ist. (Taf. III, Fig. 21, 22.)

Die Hauptergebnisse der eben gesehilderten Untersuchnngen sind aber folgende:

1) Das quergestreifte Muskelprimitivbündel regenerirt sich nur aus den ron den alten Muskeln abgespaltenen Spindelzellen, die Entwickelung des Primitivbundels geht analog der Embryonalentwickelung ror sich, eine directe Umwandlung von Bindegewebszellen oder Leukncyten in Muskulatur ist undenkbar.

2) Das Sarcolemma ist ein Product des Muskelprimitivbündels, eine Zellhaut oder Cuticula und besitzt weder Kerne noch Fasern, hat daher mit dem Bindegewebe nichts zu thum.

\section{Blutgefïsse.}

Ueber die Regeneration der Gefasse ist in älterer und nenerer Zeit vielfach gearbeitet worden, da die Neubildung dieser Organe naturgemäss fiir die gesammte Regeneration der Gewebe ron grosser Wichtigkeit sein musste, weil sie die Bahnen fiir die Emährungsflïssigkeit bilden. Es wird deshalb durchaus nicht auffallen, dass iiberall da, wo eine intensive Nenbildung von Geweben stattindet, auch Blutgefüsse in grosser Anzahl vorhanden sein miissen, um eben eine verhältnissmässig grössere und dem Regenerationsprocesse entsprechende Menge ron Nahrungstliissigkeit zuzuftihren. So dringen zur Beschleunigung der Wachsthumsenergie in die sich neubildende sehr zellenreiche Epidermis von Proteus vielfache Capillaren ein, während in der normalen durchaus keine rorhanden sind.

Beriicksichtigt man damn nuch das Verhalten der Leukocyten, die, wie bekannt, aus den Gefäsen auswandem und die, wie schon mehrfach erwähnt, eine so grosse Rolle bei der Regeneration spielen, so wird anch das fribe Auftreten von Blutgefissen in fast allen regenerirenden Theilen verständlich.

Schon in dem zelligen Blastem, welches gleich nach der Vernarbung der Schnittwunde die erste Anlage der axialen Gewebe im Schwanze der Amphibien wie Reptilien repräsentirt, finden wir Blutgefisse in ausserordentlich grosser Anzahl.

Während dieselben aber bei den Amphibien ziemlich fein und mit sclwachem Lumen versehen sind, treten uns bei den Reptilien grosse Lacunen mit kulbenfürmigen Enden entgegen, deren Lumen oftmals beleutender ist, wie das der durchsehnittenen Gefasse.

Es wird num an dieser Stelle unsere Aufgabe sein, nachzuweisen, auf welche Art und von welchen Elementen aus dic neuen Blutgefässe ihren Ursprung nehmen, und deshalb miissen wir 
einen kurzen Blick auf die normale Entwickelung der Blutgefüsse werfen, die hente derartig wohlbekannt ist, dass die Angabe der hauptsächlichsten Arbeiten genïgen wird.

Naturgemaiss handelt es sich hier nur un dic postembryonale Entwickelung der Gefässe, da ja beim Embryo ein anderer Bildungsmodus rorkommt, welcher hicr keine Beriicksichtigung finden kann.

Eine gute Arbeit liegt uns bereits aus dem Jahre 1869 von Golubew ${ }^{1}$ ) vor, der die Darstellungen ron Kölliker, His, Auerbach, Chrzonszszewshiy $\left.{ }^{2}\right)$ Eberth $\left.{ }^{3}\right)$ und Anderer zum Theil bestätigt, zum Theil erweitert.

Die Gefiisse erseheinen nach $G$. bei ganz jungen Larven von Rana temporaria lange vor dem Auftreten der hinteren Extremitäten, und zwar an der dorsalen Seite früher als an der ventralen. Immer geht das Erscheinen sternförmiger Gewebselemente dem Anftreten der Gefüsse roraus und diese Thatsache ist so constant, dass eben aus miteinander in Verbindmg tretenden Sternzellen sich später Gefisse entwiekeh. Jedoch treten nach $G$. diese Stemzellen in kcine Beziehung zur Gefässbildung, dieselbe wird viehmehr einzig und allein durch Sprossung rermittelt.

Die feinen trichterförmigen Ausläufer sind die Endzellen der Gefässe sell,st, die sich ausserordentlich weit vorsehieben, um damn mit anderen Gefässenden zusammenzutreffen und mit ihnen die erste Gefässsehlinge zu bilden.

Die sich vereinigenden Gefässe scheinen erst eine Zeit lang neben einander herzulaufen, bis sie rerschmelzen, und dann besitzt dieses Vereinigungsstiick noch kein Lumen, sondern ist durch einen "Pfropf" verstopft. Allmählich geht die Aushöhung der nenen Gefüsssprosse ron der trichterförmigen Basis her vor sich und der Pfropf wird dann ebenfalls durch das Hineintreten von Blutkörperchen durchbrochen.

Von nencren Arbeiten ist wohl die wichtigste die ron Ziegler $\left.{ }^{4}\right)$, welcher die Gefässnenbildung in normalen Granulationen und zwischen Glasplättchen, die er unter dic Haut der Untersuchungsthiere einschob, studirte. $Z$. gelangte zu der Annahme, „lass im Allgemeinen die Gefässneubildung in Granulationen auf dem Wege der Sprossenbildung geschicht. Die ursprünglich soliden Sprossen werden durch Aushöhlumg in Gefảsse iibergeführt. Sie sind nicht als protoplasmatische Ablagerungen aus den Bhte anfufassen, sondern als Zcllfortsätze zunächst der die Gefísswand constituirenden Zellen, wahrseheinlich aber anch von ausserhalb der Gefässwand gelegenen Elementen, welche, wie dic Fibroplasten, Abkömmlinge farbloser Blutkörperchen und durch Verschmelzung mehrerer entstanden simt. Sie bilden verschieden gestaltete Ausläuftr, welche untcreinander sowohl als mit Gefässen oder deren Sprossen in Verbindung treten Sehr wahrscheinlich wird ein Theil dieser Fortsätze später zu Gefíssrühren umgestaltet und entstehen also die Gefïsse intracellulär.

Dic Sprossenbildung der Gefässe ist ein eigener activer Vorgang, nicht ron der Richtmug des Blutstromes al,hängig. In den Zellennetzen, welche mit der Gefässwand oder deren Sprossen in Verbindung treten, zeigen sich nieht selten in Innern einzelner Verbindungsfirlen lomogene,

1) Arch. f. mikj. Anat. Baud V. p. 49. m. Taf, V. Beiträge zur lienntoiss des Baues und d. Entwiclelungsgeschichte der Capillargefässe des Frosches.

2) Virchow's Areh. Bd. 35. Taf. V. Fig. 2.

3) Würzburger Naturwissensch. Zeitschrift. Bd. VI. p. 29, und separat. Würzl. Stahel 1865.

4) Untersuchurgen über pathologische Bindegewebs- und Gefïssneubildung. Würzburg, Staudinger 1876. 
zun Theil mit Höhlung versehene Fïden, die man wohl nit der Bildung eines Gefässlumens in Zusammenhang bringen muss. Eine intercellukire Gefassbildung ist indessen nach $Z$. neben der gewöhnlichen intracellulären in Granulationen nicht ganz auszuschlicssen.

Ganz entgegengesetzt belauptet Thin ${ }^{1}$, dass die Bhtgefässe in den Spalträumen des Bindegewebes ihren Ursprung nehmen und dass ihre Wandung, auch die Endothelauskleidung, erst dureh secundäre Anlagerung von Bindegetrebszellen entstelıt. Jeder Capillarlildung würde also zunächst cin Erguss von Plasma in die interfasciculären Spalten voraufgehen, der erst damn von Seiten der extravasirten weissen Blutkörperchen die Bildnng der aus spindelzellen aufgebanten Capillarwand folgen wiirde.

Ferner sind zu erwähnen die Arbeiten von Terdiesclia, Schultz $\left.{ }^{2}\right)$, Pftzer ${ }^{3}$ ), Ratab ${ }^{4}$ ) und Anderer, welche sich meistens nur mit der Bildung und Resorption des nach Verlctzungen entstehenden Thrombus beschäftigen und die Narbenbihhung berïcksichtigen. Sie kommen alle zu dem Resultate, dass dic Neubildung der grösseren Gefässe durch die Wuchcrung der Endothelzellen eingeleitet wird und inter Zutritt ron Lenkocyten ihren weiteren Verlauf nimmt.

In der nenesten Auflage seines ,Lehrbuches der allgemeinen und speziellen pathologischen Anatomie mul Pathogenese", (Jena 1882), spricht Ziegler sich im Anschluss an seine vorher eingehend besprochene Arlueit p. 131 dahim ans, dass ,die Entwickehng nener Blutgefässe auf dem Wege der Sprossenbildung von Seiten der Wrand praeexistirender Gefässe erfolgt." Die Vermuthung, dass anch Lenkocyten mnd Bindegewebskörperehen sich an der Neubildung betheiligen, lässt er neuerdings vollkommen fallen.

Instergültig sind ferner die Arbeiten von Anold ${ }^{5}$ ) über die Gefasssentwickelung; es wird hier zuerst nachgewiesen, dass es sich bei der Neubildung der Endothelzellen nicht mu einen gewöhnlichon Zelltheihngsprocess handele, sondern dass hier eine wahre Knospung stattfindet, bei welcher das primum agens nicht voun Zellkern, sondern rom Protoplasma ausgeht.

Diesen letztgenannten Arbeiten wollen wir bei der Betrachtung unseres Regenerationsprocesses folgen und rergleichen, in wie fern sich dic Beobachtungen der erwähnten Forscher mit unseren eigenen rereinigen lassen.

Bei den Amphibien ist nach der Amputation des Schwanzes oder einzcher Gliedmassen die Blutung, falls die Operation in Wasser vorgenommen wurde, ziemlich minimal. Aus den Hanptgefảssen ergiesst sich ein feiner Bhtstreifen in das Wasser, der bald Gerinnungserseheinumgen zeigt und num von den Thieren eine kurze Zeit mit nmhergeschleppt wird. Bald stüsst sich derselbe durch dic Bewegung der. Thiele ab und wird läufig die willkommene Beute desselben Individumms, welches soeben verletzt wurde. Diesen Fall habe ich oftmals bei Urodelen und ihren Larven beobachten künnen; er ist ein weiteres Zeichen, wie gering die Schmerzempfindung bei diesen Thieren sein muss.

1) On the formation of blood ressels, as observed in the omentum of young rabbits. Quart. journ. of microse. science. $1.2+1-251$.

2) Ueber die Vernarbung von Arterien nach Unterbindungen und Verwundugen. Berner Dissertation. Leipzig 1877. Deutsche Zeitsehrift f. Chirurgie. Bd. IX. p. $84 \mathrm{ff}$.

s) Ueber den Vernarbungsrorgang an dureh Sehnitt rerletzten Blutgefässen, Königsberger Dissert. 1879.

4) Ueber die Entwickelung der Narbe im Blutgefäss nach der Unterbindung Bd.XXIII. p. 156-202. Langenbeck's Areh. t. klin. Chir. und Tirchow's Areh. Bd. 7т. p. 397-420.

5) Firchow's Archiv. Bu. 53 und jú. 
Die Gefässe contrahiren sich sofort nach Abstossung des geromnenen Blutes, dessen letzter Theil als Thrombus dient und die Lumina vollkommen verstopft.

Beim erwachsenen Landsalamander ist die Blutumg sehon bedeutender; anch reagiren die Thiere heftiger gegen die Verletzung, ebenso wie die Eidechsen und Ascalaboten, welehe sich sofort in einen dunkelen Winkel oder unter Steine zu verkrieehen suchen.

Eine Eidechse kann man leicht durch mehrfache kurz hintereinander ausgeführte Amputationen durch den Blutverlust so schwächen, dass der Tod eintritt. Hier liegen aber auch spezielle norphologisehe Verhältnisse vor, die eine stärkere Bhutung bedingen, wie bei den Amphibien. Dureh Schïbl $\left.{ }^{1}\right)$ wurde neuerdings nachgewiesen, dass die vielfach verïstelten Gefiisse im Fettkörper der Lacertiden ein Wunderuetz bilden. Wird dasselbe nun durch den Bruch des Schwanzes verletzt, so tritt natiulich auch eine grössere Blutung ein wie bei den Urodelen, welchen dasselbe fellt, oder bei denen es nur in geringerem Maasse entwickelt ist. Die Caudalarteric und Vene besitzen einen so geringen Durchmesser, dass durch sie allein wenig Blut zum Austritt gelangen könnte; er ist bei einzelnen Arten so klein, dass oftmals die feinsten Caniilen zur Injection noch zu grob sind, während sich die Blutgefässe des Schwanzes der Urodelen ziemlich leieht injiciren lassen.

Bei den Urodelen und deren Larven habe ich die Regeneration der Blutgefässe von den ersten Stadien an betrachten können und gefunden, dass hier die Verhïltnisse so klar und ïbersichtlich liegen, dass die Deutung der Bilder durchaus keine Schwierigkeiten bereitet. Während die Capillargefässe sich einfach dadurch sehliessen, dass die Zellwandung an der Schnittstelle sich contrahirt, wird der kleine Pfropf, welcher dic Arteria candalis verstopft, sehr bald durch einen kürnigen Zerfall der Elemente in feine Partikelehen aufgelöst, die dann, wem der Epithelialiiberzug: ¿le Wunde vollendet ist, mit in das zellige Blastem hineinragen und hier höchst wahrseheinlich ron den Leukocyten aufgenommen werden, welche in grosser Anzahl in der Gegend des verletzten Bhutgefässes erscheinen. Aneh einige wenige Zellen der Gefässwandung, besonders die, welche durch den Schnitt verletzt wurden, zerfallen und gehen mit dem Thrombus zu Grunde. Sehr bald aber tritt nit dem Wachsthum des axialen Gewebes anch eine Proliferation der Gefisszellen auf, und zwar treiben zuerst die feinsten Capillaren seitliche Sprossen und Ḱnospen, die sich sehlingenfürmig bis dicht unter das Epithel erstrecken, wälırend die Regeneration der grösseren Gefässe erst in etwas späterer Zeit eintritt.

Ich sehe die erste Anlage einer Sprosse, ganz wie dies Arnold beschrieben hat, zuerst durch einen scitlichen Protoplasmavorsprung markirt, der eine ganz bedentende Länge erreichen kam, bis der Kern der Endothelzellc, von welcher er ausgeht, sich nun amch, und zwar durch einfache Kerntheilung wie mir scheint, theilt, dem Mitosen konnte ich bei diesen Vorgang niemals beobacliten, wohl aber oftmals einfache, schulısohlenfürmige Einsehniirungen.

Auch hier besitzen die Kerne der Endothelzellen ein viel zu geringes Kerugeriist, als dass ich an indirecte Kerntheilung denken könnte, in einzelnen Fällen fehlt sogar die chromatische Substanz, ausser einem oder zwei Kernkörperehen, gänzlich.

Auch ich wurde zuerst zu der Ansicht verfiihrt, dass Wanderzellen oder auch fixe Bindegewebskürperchen an der Bildung des neven Capillarrohres mit theihnähmen; sorgfältige und fortgesetzte Betrachtung lehrte jedoch, dass alle diese Bilder auf Täuschung beruhten und dass das

1) Ueber Wundernetzbildungen im Fettgewebe etc. Arch. f. m. dnat. Bd. XIIV. p. 92 ft. 
neue Capillarrohr nur durch Sprossung entsteht und mit anderen in Verbindung tritt, ganz wic dies schon von Arnold beschrieben wute.

Hicr finden wir also durchaus keinen Unterschied zwischen der normalen Entwickelung und dem Regenerationsprocess.

Auch bei den grösseren Gefässen findet vielleicht nur in sofern eine gewisse Abweichung ron dem von frïheren Forsehern beschriebenen Entwickelungsmodus statt, als derselbe bei den Urodelen und besonders bei den Larven derselben sehr schnell verläuft.

Die Proliferation der Endothelzellen geht anch hier selı schnell ror sich, die iibrigen Schichten der Intima und Adventitia folgen etwas später nach.

Ueberall entwickeln sich die Elemente der Reihe nach derartig, dass zuerst ein Endothelrohr gebildet wird, zu welehem eine bindegewebige Schicht und später die glatte Muskulatır in mehreren Lagen hinzutritt. Wie sich die glatten Muskelfasern theilen, habe ich mit Bestimmtheit leider nicht beobachten können, doch ist bei ihnen der indirecte Kerntheilungsprocess niclıt ausgeschlossen, da die Kerne der der Schnittfläche am nächsten liegenden Fasern reichlich chromatische Substanz enthielten.

Wie rerhält es sich nun mit den Reptilien, deren eigenthümliches Blutgefässsystem im Schwanze, wie Schöbl ganz richtig bemerkt, schon für deu Regenerationsprocess besonders eingerichtet zu sein scheint?

Ich habe nicht nur bei den grösseren Gefässen, sondern auch bei allen kleinen Gefiissschlingen des Wundernetzes eine Verstopfung durch Blutgerinnsel beobachten können. Dies hängt wohl erstens mit dem Zutritt der Luft und zweitens mit dem langsameren Regenerationsprocess der gesammten Gewebe zusammen.

Ist der Schorf am abgebrochenen Schwanzstumpfe einer Eidechse abgefallen und lıat sich das bekannte, der Querachse des Thieres sich anpassende, aus Spindelzellen bestehende Narvengewebe gebildet, so tritt auch die Rednction des Thrombus und die Bildung nener Gefisse auf.

Leider ist eine directe Beobachtung des Entwickelungsvorganges bei diesen Thieren nicht möglich, wie bei den kleinen Larven der Urodelen z. B., und man muss desshalb seine Zuflucht zu Sclmittserien nehmen.

Durch Combination von Längs- und Querschnitton kann man sich nun ïberzeugen, dass sehr bald ein ausserordentlich reiches Netz von Capillaren und Lacunen entsteht und dass besonders die Hauptgefässe in grosse, mit Blutkörperchen dicht angofüllte Lacunen auslaufen, deren Wandung aus einer einzigen Schicht feiner, zarter Zellen besteht, deren Lumen aber oftmals das der Gefässe um das 4 -5fache ïbertrifft.

Zuerst sind diese Lacunen kkein und vollkommen geschlossen, später entwickeln sich von hier aus nach allen Richtungen hin feine Capillaren, die hier aber, wie mir scheint, durch den Druck des Blutes ihre Richtung erhalten und nicht, wie bei den Urodelen, eine von demselben unabhängige Wachsthumsrichtung einschlagen.

Einen Zusammenhang der Zellen der Lacunenwandung mit den Endothelzellen der alten Gefässe konnte ich in jedem Falle constatiren, nicht aber ob dieselben auch ron diesen abstammen, da, wie gesagt, eine Untersuchung des frischen Objectes unmöglich ist; doch glaube ich durch die Analogieen hei anderen Thieren vollkommen berechtigt zu sein, dies anzunchmen.

Ueber die folgende Entwickelung des Gefässnetzes ist weiter nichts zu sagen, als dass eine 
Arteria und Vena candalis sich niemals wieder vollkommen ernenert, der regenerirte Schwanz wird vielmehr anch im ältesten Stadimm nur durch ein grosses Netzwerk von feinen Geföissen durchzogen, denen meistens die Muskularis fehlt, die aber durch ihre Anzahl vollkommen die stärkeren Gefässe ersetzen.

So komme ich zn dem Schluss, dass die Regeneration der Gefässe bei den Amphibien sich vollkommen dem normalen postembryonalen Entwickelungstypus anpasst und dass die kleinen Abweiehungen bei den Reptilien berlingt sind durch die morphologischen Structurverhältnisse des normalen Schwanzes sowohl, wie dureh die Aupassung an die abweichende Skeletbildung bei der Regeneration dieses Theiles.

Vor Allem muss aber der Grundsatz festgehalten werden, dass die Elemente der Wandung des neuen Gefässes nur aus denen der alten entstehen köunen und dass ein Hinzutreten von Leukocyten oder bindegewebigen Elementen wenigstens beim Beginn der Regeneration höehst unwahrscheinlich ist. 


\section{Schluss.}

Wenn wir nun noch einmal die gesammte Reihe der Ergebnisse in betreff der Regenerationsfrage überblicken, wie sie oben dargestellt wurde, so ergeben sich hieraus einige Schlnssfolgerungen, die vielleicht nicht nur für die in Rede stehenden Verhältnisse, sondern für die gesammte Biologie ihre Bedeutnng besitzen. Schon in der Vorbemerkung wurde erwähnt, dass bei der Untersuchung' der Regenerationserscheinungen Fragen gestreift werden, welehe mit zu den schwierigsten Problemen unserer Wissensehaft gehören; sehen wir jetzt, was aus denselben zur endgïltigen Entseheidung und Lösung dieser Probleme beizutragen geeignet scin kamn.

Unbedingt ist es die Zellenlehre, welehe bei dieser Untersuchung zuerst in Betracht kommen muss; bauen sich doch alle Gewebe und Organe nicht nur beim Embryo, sondern, wie wir gesehen haben, anch bei der Regeneration aus diesen einfachen, sogenamnten Elementarorganismen anf. Ieh bin schon bei der Besprechung der Epithehregeneration auf einige Streitfragen näher eingegangen, die in der Zellenlehre noch herrschen; inzwischen sind jedoch wieterum neue bahmbrechende Arbeiten erschienen, welche zum Theil eine veränderte Auffassung der dort geschilderten Verhältnisse bedingen, demnoch glaube ich nicht gezwungen zu sein, irgend welche von meinen dort auf Grund meiner Beobachtungen ausgesprochenen Ansichten zuriicknehmen zu miissen; wohl aber lassen dieselben sich bedeutend erweitern. Die Frage, ob eine freie Kernbildung, eine freie Zellbildung existire, musste ich dort offen lassen; auch meine neneren Untersuchungen geben mir num keinen Grund, eine solche freic Kern- und Zellbildung vollkommen in Abrede zu stellen. Ob dieselbe allerdings in dem Maasse auftritt, wie ich es damals anzunelmen geneigt war, ob nicht vielleicht kleinste Kernpartikelchen im Stande sind, um sich herum und aus sich heraus wiederum Kerne und Zellen zu erzeugen, das endgïltig zu entscheiden bin ich auch heute ebensorenig im Stande, wie damals. Logisch seheint mir kein Grund aufführbar, weleher eine freie Kern- und Zellbildung undenkbar machen kömnte, man hat sich aber hent zu Tage daran gewöhnt, den alten Virchow'schen Satz: omnis cellula e cellula mit Flemming dahin zu ergänzen: omnis nueleus e nucleo. Fast simmtliche Vertreter der modernen Histologie wenden sich dieser Anffassung zu und namentlich suchen die jüngsten Arbeiten von Flemming, Strashurger, Pfitzner und Brass erueutes Beweismaterial beizubringen. Allerdings sagt Flemming in seinem Zellenbuche in einem Passus ïber die Regeneration ${ }^{1}$, nachdem er einige der hierauf bezitglichen Arbeiten, namentlich die von Arnold

1) Flemming, W. Ueber Zellsubstanz, Kern- und Zelltheilung. Leipzig 1882; pag. 369 
Elerth, Hoffmann, Kilels und Mayzel eitirt hat: „Es wäre angesichts dieser Dinge rollkommen unberechtigt, das Vorkommen freier Kernbildung zu leugnen, jedoeh seheint mir, dass man es anch hier noeh nicht für erwiesen halten kamn, sondern zu berỉeksichtigen hat, dass die abnormen Verhältnisse in einer Gewebswunde auch Verïnderungen der Zellen mit sieh bringen künnten, welehe mit einer Zellneubildung doeh rielleicht nichts zu thu haben und welehe gerade den besprochenen Bildern zu Grunde liegen künnten."

Naeh allem, was wir daruber wissen, ist diese Frage noch als eine offene zu betraehten; wenigstens darf man die einschlägigen Bemerkungen von Balfour, Kölliker und Anderen auch nicht so ohne weiteres als blosse Phantasieen betrachten und unbeachtet lassen. Ieh finde also für diese Frage auch keine direkte Lösung, sondern kam nur auf die Ausführungen rerweisen, die ich pag. 55 und 56 bereits gegeben habe.

Was dagegen die Lehre von der Zelltheilung anbetrifft, so glaube ieh hierzu einen Beitrag geliefert zu haben, der diesen Vorgang in anderer Weise erscheinen lisst, als man iln in der letzten Zeit aufzufassen gewohnt ist. In der gesamuten neweren, nieht nur histologischen, sondern anch zoologisehen und systematischen Literatur, findet man ein eigenthümliehes Merkmal allen Arbeiten aufgedriickt; sie sind beeinflusst durch die bahmbreehenden Entdeekungen von Flemming, Straslurger Pfitzner und Anderen, eharakterisi't durch eine sonderbare Hast, mit der tiberall nach den sogenannten karpokinetisehen Figuren gesueht wird. Aus meinen vorhergegangenen Darstellungen bereits wird herrorgegangen sein, dass ich nicht zu den Proselytenmachern für diese sugenannte indirekte Kerntheilung und Zelltheilıng gehöre; vielmelır muss ich, gestiitzt auf das was, ieh gesehen habe, annehmen, dass der Process der Kern- und Zelltheilung ein viel einfacherer ist, als er jetzt gewöhnlieh dargestellt wird. Es findet sich an den so ausserordentlieh zarten embryonalen Gewcben, wic sie an den verletzten Stellen des Thierkörpers auftreten, ein Modus der Zelltheilung, wie er jüngst an einzelnen Protozoen, namentlich ron Gmber und Brass beobaehtet worden ist. In allen den Geweben, welche dureh den Einfluss der Verletzung, den pathologischen Reiz sich zu Embryonalgeweben wiederum ungebildet haben, finden sich nur ganz selten typiseh ausgeprägte Fadennetze in den Kernen, das Chromatin ist in demselben vielmehr ganz diffus vertheilt; und trotzdem sind diese Zellen in Stande, dureh massenhafte Proliferation neue Gewebselemente aus sieh hervorgehen zu lassen.

Ich muss also neben der indirekten Kerntheilung, welche der allein dominirende Modus der Theilung geworden zu sein schien, auch noch und zwar gerade bei der Nenbildung der Gewebu den viel einfacheren Vorgang der direeten Einsehnirung oder auch Sprossung und Knospung nieht 1ur für die Leneocyten in Ansprueh nehmen, sondern für die gesammten Gewebselemente, welche liier in Frage kommen. Damit stelle ich mich allerdings in einen direkten Gegensatz zu den Anschaumgen, wie sie selbst in die Lelubiicher der pathologischen Anatomie iibergegangen sind und durch Ziegler ${ }^{1}$ ) ihren Ausdruck gefunden haben: „Der eben beschriebene Vorgang der indireeten Kiem- und Zelltheilung kam als Paradigma für die pathologischen Zellbildungsvorginge gelten. Beweisende Untersuehungen, dass die Kerntheilung auf anderem WVege, d. h. direet ohne Strueturveränderungen in ilnem Innern dureh einfache Durchschniurung sich vollziehen kann, liegen nicht

1) Ziegler, E. Lehrbuch der allgemeinen und specielien pathologischen Avatomie und Pathogenese. Jena $18 \triangleleft 2$. 2. Auflage pag. 116 . 
vor, und auch fiur die freie Entstehung eines Kernes oder einer Zelle aus einem Blastem sind keine sicheren Beobachtungen aus dem Gebiete pathologischer Zellenbildung beizubringen." Ferner sagt Ziegler (pag. 11i): „Man hat eingesehniurte, bohnenförmige keme, die man fand, als Vorstadien der Theilung angesehen und in der Vermehrung der Kernkörperehen glanbt man den ersten Schritt zur Theilung erblicken zu diurfen. Diese Anschaumg muss verlassen werden. Diese verschiedenen Kernformen haben inre Entstehung theils in der Contraction der Kerne, theils in einer Schrumpfung derselben bei der Härtung; hüchstens eine Vergrösserung des Kernes kann in eine Beziehnng zur Theilung gebracht reeden. Die Vermehrung der Kernkörperchen steht in keinem Zusammenhang mit der Kerntheilung.“

Wo bleiben num bei dieser so sehroft und prïgnant ausgesproehenen Ansicht die Lenkocyten, bei denen noeh niemals eine indireete Theilnng nachgewiesen werden konnte, wo bleiben die an den ersten Regenerationsstadien der Epidermis erwachsener Urodelen beobachteten Theilungserscheinungen, wie soll man sich endich die ron Brass nachgewiesenen Theilungsphaenomene an hungernden Zellen erklären?

Unbedingt geht Ziegler sowohl, als anch die anderen Forscher, die diesen Ansichten huldigen, zu weit darin, wemn sie die directe Zelltheilung iiberhaupt lengnen. Gerade in der pathologischen Nenbildung ljei den Urodelen spielt dieselbe eine ganz bedeutende Rolle, wie wir gesehen haben. Eigentlich widersprieht sich anch Ziegler selbst, wenn er die oben angeführten Sätze in voller Geltumg erhalten will, denn er war es ror allem, der nachwies, dass bei der Gefässneubildung die Mutterzelle einen kürzeren oder längeren Fortsatz treibt, der erst später Kerne erhält und sich ron seiner Mutterzelle abgrenzt. Bei diesem Vorgang hat weder Ziegler, noch irgend jemand ron den neneren Untersuchern eine indireete Kerntheilung wahrnehmen können; ich halte dieselbe bei diesen Knospungserseheinungen ganz und gar aus- geschlossen.

Dass andererseits anch eine Proliferation vollstänlig ehromatinloser Zellen stattfindet, habe ich schon pag. 55 angedeutet; anch in einer kurzen Mittheilung im zoologisehen Anzeiger ') bin ich hierauf eingegangen. Hier muss kurz recalitulirt werden, dass ich mit Dayzel vor allem darin ïbereinstimme, dass die jüngsten proliterirenden Zellen am Wundrande einen homogenen, bläschenfürmigen Kern besitzen, dass die jungen Zellen ursprünglich platt, später kngelig sind, und dass niemals, weder im Zellenleibe, noch im Kerne eine bestimmte Anordnung ler Chromatinfäden zu erkemen ist. Und demnoch rermehren sich diese Zellen, und noch dazu mit ansserordentlicher Schmelligkeit! Binnen 2 Stunden ist bei Siredon eine $1 \mathrm{~mm}$ breite Wunde wieder vollständig mit Epithel bedeckt, das unbedingt aus dem alten seinen Ursprung nimmt. Die Phaenomene der Karyokinese können hier also gar nicht anftreten, sie sind einfach unmöglich, weil Chromatin in diesen nengebildeten, ausserordentlich zarten Zellen entweder noch vollständig fehlt, oder doch noch nicht, wenn wir der Ansehaumg ron Brass huldigen, als Nahrungsplasma, oder, wie ich es nemen möchte, als Reservenahrstoffe, deponirt werden komnte.

Sollen num auel hier diejenigen Formen, die man friher als Stadien der directen Zelltheilung beschrieben hatte, schuhsohlenfürmige Einsehnürung der Kerne, Frimmungen und Vergrösserungen derselben, als Kunstproducte gedentet werden, oder wird man sich hier zu der Annahme entschliessen künnen, dass dieselben an dieser Stelle, wie auch in anderen Gewebsformen, zur Kern-

1) Brass und die Epithetregeneration. Zool. Anz. 1853. pag. 633. 
theilung resp. Zelltheilung hinỉber füluren? Es scheint mir nichts logischer zu sein, als diesen letzteren Schluss direct aus den angegebenen Beobachtungen abzuleiten: eine rege Proliferation ist vorhanden; Chromatin dagegen fehlt entweder vollständig, oder ist nur in unregelnässigen Klümpchen oder Körnchen eingelagert. Ist es da nicht ausserordentlich plausibel, anzmehmen, dass hier cine sogenannte directe Kern- und Zellentheilung eintritt?

Befreien wir uns doch eimmal vou dem Wahn. welcher uns so lange befangen hat, dass zu jeder Zelltheihung wirklich diese typischen Figuren gehören miissten, wie sie ja allerdings auch in vielen Gerreben anftreten. Die directe Theilung ist doch sicher ein viel einfacherer Torgang, und bekanntlich gehören die einfachsten Torgänge in der Natu zu den hänfigsten. Sie wird eingeleitet durch eine einfache Einschniirung, wihrend im anderen Falle auch in emiryonalen Zellen erst grosse und besondere Torbereitungen getroffen werden miissen, entweder von Sciten les Chromatins oder des ungefärbten Protoplasmas oder sonst eines Substrates in der Zelle, das morphologisch bisher noch nicht nachgewiesen werden komnte.

Sehen wir uns die Arbeiten, welche über die indirecte Ker'u- und Zeltheilung handeln, hierauf noch einmal genauer an, so werlen wir uns der Ansicht nicht verschliessen kümnen, dass trotz der reichlichen Befunde, welche von allen Seiten constatirt wurden, trotz der zahlreichen Bestätigungen, welehe die Flemming'schen und Strasturger'schen Beobachtungen erhielten, die karyokinetischen Figuren im Verhältniss zu dem Gesammtwachsthum der einzelnen Gewebe immerhin doch nur spärlich auftreten. Für manche Grewebsarten sind sie allerdings, wie ich ja sehr gern zugebe, der alleinige Typus, nach welchem der Zelltheilungsprocess vor sich gehen kann; so wird man z. B. die Theilungstiguren an Eiern und an Spermatoblasten wohl niemals vermissen, auch wird stets an denjenigen Geweben, aus welehen dureh besondere Differencirungen mehrere verschicdenartige Gebilde herrorgehen, eine solehe Metamorphose des Kernes eintreten. Das ist beim ausgebildeten Thiere vor allem einmal der Fall in der Epidermis, aus derselben gehen die versehiedenartigsten Organe lervor: es werden Driisen aus derselben gebildet, Hautsinnesorgane, Follikel der verschiedenartigsten Gestalt, Papillen, IIaare, Federn u. s. w.

Durchmusterv wir mun genan diejenigen Theile, in wehehen sich in der Epidermis die meisten Kerntheilungsfiguren vorfinden, so ist es nicht schwer, zu erkennen, dass höchst wahrscheinlich alle diese typischen Figuren nur dort auftreten, wo es zur Bildung eines speciellen Organes kommt. Ich müchte auf meine oben genaucr dargestellen Beobachtungen verweisen, dass diese Figuren bei den Larven von Tritonen, bei Protens und Siredon sowohl bei der Bildung der Hantdrïsen, nicht nur der Cutisdrïisen, sondern auch der sogenannten Leydig'schen Schleindriisen und bei der Bildung der Hautsinnesorgane auftreten. Es geht also hier aus den einfachen Epidermiszellen durch Theihung ein ganz specifisches Organ hervor, das vor allen andere physiologische Functionen zu erfuillen hat, als die umgebenden Epithelzellen.

Nach den Ausfïhrungen ron Brass und den oben erwähnten Thatsachen diirfte es nun nicht unwahrseheinlich sein, dass gerade diejenigen Epithelzellen, aus denen sich die luetreftenden Organe entwickeln, eine besondere Menge ron Reservenahrstoffen als Chromatin in sich aufgehäuft hahen, dureh welche dam das Bild der sogenamnten indirecten Kerntheilung hervorgebracht wird. Dass aber neben dieser indirecten in der Epidermis auch die directe Kerntheilung rorkommt, glaube ich unbedingt annehmen zu miissen, da cinzelne Bilder, wie ich sie namentlich ron Siredon und Tritonenlarven erhiclt, nicht anders gedentet werden kömen. Ich verweise umentlich auf die eigen- 
thïmliche Gestalt, welche cinzelne Mantelzellen des in Taf. III, Fig. 13 abgebildeten Hautsinnesorganes aufweisen, die aus mechanischen Ursachen nur als in Proliferation begriffen aufgefasst werden können.

Auch bei anderen Geweben kanu ich in den ersten Stadien der Regeneration keinen anderen Kern- und Zelltheilungsvorgang auffinden, als den der genannten directen Theilung. Oftmals geht diese Theilung unmittelbar von den Kemen aus, wie das beim Riickenmark angedeutet wurcle, da hier die sogenannten Körner, welche in dem embryonalen Gewebe des Wundrandes anftreten, entweder vollständig freie Kerne repräsentiren, oder doch mu' von einem so geringen Protoplasmanantel umgreben sind, dass derselve bei diesen Erscheinungen nicht in Betraeht kommt.

Hierdurch wird ein Gegensatz documentirt zu der von Strasburger ausgesproehenen Ansicht, dass das primum agens be: der Zelltheihng ausgehe von dem Protoplasma; er äussert sich geradezu dahin, dass das Zellplasma in den Kern eindringe und hier einen Gegensatz in demselben herbeiführe, der zur Theilung den Anstoss gebe. Dieses Eindringen ron Protoplasma in den Kern wird hier zur Unmöglichkeit; jedoch anch bei solchen Zellen, bei denen der protoplasmatisehe Hof eine bedentende Stärke erreicht hat, wie z. B. bei den typischen Ganglienzellen des Ruickenmarkes, kamn jch mich nicht zu der Strasturger'schen Ansicht bekennen. Im Gegentheil glaube ich, dass überall, wo es sich $\mathbf{m}$ eine einfache Zelltheilung handelt, bei der Regeneration der Anstoss zur Theilung stets rom Kerne ansgeht, mag auch das Chromatin in demselben noch so diffus rertheilt sein.

Anders liegen die Verhältnisse allerdings bei denjenigen Formen der Theilung, die man als Knospung bezeichnen muss und die ganz allgemein nu dem Bindegewebe zukommen. Sowoll bei den Gefässen wie bei den Urzellen des späteren tibrillären Bindegewebes tritt dieser Theilungsmodus ein, bei den jüngsten Zellen ebenfalls ohne die typischen karyokinetischen Figuren.

Naturgemäss werden uns neben den für die Zellenlehre so wichtigen Thatsachen der Theilung und Umwandlung der Elementarorganismen auch die Fragen nach der Herkunft der verschiedenen Gewebe interessiren müssen. Bekanntlich sind in nenerer Zeit ziemlich viele Theorien fïr die Gewebsbildungen aufgestellt worden, von denen die älteste wohl Remali zuzuschreiben ist. Remak hielt vor allen Dingen das genetische Princip bei der Eintheilung und Classificirung der Gewebe als Basis fest, und auch Rauber ${ }^{1)}$ spricht sich neuerdings in Simne der älteren Anschaumg aus. Dem gegeniiber steht die Auffassung der Eintheilung der Gewebe nach ihrer Function, deren Haul'tvertreter heute wohl noch Leuckirt sein diuffte. Entsprechend seiner Ansicht einer secundären Furchung bekennt sich Waldeyer zu folgendem histologischen systeme: er theilt die Gewebe in die zwei Hauptklassen der arehiblastischen und parablastischen. Die Theorie von His iiber die Entstehung des Parablastes aus dem urspringlich ungefurchten Dotter les Eies, branehe ich hier nieht weiter zu erörtern, da sie dureh den nenesten Aufsatz von Kölliker ²) einer gemanen Bespreehung unterzogen wird.

Diese angefïhrten Eintheilungen der Gewebe führen uns zur Betrachtung der Keimbliitter und damit anch naturgemäiss zu dem von Haeclel anfgestellten Satze von der Homologie der Keimblïter; eine grosse ZahI von hervorragenden Forsehern hängt den ron Haeckel in seiner Gastraea-

$\left.{ }^{1}\right)$ Sitzungs-Berichte d. naturf. Gesellsch. zu Leipzig. 10. Jahrg. 1883, pag. 13. Die Entwickelung der Gerebe des Säugethierhörpers und die histologischen Systeme.

2) Zeitschr. f. wiss. Zool. Bul. IL. Pag. 179. ff. „Die embryonalen Keimblätter und die Gewebe." 
theorie ansgefülrten Sätzen iber die Homologie dieser Primitivorgane noch heute an. Aber schon ror Jahren wandte sich Leuckurt gegen die Amnahme, dass diese Keimblätter als histogenetische Primitivgebilde zu betrachten seien. Später schloss Götte sich disen Ansichten an, und anch Kölliker $\left.{ }^{1}\right)$ sprach es unmmwnden aus: „Die 3 Keimblätter sind keine histologischen Primitivorigane, vielmchr hat jedes derselben die Fähigkeit, alle Haup,tgewebe aus sich zu erzengen."

Forschen wir nun, ol, aus den von mir aufgeführten Verhältnissen sich etwas zur Entseheidung dieser Streitfrage beibringen lïsst.

Wir haben gesehen, dass aus der Epidermis wiederm nur Epidermis hervorgeht, die aus ursprỉnglich vollständig gleichartigen Zellen besteht, aus denen erst später durch Differencirungen die besonderen eigenthümlichen Organe der Haut gebildet werden. Ebenso entsteht das Nervensystem, sowohl der Centralcanal, wie das peripherische, direct aus dem friiheren Nervensystem, und zwar ans dem hier in Betracht kommenden Centraltheil, dem Riickenmark. Es bilden sich aus demselben durch Hervorwachsen ans den Epithelzellen des Centralcanales die spinalganglien, ans diesen sprossen wiederum die peripheren Nerven hervor. Ebenso verhält es sich mit der Muskulatur. Auch die neugebildeten Muskelfasern gehen aus den alten hervor, und zwar nach den oben dargestellten Thatsachen durch Abspaltung besonderer Formelemente, die als embryonale Muskelfasern zu deuten sind.

Die grosse Gruppe der bindegewebigen Substanzen vermag allerdings wohl Gewebe der verschiedensten Art herrorzubringen; wir haben hier wiederum eine Bestitigung der alten Auffassung, nach weleher die Bindesubstanz in eine Gruppe zu vereinigen sein diurfte. Aus den embryonalen Bindegewebszellen geht hervor die Cutis mit ihren Chromatophoren, es gehen die bindegewebigen Scheiden der Muskeln, das Perimysium und das skelet, soweit es aus Faserknochen besteht, daraus hervor. Ob allerdings Knorpelzellen. überhaupt die erste Anlage des Knorpels, aus gewölnhlichen Bindegewebszellen sich regeneriren kam, oder ob hierzu nur die alten, embryonal gewordenen Knorpelzellen des Wundrandes tauglich sind, das konnte ich ans meinen Praeparaten nicht definitiv entscheiden. Fï die Anffassung, dass auch Knorpel sich ans dem axialen Blasteme, welches den regenerirten Schwanz der Lrodelen durchzieht, heransbilden kann, sprechen allerdings gewisse Thatsachen, deren ich bereits an dem betreftenden Orte gredacht habe. Aus dem Bindegewebe bilden sich ferner die Gefässe, und zwar durch eine eigenthümliche Knospung der einzehnen Zellen.

Diese eben besprochenen Gewebe nehmen ihren Ursprung bei den höheren Thieren und namentlich bei den hier in Frage kommenden Amphibien und Rejtilien aus 2 Keimblättern, dem Ektoderm und dem Mesoderm; ein entodermales Gewebe kommt bei unseren Untersuchungen nur einmal in Betracht, und das ist die Chorda. Dieser Vorläufer des Skeletsystemes nimmt, nach den iibereinstimmenden Beobachtungen aus dem Entoderm seinen Ursprung; eine Regeneration dieses Gewebes findet, wie wir gesehen haben, nur bei den Larven der Anuren statt; selbst bei den jümgsten Tritonenlarven, namentlich aber anch bei den älteren Larven und den erwachsenen Thieren findet eine Regeneration der Chorda niemals statt. Liegt das nun vielleicht daran, dass das Entoderm, aus dem sie sich ja entwickelt, hier im Schwanzende vollständig fehlt?

1) Entwicklung der Keimblätter Jes Kaninchens, pag. 45 . 
Somit kümnen wir im Grossen und Ganzen eonstatiren, dass eine Gewebeform nur im Stande ist, bei der Regeneration wiederum dasselbe Gewebe zu erzengen, oder, wenn wir die verschiedenartigen Gewebe der Bindesulsstanzen mit in Betraeht ziehen, Gewebe zu erzeugen, welehe ursprizinglieh aus demselben Keimblatt ihren Ursprung genommen haben. Freilieh werden wir bei den höheren Thieren nicht so typisehe Resultate erlangen künnen, wie dies bei den Regenerationserscheinungen niederer Thiere der Fall ist; aber doeh muss ieh ror Allem eine Thatsache hervorheben, die unbedingt zu Gunsten der Lehre von der Homologie der Keimblätter sprieht, und das ist die Regeneration der Muskeln.

Wir haben gesehen, dass die quergestreifte Muskelfaser sich nur direet ans den alten quergestreiften Muskehn neubilden kann. Naeh den nenesten Arbeiten über die Genese der Muskelfasern sind diese jetzt scharf von dem Bindegewebe zu trennen; denn sie nehmen naeh den Ausführungen von O. und R. Hertwig ${ }^{2}$ ) ihren Ursprung ans dem Epithel der Leibeshöhle; es sind also Gebilde epithelialer Abkunft und nach ihrer Genese etwas vom Bindegewebe durehaus versehiedenes.

Jedenfalls muss ieh mieh nach den angeführten Thatsachen gegen die Theorie wenden, dass aus jedem der drei Keimblätter sämmtliche Grundgewebe des thierisehen Körpers hervorgehen können; es seheint mir vielmehr, dass diese Untersuchungen iiber die Regeneration nicht geeignet sind, gegen die Homologie der Keimblätter zu sprechen.

Dureh diese eben abgeschlossene Darstellung werden wir zu einer andern Frage hinübergeführt, welche bei der Regeneration ebenfalls eine nicht zu unterschätzende Rolle spielt. Es ist dies die Frage nach dem Einfluss, welehen die ontogenetisehe md phylogenetische Entwickelufg des betreffenden Thieres anf die Regenerationsverhältnisse desselben geltend zu machen im Stande sind. Einer Recapitulation der ontogenetischen Processe begegnen wir naturgemïss am häufigsten; so regeneriren sich die Epidermis, die Extremitäten, die Gefässe, die peripheren Nerven der Amphibien nach demselben Typus, naeh dem die embryonale Bildnng derselben Organe ror sieh gegangen ist. So sehen wir auch, dass die Inskulatur sowohl bei den Amphibien, wie bei den Reptilien sich streng segmentweise anordnet, was namentlieh bei dem ungegliederten Wirbelrolur der Reptilien sehr anffallend ist und nur als eine Wiederholung ontogenetischer Vorgånge gedentet werden kann.

Der Einfluss der Phylogenie wird sieh bei der Regeneration der höheren Thiere nieht in dem Masse geltend machen, wie dies bei niederen vielleieht noeh der Fall sein kann. Dass aber ein gewisser Einfluss der Phylogenie auf die Regenerationsprocesse nachzuweisen ist, hat Fritz Mieller ${ }^{2}$ ) dureh seine sehönen Beobaehtıngen an einigen Krebsen dargethan. Bei einer Garneele (Atyoida Potinirim) hat die regenerirte Scheere eine deutliehe Hand, welehe der normalen fast vollständig fehlt, da diese fast nur aus den normalen Fingern besteht. So zeigt sich die neugebildete Seheere ähnlich derjenigen der verwandten Gattung Caridina, doeh noeh ursprümglieher dadureh, dass die Finger nicht löffelartig ansgehöhlt und am Ende mit nur sehr wenigen ganz kurzen Dornen besctzt sind. Noch sehlagender ist ein zweiter Fall: Das ron den ibrigen abweichend gebante fünfte Fusspaar, welches dnreh den Mangel einiger beweglicher Borsten und dureh eine am letzten Gliede ausgebildete Bïrste ausgezeichnet ist, wird bei der Regeneration zuerst nach dem

1) Die Coelomtheorie. Jena 1881.

2) Haeckel's biogenetisches Grundgesetz bei der Neubildnng rerlorener Glieder. Kosmos Rd. 11I. pag. 385 ff. 
Typus der vorhergehenden Beinpaare angelegt, und erhält seine typische Gestalt erst nach der letzten Häutung. Hieraus schliesst Müller, dass wahrscheinlich bei den Vorfahren der Atyoida die 3 letzten Bcinpaare des Mittelleibes gleich gebildet waren, dass erst später das fünfte Fusspar. einen oder zwei der Sehenkeldomen verlor und an seinem Endgliede einen Ḱamm zum Reinigen namentlich der Hinterleibsfusspare erhiclt.

Ob die von $J$. Lubloek ${ }^{1}$ ) gemachte Beobachtung, dass die Zahl der Fïhllerglieder von Thysamia nach starker Verletzung sich nicht vollständig regenerirt, dass aber das Endglied grüsser, als das normale wird, ebenfalls hierher gehört, wage ich nicht zu entscheiden. Weitere Beobachtungen in dieser Richtıng liegen meines Wissens nicht vor. I

Im Verlaufe des Regenerationsprocesses der Wirbelsäule sehen wir vor allem bei jüngeren Urodelen und deren Larven Vorgänge auftreten, durch welche auf pliylogenetisehe Verhältnisse hingewiesen wird; die Segmentation wird nämlich wie bei den Petromyzonten zuerst angedentet dureh die Bildung von oberen Bögen, und erst secundär differeneirt sich der Knnorpelstab zu Wirbelkörpern. Bei der liegeneration des Rückemmarkes werden wir schen, dass gerade so auf ähnliche Verhältnisse bei den Petromyzonten hingedentet wird, so dass es wahrscheinlich wird, dass hier wirklich phylogenetische Entwickelungsvorgänge recapitulirt werden. Allerdings treten diese Bögen, wie das ja anch zu vermuthen ist, zuerst als ein bindegewebsartiges Gebilde auf, aus dem sich erst nach und nach dureh Bildung ron Grundsubstanz Korpel differeneirt. Die unteren Bögen treten etwas später anf, als die oberen: sind jedbeh zu der Zeit, wenn die oberen sich be. reits knorpelig ausgebildet haben, auch sehon als bindegewebige Anlage zu erkennen, in der die einzehen Zellen dieht gedrängt neben einander stehen, wie das beim embryonalen Bindegewebe iiberall der Fall ist. Niemals habe ich auch bei den jüngsten Larven beobachten können, dass sich Gebilde regeneriren, die sich eventuell mit den Urwirbeln vergleichen liessen; vielmeln sind neue Segmente, die sich anlegen, stets Bildungen eigener Art; mit der begimnenden Segmentirung der Wirbelsäule hängt auch die segmentweise Anordnung der Muskeln zusammen, deren Regeneration vorher besprochen wurde.

Im biologischen Centralblatt vom 15. December 1883, Nr. 20, pag. 625, habe ieh darauf hingedentet, dass vielleicht auch am regenerirten Sehwanze der Eidechsen sich noch ein Einfluss der phylogenetischen Entwickelung benerkbar macht.

Am regenerirten Schwanze der Eidechsen finden wir stets in bestimmten Stadien ein dunkles Pigment auftreten, so dass der Schwanzstnmmel fast sehwarz erseheint. Hauptsächlich ist das der Fall bei südlichen Formen, Lacerta unuralis, und den Geckotiden; aber anch bei unserer Lacerta agilis hat der regenerirte Schwanz im jungen Stadium eine ganz andere Farbe, als der normale und licbt sich stets dunkler von diesem ab. Diese dunklere Farbe scheint im ersten Moment sehr leicht dadurch erklärt zu werden, dass das Pigment im regenerirten Sehwanze nicht allein in der Cutis, sondern auch zwischen den Epidermiszellen sich vorfindet, und zwar in so bedentender Menge, dass man durch die jetzt opake Epidermis hindurch die Chromatophoren der Cutis kaum wahrnehmen kann. Es führt also die Epidermis Pigmentzellen, wie dies bei Embryonen von Lacerta und anderen Thieren von Kerbert nachgewiesen wurde; und es geht auch die Bildung dieser Pig-

1) Transactions of Linnean Society. London. XXVII. 1870, pag. $277 \mathrm{ff}$. 
mentzellen in derselben Wreise am regenerirten Schwanze vor sich, wie beim Embryo, indem nämlich farblose Wanderzellen in die Epidermis von der noch embryonalen Cutis aus eindringen, sich in den lymphatischen Gewebenetz derselben ausbreiten und nun ihren Inhalt der Pigmentmetamorphose unterwerfen.

Dieses Pigment in der Epidermis, welches ich rom regenerirten Schwanze einer Lacerta muralis von Mahon auf den Balearen anf Taf. III, Fig. 15 aljgebildet habe, wandert num später aus der Epidermis aus, sowohl beim Embryo, wie auch bein regenerirten Schwanze mserer einheimischen Lacerten und der Lacerta muralis; ebenso auch bei den Ascalaboten. Der regenerirte Schwanz der Faraglione-Eidechse hingegen, und besonders der Lacerta Lilfordi, welche ich in vielen Exemplaren untersuchen konnte, behält zeitlebens in seiner Epjidermis eine bedeutende Pigmentanhïufung, und hebt sich so schon durch seine dunklere Fïrbung ganz deutlich von dem iibrigen Fïrper ab. Die Untersuchung der normalen Haut der Lacerta Lilfordi und Faraglionensis, welehe hierdurch veranlasst wude, fürderte demn anch liesultate zu Tage, welche mit den oben besprochenen Thatsachen insofern in Einklang stehen, als auch in der normalen Epidermis dieser Thiere sich eine so bedentende Menge von Pigment nachweisen liess, dass hierdurch allein sehon die dunkle Farbe der Thicre erklärt werden konnte. Dureh dicsen Befund wurde ich weiter zu dem Schlusse geführt, dass die rorübergehende Anhäufung ron Pigment in der Epidermis des Embryo wie des regenerirten Schwanzes urspriinglich bei diesen Thieren etwas normales gewesen ist: dass also sämmtliche Eidechsen, 'die hier in Frage kommen, nrspruinglich eine sehwirzliche Farbe besessen haben, und dass erst nachträglich durch eine allmähliche Rückwanderung der schwarzen Chromatophoren aus der Epidermis in die Cutis die Ampassung der Farbe dieser Thiere an die verschiedenen Localititen bewirlit wurde.

Leydig hat zur Erkliirung der schwarzen Gesammtfärbung ron Thieren die Feuchtigkeit herbeigezogen. Er fand Exemplare von Lacerta vivipara, die fast ganz schwarz gefiubt waren, so dass er sie deshalb als Varietas nigra beschrieb und zwar stammten diese sämmtlich von sehr durehfenchteten Plätzen her. Emer ${ }^{1}$ ) hat vor Allen nachgewiesen, dass die dunkle Färbung auf isolirten Felsen stets mit Pflanzenarmuth Hand in Hand geht, und dass sie fehlt, wem diese nicht rorhanden, selbst an Oertlichkeiten, wo die Feuchtigkeitsverhältnisse dieselben sein miissen, wie dort, wo die dunkle Färbung vorkommt. Auch Eimer hält die Feuchtigkeit für ein die dunkle Fürbuug begiinstigendes Moment, und macht zuerst darauf aufmerksan, dass es Vererbung (Phylogenese) sein wird, welche bei dieser Dunkelfärbung der Eidechsen mitwirkt. Um so anffallender muss es jeden Leser der Eimer'schen Arbeiten beriihren, wenn derselbe, trotz dieser doch wohl rollstïndig geniigenden Erklärung für die dunkle Farbe der auf isolirten Felsen vorkommenden Eidechsenarten, nun noch die Anpassung in Betracht zieht; jedem Fachgenossen wird es ja bekannt sein, dass gerade Eimer die dunkle Firbung der Faraglioneeidechse als Aupassung an den dunklen Untergrund des Felsens oder die dunklen Spalten in demselben zu erklären versucht hat.

Gegen diese Eimer'sche Hypothese muss ich mich mun vor allem aus den angegebenen morphologischen Grïnden wenden. Ich halte dafuir, dass die Eidechsen überall dort, wo sie sich

\footnotetext{
Bd. I, p. 252

1) Untersuchungen über das Variiren der Mauereidechsen etc. Troschel's Archir f. Naturgesch. Jahrg. XXXXVII.
} 
völlig ungestört und von Feinden rollkommen unbelästigt vermehren kömnen, namentlich wenn hierzu noch günstige andere Bediugsungen hinzukommen, - und hierzu können wir ja die Fenchtigkeit mitrechnen, - nun nicht melı durch die Selection grezwungen werden, ihre Farbe dem Untergrunde in so genauer Weise anzupassen, wie dies an denjenigen Stellen der Fall sein muss an denen sic den fortwihrenden Verfolgungen ihrer Feinde ausgesetzt sind. Sehen wir uns einmal nach den Hauptfeinden der Eidechsen um, so grehüren dazu vor allen die Schlangen, ferner einzelne Vügel (in unseren Breitegraden der Storch z. B.); als hauptsächlichster diurfte jedoch, wie dies schon mehrfach angedeutet wurde, wohl der Mensch zu betrachten sein.

Den Faraglionefelsen betritt selten ein menschlieher Fuss; nur dieser schwarzen Eidechsen wegen wird er von einem kïhnen Fischer gegen hohe Belohnung ab und zu bestiegen; auf der Isla del Eyre wird die Lacerta Lilfordi ebenfalls rom Nenselen nieht verfolgt, sondern sogar, wie dies Braun in seiner Monographie reitläufig erïrtert hat, und wie ich es aus eigener Anschauung bestätigen kann, mit Speiseresten und namentlich Friicliten von den 2-3 Bewohnern gefüttert. Schlangen fehlen an den bejden angegeluenen (Orten vollkommen; von niederen Thieren leben dort nur einige wenige Formen von Insckten me Würmern, und auch die den Eidechsen sonst so energisch nachstellenden Tögel fehlen hier den grössten Theil des Jahres iiber ganz. Nur als Zugrügel berïhren sie ab und zu diese isolirten Felsen, auf denen nur einige Möven und der Nachtreiher, Ardea nyeticorax nistcn; sie beide nähren sich aussehliesslich von Fischen und verschmähen in der Gefangenschaft selbst nach längerem Hungern vorgeworfene Eidechsen vollkommen. Ans den angeführten Thatsachen geht hervor, dass unsere Eidechsen auf ihren Felsen fast unbehelligt leben; und wic es auf den eben besprochenen Orten ist, so wird es wahrscheinlich anch auf den anderen Felsen sein, wo schwarze Eidechsen angetroffen werden.

Ich glaube also zu dem Schluss bercehtigt zu sein, dass die schwarze Farbe der Faraglioneeidechse und der Lacerta Lilfordi erklärt werden kann allein als ein Rïickschlag und nicht etwa als cinc Anpassung an die Ungehung. Hierfür scheinen mir anch die Uebergangsformen zu sprechen, welche ron Eimer genau beschrieben sind, und wie ich sie auch in älnlicher Weise auf der Isla del Rey bei Mahon und auf den Sireneninseln, sowie auf dem Monacone bei Capri gefunden habe.

Dass dieser Riickschlng hier nun vielleicht andere, physiologische Grinde haben kann, will ich in Folgendem noch kurz erörtern. Die Eidechsen sind, wie fast alle Reptilien, Heliophilen. Bekanntlich werden nun dureh die schwarze Farbe die meisten Wärmestrahlen resorljirt, und daraus erklärt sich die ïberraschonde Uebereinstimmung zwischen den Sumpfthieren und den Alpenthieren, dic beide eine grössere Quantität von Wäirme zu resorbiren gezwungen sind, als ihre Gattungsverwandten. Wir besitzen, nach Leydig, sehwarze Varietiten der vesschiedensten Thiergruppen, welche an fenchten Orten leben, wir luesitzen auch eine grosse Zahl von alpinen Thieren, namentlich Insekten, die sich dureh Melanismus auszeichnen. Ich glanbe, auch dieser physiologische Grund darf bei der in Rede stehenden Betrachtung nicht untersehätzt werden; ich muss jedoch wiederholt darauf hinweisen, dass unsere jetzt lebenden Eidechsen zu dieser Anpassung der schwarzen Farlue oder vielmehr zu dem Rücksehlag, der sich bei bestimmten Formen zeigt, besonders disponirt sind, da vermuthlich ihre Vorfahren sämmtlich eine sehwärzliche Färbung besessen haben. Dass hier wirklich ein Ritekschlag bei den schwarzen Eidechsen, wie bei der Regeneration des Schwanzes cintritt, seheint mir der Umstand zu beweisen, dass der Feuchtigkeit doch nur eine 
bedingte Wirkung zugesehrielen werden kann. Es miissten sonst ja die im Wasser lebenden Urodelen eine schwarze Färbung besitzen, und das ist durchaus nicht der Fall. Im Gegentheil sind die regenerirten Schwänze dieser Thiere, wie schon Bonnct gesehen hat, fast vollkommen durchsichtig und pigmentlos, während doch die normale Haut ziemlich viel Pigment besitzt.

Aus den angefülıten Thatsachen num, dass sich das Pigment nicht nur innerhalb der Epidermis der Embryonen, sondern anch in den jungen Stadien des regenerirten Schwanzes vorfindet, und dass es sich in der gesammten Epidermis der sogenannten schwarzen Eidechsen nachweisen lässt, habe ich nun den Schluss gezogen, dass bei der Regeneration auch die phylogenetische Entwickelungsreihe einen bestimmenden Einfluss auf gewisse Structurverhältnisse des K̈̈̈rpers mit ausiibt.

Einen bedeutend stärkeren Einfluss auf die Neubildung der Organe und Gewebe, als den bis jetzt angegebenen Verhältnissen, müssen wir nun der functionellen Anpassung zuschreiben. Gleich bei der ersten Wundheilung tritt uns eine solche entgegen, indem nämlich bei den auf dem Lande lebenden Thieren, sowohl bei den Reptilien als den höheren Wirbelthieren, nach der Verletzung eine Schorfbildung entsteht, die bei den im Wasser lebenden Thieren nicht vorkommt.

Ferner sehen wir bei der Regeneration häufig eime Recapitulation von Bildungsweisen auftreten, die nicht embryonal sind, aber doch bereits im normalen, wachsenden Schwanzende der Urodelen vorkommen. Hier ist vor allem des Knorpelstabes zu gedenken, ans den sich im normalen, wachsenden Schwanzende eine grosse Zahl ron Wirbeln hervorbildet; ans einem ähnlichen Kunorpelstabe gehen bei der Regeneration die sämmtlichen Wirbel der Urodelen hervor. Ebenfalls hierher gehört die Regeneration der Spizalganglien, die nach dem Typus der normalen Bildung im wachsenden Schwanzende der Amplibien neugebildet werden.

Während aber diese angefülnten Beispiele doch noch als Recapitulation einer gewissen normalen Bildungsweise aufzufassen sind, künnen andere, wie das bereits weitläufig ausgeführt worlen ist, durehaus nicht mit der normalen Bildung verglichen werden. Es fehlt diesen Bildungen jede Analogie mit der normalen Entwickelung und deshalb kann man sie allein mit Znhilfenahme der functionellen Anpassung erklären. Hierher gehört das Wirbelrohr der Reptilien, welches als ein vollkommen eigenartiges Gebilde betrachtet werden muss; hierher gehört die eigenthümliche Anordnung der Blutgefässlacunen in den ersten Regenerationsstadien des Reptilienschwanzes; vor allen Dingen aber die eigenthïmliche Innervation, welche sich in dem neugebildeten Schwanze rler Eidechsen vorfindet. Schon vor Roux haben verschiectene Forscher gerade in Bezug auf die Regrenerationsfrage ähnliche Ansichten ausgesprochen, wie sie ron Roux neuerdings mit besonderen Namen bezeichnet und durch eine Reihe von Thatsachengestiitzt wurien. So sagt z. B. Thiersch in seinem Aufsatze: Ueber die feineren anatomischen Veränderungen nach Verwundung der Weichtheile ${ }^{1}$ ): „Vom Augenblicke der Verwundung an vollzieht sich ror unseren Augen eine Reihe merkwiindiger Vorginge, die mit dem Anschein der Zweckmässigkeit einem vorgesteckten Ziele gleichsam zustreben." Wir müssen hente das Hauptgewicht auf das Wort Anschein legren, denn „die Zweekmässigkeit ist keine gewollte, sondern eine gewordene, keine teleologische, sunderu eine uaturhistorische, auf mechanischem ITege entstandene; denn nicht das einem vorgefassten Zweeke entsprechende, sondern tas, was die nothwendigen Eigen-

2) Handbuclı der allgemeinen und speciellen Chirurgie, ron Pitha und Billroth. Erlangen 1867. pag. 531. 
schaften zum Bestehen unter den gegebenen Verhältnissen hatte, hieb iibrig;"“ so sagt Ronx in seinem Buche.

Die Intention zum Wachsthum des Eidechsenschwanzes geht bereits mehr vom Bindegewebe aus, als bei den Amphibien: wenigstens sehen wir, dass in den jüngsten Stadien das regenerirte Epithel, welehes allerlings den Conus rollständig iiberdeekt, durch das Bindegewebe nach vorn gedrängt; auf der Spitze res Kegels ist dasselbe an diunnsten, unl es scheint, als besitze hier die Epiclermis nieht mehr dieselbe Proliferationsfühigkeit, wie bei den Amplibien; es kommt hier wenigstens niemals zu solchen hypertrophischen Bildungen, wie sie als Kugelbildungen und Lacunen in der Haut der Amphibien beschrieben worden sind. Das Binclegervebe selbst bildet zuerst eine Art von Narbengewebe, in welchem sieh die oben beschriebenen Laeunen der Blutgefisse in ausgicbiger Weise vorfinden. Dam tritt beim Grösserwerden des regenerirten Kegels als Stiitze das axiale Irirlehrohr auf, und nach und nach entsteht dam Cutis, Muskulatur und peripherisches Nervensystem. Ifier ist bei der Regeneration sehon ein Ueberwiegen der Bindesubstanzen zu constatiren, und dieses ist es, welches nach den Beobaehtungen der älteren Forseher nnd nach Roux hauptsächlich proliferationsfähig ist, und das schliesslich bei den hüheren Thieren ausser dem Epithel und der Muskulatur allein noch regenerationsfähig bleibt. So sagt Thiersch in seinem eitirten Autsatze pag. 534: „Freilich fällt diese Regeneration um so unvollständiger aus, je höher der Organismus ist, und als histologisehen Austluck dieser Insufficienz miissen wir die Narbe betrachten." Diese Narbe besteht bei den höheren Thieren nur aus Bindegewebsellen, deren Herkunft allerdings noch zweifelhaft ist: man fasst sic eimmal anf als Producte der älteren, embryonal gewordenen Bindegewebszellen; andere jedoch lassen sie aus eingewanderten weissen Blutkïrperehen entstehen.

Beim Durehlesen der Roux'schen Arbeit muss ein Punkt besonders auffallen: Roux luält nämlich die Darwin'sehe Theorie nicht für ausreichend zur Erklärung der Erscheinungen, welche durch die functionelle Anpassung bedingt werden. Er komunt zu dem Schhss, dass die Aenderung der Lebensbedingungen in allen betroffenen Organen zugleieh zweckmässige Aenderungen hervorzubringen rermag, und gerade diese Gleichzeitigkeit der Wirkung in Millionen Theilen stellt er als charakteristisch der Wirking der Zuchtwahl gegeniiber, welehe immer nur ganz wenig Zweekmässiges allein gleichzeitig ausbilden kann. Es ist aber num nicht einzusehen, warum bei der Zuchtwahl nicht aneh viele giunstige Anpassungen gleichzeitig von dem betreffenden Thiere acquirirt werden könnten; vor Allem muss aber hier auch auf die Gesetze der correlativen Entwiekelung mit Riieksielit genommen werden. Anch bei rer Regeneration sincl diese Gesetze der correlativen Entwiekelung in gleichem Masse in Betracht zu ziehen, wie die der funetionellen Anpassung, und wir werden vor allen Dingen eine fortreffliche Stiitze für diese Behauptung in der Regeneration der Extremitäten funden. Wie sieh die Papillen auf der Zunge einzelner Vögel in ihrcr ursprüugliehen Anlage als Embryonalfederanlagen zeigen, die später erst in eigenthünlicher Weise mit einander versehmelzen, wie diese Bilnungen nur als eine Stiitze für den Durwin'sehen Satz gelten können, dass gleiche Organe unter gleichen Bedingungen anch gleiche Producte hervorbringen, wie also diese eigenthiimliche Papillenbildung nu dureh das Gesetz der Correlation entstanden gerlacht werden kann, so müssen wir auch bei der Regeneration der Extremitäten in Betracht ziehen, dass entspreehend diesen Gesetzen eine Neubildung vou Extremitäten eigentlieh nur in der Weise vor sich gehen kann, dass die neugebildeten Glieder sich naeh dem Typus entwickeln, nach welchem ihre eorrelaten Organe gebildet worden sind. 
Hierdurch wird ror allen Dingen erklärt, wesshalb auch bei der Regeneration die vordere Extremität 4, die hintere 5̆ Phalangen besitzt, cin Verhältniss, welches durch eine reine Recapitulation ontogenetischer Vorgänge noch nicht zu erklüien wäre.

Was die Regenerationsfähigkeit der verschiertenen, hier in Frage kommenden Thiergruppen anbelangt, so habe ich bereits, sowohl im allgemeinen Theil, wie bei der Beschreibung der einzehen Gewebe daranf hingewiesen, dass nicht sämmtliche Amphibien und Reptilien die gleiche Fähigkeit, verloren gegangene Glieder wierler zu erzengen, besitzen. Bei den Anuren zeigen ïberhaupt nur dio Larren ein einigermassen ausgebildetes Reprorluctionsvermögen, da sie wenigstens im Stande sind, Theile des verloren gegangenen Schwanzes wieder zu erzengen; ganz hingegen fehlt ihnen die Fähigkeit, abgeschnittene Gliedmassen nen zu bilden. Von den Urodelen zcichnen sich besonders die Ichthyoden durch eine fabehnafte Reprodnctionskraft aus, mul nicht nur die Larven, sondern anch die ausgebildeten Thiere sind im Stande, fast sämmtliche rerloren gegnngene Theile des Körpers zu regeneriren.

Um so wunderbarer muss es uns erscheinen, wenn einzelnen Species aus diesel Klasse jene Fähigkeit nicht in dem Masse zukommt, wie den anderen. Hier ist vor Allem Protens anguineus zu nennen, der in Vergleich zu seinen nächsten Artverwandten ein ausseror(entlich geringes Reprodnctionsvermügen besitzt. Schon bei der Betrachtung des normalen Schwanzes muss es anffallen, dass diesen der Knorpelstab, ans welchem die letzten Wirbel hervorgehen, fast vollkonmen fehlt; die Wirbelsäule ist bis zmm letzten Ende rerknöchert, und clie Chordareste treten bis sehr weit nach hinten auf. Betrachten wir die Lebensweise dieses Thieres, so sehen wir, dass der Protens in den Höhlen Krains, in denen er bekanntlich vorkommt, fast gar keine Verfolger und Feinde besitzt; auch unter sich leben die Thiere, wie man sich leicht an den in der Gefangenschaft gehaltenen Exemplaren ïberzengen kann, ausserordentlich friedlich. Niemals kann man beobachten, dass sie sich untereinander die Kiemen abfressen, wie das zusammenlebende Tritonen-oder Salamanderlarven und anch Axolotls mit Vorkebe thun.

Diese beiden Thatsachen, die geringe Entwickelung des bei den iibrigen Urodelen so stark ansgeprägten knorpeligen Endes der Wirbelsäule und die Anjassung an das Höhlenleben, in Folge dessen eine Verfolgung dureh Fcinde fast gänzlich ansgeschlossen wird, mögen beide darauf hingewirkt haben, dass die Reproductionstäligkeit auf einen geringeren Grad herabsank.

Auch ron Triton marmoratus wird ron Schreiber etwas ähnliches behauptet; derselbe sagt in seinem Aufsatze iiber Plerurodeles $\left.{ }^{1}\right)$ : „Nach meiner Erfahrung zeigt Triton marmoratus durchaus kein Reproductionsremögen, indem er selbst kleine Verletzungen des Kammes und dergleichen wenigstens in der Gefangenschaft nie wieder ersetzt, und bei grösseren Verletzmngen regehmässig eingeht.“ An meinen längere Zeit in Gefangenschat't gehaltencn Exemplaren ron Triton marmoratus konnte ich ähnliches constatiren; niemals wochs eine abgeschnittene Extremität zur normalen Grösse wieder nach, es bildete sich mu ein etwas deformirter Kregel an deun Amputationsstumpf; auch der Schwanz wurde nur in sehr geringem Masse reproducirt und behielt lange Zeit ein eigenthimliches, durehsichtiges Anssehen.

Bei den Reptilion tritt uns diese Thatsache, dass einzelnen Gruppen die Regencrationsfihigkeit in viel geringerem IIasse zukommt, in noch viel höherem Grade entgegen, als bei den

${ }^{1)}$ Dex zoologische Garten, Nov. 1878. pag. 325, iu einer Anmerkung. 
Amphibien. Wir haben gesehen, dass die Chelonier, die Crocodilier und die Ophidier durchans nicht im Stande sind, verloren gegangene Theile auch nur einigermassen zu regeneriren, dass dagegen diese Fähigkeit den Lacertiden und Ascalaboten in hohem MIasse zukommt, aber auch hier nur in Bezug auf den Schwanz. Schon Spallanzani stellte den sehr weisen Satz auf, dass die Natur nicht alles reproducirt, was man abschneidet, und Bonnet und Blumenzach suchten in dieser Beziehung die Erfahrungen des berühmten Naturforschers zu ergüinzen.

Versuchen wir die neneren Beobachtungen über die Regeneration mit denen der älteren Forscher in Einklang zu bringen, so wird vor allen Dingen ein Grundsatz in Betracht zu ziehen sein, welcher aus den älteren Arbeiten in dem von mir pag. 38 formulirten Satze ansgedrïekt ist, dass die Regeneration abhängig sei von äusseren Umständen, besonders aber den Einflïssen der Jahreszeit und der Witterung, wie von dem Medium, in dem sie sich vollzieht. Dies hat mich zu einigen Versuchen veranlasst, die Regeneration ron Urodelenlarven in gewiirmtem Wasser zu controlliren.

Ieh sah bei gleicher Emälıung sïmmtlicher bei denjenigen ein stärkeres Waehsthum der nengebildeten Theile eintreten, welche sich im Wasser von ca. 15-18 ${ }^{\circ} \mathrm{C}$. befanden; steigerte ich jedoeh die Temperatur anf $20^{\circ} \mathrm{C}$, so sank die Reproduetionsfähigkeit nieht nur, sondern es gingen die Thiere trotz der aufmerksamsten Pflege und Durchliftung des Wassers meist bald zu Grunde.

Im Uebrigen ergaben diese Versuche, wie noch einige andere, die jedoch noch nicht als abgeschlossen zu betrachten sind, stets das Resultat, dass sowohl die Amphibien, wie die Reptilien nm ginnstigsten und vollständigsten dann regeneriren, wenn man die Verhältnisse, unter denen sie gehalten werden, so viel als möglich denen anpasst, denen sie in der Freiheit ausgesetzt sind.

Ueber die Regenerationsdaner füge ich zur Orientirung am Schluss cinige Tabellen an, die von Siredon entuommen sind. Jedes der Versuchsthiere wurde in versehiedenen Zeitintervallen t-6 mal amputirt, und das Aussehen des nachgewachsenen Theiles an dem nebenverzeichneten Datum notirt.

Aus den bis jetzt zusammengefassten allgemeineren Resultaten lassen sich nun für die Gewebsneubildung bei den Amphibien und Reptilien einige Gesetze formuliren, denen eine weitgehende Bedeutung zukommt. Für die Gewebe sind dies vor Allem die folgenden:

1. Sowohl bei Amphibien wie bei Reptilien sind verletzte Gewebe nur im stande, wiedernm gleichartige Gewebe zu erzengen. Die Lenkocyten iibernehmen bei der Gewebslildnng nur die Function der Ernährung; a usserdem nelmen sie zerfallende Gewebsproducte auf und assimiliren dieselben, nm sie an anderen Orten wieder zu deponiren. Nienals werden sie selbst zu fixen Gewebszellen, weder in der Bindesubstanz noch sonst wo.

2. Sämmtliche der in Frage kommenden Gewebe der Amphibien nnd Reptilien sind im Stande, sich zu regeneriren; entweder direct a us ihren Elumenten, oder aus einer Matrix, so lange diese Matrix unverletzt ist. Als Matrix für die Epidermis ist das Rete IIalpighii, fü r das centrale Nervensystem das Epithel des Centraleanales, für die Muskulatur die Muskelköperchen zn betrachten.

3. Zuerst regeneriren sich Epithel und Bindegewebe: beides scharf getrennt, ursprïnglich aus gleichartigen Zellen bestehend, die sich später differenciren. 
Noch einige allgemeinere nene Gesetze lassen sich hieraus ableiten, und etwa in folgen der Treise:

A. Die Regeneration ist weder eine reine Recapitulation ontogenetiscler oder phylogenetischer Entwickelnngsvorgänge, noch ist sie allein erklärbar dureh die Verhältnisse der functionellen Anpassung; sie muss vielmelır als eine Vererbungserscheinung aufgefasst werden, bei welcher besondere, oft sehr complicirte Anpassungen der Gewebe mitwirken" ebens" wie die Gesetze der correlativen Entwickelung.

B. Weder durch den Reiz der Verwndung, nocl durch die gesteigerte Zufulur von Nahrungsmaterial (Thiersch), noch durch die Wegname des Wachsthumswiderstandes (Boll) allein sind wir im Stande, die Regenerationserscheinnngen zu erklären; es sind hierfïr die unter A angefuhrten Principien unbedingt die massgebend eren. 


\section{Versuchsthier No. 1.}

\begin{tabular}{|c|c|c|c|c|c|c|c|}
\hline & $\begin{array}{l}\text { Amputirte } \\
\text { Gliedler }\end{array}$ & $\begin{array}{l}\text { Datum } \\
\text { des } \\
\text { Nach- } \\
\text { wuchses }\end{array}$ & $\begin{array}{l}\text { Aussehen } \\
\text { diss } \\
\text { Nachwuchses }\end{array}$ & & $\begin{array}{l}\text { Amputirte } \\
\text { Glieder }\end{array}$ & $\begin{array}{l}\text { Datnm } \\
\text { des } \\
\text { Nach- } \\
\text { wachses }\end{array}$ & $\begin{array}{l}\text { Aussehen } \\
\text { dex } \\
\text { Nachwuchses }\end{array}$ \\
\hline 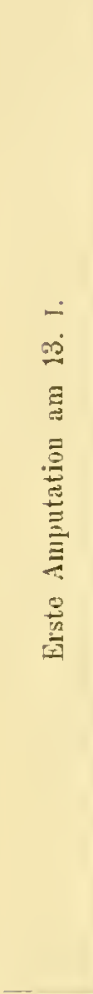 & $\begin{array}{l}\text { Schiwanz in der } \\
\text { Länge vou ca. } 5 \mathrm{~mm} \\
\text { und die sämmtlichen } \\
\text { Kiemen der rechten } \\
\text { Seite. }\end{array}$ & $\begin{array}{c}\text { An } \\
1 .\end{array}$ & 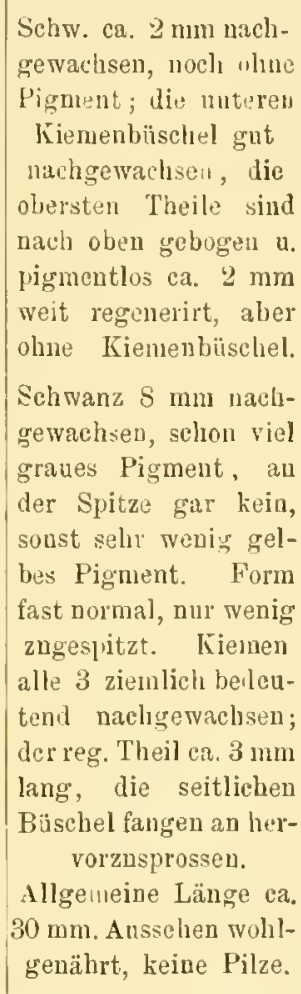 & 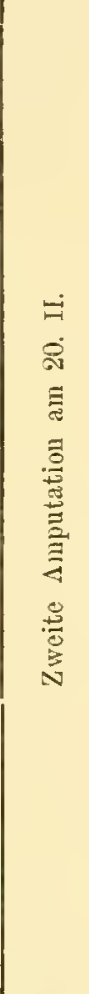 & $\begin{array}{l}\text { Schwanz in der } \\
\text { Länge von ca. } \\
1 \mathrm{~cm} \text { amputirt. } \\
\text { NB. Schuittrounde } \\
\text { etwas schräg ge- } \\
\text { worden. }\end{array}$ & $\begin{array}{l}\text { Am } \\
23 . \text { Ill. }\end{array}$ & $\begin{array}{l}\text { De: Schwanz ist } \\
\text { ca. } 1 \mathrm{~cm} \text { nachge- } \\
\text { waclisen, etwas } \\
\text { schräg nach unten } \\
\text { zu. Kiemenbüschel } \\
\text { wieder völlig nor- } \\
\text { mal, nur um wenig } \\
\text { kürzer, als die der } \\
\text { linken Seite. }\end{array}$ \\
\hline 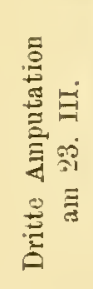 & $\begin{array}{l}\text { Rechter Hinterfuss } \\
\text { etwa in der Mitte } \\
\text { der Tibia u. Fibula, } \\
\text { doch mehr nach } \\
\text { dem Kniegelenk } \\
\text { zu. }\end{array}$ & $5 \mathrm{IV}$. & $\begin{array}{l}\text { Die Wunde hat sich } \\
\text { völlig verschlossen } \\
\text { und zeigt ein } \\
\text { weissliches Narben- } \\
\text { gcwebe. }\end{array}$ & 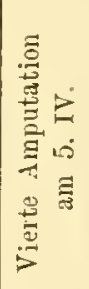 & Rechter Bulbus. & 22. IV. & $\begin{array}{l}\text { Vom Bulbus noch } \\
\text { keine Spur. Rech- } \\
\text { tes Hinterbein } \\
\text { spitz, sonst normal. }\end{array}$ \\
\hline 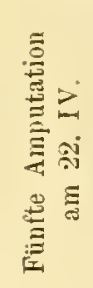 & $\begin{array}{l}\text { Schwanz ca. } 1 \mathrm{~cm} \text {; } \\
\text { rechter Hinterfuss; } \\
\text { linker Vorderfuss. }\end{array}$ & 26. IV. & $\begin{array}{l}\text { Alles in gutem Wachs- } \\
\text { thum, bei der Extremi- } \\
\text { tät } 1 \text { ragen Ulna und } \\
\text { Radius hervor. }\end{array}$ & & & & \\
\hline
\end{tabular}




\section{Versuchsthier No. 2.}

\begin{tabular}{|c|c|c|c|c|c|c|c|}
\hline 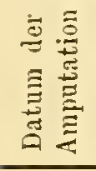 & $\begin{array}{l}\text { Amputirte } \\
\text { Glieder }\end{array}$ & $\begin{array}{l}\text { Datum } \\
\text { des } \\
\text { Nach- } \\
\text { wuchses }\end{array}$ & $\begin{array}{l}\text { Ausselien. } \\
\text { des } \\
\text { Nachwuchises }\end{array}$ & 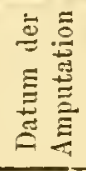 & $\begin{array}{l}\text { Amputirte } \\
\text { Glieder }\end{array}$ & $\begin{array}{l}\text { Datum } \\
\text { des } \\
\text { Nach- } \\
\text { wuchses }\end{array}$ & $\begin{array}{l}\text { Aussehen } \\
\text { des } \\
\text { Nachwuchses }\end{array}$ \\
\hline 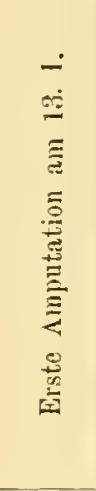 & $\begin{array}{c}\text { Schwanz ca. } 1 \mathrm{~cm} \\
\text { lang. }\end{array}$ & 1. II. & $\begin{array}{c}\text { Schwanz ca. } 1,5 \mathrm{~mm} \\
\text { lang, noch ohue Pig- } \\
\text { ment. }\end{array}$ & 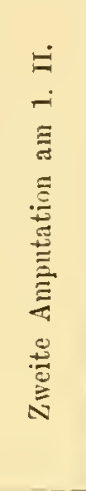 & $\begin{array}{l}\text { Rechter Vorderfuss } \\
\text { durch den Humerus } \\
\text { abgeschnitten. }\end{array}$ & 20. II. & $\begin{array}{l}\text { Der regenerirte } \\
\text { Schwanz vom 13. I. } \\
\text { ziemlich gut nach- } \\
\text { gewachsen,ziemlich } \\
\text { viel schrarzes um } \\
\text { gelbes Pigment. } \\
\text { Länge des Nach- } \\
\text { wuchses } 9 \text { mm; } \\
\text { Fuss am } 1 \text {. II. } \\
\text { stummelförmig } \\
\text { nachger., Kuppe } \\
\text { ohne Pigment, Uu- } \\
\text { ters.m.röthl. Narbe }\end{array}$ \\
\hline 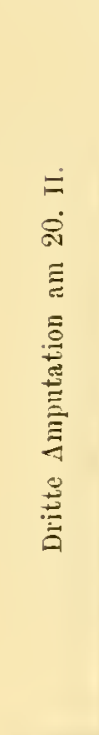 & $\begin{array}{l}\text { Wiederholt der } \\
\text { rechte Vorderfuss } \\
\text { amputirt. }\end{array}$ & 23. III. & $\begin{array}{l}\text { Schwanz nul noch } \\
\text { durch seine etwas } \\
\text { spitzere Form und } \\
\text { den Mlangel so scharf } \\
\text { umschricbener Pig- } \\
\text { mentflecke als regene- } \\
\text { rirt erkennbar. Vor- } \\
\text { derfuss } 3 \text { mm lang } \\
\text { regener. Farbe weiss- } \\
\text { lich; bei den Austreng. } \\
\text { die das Thier macht, } \\
\text { um sich aus der Hand } \\
\text { zu befreien, werden } \\
\text { die Blutgefässe inji- } \\
\text { cirt, sodass der re- } \\
\text { generirte Theil stark } \\
\text { gerötlet erseheint. } \\
\text { Allgemeine Länge } \\
\text { 85 mm, } \Lambda \text { nssehen } \\
\text { wohlgenährt. }\end{array}$ & 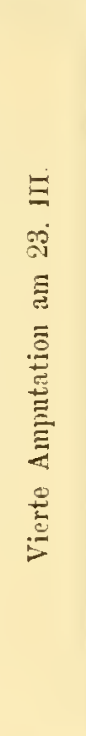 & $\begin{array}{l}\text { Sämmtliche Kie- } \\
\text { men der rechten } \\
\text { Seite am Grunde. }\end{array}$ & 5. IV. & $\begin{array}{c}\text { Es bilden sich lil. } \\
\text { weissliche Höcker } \\
\text { auf den Kiemen- } \\
\text { stumpfen. Rechter } \\
\text { Vorderfuss } 5 \mathrm{~mm} \\
\text { lang nachgewacbs., } \\
\text { röthlich. }\end{array}$ \\
\hline 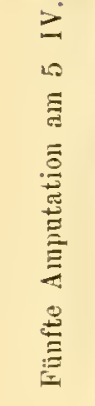 & $\begin{array}{l}\text { Schranz ca. } 2 \mathrm{~cm} \\
\text { mit allen Regene- } \\
\text { rirten abgeschnit- } \\
\text { ten, oben bleibt } \\
\text { eine kleine Spitze } \\
\text { normal herror- } \\
\text { ragen. }\end{array}$ & $22.1 \mathrm{~V}$ & $\begin{array}{l}\text { Kiemen weissliche } \\
\text { Stumpfe. Rechtes } \\
\text { Vorderbein Finger- } \\
\text { theilung, röthlich. }\end{array}$ & 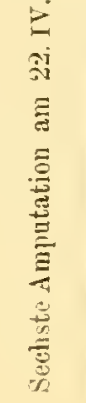 & $\begin{array}{c}\text { Sehwanz ca. } 5 \text { min. } \\
\text { Rechtes Vorder- } \\
\text { bein. }\end{array}$ & 26. IV. & $\begin{array}{l}\text { Extrem. 2 stumpt: } \\
\text { hiemell stummıl- } \\
\text { förmig. }\end{array}$ \\
\hline
\end{tabular}


Versuchsthier No. 3.

\begin{tabular}{|c|c|c|c|c|c|c|c|}
\hline 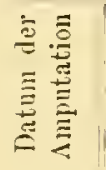 & $\begin{array}{l}\text { Amputirte } \\
\text { Glieder }\end{array}$ & $\begin{array}{l}\text { Datum } \\
\text { des } \\
\text { Nach- } \\
\text { wuchses }\end{array}$ & $\begin{array}{c}\text { Aussehen } \\
\text { des } \\
\text { Nachwuchses }\end{array}$ & 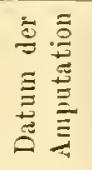 & $\begin{array}{l}\text { Amputirte } \\
\text { Glieder }\end{array}$ & $\begin{array}{l}\text { Datum } \\
\text { des } \\
\text { Nach- } \\
\text { wuchses }\end{array}$ & $\begin{array}{c}\text { Aussehen } \\
\text { des } \\
\text { Nachwuchses }\end{array}$ \\
\hline 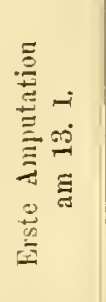 & $\begin{array}{c}\text { Schwanz ca. } 1 \mathrm{cms} \\
\text { lang. }\end{array}$ & 1. II. & $\begin{array}{c}\text { Schwanz ca. } 1,5 \mathrm{~mm} \\
\text { nachgewachs., noch } \\
\text { olne Pigment, od. } \\
\text { nur vereinzelte } \\
\text { Zellen }\end{array}$ & 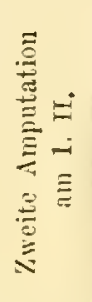 & $\begin{array}{c}\text { Linkes Hinterbein } \\
\text { völlig amputirt in } \\
\text { der Mitte des } \\
\text { femur. }\end{array}$ & $\therefore 0$. II. & $\begin{array}{l}\text { Schwanz ca. } 7-9 \mathrm{~mm} \\
\text { nachgew. mit diffusem } \\
\text { gelb. u.'schw. Pigment. } \\
\text { Form normal, nur oben } \\
\text { etwas abgedacht. } \\
\text { Fuss zeigt eine kl. ca. } \\
1 \text { mm lange Spitze ohne } \\
\text { alles Pigment. }\end{array}$ \\
\hline 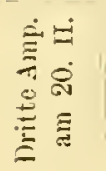 & $\begin{array}{l}\text { Linker Hinterfuss } \\
\text { wiederh. amputirt } \\
\text { dazu der rechte } \\
\text { ob.Kiemenbüschel. }\end{array}$ & 23. III. & $\begin{array}{l}\text { Fuss niclit bedeut. } \\
\text { nacbgew., ea. 2mm. } \\
\text { liemenb. halb so } \\
\text { lang wie d. norm., } \\
\text { ab. m. kitisch. bes. }\end{array}$ & 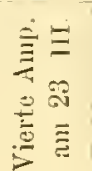 & $\begin{array}{l}\text { Rechter Bulbus } \\
\text { exstirpirt. }\end{array}$ & 5. IV. & $\begin{array}{l}\dagger \text { am 1. April, da das } \\
\text { Thier ans dem Gefäss } \\
\text { herausgesprungen war. }\end{array}$ \\
\hline
\end{tabular}

Versuchsthier No. 4.

\begin{tabular}{c|c|c|c|c|c|c|c}
\hline & $\begin{array}{c}\text { Datum } \\
\text { des } \\
\text { Nach- } \\
\text { wuchses }\end{array}$ & $\begin{array}{c}\text { Aussehen } \\
\text { des }\end{array}$ & $\begin{array}{c}\text { Naehwichses } \\
\text { Glieder }\end{array}$ & $\begin{array}{c}\text { Datum } \\
\text { des } \\
\text { Nach- } \\
\text { wuchses }\end{array}$ & $\begin{array}{c}\text { Aussehen } \\
\text { des }\end{array}$ \\
\hline
\end{tabular}




\section{Versuchsthier No. 5.}

\begin{tabular}{|c|c|c|c|c|c|c|c|}
\hline 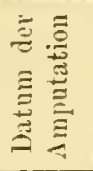 & $\begin{array}{l}\text { Amputirte } \\
\text { Glieder }\end{array}$ & $\begin{array}{l}\text { Datum } \\
\text { des } \\
\text { Nach- } \\
\text { wuclises }\end{array}$ & $\begin{array}{c}\text { Aussehen } \\
\text { des } \\
\text { Nachwuchses }\end{array}$ & 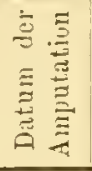 & $\begin{array}{l}\text { Amputirte } \\
\text { Glieder }\end{array}$ & $\begin{array}{l}\text { Datum } \\
\text { des } \\
\text { Nach- } \\
\text { wuchses }\end{array}$ & $\begin{array}{l}\text { Aussehen } \\
\text { des } \\
\text { Nachwuchses }\end{array}$ \\
\hline 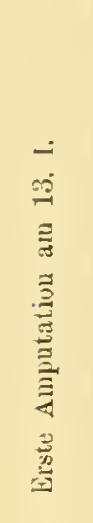 & Beide Vorderfüsse. & 20. II & $\begin{array}{l}\text { Füsse gut nach- } \\
\text { gewachsen, wenig } \\
\text { Pigment, Thei]ung } \\
\text { noch nicht zu er- } \\
\text { kennen. }\end{array}$ & 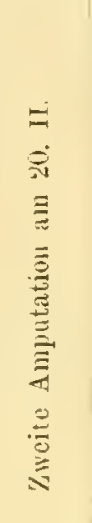 & $\begin{array}{l}\text { Linkes Vorderbein } \\
\text { und Schwanz } 1 \mathrm{~cm}\end{array}$ & 23. III. & $\begin{array}{l}\text { Rechtes Vorderbein } \\
\text { vom 13. I. gut re- } \\
\text { generirt, vior dcut- } \\
\text { liche Finger, doch } \\
\text { noch etwas heller wie } \\
\text { die normalen. Linkies } \\
\text { Vorilerbein weisslich } \\
\text { und ziemlich gut ca. } \\
4 \mathrm{~mm} \text { nachgewachsen. } \\
\text { Schwanz } 6-8 \mathrm{~mm} \\
\text { gut nachgewachsen, } \\
\text { viel schwarzes, wenig } \\
\text { gclbes Pigment. }\end{array}$ \\
\hline 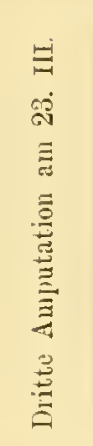 & $\begin{array}{l}\text { Seliwanz } 9 \mathrm{~mm} \\
\text { abgeschnitten. }\end{array}$ & $5.1 \mathrm{~V}$. & $\begin{array}{l}\text { RechterVorlerfuss } \\
\text { völlig normal, } \\
\text { linker röthlich, be- } \\
\text { ginnende Fingerbil- } \\
\text { dung, Schwanz } \\
\text { ca. } 1 \mathrm{~mm} \text { nachge- } \\
\text { wachseu }\end{array}$ & 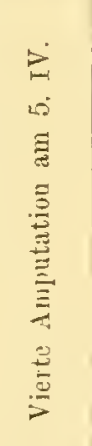 & $\begin{array}{l}\text { Schwauz ca. } 5 \mathrm{~mm} \\
\text { und rechter Bulbus. }\end{array}$ & 22. IV. & $\begin{array}{l}\text { Bcine fast normal, } \\
\text { link. Vorderfuss etwas } \\
\text { röth]. Schwanz wenig, } \\
\text { Bulbus gar nicht. }\end{array}$ \\
\hline 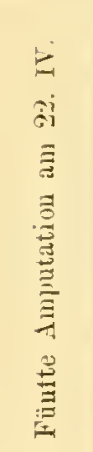 & $\begin{array}{l}\text { Schwanz ca. } 5 \mathrm{~mm} \\
\text { rechter oberer } \\
\text { Triemenbüschel. }\end{array}$ & 2i. IV. & $\begin{array}{l}\text { Linker Vorderfuss } \\
\text { Zehentheilung. } \\
\text { Bulbus keine Spur. }\end{array}$ & 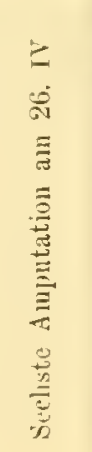 & $\begin{array}{c}\text { Extr. } 1 \\
\text { Mitte d. hum. und } \\
\text { Extr. } 4 \\
\text { Mitte des femur. }\end{array}$ & & \\
\hline
\end{tabular}




\section{Versuchsthier No. 6.}

\begin{tabular}{|c|c|c|c|c|c|c|c|}
\hline 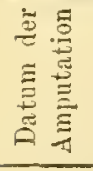 & $\begin{array}{l}\text { Amputinte } \\
\text { Glieder }\end{array}$ & $\begin{array}{l}\text { Datum } \\
\text { des } \\
\text { Nach- } \\
\text { wuchses }\end{array}$ & $\begin{array}{l}\text { Aussehen } \\
\text { des } \\
\text { Nachwuchses }\end{array}$ & 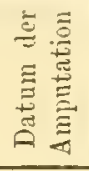 & $\begin{array}{l}\text { Amputirte } \\
\text { Glieder }\end{array}$ & $\begin{array}{l}\text { Datum } \\
\text { des } \\
\text { Nacl. } \\
\text { wuchses }\end{array}$ & $\begin{array}{c}\text { Ausselien } \\
\text { des } \\
\text { Nachwuchses }\end{array}$ \\
\hline 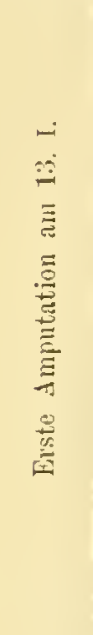 & Linkes Hinterbcin. & 20. II. & $\begin{array}{l}\text { Das Hintcrbein gut } \\
\text { nachgewachsen. } \\
\text { Theilung r. Finger } \\
\text { noch nicht un selhen. }\end{array}$ & 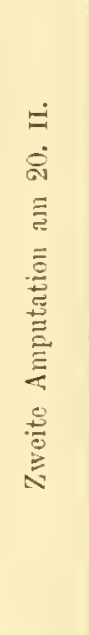 & $\begin{array}{l}\text { Rechter Hinterfuss. } \\
\text { Schwanz ca. } 1 \text { cm } \\
\text { lang. } \\
\text { Bubbus dext. }\end{array}$ & 23. III. & $\begin{array}{c}\text { Das linke Hinterboin } \\
\text { rom 13. I. völig gut } \\
\text { differ. mit } 5 \text { Fingern } \\
\text { a ier kloincr u. weniger } \\
\text { Pigment. } \\
\text { Das rechte Hinterbein } \\
\text { stummel ron ca. } 3 \mathrm{~mm} \text {. } \\
\text { Schwanz ca. } 4-5 \mathrm{~mm} \\
\text { machgewachsen, dun- } \\
\text { kel jigmentirt. } \\
\text { Bulbus überdeckt ron } \\
\text { der Epidermis, schim- } \\
\text { mert als schwärzlicher } \\
\text { Fleck durch, ohne jed. } \\
\text { den goldenen Rand zu } \\
\text { laben, wie bei norn. }\end{array}$ \\
\hline 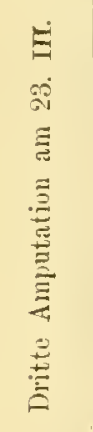 & $\begin{array}{l}\text { Schwanz ca. } 9 \mathrm{~mm} \\
\text { lang abgeschnitten. }\end{array}$ & 5. IV. & $\begin{array}{l}\text { Bulbus fast rund- } \\
\text { lich herrorragenil. } \\
\text { Recht. Hinterfuss } \\
\text { Fingertheilung in } \\
\text { Anfang. } \\
\text { Linker Vorderfuss } \\
\text { vom norm. nicht } \\
\text { zu unterscheiden. }\end{array}$ & 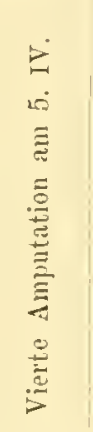 & $\begin{array}{l}\text { Schwanz ca. } 5 \mathrm{~mm} \\
\text { weit abgeschnitten. }\end{array}$ & $22 . \mathrm{IV}$. & $\begin{array}{l}\text { Linkes Hinterb. uorm. } \\
\text { RechterHinterf. Zelien } \\
\text { ausgebildet fast norm. } \\
\text { Bulbus rundlich her- } \\
\text { rorragend, lhat schon } \\
\text { gold. Pigment. } \\
\text { Schwanz gering nach- } \\
\text { gewachsen, pigmentlos. }\end{array}$ \\
\hline 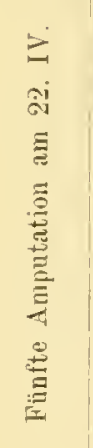 & $\begin{array}{c}\text { Schwanz ca. } 5 \mathrm{~mm} \\
\quad \text { weit. } \\
\text { Rechter Vorderfuss. }\end{array}$ & 26. IV. & $\begin{array}{l}\text { Bulbus mit gold. } \\
\text { Pigment noch et- } \\
\text { was kleiner wie } \\
\text { normal. } \\
\text { Extremitäten 1, 3, } \\
4 \text { normal, } 2 \text { gut } \\
\text { im Wachscu, rnnd- } \\
\text { licher. Wulst. }\end{array}$ & 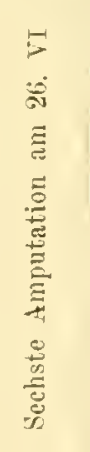 & $\begin{array}{l}\text { Schwanz ca. } 4 \mathrm{~mm} \text {. } \\
\text { Extremität } \\
3 \text { am femur. }\end{array}$ & & \\
\hline
\end{tabular}




\section{T' a f e l - Er k lär u ng.}

\section{vaf. I.}

Fig. 1. Frontalschnitt durch das drei Tage alte regenerirte Schwanzende einer Froschlarve. ir kugelförmige Bildung der Epidermis, in welcher nur wenig Protoplasma mit eingestrenten Kernen zu finden ist. $E$ Epidermis, $C$ Cutis, $B$ zelliges Blastem, $C h W$ neue Chordazellen, hervorgegangen aus dem Randwachsthnm der Chordaepithelzellen, Ch Chorda, $1 I$ Mushmlatur, i $C h s$ innere cuticulare, a Ch $S$ inssere zellige Chordascheide.

Fig. 2. Querschnitt durch ein altes regenerirtes Wirbelrohr von Platydactylus verus, nahe an der Uebergangsstelle in den normalen Schwanztheil. (Regenerirter Theil des Schwanzes $15 \mathrm{~cm}$ lang). $R M$ Rüekenmark, $B d g$ Bindegerrebe, $B g$ Blutgefüsse, $f_{i}$ änssere, verkalkte, $f_{1}$ innere, verkalkte Lamelle des hnorpels

Fig. 3. Querschnitt durch den regenerirten Schwanz von Senira bicolor. Altes Stadium, etwa anf der Mitte des regenerirten Theiles. I $M$ Rückenmark, $F$ Fettgewebe, $M$ Muskulatur, $C$ Cutis, mit regenerirten Knochenplatten in den Schuppen, $S$ Sehnen der Muskeln des voraufgebenden Segmentes, welche in den Muskeln des folgenden Segmentes verlanfen, $V$ Ventralseite.

Fig. 4. Regenerirtes Hautsinuesorgan von Pleurodeles Waltlii, altes Stadium. $N Z$ Nervenzellen mit Fortsätzen $H$, welche bis über die Hornschicht herrorragen, $R S$ Mantelschicht.

Fig. 5. Regenerirte Epidermis von Triton taeniatus (Larve von $15 \mathrm{~mm}$ ) nach 24 Stunden. Schnitt dureh eine rerdickte Stelle. a änssere, b innere Suhicht. Die Kerne liegen in einem gleichmässigen geköruelten Plasma, in welchem \%ellgrenzen nieht zu unterscheiden sind. Dagegen befindet sich um jedel Kern eine hellere Zone. Die dunkel gefärbten lugeligen Elemente sind zerfallene Leukncytan. T inction Methylviolett.

Fig. 6. Querschnitt durch einen älteren regenerirten Schwanz ron Hemidactylus frenatus. $R$ M Rückemmark, II Muskulatur, E Epidermis, C Cutis (vollstïndig zellig). V Ventralseite.

NE. Die Querschnitte der grossen peripheren Nerren, ron denen \& gezeichnet sind, innerhalb des das Wirbelrolır nmgebenden Fettkörpers, sind in der Zeichnung deutlich sichtbar, aber durch keinen Buchstaben bezeichnet worden.

Fig. 7. Querschnitt durch den hinteren Theil eines regenerirten Schwanzes ron Pleurodeles Waltlii. fast röllig einen gleichen Schnitt durch das normale Schwanzende gleichenl. $P M$ Rüchenmark. bestehend ans einem einfachen Rohr mit zienlich weitem Centralcanal, der nmgeben ist vou ziemlich dunlielgefärbten, länglichen Epithelzellen. Die weisse Substanz lat schon einen bedentenderen Untang erreicht. $R F$ Wirbelkörper. bestelıend aus Hyaliuknorpel mit ron ihm ausgelsenden, oberen und unteren Bögen, welche noch zum grossen Theil aus Spindelknorpel bestehen. $M$ Dunkle Flemente des Blastems, aus dem sich die Inskelfasern bilden. $C F_{r}$ Candalgefâsse, lacunenartig. Die Epidermis ist schon sehr vollståndig regenerirt, die Cutis zeigt noch rölig zellige Natur. Tinction Methylviolett. 
Fig. 8. Schnitt durch eine junge, regenerirte Epidermis ron ca. 6 Stunden ron Triton cristatus, adult. $L$ lymphartiger Saum, welcher die Querschnittfläche bedeckt, $E$ Epidermis, $H$ Hornschicht, $C$ Cutis mit Pigmentzellen, $\operatorname{Dr}$ Drüsen, II Muskulatur.

Fig. 9. 'Triton taeniatus, Larve. Einstülpung der Schleimdrüsen, älteres Stadium. $H S$ Hornsehicht, $D$ Drüse, umgeben ron eingewanderten Bindegewebszellen $B, S S$ Schleimschicht der Epidermis, $S D$ Hautschleimdrüse (einzellig, Leydig'sche Drüse), $C$ Cutis.

Fig. 10. Dasselbe, jüngeres Stadium, Perlbildung. Zusammenrïcken der mit $a-k$ bezeichneten Zellen um einen idealen Mittelpunkt $C$; Ep äussere Schicht der Epidermis, noch ohne Hornschicht.

Die bekannten karyokinetischen Figuren sind besonders häufig in der Umgebung solcher sich neu bildenden Drüsen.

Fig. 11. Längsschnitt durch die $1 \frac{1 / 2}{2}$ Tage alte Epidermis von Triton taeniatus. Methylriolett.

Die dunkel gefärbten Elemente sind rothe Blutkörperchen und Leukocyten. - Tinction

Fig. 12. Larre von Triton taeniatus mit regenerirten linken Extremitäten, um die Stellung derselben zum Körper zu demonstriren. Vergr. 2:1.

Fig. 13. Larre ron Hyla arborea, kurz ror der Metamorphose mit 11 Tage altem, regenerirten Schwanzstïck und amputirtem Hinterbein, welches jedoch keinen Nachwuchs zeigt.

Fig. 14. Schwanztheil der Larre von Pelobates fuscus mit 8 Tage altem regenerirten Schwanzstück. Die senkrechte punktirte Linie bezeichnet die Schnittfäcbe, die andere die Umrisse des normalen Schranzes.

\section{Taf. II.}

Fig. 1. Querscbnitt durch das 5 Monate regenerirte Pückenmark ron Pleurodeles Waltlii, an der Uebergangsstelle in den normalen Theil. C C Centralcaual, Ar Arterie, $r$ Venen. Zwischen den normalen Ganglienzellen sielt man am Anssenrande der Epithelzellen bis in die weisse Substanz hinein viele stark gefärbte runde Elemente (Körner). Die weisse Substanz ist selır ausgebildet, der Centralcanal ron normaler Grösse.

Fig. 2. Schnitt durch das Rückenmark desselben Exemplares, nur weiter nach hinten. Bezeichnung wie in Fig. 1. Sp.G Spinalganglien. Es filden sich fast keine typischen Ganglienzellen mehr, sondern nur dunkel gefärbte, stark lichtbrechende Körner um das Epithel des Centralcanales herum; die bindegewebige Hülle ist an den Seiten stark rerdickt, der Centralcanal und die Epithelzellen desselben sind ron normaler Grösse. Tinction Methylviolett.

NB. Weder in Fig. 1 noch in Fig. 2 sind die rundlichen Körner durch den Lithographen scharf genug hervorgehoben rorden.

Fig. 3. Längsschnitt durch einen alten regenerirten Schwanz ron Platydactylus mauretanicus, um das Ende des Rückenmarkes im Wirbelrohr zn zeigen.

Fig. 4. Sagittalschnitt durch einen etwa 14 Tage alten regenerirten Schwanz von Siredon. Vergr. 10:1. R M Rückenmark, $C h$ letzter Chordarest eines normalen Wirbels, $K S t$ regenerirter Kunorpelstab mit Wirbelsegmenten, $M$ Muskulatur.

Fig. 5. Längsschnitt (frontal) durch einen normalen Wirbel und den Uebergang in die regenerirte knorpelige Wirbelsüule von Pleurodeles Waltlii. Punktirte Linie $S F$ Schnittläche, $S p K^{*}$ Zellknorpel, $I v H$ Intervertebralkuorpel, $C h$ Chordarest, fast intervertebral liegend, $C h K$ Chordaknorpel, $V$ H $R$ Markrånme des Wirbelkörpers, der sehr tiefe mittlere Einschnitte und Buchten zeigt. Tinction Methylriolett.

Fig. 6. Triton taeniatus, adult. Linke, vordere Extremităt nach ca. 25 Tagen. H Humerus, $R d$ Radius, $U l$ Ulna, $C L$ Carpallücke, $B c$ Basale commune, 1,2 radiale Zehen, 3, 4 nlnare Zehen. Tinction Methylviolett. 
Fg. 7. Triton taeniatus, Larve. Regenerirte rechte hintere Extremităt von 12 Tagen. Flächenschnitt. F Femur mit deutlichem Centrum ron Hyalinknorpel, To Tibia; Centrum mit dunklen prochondralen Elementen und deutlicher Grundsubstanz, $F b$ Fibula mit dunklen Elementen und wenig Grundsubstanz, $B c$ Basale commune, 1, 2 tibiale Zehen, 3, 4 fibulare Zehen. Die Centren $F, T b, F b, B c, 1,2$ sind dentlich von einander gesondert, in 3 findet sich eine sclwache prochondrale Centrirung. Tinction Strasscr'sche Haematoxylinlösung.

Fig. 8. Theil aus einem Längsschnitt durch den regenerirten Schwanz von Triton cristatus, Larve, um die Neubildung eines Capillargefässes und von Pigmentzellen zu zeigen. \& zwei zur Bildung des Capillargefässes neu linzutretende Bindegewebszellea, $a, c$ in Bilduug begriffene Pigmentzellen.

Fig. 9. Ende des regenerirten Schwanzes von Platydactylus mauretanicus. Fnde des Wirbelrobres mit der eigenthümlichen Endrerdickung.

Fig. 10. Knorpel mit prochondralen dunklen Elementen aus dem Centrum des Basilare commune des rechten Vorderfusses ron Triton taeniatus, Larve. Tinction Methylviolett.

Fig. 11 u. 12. Schemata der regenerirten Wirbel von Pleurodeles Waltlii. Fig. 11. Querschnitt durch eine Intervertebralstelle, Fig. 12 durch eine Vertebralstelle. $R$. II Rückenmark, $Y B$ Neuralbógen, $W h_{1}$ Wirbelkörper, $A c$ Arteria caudalis, $V e$ Vena caudalis, $H B$ Haemalbögen.

Fig. 13 u. 14. Schemata der Regeneration der Gliedmassen. Fig. 13 von Triton taeniatus adult. A rechte vordere Estremität, $B$ rechte hintere Estremität. Fig. 14. Triton taeniatus, Larre von $25-30 \mathrm{~mm}$. $A$ vordere, $B$ hintere linke Extremität.

\section{Taf. III.}

Fig. 1. Theil eines Querschnittes durch einen jüngeren, regenerirten Schwanz von Lacerta agilis, um die Schuppenbildung zu demonstriren. $R$ II Rete Malpighii, $P$ Cutispapille, $H$ Hornschicht, $F$ Follikel, $S$ spongiöses Bindegewebe, $C$ Cutis. $f B g$ fibrilläres Bindegewebe.

Fig. 2. Theil eines Querschnittes durch einen älteren, regeverirten Sclıanz von Lacerta agilis. Ep Epidermis, $S$ spongiöses Bindegewebe, $\mathrm{fBg}$ fibrilläres Bindegewebe, Blg Blutgefässe.

Fig. 3. Vollständiger Querschnitt durch ein junges regenerirtes Schwanzstück ron Lacerta muralis. Ep Epidermis, $R . M$ Rückenmark, Blg Blutgefässe, $M$ Muskulatur, $K$ Knorpelrohr, $B$ Bindegewebe.

Fig. 4. Längsschnitt durch die Uebergangsstelle des normalen in den regenerirten Theil des Schwanzes von Lacerta agilis. $S F$ Schnittfäche, $S p G g l$ letzte Spinalganglien, $N R M$ normales Rückenmark, $A S$ eigenthümliche Erweiterung des Centralcanales an der Uebergangsstelle in den regenerirten Theil, $\boldsymbol{N}$ St grosse peripherische Nervenäste, von den Spinalganglien ausgehend, Sch Follikel, welche zur segmentweisen Schuppenbildang fübren, $R P M$ regenerirtes Rückenmark, $W R$ knorpeliges Wirbelrohr, $N I I$ letzte normale Muskulatur, Reg $M$ regenerirte Musculatur, $B g$ Bindegewebe, $F$ Fettkörper mit Pigmentzellen.

NB. Die Pigmentzellen sind nur an der linken Seite der Figur angegeben.

Fig. 5. Qnerschnitt durch den letzten Theil eines ziemlich alten regenerirten Schranzes ron Lacerta agilis. Anlage des Wirbelcanales und regenerirtes Rückenmark. $f B g$ fibrilläres Bindegewebe, Blg Blutgefässe, welche innerhalb des Zellknorpels verlaufen und zum Theil lacunenartig erweitert sind. Ep Epithel des Centralcanales des Rückenmarkes, $C C$ bedeutend erweiterter Centralcanal, der an den Seiten $C C^{1}$ durch eigenthümliche Hyperplasie zwei kleinere Divertikel gebildet hat.

Fig. 6. Querschnitt durch ein altes regenerirtes Rückenmark von Platydactylus verus. $B g$ bindegewebige Scheide, $V$ Vacuolen, $C C$ Centralcanal, $E p$ Epithel desselben, $Z$ Kerne, die etwa den Kornern im Rückenmarke der Amphibien entsprechen. 
Fig. 7. Querschnitt durch ein junges regenerirtes Rückenmark von Phyllodactylus europaeus, nahe an der Uebergangsstelle in den normalen Theil. $B g$ bindegewebige Scheide, Blg Blutgefässe derselben, $V$ Vacuelen, $E p$ Epithel des Centralcanales $C C$.

Fig. 8. Querschnitt durch ein altes regenerirtes Rïckeumark von Hemidactylus frenatus. $B g, E p, C C$ wie in Figur 7.

Fig. 9. Querschnitt durch ein sehr altes regenerirtes Rückenmark von Lacerta ocellata. (Der regenerirte Theil des Schranzes ca. $20 \mathrm{~mm}$ Jang). CC, Ep, $V, B g$ wie in Fig. 6-8. $k$ stark lichtbrechende Körner, $Z$ Körner mit Kerukörperchen, die den Uebergang zu echten Ganglienzellen bilden, $B$ ム Bindegewebskörperchen der Scheide.

Fig. 10. Querschnitt durch das regenerirte Rückenmark ron Anguis fragilis. $C C, E p$ und $B g$ wie vorher, Glz Uebergangsformen zu Ganglienzellen mit hellem protoplasmatischen Hof. (Ausläufer von letzteren Zellen nicht mit Sicherheit zu erkennen).

Fig. 11 u. 12. Querscbnitt durch das normale Rückenmarksende ron Proteus anguiueus, um die Entstehung der letzten Spinalganglien zu zeigeu. $N B$ Neuralbögen, $C C$ Centralcanal, Blg Blutgefăsse, $S p$ Ggl Spinalgauglien, bei Fig. 11 noch im Zusammenhang mit dem Epithel des Centralcanales. in Fig. 12 auf der linken Seite bereits durch herumwucherndes Bindegewebe getremnt.

Fig. 13. Theil eines Querschnittes durch das normale Schwanzende von Proteus anguineus, um die normale Entwickelung eines Hautsinuesorganes zu demonstriren. Zwischen den normalen Epidermiszellen finden sich dunkel tingirte Elemente $L c$, die meistens eine bohnen- oder nierenförmige Gestalt besitzen, und die als Wanderzellen oder Leukocyten gedeutet werden müssen, bei $L c^{\mathbf{l}}$ ein Theilungsstadium. M $Z$ MIantelzellen, $N$ : Nervenzellen mit einer typischen karyokinetischen Figur in einer Zelle, $N$ Nerv, Blg Blutgefïss, $C$ Cutis.

Fig. 14. Querschnitt durch den regenerirten Schwanz ron Proteus anguineus, mit in Bildung begriffenen Sinuesorganen und Drüsen. $S$ jüngeres, $S^{1}$ älteres Stadium eines Sinnesorganes, $\operatorname{Ir}$ Drüsenanlage, $f B g$ fibrilläres Bindegewebe der Cutis (embryonal), $s p B g$ spongiöses Bindegewebe. Statt der in der normalen Epidermis so häufig auftretenden Leukocyten befinden sich in der regenerirten vielfache Verästelungen ron Capillaren Ca.

Fig. 15. Querschnitt durch die regenerirte Epidermis von Lacerta muralis, junges Stadium. $I$ Horusehicht, Ep mittlere Schicht der Epidermis, $R M$ Rete Malpighii, oberhalb dessen sich eine starke Ausbreitung von Pigmentzellen $P$ befindet, $C$ Cutis, in der auf diesem Stadium Pigment völlig fehit.

Fig. 16. Regenerirtes Bindegewebe der Cutis von Hemidactylus frenatus. Eigenthümliche Anordunng des Protoplasma's in den an Pflanzen- oder Chordazellen erimuernden Zellen.

Fig. 17. Regenerirtes Fettgerebe ron Phyllodactylus europaeus, F Fettzellen, noch ohne Metamorphose, Bg Bindegewebe mit Gefässen, welches sich zwischen die ersteren einschiebt.

Fig. 18 u. 19. Regenerationsstadien der peripheren Nerven von Phyllodactylus europaeus. A Axencylinder, $E$ Kerne der Schwann'schen Scheide, welche in Fig. 18 noch fast gar nicht ausgebildet ist, $P$ Perineurium, $\mathrm{Bg}$ Bindegewelse, Blg Blutgefässe.

Fig. 20. Querschnitt durch ein älteres regenerirtes Muskelprimitivbündel von Proteus anguineus. $M K$ Muskelkerne im Inneren der contractilen Substanz, $P i$ Perimysium internum.

Fig. 21. Querschnitt durch sehr alte regenerirte MuskuJatur von Phyllodactylus enropaeus. $M_{K}$ Muskelkerne fast bis auf das Kernkörperchen reducirt. $P e$ Perimysium externun, $P i$ Perimysium internum, CF Cohnheim'sche Felder, von denen nur die gröberen Linien angedeutet sind. An der rechten Seite der Figur sind die quergeschnittenen Muskelbündel aus dem Perimysium internum herausgefallen.

Fig. 22. Querschnitt durch sehr junge regenerirte Muskelfasern von Phyllodactylus europaeus. $M K, P e, P i$ wie in Figur 21, IS innere Protoplasmasäule, welche noch nicht in contractile Substanz umgewandelt ist. 
Fig. 23. Erste Anlage der neugebildeten Muskulatur von Pleurodeles Waltlii. Die ron den Muskelspindeln der alten Muskulatur abstammenden Kerne $\| K^{*}$ zeichnen sich durch ansserordentlich stark lichtbrechende Contouren nnd gröbere Anordnung der chromatischen Substanz im Innern vor den Bindegewebszellen $\mathrm{Bg}$ aus.

Fig. 24. Lăngsschnitt durch die neugebildete Muskulatur ron Protens anguineus. Sp Muskelspindel mit drei Kernen, $F$ Mushelfasern, in welchen sowohl eine deutliche Längsstreifung, als anch beginnende Querstreifung zu erkennen ist, $B$ zwei Bindegewebszellen mit karyokinetischen Figuren.

Fig. 25. Verdickter Endtheil einer durchschnittenen Huskelfaser von Lacerta agilis. Anhänfung von Iruskelkörperchen $M K$ in diesem Theile, Uebergang des Perinysium $P i$ in das Bindegewebe $B y$. 


\section{C o r r i g e n d a.}

Pag. II im Motto lies: "saecula" statt, saeeula".

1 \%eile 4 ron ohen lies: "Eine" statt "Ein".

"2 $270 n$ " 7 ,

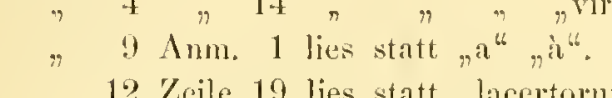

"12 Zeile 19 lies statt "lacertorum" "lacertarum":

$" 14$ Anm. 2 lies: "apris" statt "aprês".

$" 15$ Zeile 23 von oben lies, ce" statt ${ }^{\prime \prime} \mathrm{e}^{\text {". }}$

"15 Amm. 2 lies: "2 2ue" statt, "2en".

"15 "28 von oben lies: "L'illustre" statt „S "illustre".

"19 Amm. 2 lies: "plysique" statt "phisique".

"25 ": " "animal" statt ,animale".

27 Zeile 27 von oben lies: "caeruleocephala" statt ,eeruleoephala".

"2! "19 " "Naboyia agilis" in Komma einzusehliessen.

"50 " 4 ron oben lies: "Kerlert" statt "Kerber".

" 51 " 5 ron inten lies: "durelgefïhrt" statt "dargestellt".

60) Anm. 1 Zeile :3 lies: . Lenkocyten" statt "Lencucythen".

" lit Zeile 25 von oben lies: "Fig. 8" stint Fig. 18".

$65 "$ li, $"$ " "Taf. II" statt "Tat. I".

(6), " 8 " $"$ " "liegende" statt "liegenden".

"60 Zeile 3 von oben lies: "welehe" statt "weleher".

" tis "3, nuten lies: "versclwindet" statt "rorsehwindet".

69 "12" $"$ " "des" statt "der".

71 fehlt vor dem Absatz die No. II.

"72 "2l ron oben lies: "anssieht" statt "anssehen".

"72 " 8 " unten lies: "Gewehe" statt "Gewehes".

"75, "12, "Wahleyer" ntatt "Waldeger".

" 81 " " " oben lies: "Apposition" statt "Opposition".

is letzte Zeile, streiche man hinter , stets" das Semieolon.

\$s Zeile 1 von ohen fehlt hinter "eigenthïmlicl," ein Komma.

$" 10.4 \quad 17, "$ lies: "pistoeoele" statt popiselintoele".

"I:! " $19 "$ " $"$ "Neubilinng" statt "Nenbilung".

"141 "20 " darf hinter "was" kein Komma stehen.

151 " $6 "$ " fehlt hinter "gedrängt" has Wort "wird".

"145 " 1 von oben felılt hinter "folgen" der Bindestrich. 


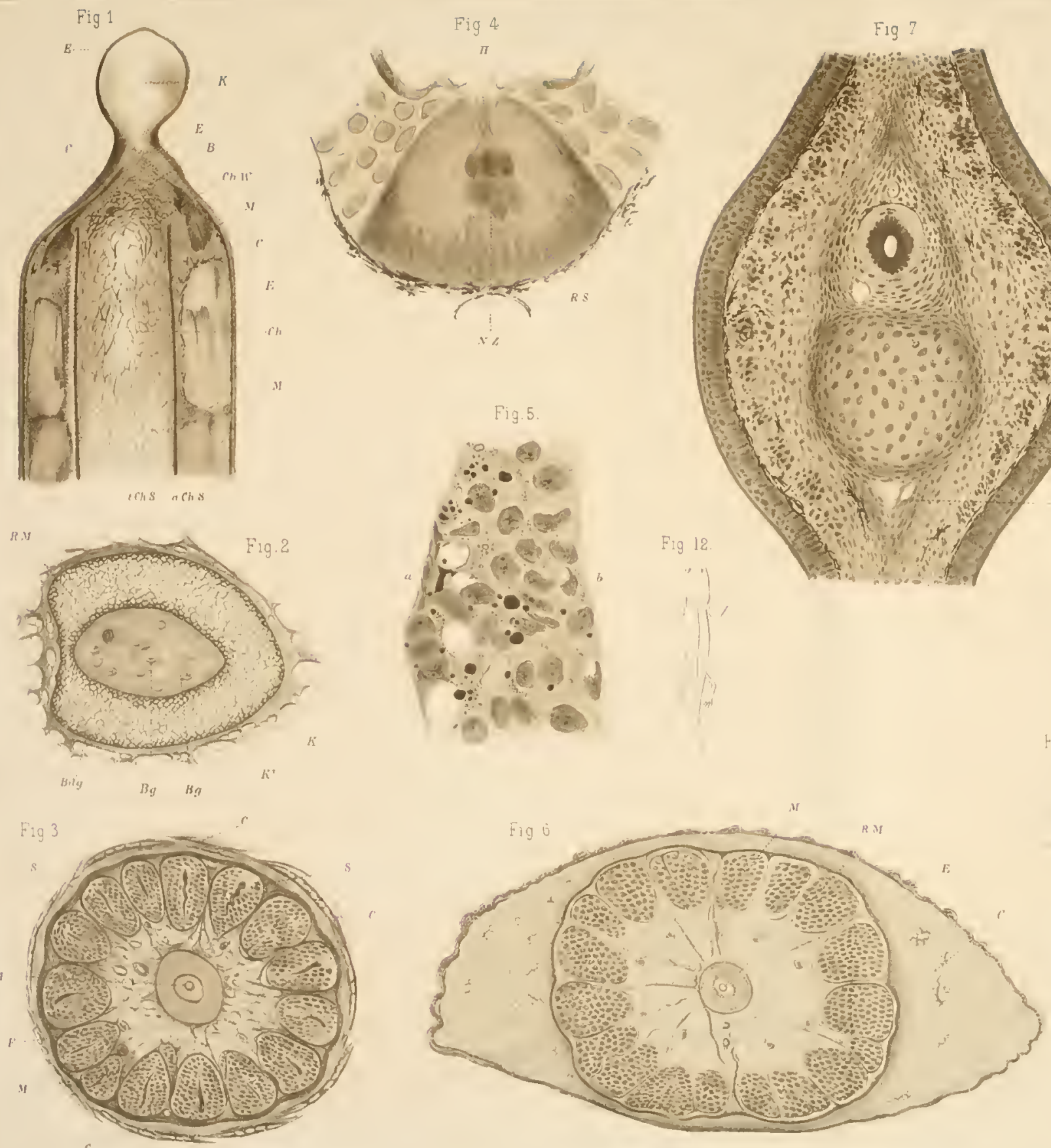

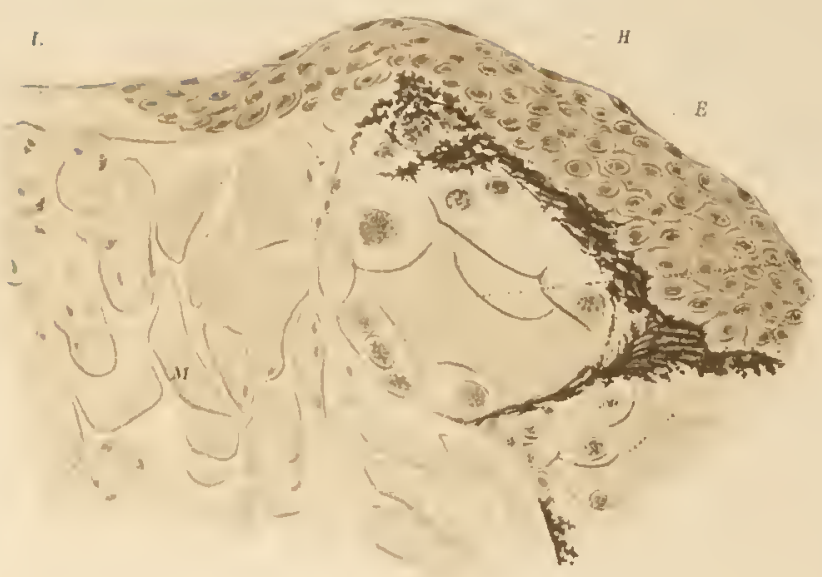

Fig. 9
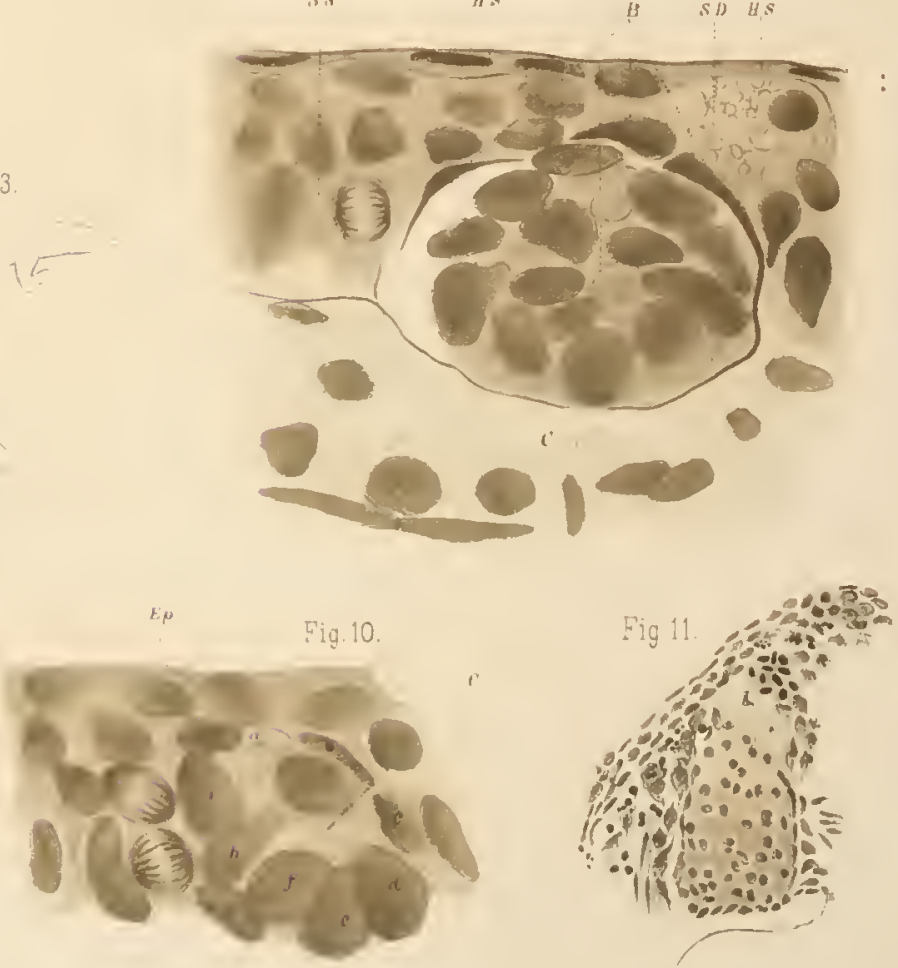


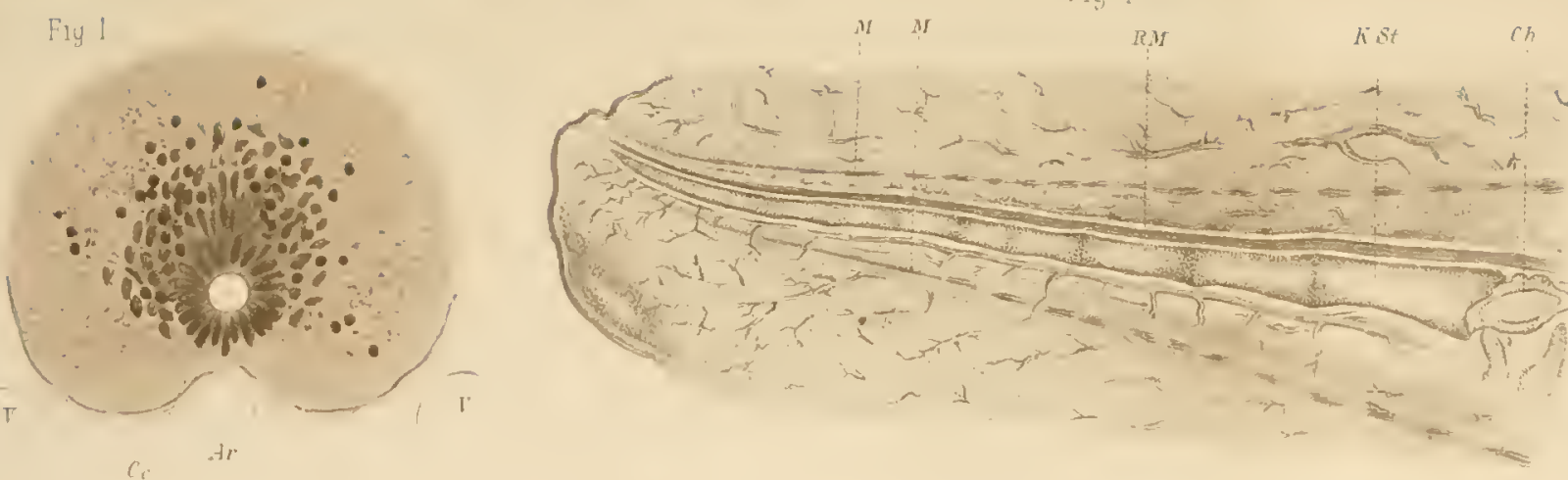
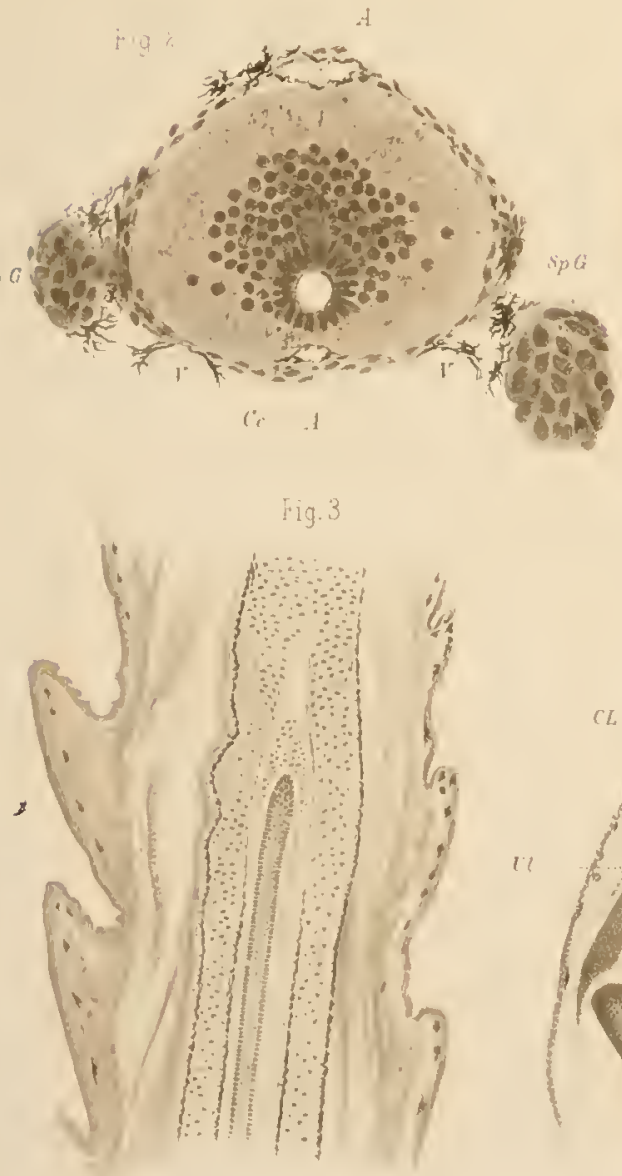
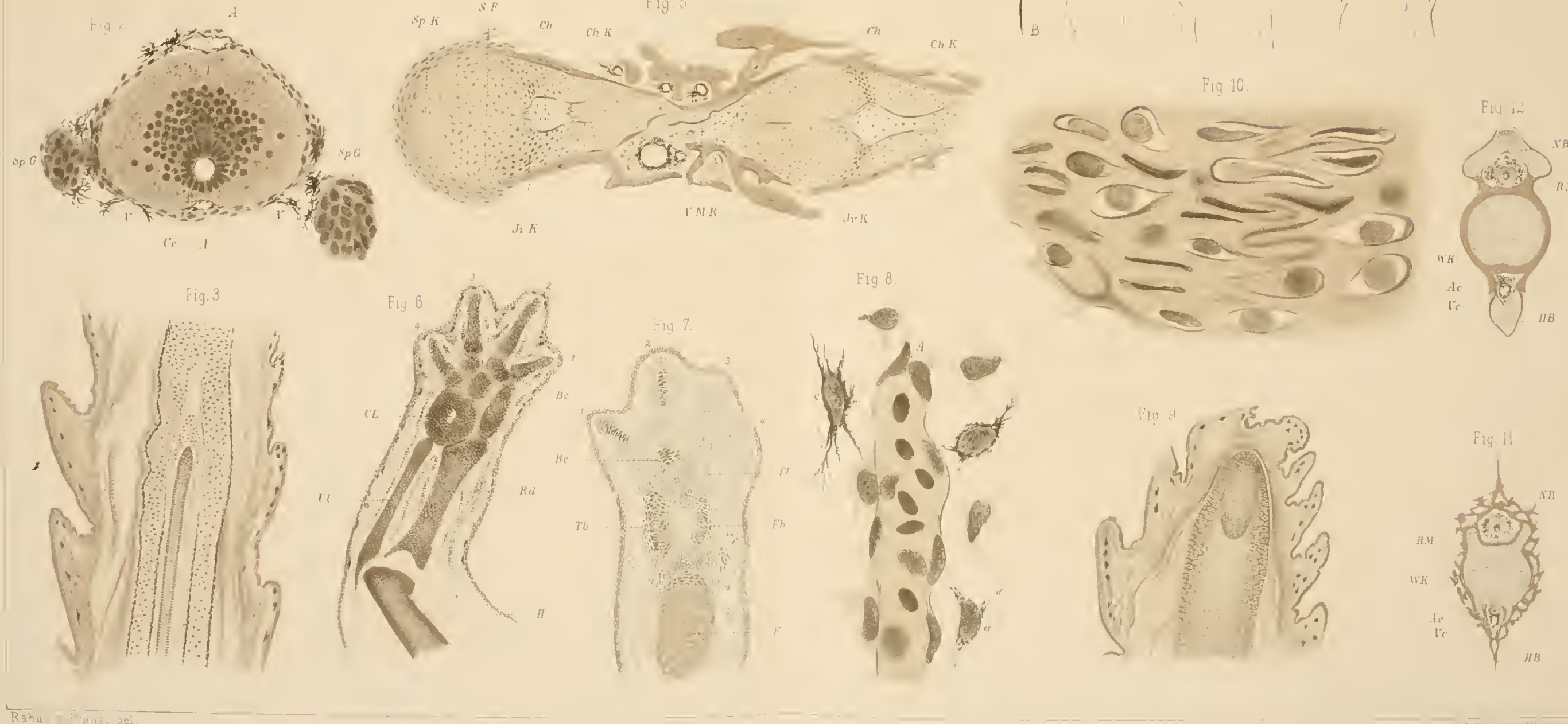



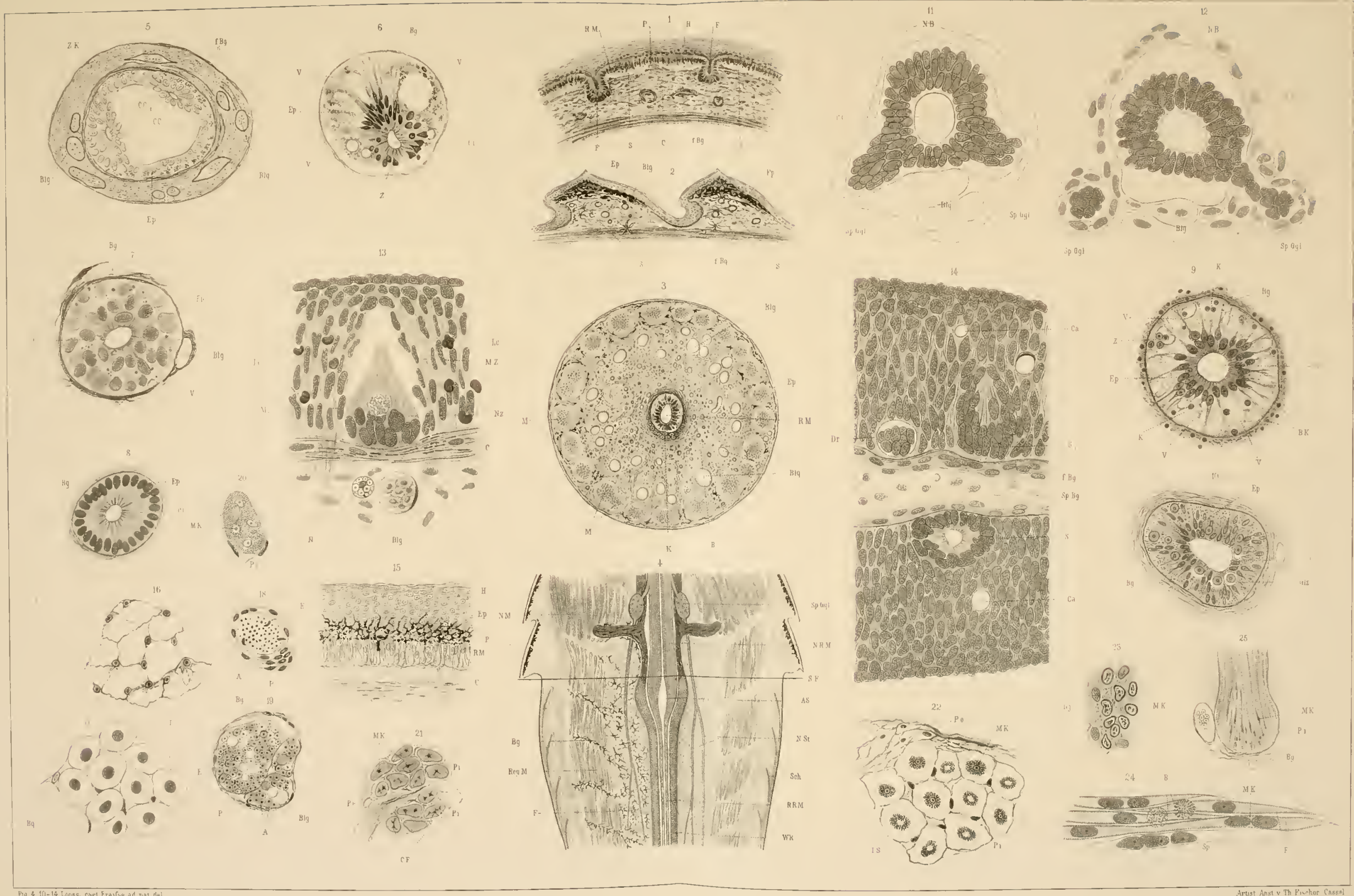







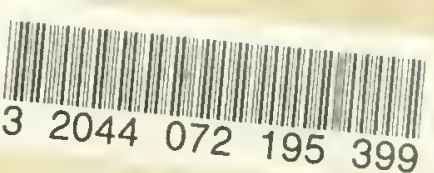


